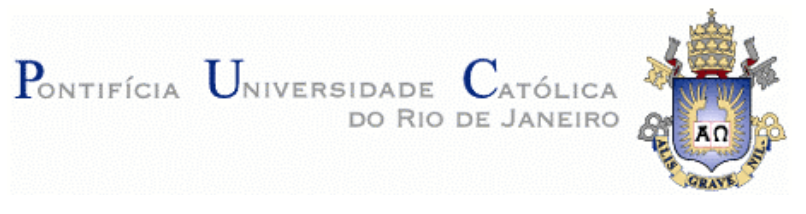

Lizeth Stefanía Benavides Cabrera

Transdutor de pressão de alta sensibilidade destinado a aplicações biomédicas, baseado na leitura de fase de sensores GMI

Dissertação de Mestrado

Dissertação apresentada como requisito parcial para obtenção do grau de Mestre pelo Programa de PósGraduação em Engenharia Elétrica da PUC-Rio.

Orientador: Prof. Eduardo Costa da Silva Co-Orientadora: Profa ${ }^{a}$ Elisabeth Costa Monteiro

Rio de Janeiro

Abril de 2017 


\section{Transdutor de pressão de alta sensibilidade destinado a aplicações biomédicas, baseado na leitura de fase de sensores GMI}

Dissertação apresentada como requisito parcial para obtenção do grau de Mestre pelo Programa de Pós-Graduação em Engenharia Elétrica do Departamento de Engenharia Elétrica do Centro Técnico Científico da PUC-Rio. Aprovada pela Comissão Examinadora abaixo assinada.

Prof. Eduardo Costa da Silva

Orientador

Departamento de Engenharia Elétrica - PUC-Rio

Prof $^{a}$. Elisabeth Costa Monteiro Co-Orientadora

Programa de Pós-Graduação em Metrologia - PUC-Rio

Prof. Carlos Roberto Hall Barbosa

Programa de Pós-Graduação em Metrologia - PUC-Rio

Prof. Daniel Ramos Louzada Programa de Pós-Graduação em Metrologia - PUC-Rio

Prof. José Franco Machado do Amaral

Faculdade de Engenharia - UERJ

Prof. Márcio da Silveira Carvalho Coordenador Setorial do Centro Técnico Científico - PUC-Rio

Rio de Janeiro, 5 de abril de 2017. 
Todos os direitos reservados. É proibida a reprodução total ou parcial do trabalho sem autorização da universidade, do autor e do orientador.

\section{Lizeth Stefanía Benavides Cabrera}

Graduada em Engenharia Eletrônica pela Universidade de Nariño - Colômbia 2015. Publicou um artigo no Latin American Conference on Computational Intelligence. Têm atuado no desenvolvimento de circuitos eletrônicos, instrumentação eletrônica e transdutores magnéticos.

Ficha Catalográfica

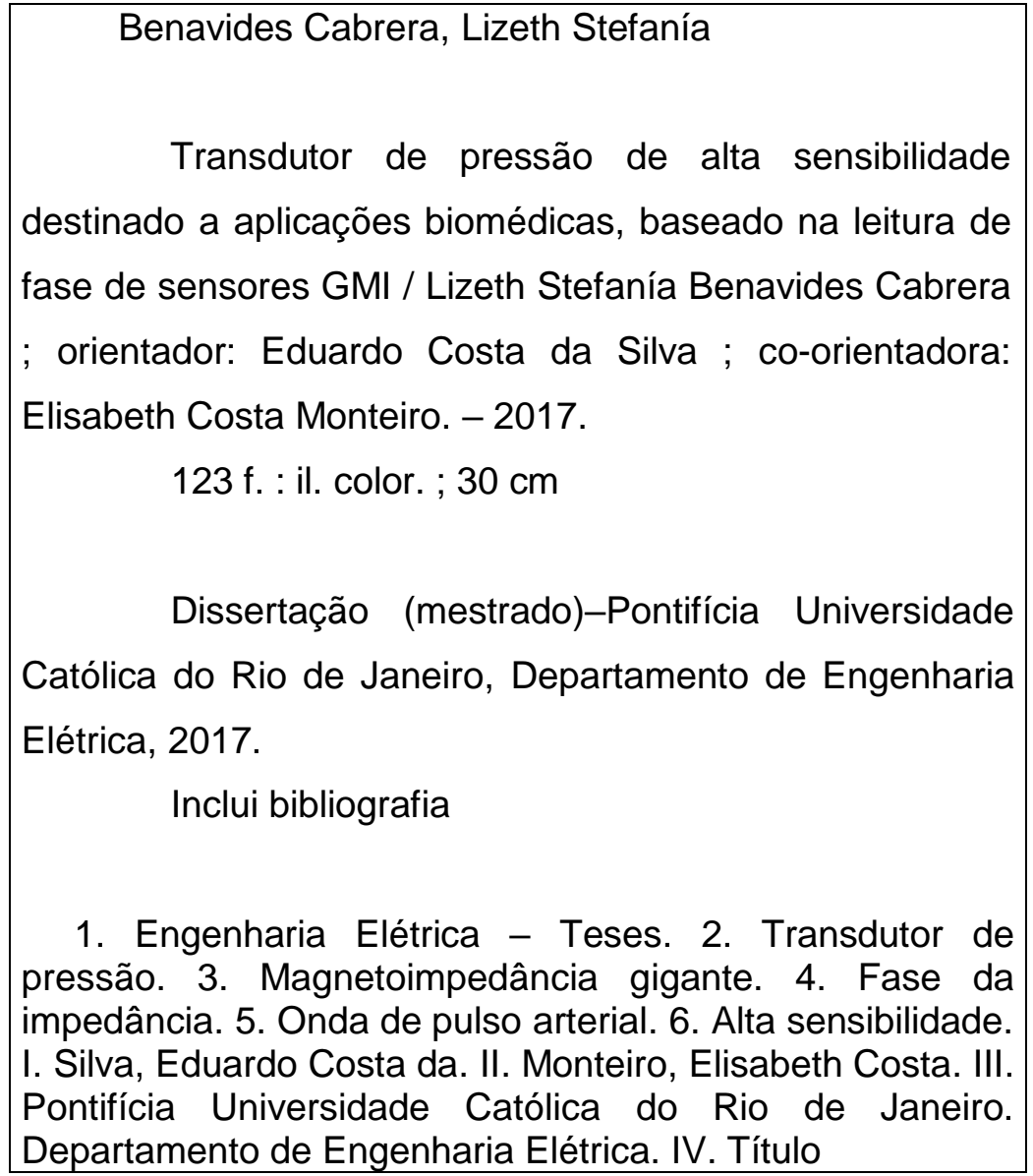
CDD: 621.3 
Dedico este trabalho a Nuestra Señora de las Lajas, por iluminar cada passo do meu caminhar, a minha mãe, modelo de devoção, compreensão e dedicação, a meu pai, exemplo de disciplina e segurança e a minha irmã pela ajuda incondicional. 


\section{Agradecimentos}

Aos meus pais, Luis e Monica, pelo amor, pela confiança, pelo apoio incondicional, pela compreensão nos momentos de ausência, e pelo apoio à minha formação acadêmica.

Ao meu orientador professor Dr. Eduardo Costa da Silva, pela aceitação, acreditação, auxílio, ensinamentos, dedicação, paciência, revisões, sugestões e contribuições substanciais ao trabalho, obrigado pela amizade e apoio incondicional. É uma pessoa admirável que respeito e aprecio e não tenho mais que agradecimentos e estima.

À minha co-orientadora Professora Dra. Elisabeth Costa Monteiro, pela ajuda incondicional, dedicação, aportes, revisão, auxílio, assessoramento, gentileza e amizade. Suas contribuições foram fundamentais no desenvolvimento deste trabalho.

Ao Professor Luiz Antônio Pereira de Gusmão, pelo apoio, ajuda e participação no desenvolvimento desta pesquisa. Por ter colaborado de forma incondicional e estar sempre solícito no laboratório.

Aos Professores do Departamento de Engenharia Elétrica e do Programa de PósGraduação em Metrologia da PUC-Rio, pela sólida formação acadêmica.

À equipe de suporte técnico do Departamento de Engenharia Elétrica da PUC-Rio em especial aos técnicos Manuel Ramos Martins e Evandro Costa dos Reis pela ajuda.

À PUC-Rio, por acreditar na pesquisa científica como instrumento de desenvolvimento social e evolução humana.

À CAPES, pelos auxílios financeiros concedidos.

Aos meus amigos, pelo apoio, ajuda, tolerância, compreensão e por todos os momentos compartilhados. Foram, são e serão parte de minha vida e da minha família até que Deus permita. 


\section{Resumo}

Benavides Cabrera, Lizeth Stefanía; Costa da Silva, Eduardo (Orientador); Costa Monteiro; Elisabeth (Co-orientadora). Transdutor de pressão de alta sensibilidade destinado a aplicações biomédicas, baseado na leitura de fase de sensores GMI. Rio de Janeiro, 2017. 123p. Dissertação de Mestrado - Departamento de Engenharia Elétrica, Pontifícia Universidade Católica do Rio de Janeiro.

Esta dissertação tem por objetivo o desenvolvimento de um transdutor de pressão de alta sensibilidade, baseado nas características de fase da impedância de sensores de Magnetoimpedância Gigante. A configuração do dispositivo visa a aplicações biomédicas, tais como medições da onda de pulso arterial e de sua velocidade de propagação. Projetou-se um sistema de transdução de pressão em tensão, que contém um módulo intermediário baseado em um magnetômetro GMI. O protótipo implementado inclui uma estrutura mecânica, responsável pela transdução de pressão em campo magnético, e um circuito eletrônico, responsável pela conversão deste em uma tensão elétrica de saída. A conversão de pressão em campo magnético é feita por meio de uma fonte de campo magnético aderida a uma membrana elástica. Foram realizados estudos comparativos empregando agulhas magnetizadas e ímãs permanentes como fontes móveis de campo. Por sua vez, o elemento sensor GMI utilizado foi experimentalmente caracterizado, a fim de se obter suas curvas características de módulo e fase, em função do campo magnético. $\mathrm{O}$ circuito eletrônico de transdução foi projetado e avaliado de forma computacional e experimental. As principais características do mesmo são detalhadas ao longo do texto e as previsões teórico-computacionais são comparadas com os resultados experimentais obtidos. Por sua vez, parâmetros chave do protótipo desenvolvido são minuciosamente analisados, tais como: sensibilidade, linearidade e resposta em frequência. Também, avalia-se a densidade espectral de ruído do transdutor desenvolvido e estima-se sua resolução na banda de passagem. Os resultados obtidos indicam que o protótipo de baixo custo desenvolvido apresenta alta resolução e alta sensibilidade, além de uma banda de passagem compatível com a requerida pelas aplicações biomédicas nas quais deseja-se empregá-lo. Dessa forma, espera-se que o dispositivo desenvolvido contribua para o avanço tecnológico do ferramental utilizado no setor da saúde. 


\section{Palavras-chave}

Transdutor de Pressão; Magnetoimpedância Gigante; Fase da Impedância; Onda de pulso arterial; Alta Sensibilidade. 


\section{Abstract}

Benavides Cabrera, Lizeth Stefanía; Costa da Silva, Eduardo (Advisor); Costa Monteiro; Elisabeth (Co-Advisor). High sensitivity pressure transducer for biomedical applications, based on GMI sensor phase reading. Rio de Janeiro, 2017. 123p. Dissertação de Mestrado Departamento de Engenharia Elétrica, Pontifícia Universidade Católica do Rio de Janeiro.

This dissertation aims at the development of a high sensitivity pressure transducer, based on the phase impedance characteristics of Giant Magnetoimpedance sensors. The configuration is intended to employ the developed device in biomedical applications, such as in measurements of arterial pulse wave and pulse wave velocity. A transduction system of pressure into voltage was designed, which contains an intermediate module based on a GMI magnetometer. The idealized prototype contains a mechanical structure, responsible for converting pressure into magnetic field, and an electronic circuit, responsible for converting the latter into a voltage output. The conversion of pressure into magnetic field is performed by means of a magnetic field source adhered to an elastic membrane. Comparative studies were carried out using magnetized needles and permanent magnets as field sources. In turn, the GMI sensor element was experimentally characterized in order to evaluate how its impedance magnitude and phase are affected by the magnetic field. The influence of the cable length used to interconnect the GMI sensor to the electronic circuit is also discussed. The electronic transduction circuit was designed and analyzed by computational and experimental evaluations. The main features of the circuit are detailed throughout the text and the theoretical and computational predictions are compared with the obtained experimental results. Furthermore, the key parameters of the developed prototype are meticulously analyzed, such as: sensitivity, linearity and frequency response. Also, the spectral noise density of the developed transducer is evaluated and its resolution in the passband is estimated. The obtained results indicate that the developed prototype presents low cost of manufacture and operation, high resolution, high sensitivity and a passband compatible with the requirements imposed by the biomedical applications of interest. In this way, it is intended that the device developed in the present Dissertation contributes to the technological enhancement of measurement 
equipment used in health sector.

\section{Keywords}

Pressure transducer; Giant Magnetoimpedance; Impedance Phase; Arterial pulse wave; High Sensitivity. 


\section{Sumário}

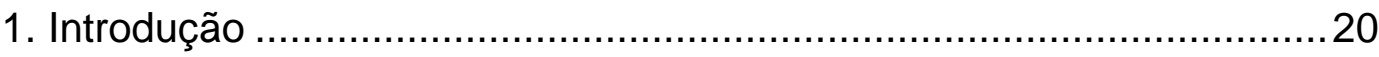

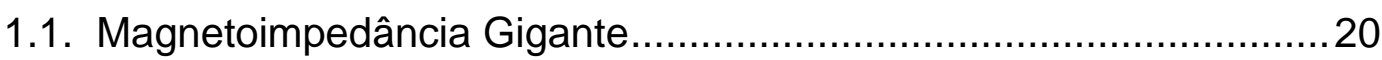

1.1.1 Magnetoimpedância Longitudinal - LMI .....................................22

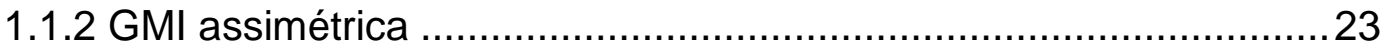

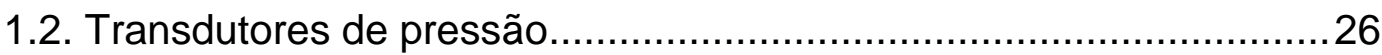

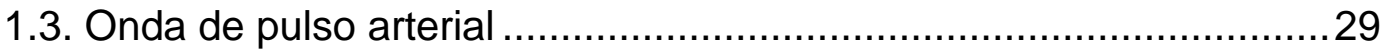

1.3.1 Morfologia do registro da onda de pulso arterial ............................34

1.3.2 Velocidade de onda de pulso arterial ............................................38

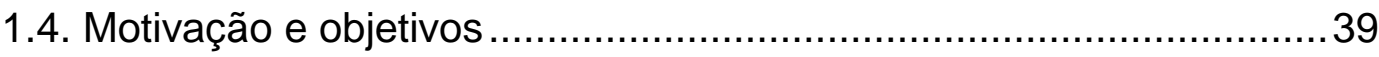

1.5. Organização da Dissertação ............................................................. 41

2. Circuito Eletrônico de Transdução ………………............................43

2.1. Caracterização Experimental do Sensor GMI .................................43

2.1.1 Sistema de caracterização das amostras GMI ...............................44

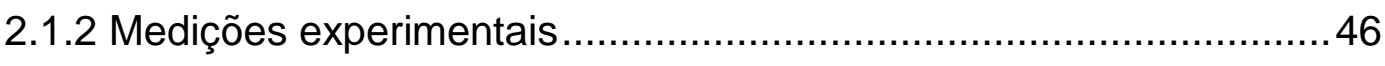

2.1.3 Modelo elétrico da amostra GMI ................................................53

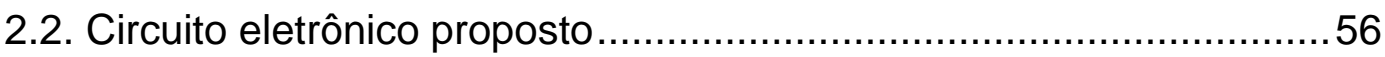

2.3. Resultados computacionais do circuito eletrônico .............................61

2.4. Resultados experimentais do circuito eletrônico ..............................70

3. Protótipo do Transdutor de Pressão GMI ...........................................79

3.1. Descrição do protótipo do transdutor de pressão ..............................79

3.2. Agulha magnetizada como fonte de campo magnético ......................81

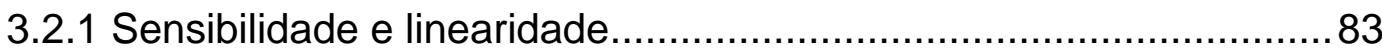




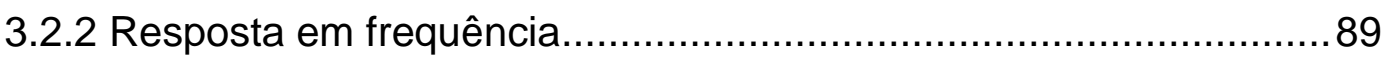

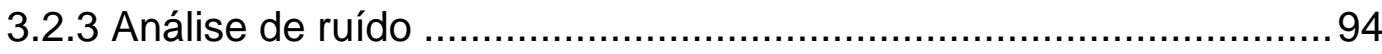

3.3. Ímã permanente como fonte de campo magnético ...........................99

3.3.1 Sensibilidade e linearidade....................................................... 101

3.3.2 Resposta em frequência........................................................... 103

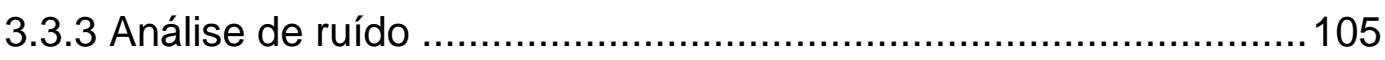

3.4. Medição experimental da onda de pulso arterial ............................109

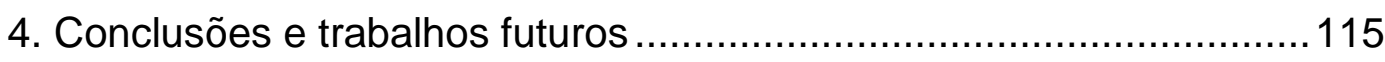

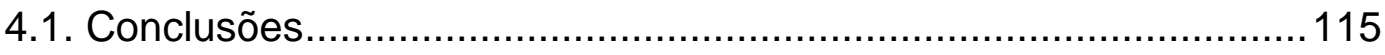

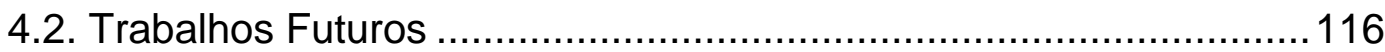

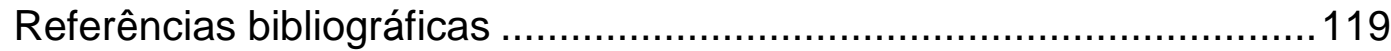




\section{Lista de figuras}

Figura 1 - Medição típica do efeito LMI [10].

Figura 2 - a) Módulo e b) fase da impedância de uma fita GMI de 3 $\mathrm{cm}$, submetida a uma corrente iC $=[\mathrm{Icc}+\mid \mathrm{ca} \cdot \operatorname{sen}(2 \cdot \pi \cdot f \cdot \mathrm{t})] \mathrm{mA}$, onde Icc é igual a $0 \mathrm{~mA}$ [18].

Figura 3 - Configuração experimental para indução de AGMI, por corrente CC, para uma amostra em forma de fio [19].

Figura 4 - GMI para vários valores de Icc [19]. 25

Figura 5 - Esfigmógrafo de Marey [30]. 26

Figura 6 - Posicionamento do transdutor de pressão para a medição da onda de pulso arterial [31].

Figura 7 - a) Matriz de sensores de pressão b) Sensor colocado na superfície da pele próximo à artéria radial [32]

Figura 8 - Protótipo do transdutor de pressão desenvolvido em trabalhos anteriores $[3,4]$.

Figura 9 - Arranjo experimental implementado para a medição da onda de pulso arterial carotídeo, usando marcadores magnéticos.

Figura 10 - Anatomia cardíaca.

Figura 11 - Ciclo cardíaco, a) os átrios se enchem de sangue, b) os átrios se contraem e empurram o sangue em direção aos ventrículos, e c) o sangue é ejetado dos ventrículos para a artéria aorta e a artéria pulmonar.

Figura 12 - Pontos de medição da onda de pulso.

Figura 13 - Formas de onda de pulso ao longo da aorta em pessoas jovens, de meia-idade e idosas [43].

Figura 14 - Composição da onda de pulso por meio da sobreposição das ondas incidentes e refletidas [44].

Figura 15 - Diagrama temporal relacionado à medição da VOP, indicando $\mathrm{o}$ atraso $(\mathrm{dT})$ entre as ondas de pulso adquiridas nos pontos A e B [49]. 
Figura 16 - Taxa de mortalidade no mundo, por causa mortis e gênero, de acordo com a Organização Mundial da Saúde (OMS) [51].

Figura 17 - Mortes associadas a doenças cardiovasculares no Brasil, entre 2004 e 2016 [52].

Figura 18 - Bobina de Helmholtz com uma amostra GMI posicionada em seu centro.

Figura 19 - Diagrama de Blocos do sistema utilizado na caracterização das amostras GMI.

Figura 20 - Arranjo experimental implementado para a caracterização do sensor GMI. Nessa configuração é utilizado o cabo de conexão longo $(85 \mathrm{~cm})$

Figura 21 - Curvas de Histerese de a) Módulo e b) Fase da amostra GMI com 2,5 cm de comprimento, excitada por $\mathrm{iC}=[80+$ $15 \cdot \operatorname{sen}(2 \cdot \pi \cdot 100 \mathrm{k} \cdot \mathrm{t})] \mathrm{mA}$, utilizando-se um cabo curto $(20 \mathrm{~cm})$ para conexão do circuito com o elemento sensor.

Figura 22 - Curvas de Histerese de a) Módulo e b) Fase da amostra GMI com 2,5 cm de comprimento, excitada por $\mathrm{iC}=[80+$ $15 \cdot \operatorname{sen}(2 \cdot \pi \cdot 100 \mathrm{k} \cdot \mathrm{t})] \mathrm{mA}$, utilizando-se um cabo longo $(85 \mathrm{~cm})$ para conexão do circuito com o elemento sensor.

Figura 23 - Curvas Médias de a) Módulo e b) Fase da amostra GMI com $2,5 \mathrm{~cm}$ de comprimento, excitada por $\mathrm{iC}=[80+$ $15 \cdot \operatorname{sen}(2 \cdot \pi \cdot 100 \mathrm{k} \cdot \mathrm{t})] \mathrm{mA}$, utilizando-se um cabo curto $(20 \mathrm{~cm})$ para conexão do circuito com o elemento sensor.

Figura 24 - Curvas Médias de (a) Módulo e (b) Fase da amostra GMI com 2,5 cm de comprimento, excitada por $\mathrm{iC}=[80+$ $15 \cdot \operatorname{sen}(2 \cdot \pi \cdot 100 \mathrm{k} \cdot \mathrm{t})] \mathrm{mA}$, utilizando-se um cabo longo $(85 \mathrm{~cm})$ para conexão do circuito com o elemento sensor.

Figura 25 - Região Linear da curva média de fase $(-1,5 \mathrm{Oe}<\mathrm{H}<-0,4$ Oe), obtida por meio de medições do elemento sensor associado ao cabo curto $(20 \mathrm{~cm})$.

Figura 26 - Região Linear da curva média de fase $(-1,5 \mathrm{Oe}<\mathrm{H}<-0,4$ Oe), obtida por meio de medições do elemento sensor associado ao 
cabo longo.

Figura 27 - Curvas Médias de (a) Resistência e (b) Indutância da amostra GMl com 2,5 cm de comprimento, excitada por $\mathrm{iC}=[80+$ $15 \cdot \operatorname{sen}(2 \cdot \pi \cdot 100 \mathrm{k} \cdot \mathrm{t})] \mathrm{mA}$, utilizando-se um cabo curto $(20 \mathrm{~cm})$ para conexão do circuito com o elemento sensor.

Figura 28 - Curvas Médias de (a) Resistência e (b) Indutância da amostra GMl com 2,5 cm de comprimento, excitada por $\mathrm{iC}=[80+$ $15 \cdot \operatorname{sen}(2 \cdot \pi \cdot 100 \mathrm{k} \cdot \mathrm{t})] \mathrm{mA}$, utilizando-se um cabo longo $(85 \mathrm{~cm})$ para conexão do circuito com o elemento sensor.

Figura 29 - Diagrama de blocos do circuito de transdução de campo magnético em tensão, baseado na leitura de fase da amostra GMI, o qual é parte integrante do transdutor de pressão desenvolvido.

Figura 30 - Representação esquemática do circuito eletrônico completo, desenvolvido para o magnetômetro GMI.

Figura 31 - Tensão de entrada do transdutor de pressão.

Figura 32 - Tensões de saída do filtro passa-faixa e do defasador.

Figura 33 - a) Tensão de saída do conversor V/I e b) Corrente que flui pela amostra GMI.

Figura 34 - Tensão na saída do filtro passa-altas. 64

Figura 35 - Tensões de saída dos comparadores. 65

Figura 36 - Tensão na saída do XOR. 65

Figura 37 - Tensão de saída do filtro passa-baixas, para $\mathrm{H}=-0,95$

Oe.

Figura 38 - Tensões de entrada do Amplificador de Instrumentação, para $\mathrm{H}=-0,95$ Oe.

Figura 39 - Resposta simulada da tensão de saída do circuito eletrônico para diferentes valores de $\mathrm{H}$, expressos em Oe.

Figura 40 - Circuito eletrônico transdutor de pressão.

Figura 41 - Resultado da medição da tensão de entrada do protótipo implementado.

Figura 42 - Resultado da medição experimental das tensões de saída do filtro passa-faixa (linha solida) e do defasador (linha pontilhada). 
Figura 43 - Medição experimental da tensão de saída do conversor $\mathrm{V} / \mathrm{I}$.

Figura 44 - Registro experimental da tensão de saída do filtro passaaltas.

Figura 45 - Resultado da medição experimental das tensões de saída dos comparadores.

Figura 46 - Resultado da medição experimental da tensão na saída do XOR.

Figura 47 - Resultado da medição experimental da tensão de saída do filtro passa-baixas.

Figura 48 - Resultado da medição experimental da tensão de saída do circuito eletrônico, para $\mathrm{H}=-0,95$ Oe.

Figura 49 - Resultado da medição experimental das tensões de saída do circuito eletrônico para diferentes valores de $\mathrm{H}$, expressos em Oe.

Figura 50 - Descrição esquemática do transdutor de pressão desenvolvido.

Figura 51 - Partes do Transdutor de Pressão, baseado na utilização de uma agulha magnetizada como fonte de campo móvel.

Figura 52 - Resposta simulada da tensão de saída do circuito eletrônico para diferentes valores de $\mathrm{H}$, expressos em Oe, para a situação na qual o sensor GMl é associado a um cabo curto.

Figura 53 - Resultado da medição experimental das tensões de saída do circuito eletrônico, para diferentes valores de $\mathrm{H}$, expressos em Oe.

Figura 54 - Arranjo experimental utilizado para obtenção das curvas de fase do sensor GMI em função da corrente de excitação do solenoide, para diferentes distâncias de separação entre sensor e fonte de campo.

Figura 55 - Caracterização experimental da fase da impedância do sensor GMI em função da corrente que atravessa o solenoide, para diferentes distâncias de afastamento entre a agulha e o sensor.

Figura 56 - Caracterização experimental da fase da impedância do 
sensor GMI em função da corrente que atravessa o solenoide, para $3 \mathrm{~mm}$ de afastamento entre a agulha e o sensor.

Figura 57 - Massas padrão utilizadas na caracterização da sensibilidade do transdutor.

Figura 58 - Arranjo utilizado para o posicionamento das massas padrão sobre a membrana do transdutor.

Figura 59 - Tensão de saída do transdutor em função da pressão, utilizando-se uma agulha magnetizada como fonte de campo magnético.

Figura 60 - Arranjo experimental para avaliação da resposta em frequência do transdutor.

Figura 61 - Representação esquemática da configuração utilizada para excitação da Bobina de Helmholtz, para a avaliação da banda de passagem do transdutor.

Figura 62 - Dependência da amplitude da tensão do gerador VGER em função da frequência de $\mathrm{BH}$.

Figura 63 - Tensão de saída do transdutor desenvolvido para densidades de fluxo magnético senoidais de mesma amplitude (16 $\mu \mathrm{T}$ ) e com diferentes frequências: a) $5 \mathrm{~Hz}$, b) $50 \mathrm{~Hz}$, c) $250 \mathrm{~Hz}$ e d) $750 \mathrm{~Hz}$.

Figura 64 - Dependência da sensibilidade do transdutor em função da frequência do campo magnético de excitação: (a) sensibilidade em $\mathrm{mV} / \mathrm{nT}$ e (b) sensibilidade em $\mathrm{dB}$.

Figura 65 - Arranjo experimental para avaliação da densidade espectral de ruído.

Figura 66 - Transformada Rápida de Fourier (FFT) do sinal de saída do transdutor, utilizando-se uma agulha magnetizada como fonte magnética móvel: (a) para frequências entre $0 \mathrm{~Hz}$ e $400 \mathrm{~Hz}$; (b) para frequências entre $0 \mathrm{~Hz}$ e $200 \mathrm{~Hz}$; e (c) para frequências entre $0 \mathrm{~Hz}$ e $200 \mathrm{~Hz}$, com limite do valor máximo da escala de tensões em $50 \mathrm{mV}$.

Figura 67 - Densidade espectral de ruído da tensão de saída do magnetômetro GMI, expressa em nT·Hz-1/2, utilizando-se uma agulha magnetizada como fonte de campo móvel. 
Figura 68 - Densidade espectral de ruído da tensão de saída do transdutor de pressão desenvolvido, expresso em $\mathrm{Pa} \cdot \mathrm{Hz}-1 / 2$, utilizando-se uma agulha magnetizada como fonte de campo móvel.

Figura 69 - Partes do Transdutor de Pressão, baseado na utilização de um ímã permanente como fonte de campo móvel.

Figura 70 - Protótipo final do transdutor de pressão, utilizando um ímã permanente como fonte de campo magnético.

Figura 71 - Caracterização experimental do sensor GMI, acoplado a um cabo longo $(85 \mathrm{~cm})$, em função da corrente que atravessa o solenoide de excitação, para $3 \mathrm{~mm}$ de afastamento entre o ímã permanente e o solenoide. A reta vermelha indica a região aproximadamente linear que se estende de $-10 \mathrm{~mA}$ a $-45 \mathrm{~mA}$.

Figura 72 - Sensibilidade do transdutor de pressão, utilizando-se um ímã permanente como fonte de campo magnético móvel.

Figura 73 - Dependência da sensibilidade do transdutor em função da frequência do campo magnético de excitação: (a) sensibilidade em $\mathrm{mV} / \mathrm{nT}$ e (b) sensibilidade em dB.

Figura 74 - Transformada Rápida de Fourier (FFT) do sinal de saída do transdutor, utilizando-se um ímã permanente como fonte de campo móvel.

Figura 75 - Densidade espectral de ruído da tensão de saída do magnetômetro GMl desenvolvido, expressa em nT·Hz-1/2, utilizando-se um ímã permanente como fonte de campo magnético móvel.

Figura 76 - Densidade espectral de ruído da tensão de saída do transdutor de pressão desenvolvido, expressa em $\mathrm{Pa} \cdot \mathrm{Hz}-1 / 2$, utilizando-se um ímã permanente como fonte de campo magnético móvel.

Figura 77 - Posicionamento do transdutor desenvolvido para medição experimental da onda de pulso a) carotídea e b) radial.

Figura 78 - Resultado das medições experimental do Pulso a) carotídeo e b) radial, adquiridos com o transdutor de pressão desenvolvido. 
Figura 79 - Componentes de frequência de interesse do sinal medido, em a) FFT do pulso radial e b) FFT do pulso carotídeo.

Figura 80 - Identificação de pontos caraterísticos da onda de pulso carotídeo, a) comportamento típico em pacientes normais (literatura), b) sinal adquirido com o transdutor de pressão desenvolvido.

Figura 81 - Identificação de pontos caraterísticos da onda de pulso radial, a) comportamento típico em pacientes normais (literatura), b) sinal adquirido com o transdutor de pressão desenvolvido. 


\section{Lista de tabelas}

Tabela 1. Valores das componentes resistivas e indutivas da impedância equivalente formada pela associação do sensor GMI com o cabo longo, em função de cada valor de campo magnético analisado.

Tabela 2. Valores das componentes resistivas e indutivas da impedância equivalente formada pela associação do sensor GMI com o cabo curto, em função de cada valor de campo magnético analisado.

Tabela 3. Comparação de sensibilidade e fundo de escala entre alguns transdutores de pressão. 


\section{Lista de quadros}

Quadro 1. Onda de pulso carotídeo normal e alterações

morfológicas.

Quadro 2. Componentes ativos utilizados na implementação do circuito eletrônico. 


\section{1. Introdução}

Transdutores são dispositivos capazes de transformar ou converter uma grandeza de entrada em outra diferente na saída, a qual apresenta uma relação especifica com a primeira [1]. Por outro lado, o sensor é apenas a parte sensitiva do transdutor. Transdutores de pressão têm como finalidade transformar pressão mecânica em um sinal elétrico para monitoramentos em diversos setores de aplicação. Os transdutores de pressão podem ser classificados de acordo com a técnica utilizada para transdução: piezoresistivo, piezoelétrico, ressonante, óptico [2]. Entretanto, pesquisas recentes demostraram que transdutores de pressão que utilizam sensores magnéticos baseados na magnetoimpedância gigante (GMI) apresentam elevada sensibilidade [3-5]. Esses estudos foram realizados utilizando as características de módulo da impedância de amostras GMI, tendo sido projetados para a medição da onda de pulso arterial por meio de uma configuração que inclui uma câmara incompressível para transdução mecânica $[3,4]$. Porém, em pesquisas mais recentes verificou-se que a construção de transdutores magnéticos baseados nas características de fase da impedância de sensores GMI permitem a elevação da sensibilidade em pelo menos 100 vezes [6]. Testes preliminares utilizando esse sensor magnético baseado nas características de fase da impedância de sensores GMI e marcadores magnéticos [7], sem câmara incompressível, indicaram o potencial promissor da utilização das características de fase da impedância desses sensores para a transdução de pressão com a elevada sensibilidade necessária para aplicações biomédicas.

\section{1.}

\section{Magnetoimpedância Gigante}

Sensores magnéticos baseados na Magnetoimpedância Gigante (GMI - Giant Magnetoimpedance) constituem uma das mais recentes tecnologias de detecção de campos magnéticos, a qual começou a ser estudada na década de 1990, 
encontrando-se ainda em fase de desenvolvimento [8-12]. O efeito GMI está presente em amostras de material ferromagnético que, quando excitadas por uma corrente elétrica alternada (CA), apresentam grandes variações de suas impedâncias (módulo e fase) em função de alterações no campo magnético externo ao qual as mesmas são submetidas $[13,14]$.

A impedância das amostras GMI é dependente da profundidade de penetração de corrente (skin depth) no material, a qual é diretamente afetada pela permeabilidade magnética. Por sua vez, a permeabilidade é função do campo magnético externo e da amplitude da corrente que atravessa a amostra. Dessa forma, tem-se que variações no campo magnético aplicado induzem alterações na impedância das amostras. Este processo prossegue até que o campo magnético externo seja suficientemente elevado a ponto de rotacionar completamente os domínios magnéticos, reorientando-os ao longo da direção do campo e saturando a impedância do material $[8,10,11]$.

Estudos destacados na literatura indicam que a sensibilidade de sensores GMI é diretamente afetada pela componente do campo magnético que se deseja medir. Em particular, o efeito GMI tem sido estudado com campos aplicados de forma perpendicular ao comprimento da amostra (PMI - Perpendicular Magnetoimpedance), transversal (TMI - Transverse Magneto-impedance) e longitudinal (LMI - Longitudinal Magneto-impedance) $[15,16]$. Neste trabalho, analisou-se apenas o tipo longitudinal (LMI), pois este tipo de Magnetoimpedância apresenta variações mais intensas da impedância com o campo externo aplicado e, consequentemente, exibe melhores resultados em termos de sensibilidade [17].

\subsection{1}

\section{Magnetoimpedância Longitudinal - LMI}

O fenômeno LMI é induzido pela aplicação de uma corrente alternada $\left(I_{c a}\right)$ ao longo do comprimento de uma amostra sensora em forma de fita ou fio, submetida a um campo magnético externo $(H)$, paralelo ao comprimento da amostra. Nesta configuração, indicada na Figura 1, tem-se que a diferença de potencial $(V)$ medida entre as extremidades da fita irá variar em função de $H$, devido à dependência da impedância da amostra, $Z_{\text {sens }}$, com o campo. Consequentemente, é possível associar a tensão $V$ medida com o campo 
magnético $H$, o que evidencia um processo de transdução de campo magnético em tensão elétrica.

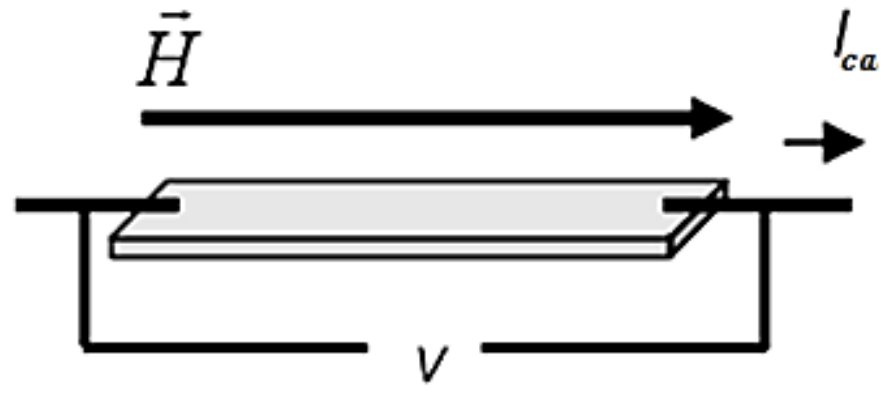

Figura 1 - Medição típica do efeito LMI [10].

Por sua vez, a impedância $Z_{\text {sens }}(H)$ da amostra GMI pode ser obtida pela seguinte expressão $[8,10]$

$$
Z_{\text {sens }}(H)=\frac{|V| e^{j \theta V}}{|I| e^{j \theta I}}=\frac{|V|}{|I|} e^{j \theta \text { sens }}=\left|Z_{\text {sens }}\right| e^{j \theta \text { sens }}=R_{\text {sens }}(H)+j X_{\text {sens }}(H),
$$

onde $|V| e^{j \theta V}$ e $|I| e^{j \theta I}$ são, respectivamente, a diferença de potencial nas extremidades da amostra e corrente de excitação, expressas na forma fasorial. Por sua vez, $R_{\text {sens }}(H)$ é a parte real da impedância e $X_{\text {sens }}(H)$ a parte imaginária.

\section{1 .2}

\section{GMI assimétrica}

Quando uma amostra GMI é excitada por corrente puramente alternada, suas curvas resultantes de módulo e fase da impedância em função do campo magnético externo $H$ são geralmente simétricas em relação ao campo, conforme indicado na Figura 2

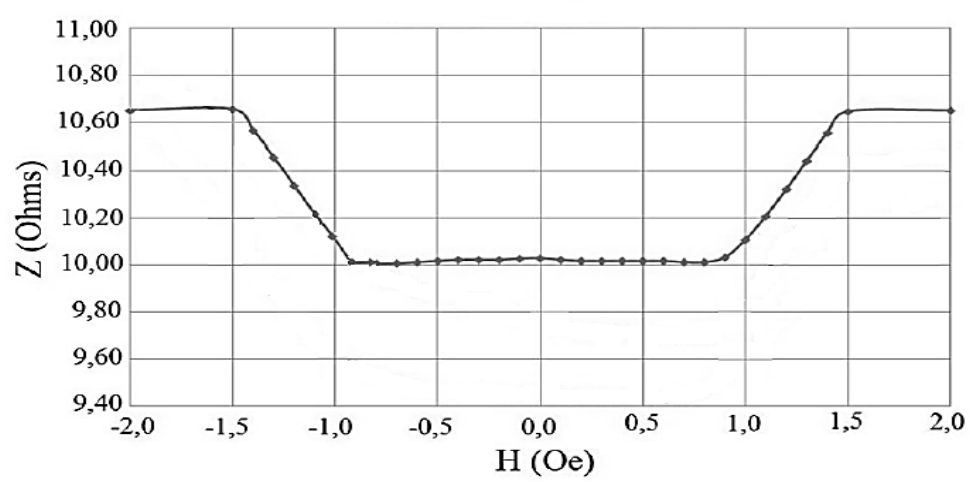

(a) 
1. Introdução

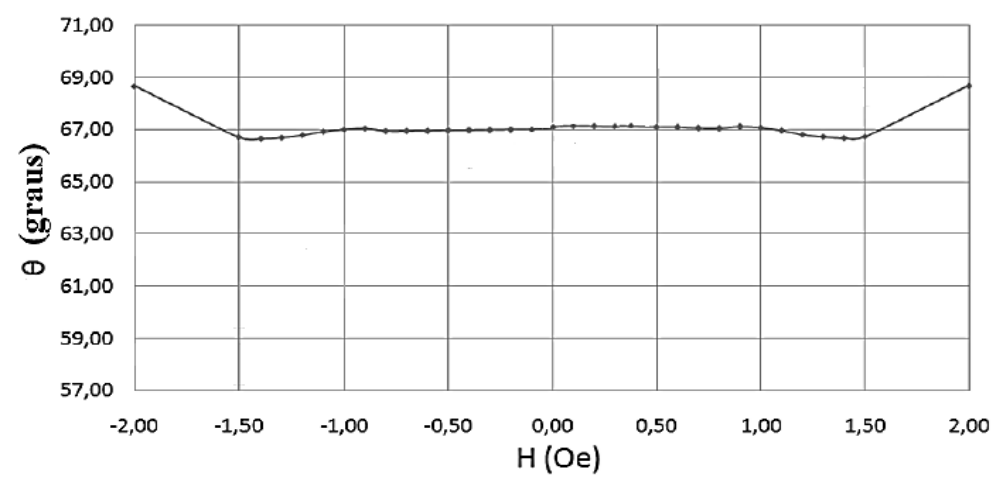

(b)

Figura 2 - a) Módulo e b) fase da impedância de uma fita GMI de $3 \mathrm{~cm}$, submetida a uma corrente ic $=\left[I_{c c}+l_{c a} \cdot \operatorname{sen}(2 \cdot \pi \cdot f \cdot t)\right] \mathrm{mA}$, onde $I_{c c}$ é igual a $0 \mathrm{~mA}[18]$.

No entanto, certos fatores podem induzir o aparecimento de um efeito conhecido como Magnetoimpedância Gigante Assimétrica (AGMI - Asymmetric Giant Magnetoimpedance), o qual é caracterizado por apresentar curvas GMI com comportamento assimétrico em relação ao campo. Dentre os fatores convencionalmente utilizados para induzir o aparecimento de tal assimetria, são destacados na literatura: corrente $\mathrm{CC}[8,13,19,20]$, campo magnético CA $[8,14,19,21,22]$ e "exchange bias" $[8,19,23,24]$. No presente trabalho, buscou-se induzir AGMI apenas por corrente CC. Para amostras GMI em forma de fio, a aplicação de uma corrente $\mathrm{CC}\left(I_{c c}\right)$, paralela à direção de propagação da corrente de excitação CA $\left(I_{c a}\right)$ e ao campo magnético externo $(H)$, induz o surgimento de um campo magnético $\mathrm{CC}\left(H_{c c}\right)$ circunferencial ao comprimento da amostra. Este campo $H_{c c}$, em conjunto com o campo magnético CA $\left(H_{c a}\right)$, gerado pela corrente CA $\left(I_{c a}\right)$, consegue alterar significativamente a forma das curvas GMI em função do campo magnético. Por sua vez, escolhendo-se adequadamente o nível CC da corrente de excitação, é possível elevar significativamente a sensibilidade das amostras GMI $[6,8,11,13]$. A Figura 3 exemplifica a situação na qual induz-se AGMI por corrente CC, para uma amostra em forma de fio [19]. 
1. Introdução

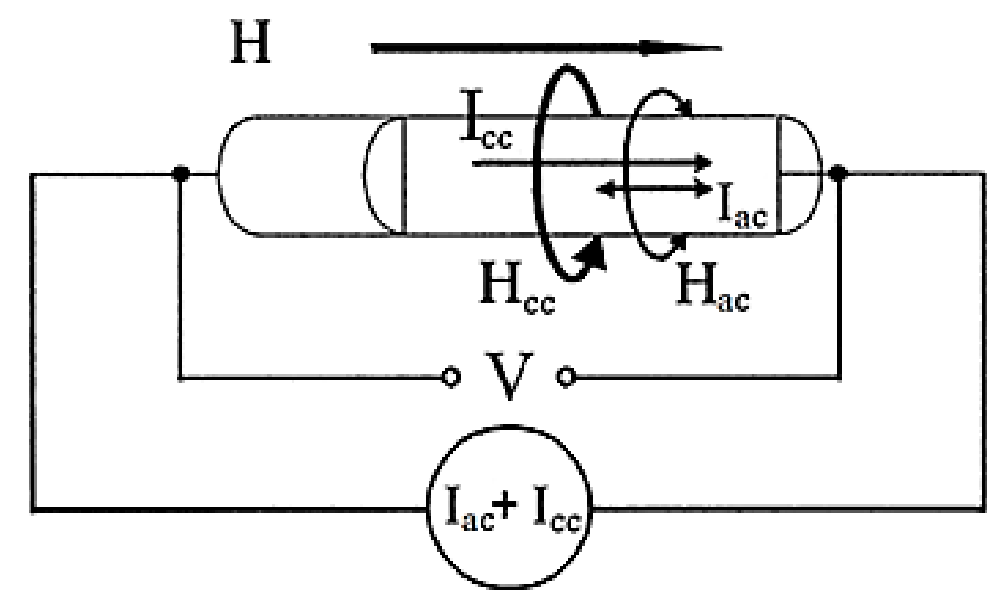

Figura 3 - Configuração experimental para indução de AGMI, por corrente CC, para uma amostra em forma de fio [19].

O efeito GMI assimétrico (AGMI) é muito importante [8,19,25-27], pois permite que se melhore ainda mais o desempenho de sensores GMI em termos de linearidade e sensibilidade $\left(\mathrm{d} \mid \mathrm{Z}_{\text {sens }} / \mathrm{dH}\right.$ e $\left.\mathrm{d} \theta_{\text {sens }} / \mathrm{dH}\right)$. A assimetria é caracterizada pelo incremento de um dos picos da curva GMI em detrimento do outro, conforme indicado na Figura 4. Nesta Figura é destacado tanto o comportamento simétrico, obtido para $\mathrm{I}_{\mathrm{cc}}$ nula, quanto comportamentos assimétricos obtidos para diferentes níveis CC de corrente.

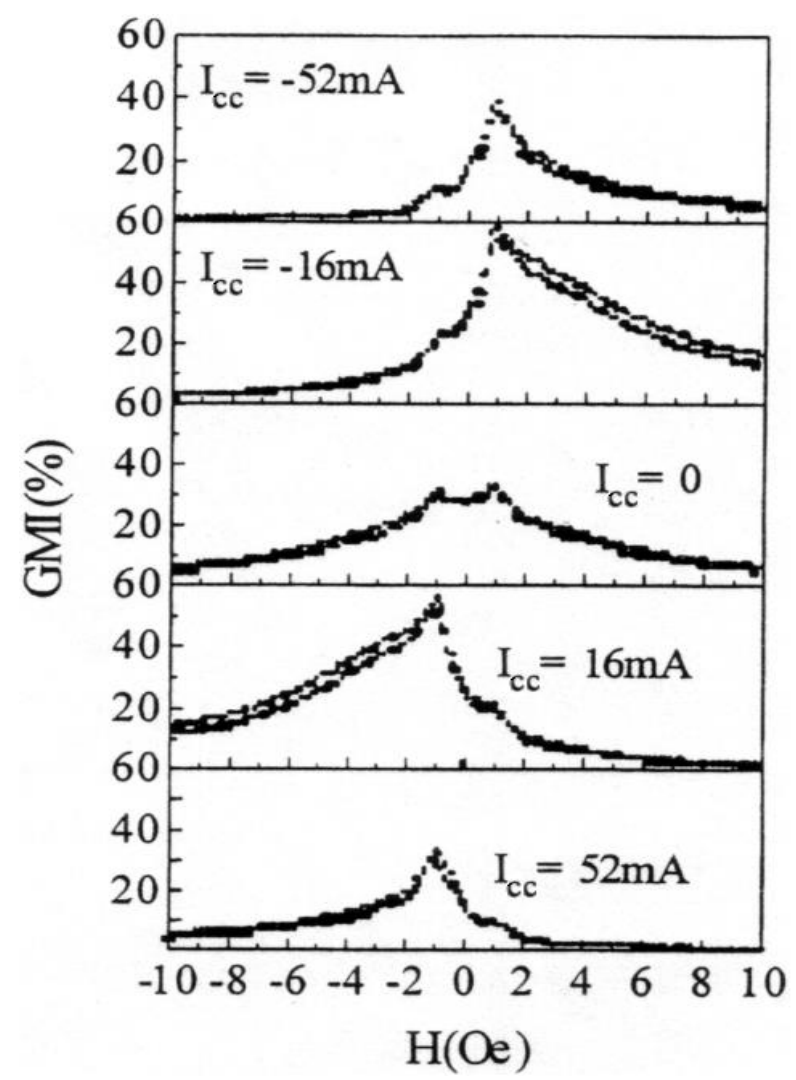

Figura 4 - GMI para vários valores de Icc [19]. 


\section{2}

\section{Transdutores de pressão}

Atualmente, transdutores são dispositivos amplamente utilizados para realizar medições de diversas grandezas de interesse, convertendo-as em sinais elétricos que podem ser facilmente adquiridos e processados. Dessa forma, transdutores são elementos fundamentais em sistemas de controle de processos físicos, onde é essencial o monitoramento de diversas grandezas de interesse. Tais dispositivos são empregados em automação e controle, diagnósticos médicos, instrumentação, aplicações aeroespaciais e navais, entre outras [28].

Sensores de pressão ou transdutores de pressão, têm como objetivo transformar uma determinada grandeza física em elétrica, neste caso, transformar força por unidade de área em uma tensão equivalente à pressão exercida. Os sensores de pressão são capazes de medir diferentes tipos de pressão (absoluta, relativa, atmosférica).

Os primeiros transdutores de pressão, desenvolvidos em 1830 foram mecanismos de transdução onde os movimentos produzidos por diafragmas, molas ou tubos Bourdon eram transmitidos ao pino de ajuste de um potenciômetro, alterando o valor de sua resistência [29]. Os primeiros procedimentos gráficos para registro de ondas de pulso foram demonstrados pela primeira vez em Paris pelo médico Étienne-Jules Marey em 1863, com um dispositivo baseado num pequeno tambor ou cilindro oco e uma extremidade coberta por uma membrana de borracha fina (Figura 5). O movimento do pulso é transmitido através do diafragma de borracha. Uma alavanca ligada ao diafragma registra a forma da onda de pulso no papel. O instrumento foi chamado esfigmomanômetro de Marey e foi usado durante anos por pesquisadores da época [30].

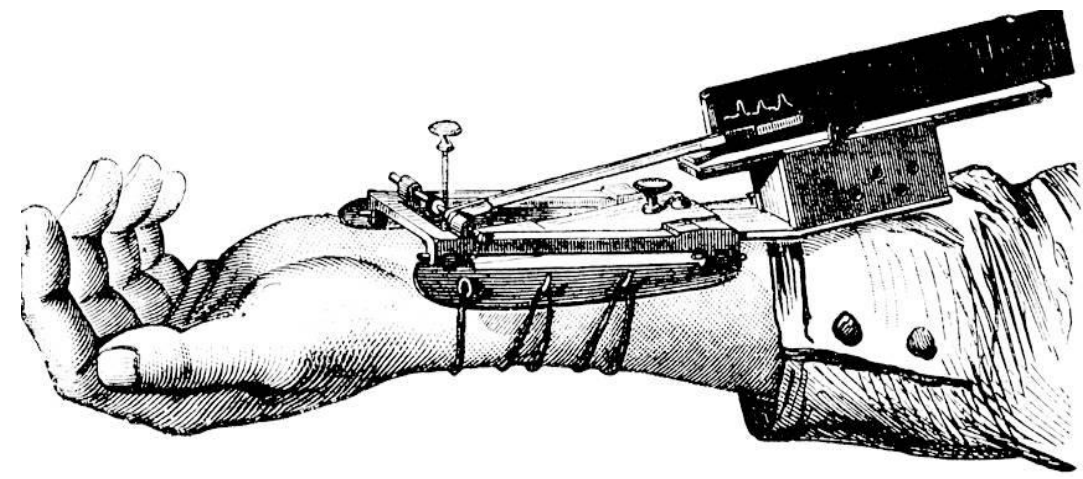

Figura 5 - Esfigmógrafo de Marey [30]. 
Vários outros esfigmógrafos foram desenvolvidos no final do século 19, com a explosão da alta tecnologia, especialmente na Grã-Bretanha, França e Alemanha. Em1967, Hans W. Keller solicitou a patente de um sensor integrado em uma pastilha de silício. Esse descobrimento permitiu enormes progressos na fabricação de sensores de pressão. No século XX surgiu a tecnologia piezoresistiva. Com o advento dessa tecnologia, uma enorme variedade de equipamentos foram desenvolvidos usando sensores de pressão, sendo que as indústrias nas áreas de microeletrônica e biomédica foram as primeiras a investir na concepção e desenvolvimento de equipamentos usando este tipo de sensores [29].

Esses instrumentos eram portáteis, razoavelmente precisos e amplamente disponíveis, de modo a oferecer informações mais detalhadas de todo o sistema arterial. Nesta sequência foi desenvolvido um transdutor para aquisição da onda de pulso usando um sensor piezoresistivo (IC-Sensor model 84), no qual a área de contato do transdutor com a pele tem um diâmetro de 19,1 mm (Figura 6), e um pequeno volume de óleo de silicone transfere a pressão do diafragma para o sensor. A sensibilidade obtida nesta configuração foi $14,5 \mathrm{mV} / \mathrm{kPa}$ [31].
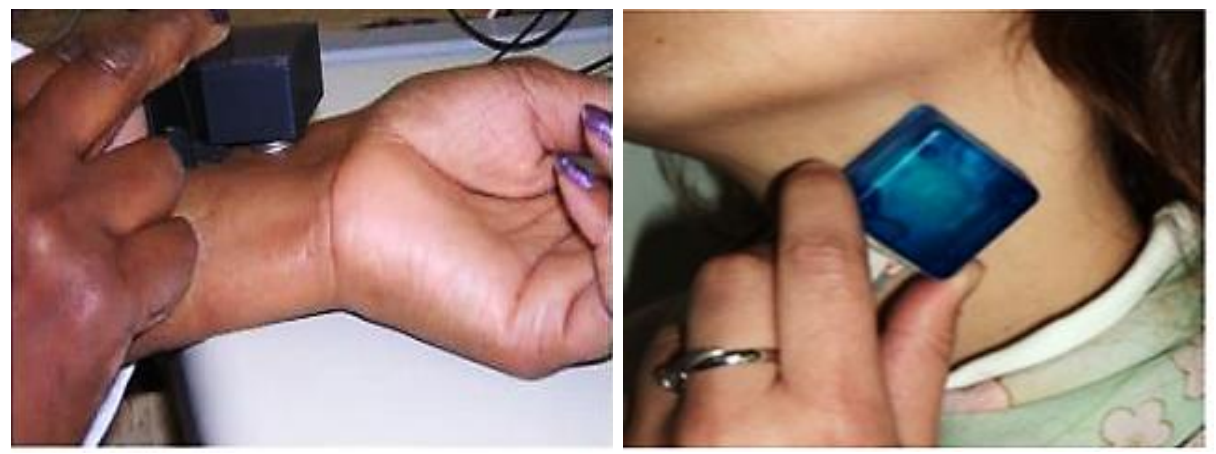

Figura 6 - Posicionamento do transdutor de pressão para a medição da onda de pulso arterial [31].

Uma das dificuldades práticas para a medição de onda de pulso está relacionada com o tamanho do sensor, já que o mesmo deve ser colocado com precisão sobre a superfície da artéria. Assim, no trabalho desenvolvido no Instituto Ansan (Korea) [32] foi implementado um conjunto de 7 sensores piezoresistivos (ATP015, APM) dispostos numa matriz em arranjo linear com comprimento de $15 \mathrm{~mm}$ (Figura 7). A sensibilidade obtida nesta configuração foi $28,58 \mathrm{mV} / \mathrm{kPa}[32]$. 

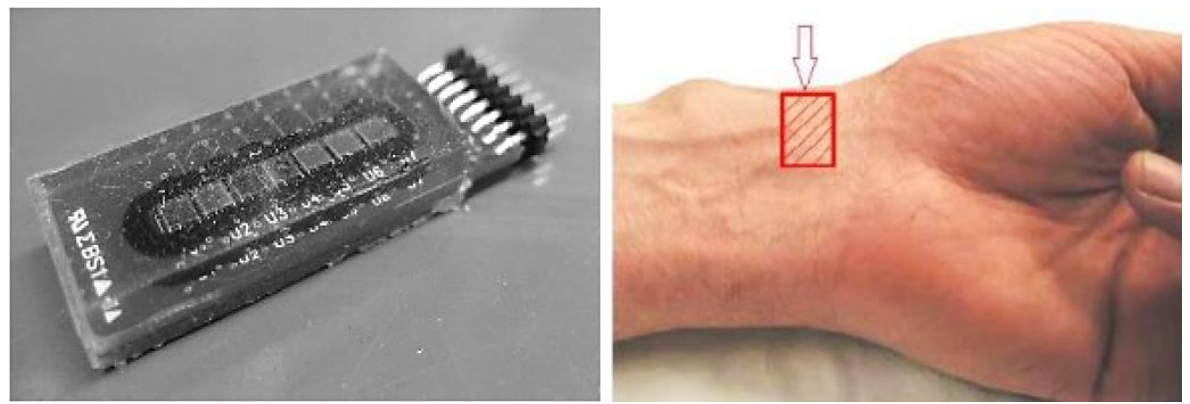

Figura 7 - a) Matriz de sensores de pressão b) Sensor colocado na superfície da pele próximo à artéria radial [32]

Recentes pesquisas nas quais foram utilizados sensores magnéticos baseados na Magnetoimpedância Gigante (GMI - Giant Magnetoimpedance) forneceram uma nova ferramenta para o desenvolvimento de transdutores de pressão com elevada sensibilidade [3-5]. Destaca-se que os magnetômetros GMI apresentados na literatura são tradicionalmente baseados nas características de módulo da impedância do efeito GMI[3-5], assim, esses protótipos de transdutores de pressão utilizando sensores GMI previamente desenvolvidos no laboratório de Biometrologia da PUC-Rio basearam-se nas características de módulo do efeito GMI (Figura 8) [3,4].
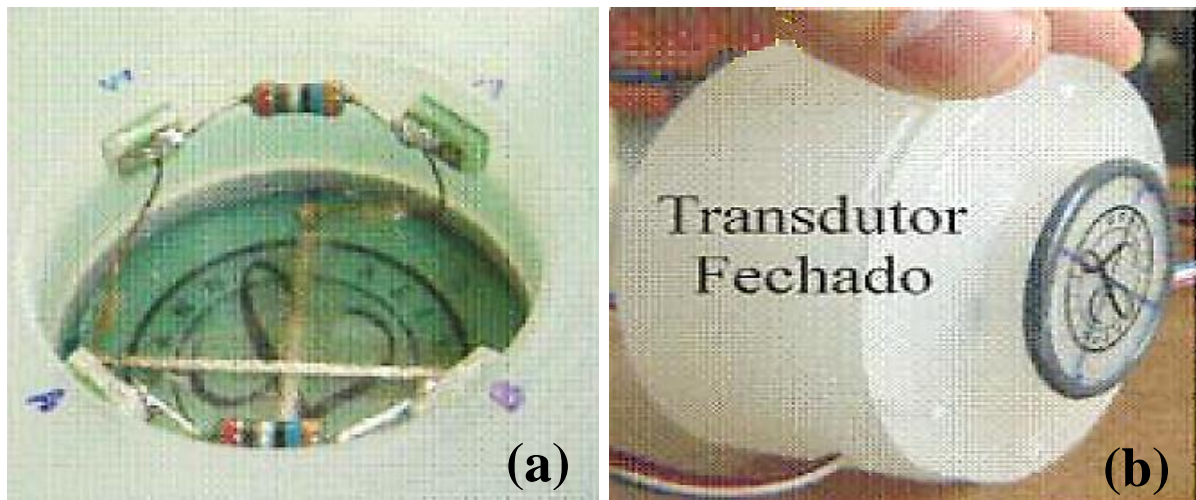

Figura 8 - Protótipo do transdutor de pressão desenvolvido em trabalhos anteriores [3,4].

Na Figura 8 (a) observa-se que o sensor é composto por duas amostras GMI dispostas perpendicularmente entre si, posicionadas sobre uma membrana elástica. As fitas são montadas como dois braços opostos de uma estrutura em ponte, a qual é completada por dois resistores. Na Figura 8 (b) é apresentada a estrutura do transdutor fechado. No centro da campânula há um parafuso, em cuja extremidade está colocado um ímã circular permanente (não mostrado), o parafuso permite variar a distância entre o ímã e as fitas, definindo assim a intensidade do campo magnético de polarização mais adequado. A sensibilidade obtida nesta configuração foi de $131,05 \mathrm{mV} / \mathrm{kPa}$ [3]. O protótipo apresentado na Figura 8 foi 
projetado para a medição da onda de pulso arterial por meio de uma configuração que inclui uma câmara incompressível para transdução mecânica (Figura 8b) $[3,4]$.

Por outro lado, pesquisas subsequentes demostraram que transdutores magnéticos baseados na fase do efeito GMI apresentam sensibilidade ainda mais elevada quando comparada aos sensores baseados no módulo da impedância [6]. Testes preliminares, utilizando um sensor magnético baseado nas características de fase da impedância de sensores GMI e marcadores magnéticos foram realizados para a medição da onda de pulso arterial, o arranjo experimental não incluiu a amplificação mecânica proporcionada por uma câmara incompressível, conforme apresentado na Figura 9 [7]. Os resultados indicaram o potencial promissor da utilização das características de fase da impedância desses sensores para a transdução de pressão e, consequentemente a possibilidade de alcançar a elevada sensibilidade necessária para aplicações biomédicas.

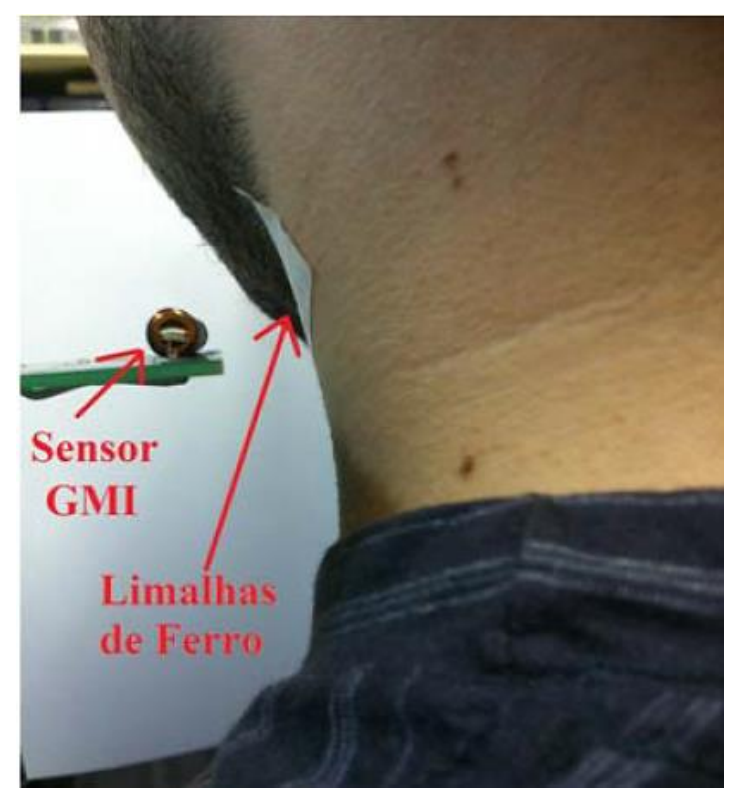

Figura 9 - Arranjo experimental implementado para a medição da onda de pulso arterial carotídeo, usando marcadores magnéticos.

\section{3}

\section{Onda de pulso arterial}

No contexto biológico, aplicado ao sistema cardiovascular, o pulso é definido como qualquer flutuação de pressão periódica no sistema, causada pelo coração. A palpação do pulso arterial é um dos procedimentos clínicos mais antigos na prática médica e um dos indicadores mais importantes que refletem o estado fisiológico das funções vitais. Por sua vez, uma onda de pulso é associada a 
variações de pressão induzidas por vibrações nas paredes das artérias, em função da passagem de fluxo sanguíneo bombeado pela contração do ventrículo esquerdo. As variações de pressão são decorrentes da expansão e contração regular do calibre (diâmetro) das artérias; sendo que sua adequada medição traz importantes informações sobre a quantidade de sangue bombeada, o estado da parede arterial, alterações vasculares e miocárdicas, entre outros. Consequentemente, a análise de tal parâmetro é muito importante para a avaliação do fator de risco cardiovascular em pacientes com hipertensão [33-35].

As características mais importantes que devem ser avaliadas no exame físico do pulso arterial são:

- Frequência: é o número de batimentos cardíacos por minuto, os quais podem apresentar variações em função da idade e condições físicas do paciente ou na presença de doenças cardíacas. A frequência cardíaca normal de um recém-nascido, até os 2 anos, é de cerca de 120 a 140 batimentos por minutos (bpm). Por sua vez, dos 8 anos até à adolescência, considera-se uma frequência cardíaca normal 80 a 100 batimentos cardíacos por minuto, enquanto que em adultos admite-se como normais frequências entre 60 e $100 \mathrm{bpm}$. Valores de frequências cardíacas acima do normal são associados a taquisfigmias e abaixo do normal a bradisfigmias. A frequência pode aumentar em decorrência de situações fisiológicas normais, como exercício, forte emoção, gravidez, ou de situações patológicas, como hipertireoidismo, hipovolemia, entre muitos outros $[33,36,37]$.

- Ritmo: permite avaliar a uniformidade de uma sequência de ondas de pulso. Diz-se que um paciente apresenta ritmo regular, quando as pulsações ocorrem em intervalos de tempo aproximadamente iguais. Por sua vez, diz-se que o ritmo é irregular, caso contrário. Alterações de ritmo são indicativos de arritmias e outras complicações cardiológicas graves $[33,37]$.

- Amplitude: pode ser avaliada por palpação, pela sensação captada em cada pulsação e está diretamente relacionada com o grau de enchimento da artéria, na sístole, e esvaziamento, na diástole. Os fatores que definem a amplitude e contorno do pulso arterial são: volume de ejeção do ventrículo esquerdo, velocidade de ejeção, complacência e capacidade do sistema 
arterial. Dependendo da amplitude, os pulsos arteriais podem ser classificados como de amplitude normal, aumentada ou reduzida $[33,36]$.

O pulso arterial tem sua origem no ciclo cardíaco que pode ser descrito por meio de etapas iniciando-se pelo transporte do sangue das veias pulmonares e do átrio esquerdo para o ventrículo esquerdo. A Figura 10 indica as principais estruturas da anatomia cardíaca.

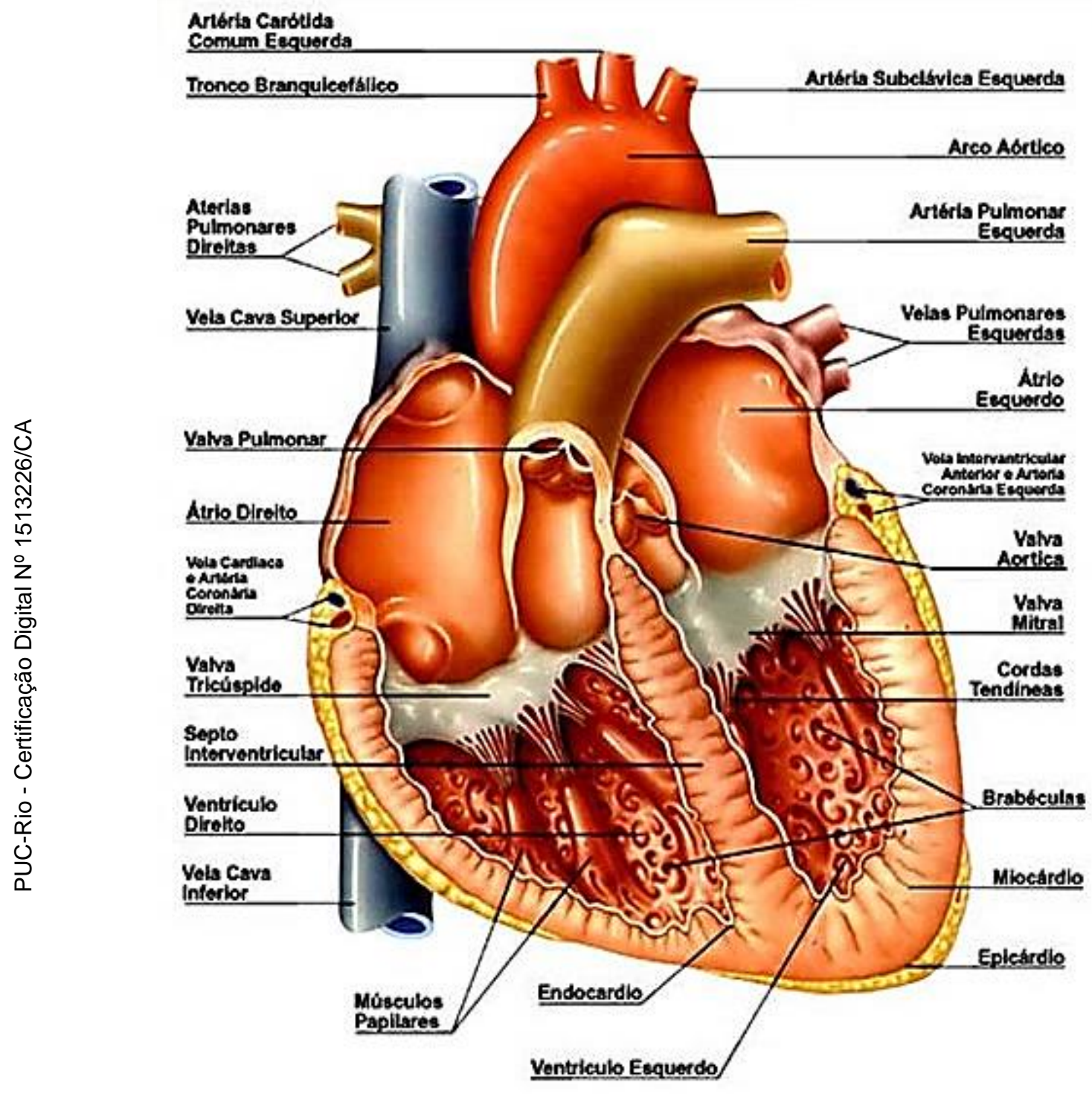

Figura 10 - Anatomia cardíaca.

Na sequência, o sangue é então ejetado para a artéria aorta, sendo que sua grande capacidade de expansão e elasticidade permitem que o fluxo sanguíneo contínuo seja distribuído pela enorme rede vascular. A ejeção rápida e abrupta de fluxo sanguíneo marca o início da onda de pulso, o qual é caracterizado por uma súbita elevação de pressão, chamada "onda de percussão" [38]. 
A sístole é iniciada quando o ventrículo esquerdo se contrai, o que faz com que a pressão em seu interior aumente, forçando a saída de sangue em direção à aorta. $\mathrm{O}$ volume de sangue bombeado faz com que a pressão no interior da aorta aumente, o que provoca um aumento no diâmetro interno da artéria. Deste modo, a diferença de pressões entre ventrículo e aorta fica cada vez menor, forçando a redução gradual da quantidade de sangue ejetado do ventrículo em direção à aorta. Em dado momento a pressão aórtica se iguala à ventricular, fazendo com que a ejeção sanguínea seja interrompida, embora ainda possa haver um pequeno fluxo residual devido à inércia. Na sequência, o ventrículo começa a distender-se dando fim à sístole $[39,40]$.

Neste momento, inicia-se o processo denominado diástole, que é o período de relaxamento ventricular. Conforme o ventrículo relaxa, a pressão em seu interior tende a cair gradativamente, tornando-se inferior à pressão aórtica, mas ainda superior à pressão atrial, o que mantém as válvulas semilunares fechadas, impedindo a saída de sangue do coração. Essa fase é denominada relaxamento isovolumétrico.

Quando finalmente a pressão ventricular torna-se efetivamente inferior à pressão atrial, que nesse momento é máxima, as válvulas atrioventriculares se abrem, deixando passar rapidamente um grande fluxo sanguíneo em direção ao ventrículo. Por sua vez, com o enchimento do ventrículo e o fim da fase ativa de relaxamento do músculo cardíaco, ocorre uma significativa desaceleração do fluxo e as válvulas atrioventriculares tendem a se fechar passivamente, fazendo com que o fluxo do átrio para o ventrículo seja quase que completamente interrompido. Na sequência, tem-se a última fase da diástole, denominada sístole atrial, caracterizada pela contração do átrio. Esta contração do átrio ocorre em um momento em que o ventrículo ainda não iniciou sua contração. Dessa forma, força-se o incremento do fluxo sanguíneo do átrio para o ventrículo, aumentando o volume sanguíneo armazenado no mesmo. Este processo aumenta o rendimento cardíaco, visto que o aumento do volume sanguíneo no ventrículo permite a ejeção do sangue do ventrículo em direção à aorta, quando a sístole acontecer [39,41]. A Figura 11 representa as principais etapas do ciclo cardíaco. 


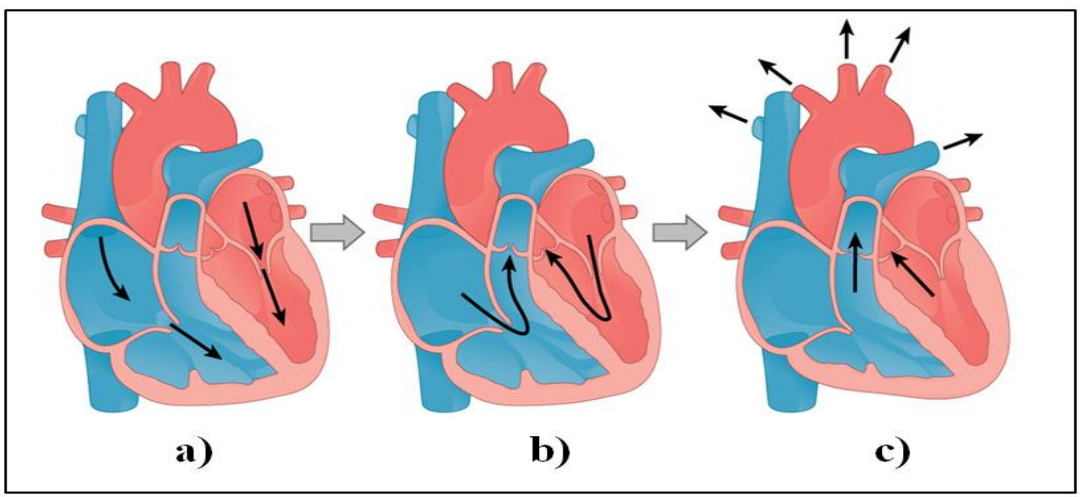

Figura 11 - Ciclo cardíaco, a) os átrios se enchem de sangue, b) os átrios se contraem e empurram o sangue em direção aos ventrículos, e c) o sangue é ejetado dos ventrículos para a artéria aorta e a artéria pulmonar.

A onda de pulso arterial sofre alterações graduais ao se deslocar do centro para a periferia do sistema cardiovascular. Consequentemente, o pulso arterial pode ser medido em diferentes partes do corpo, a fim de se poder identificar alterações específicas em determinado trecho do sistema. Convencionalmente, são realizadas medições em três pontos críticos [33,34]:

- pulso carotídeo: é o pulso mais comumente avaliado, o qual é medido nas laterais do pescoço, em função do fluxo sanguíneo que passa pela artéria carótida,

- pulso radial: medido na parte da frente do punho, e

- pulso braquial: medido na face interior da dobra do cotovelo, na posição medial ao tendão do bíceps, decorrente do fluxo sanguíneo na artéria braquial.

Adicionalmente, existem outros pontos de interesse para avaliação da onda de pulso, os quais apresentam maior dificuldade de medição, devido a sua localização. São detalhados a seguir $[33,34]$ :

- pulso femoral: medido na região anterior e proximal da coxa no ponto médio entre a sínfise púbica e a espinha ilíaca ântero-superior,

- pulso pedioso: medido no dorso do pé, região de difícil acesso por apresentar variações anatômicas que podem acarretar em dificuldades na palpação do pulso ou no posicionamento de um sensor para medição,

- pulso axilar: medido no vértice da axila,

- pulso tibial posterior: medido na parte posterior do maléolo medial do tornozelo, 
- pulso poplíteo: é geralmente de difícil medição, uma vez que não é superficial nem atravessa nenhuma proeminência óssea, pode ser acessado por meio de uma depressão localizada na parte posterior da articulação do joelho.

A Figura 12 indica alguns dos pontos de medição aqui destacados.

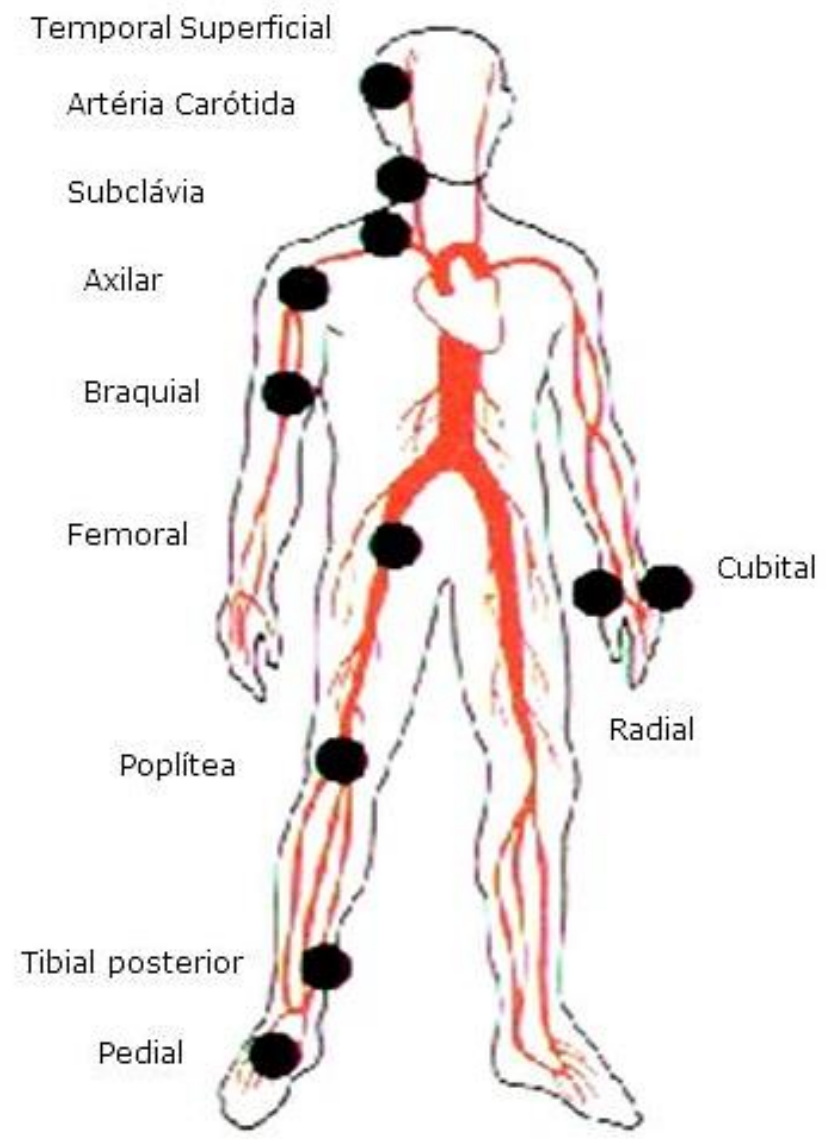

Figura 12 - Pontos de medição da onda de pulso.

\subsection{1}

Morfologia do registro da onda de pulso arterial

$\mathrm{O}$ registro da onda de pulso arterial, obtido com um instrumento de medição, permite que se avalie parâmetros relevantes para fins diagnósticos, tais como frequência, ritmo e amplitude. Além destes parâmetros, o registro também fornece informação sobre outro parâmetro de interesse, o contorno da onda de pulso.

O contorno varia ao longo do sistema circulatório, sendo afetado por condições fisiológicas ou patofisiológicas do organismo. A Figura 13 apresenta o comportamento típico de formas de onda de pulso medidas em diferentes pontos 
ao longo da artéria aorta, para indivíduos jovens, de meia-idade e idosos. Uma análise minuciosa da morfologia desta onda possibilita a obtenção de informações sobre a onda reflexiva, os períodos sistólicos e diastólicos, entre outras. Estes dados permitem conhecer a interação do coração com o sistema arterial, que de outra forma só poderia ser avaliada por meio de medições arteriais invasivas $[42,43]$.
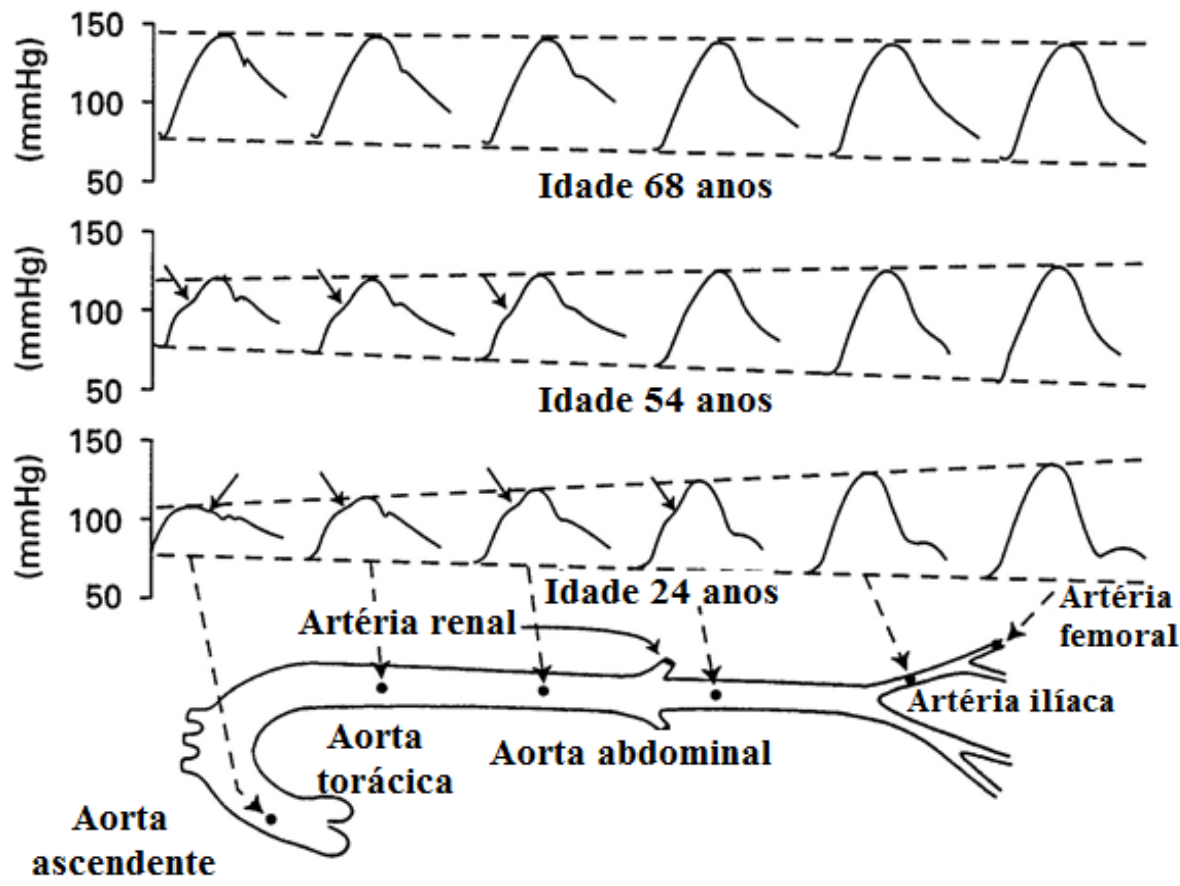

Figura 13 - Formas de onda de pulso ao longo da aorta em pessoas jovens, de meia-idade e idosas [43].

Na Figura 13 pode-se notar que a amplitude da onda de pulso, expressa em $\mathrm{mmHg}$, aumenta com a idade. Do ponto de vista fisiopatológico, este incremento está correlacionado ao envelhecimento, devido ao progressivo endurecimento das paredes das artérias principais. Por sua vez, também verifica-se que, em indivíduos mais jovens, devido à maior elasticidade da artéria central, existe considerável variação no contorno da onda de pulso medida ao longo da artéria. Além disso, pode-se observar que a amplitude da onda aumenta, para medições em pontos mais distantes da artéria central. Por outro lado, com o aumento da idade é perceptível que a amplitude tende a se tornar gradativamente mais homogênea, devido à propagação mais rápida da onda de pressão resultante, com alterações em reflexões de ondas, fazendo que o pulso central e periférico tornemse cada vez mais similares.

A onda de pressão gerada pelo ventrículo esquerdo percorre a árvore arterial e reflete-se em qualquer descontinuidade da parede arterial, por exemplo, em 
1. Introdução

artérias com calibre diminuído em determinados trechos ou pela presença de múltiplas bifurcações em determinadas áreas. Por sua vez, cada reflexão de onda causa uma onda inversa no sistema arterial [44]. Na Figura 14 ilustra-se a composição da forma de onda da pressão arterial por meio da combinação da onda incidente, dada pela contração ventricular, com a onda refletida, que retorna da periferia do sistema.

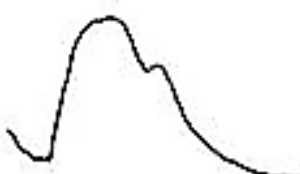

Onda incidente
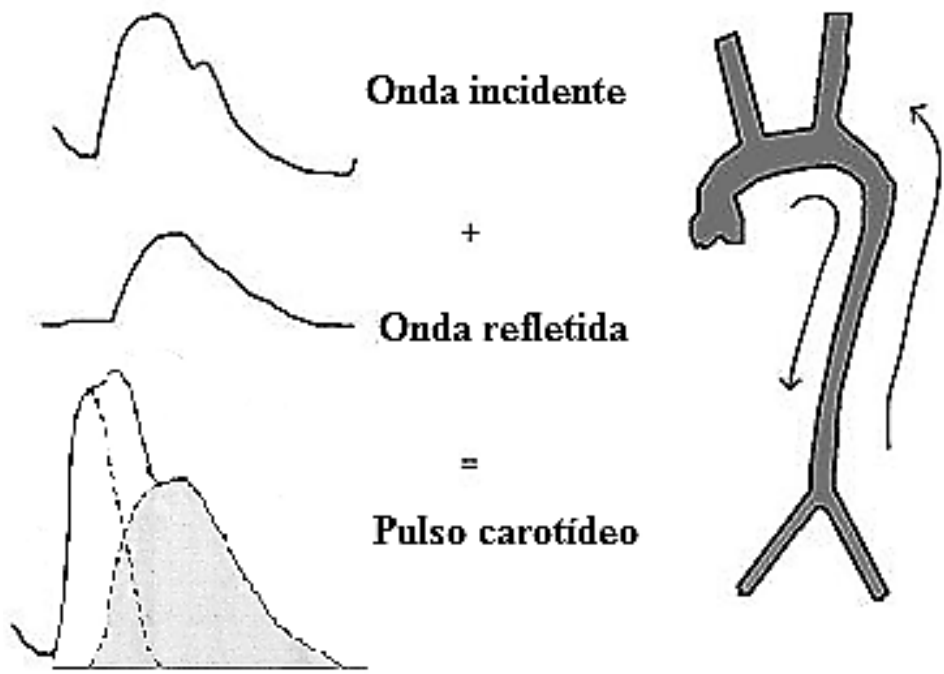

Figura 14 - Composição da onda de pulso por meio da sobreposição das ondas incidentes e refletidas [44].

Mediante a análise da forma de onda de pulso, pode-se obter importantes informações sobre o comportamento fisiológico e patológico da parede arterial, que contribuem diretamente para fins diagnósticos. A morfologia da onda de pulso é influenciada por vários fatores: movimento diastólico e sistólico da aorta, variações do fluxo sanguíneo arterial causadas pela ação de bombeamento do coração, ponto específico de medição na árvore arterial e idade do paciente $[45,46]$. Alterações em tais aspectos influenciam diretamente a onda de pulso. O quadro 1 apresenta as formas de onda associadas a um pulso carotídeo normal e a algumas variações clássicas, descritas na literatura, que estão associados a tipos específicos de patologias $[33,36]$. 
Quadro 1. Onda de pulso carotídeo normal e alterações morfológicas.

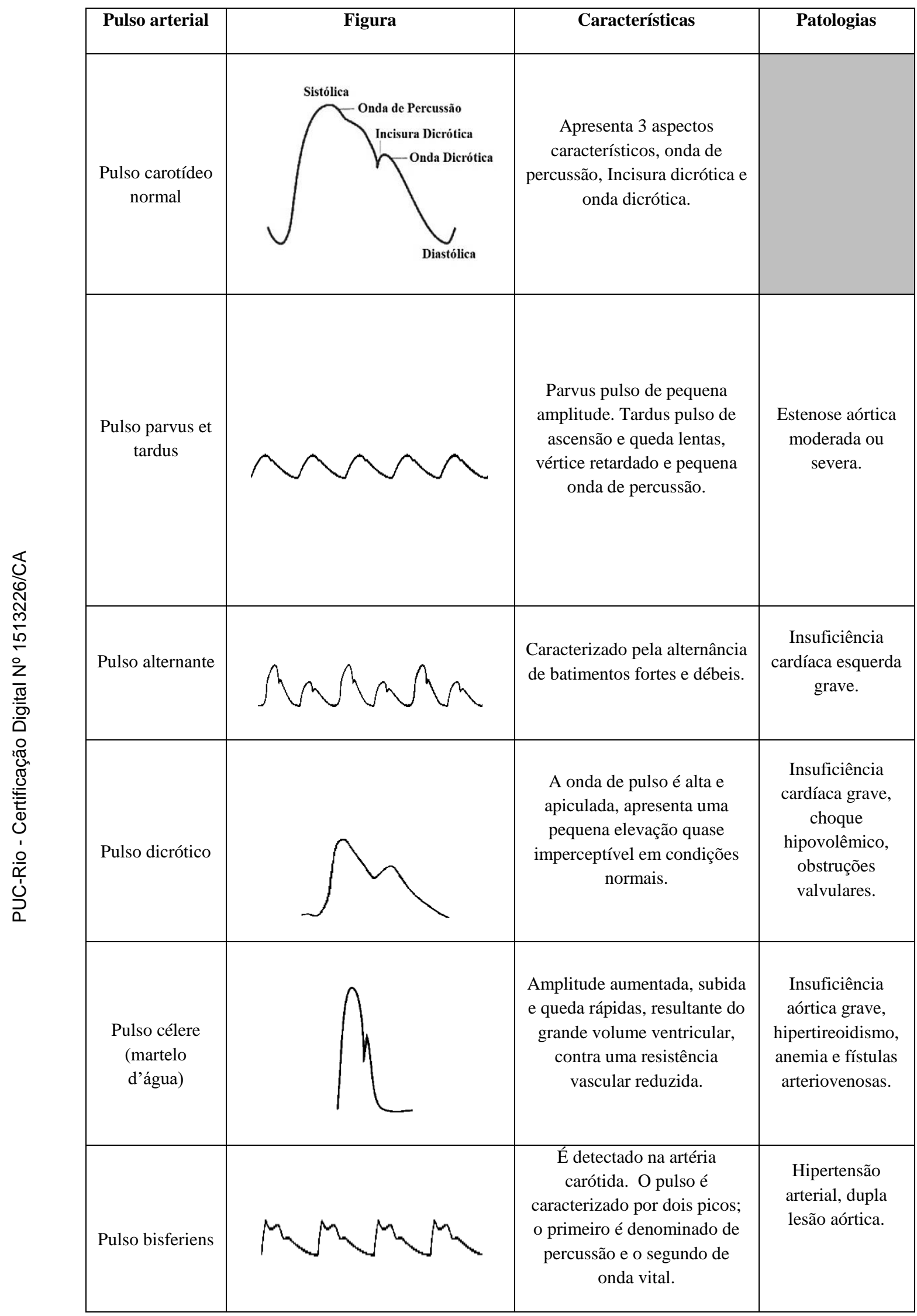




\subsection{2}

\section{Velocidade de onda de pulso arterial}

A ejeção ventricular gera uma onda de pressão que se propaga do coração para as artérias com uma determinada velocidade, denominada velocidade de onda de pulso (VOP). A onda de pulso é transmitida através dos vasos arteriais, e sua velocidade é afetada pelas propriedades visco-elásticas das artérias. Por exemplo, o aumento da rigidez arterial eleva a velocidade de propagação da onda de pulso. Outras propriedades também têm grande impacto na VOP, como a espessura da parede arterial e o diâmetro da cavidade arterial. Ressalta-se que a velocidade da onda de pulso é maior que a velocidade do fluxo sanguíneo. Essa última muda durante o ciclo cardíaco e é da ordem de alguns $\mathrm{cm} / \mathrm{s}$. A velocidade da onda de pulso, por sua vez, é da ordem de alguns $\mathrm{m} / \mathrm{s}$, variando tipicamente entre $4 \mathrm{~m} / \mathrm{s} \mathrm{a}$ $30 \mathrm{~m} / \mathrm{s}$ [47].

A VOP pode ser avaliada em qualquer artéria acessível, no entanto, estudos clínicos evidenciam que a aorta é, por excelência, o local de aumento patológico da rigidez [48]. Assim, índices periféricos não se correlacionam perfeitamente com a rigidez arterial central. O método convencionalmente utilizado para medição da VOP ao longo de um segmento arterial AB, com tamanho conhecido, consiste em medir o intervalo de tempo (dT) que uma determinada onda de pulso leva para ir do ponto $\mathrm{A}$ ao ponto $\mathrm{B}$ do intervalo $\mathrm{AB}$ analisado [49], conforme indicado na Figura 15.

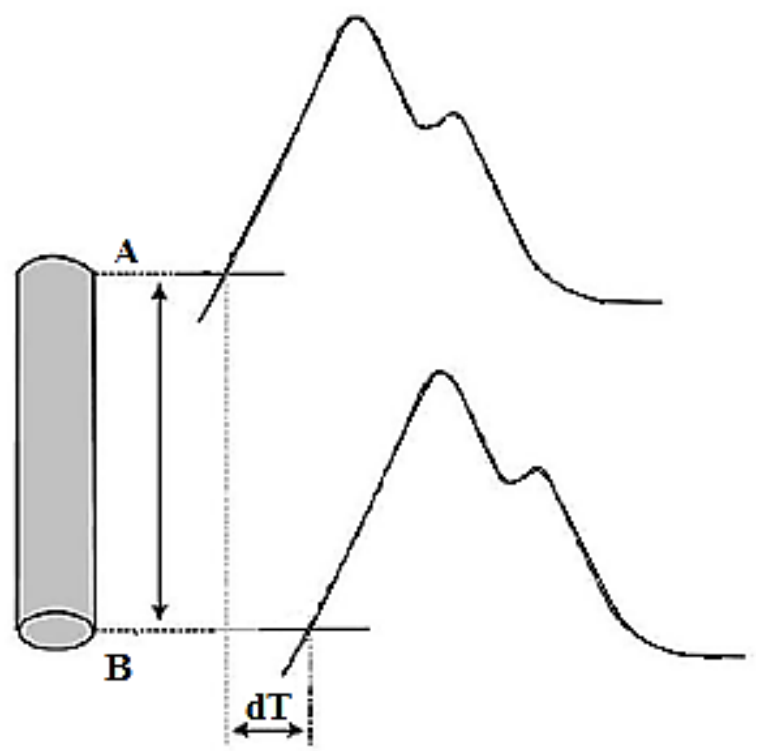

Figura 15 - Diagrama temporal relacionado à medição da VOP, indicando o atraso (dT) entre as ondas de pulso adquiridas nos pontos A e B [49]. 
Na sequência, conhecendo-se o tempo dT que a onda de pulso leva para percorrer o segmento arterial $\mathrm{AB}$, pode-se estimar a velocidade por meio de:

$$
V O P=\frac{A B}{d T}
$$

A medição da velocidade da onda de pulso caracteriza-se como uma ferramenta não invasiva e de fácil implementação, a qual possibilita a avaliação da rigidez arterial e fornece informações sobre propriedades mecânicas da árvore arterial [50]. A VOP é consideravelmente afetada por fatores tais como idade e pressão arterial média. Em pacientes jovens, os vasos tendem a possuir boa distensibilidade e, consequentemente, a VOP é baixa. Por outro lado, em pacientes idosos, a rigidez dos vasos tende a aumentar e, consequentemente, a VOP torna-se mais elevada.

A possibilidade de medição da onda de pulso com dispositivos de alta sensibilidade e baixo custo pode trazer importantes benefícios na abordagem clínica quotidiana para monitoramento do tratamento e prevenção de distúrbios cardíacos.

\section{4 Motivação e objetivos}

De acordo com a Organização Mundial da Saúde (OMS), as doenças cardiovasculares (DCV) são a principal causa de morte no mundo (Figura 16). Apesar da tendência de redução dos riscos de mortalidade por DCV no país e no mundo, algumas projeções indicam o aumento de mortes associadas a estes tipos de doenças em países de baixa e média renda. Tal incremento pode ser atribuído à adoção de modos de vida com maior exposição a fatores de risco e o difícil acesso a serviços de saúde eficazes e equitativos. Dentre os principais fatores de risco estão o tabagismo e o sedentarismo, além de dietas ricas em gorduras saturadas, com consequente aumento dos níveis de colesterol e hipertensão [51]. 
1. Introdução

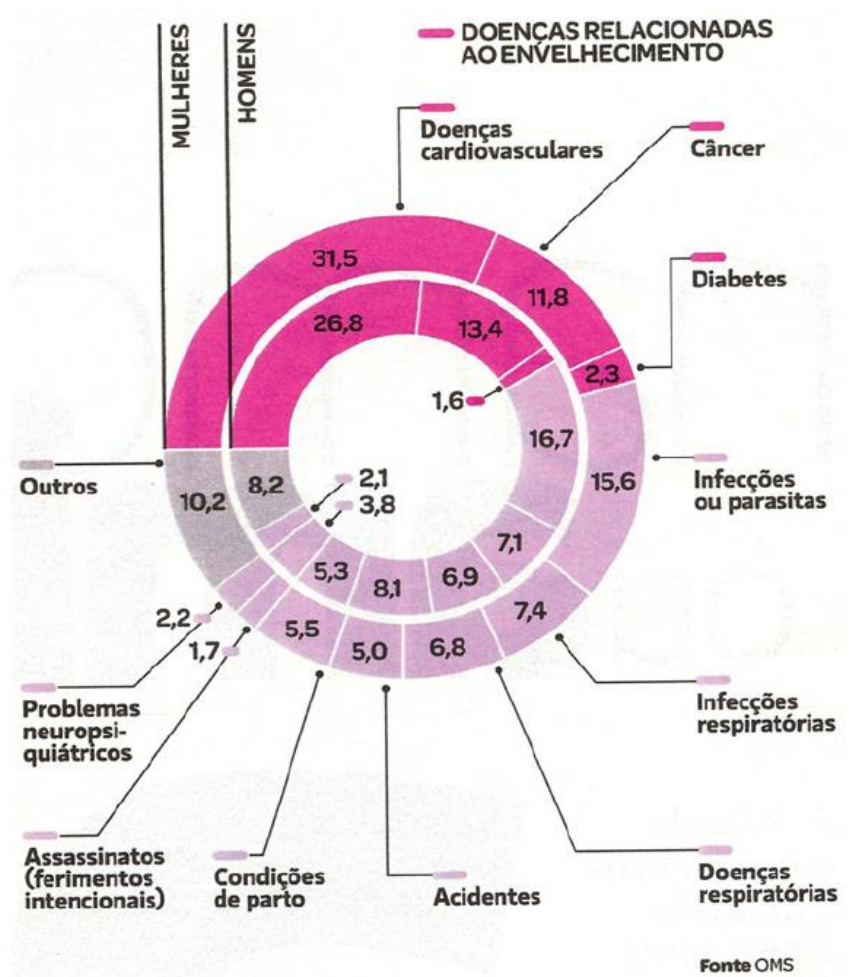

Figura 16 - Taxa de mortalidade no mundo, por causa mortis e gênero, de acordo com a Organização Mundial da Saúde (OMS) [51].

Por sua vez, a Figura 17 apresenta a taxa de mortalidade por doenças cardiovasculares no Brasil, de acordo com a Sociedade Brasileira de Cardiologia [52]. Apesar dos constantes avanços tecnológicos nos métodos de diagnóstico e tratamentos associados ao sistema cardiovascular, nota-se que os óbitos associados a doenças cardiovasculares continuam crescendo gradualmente ao longo dos últimos anos.

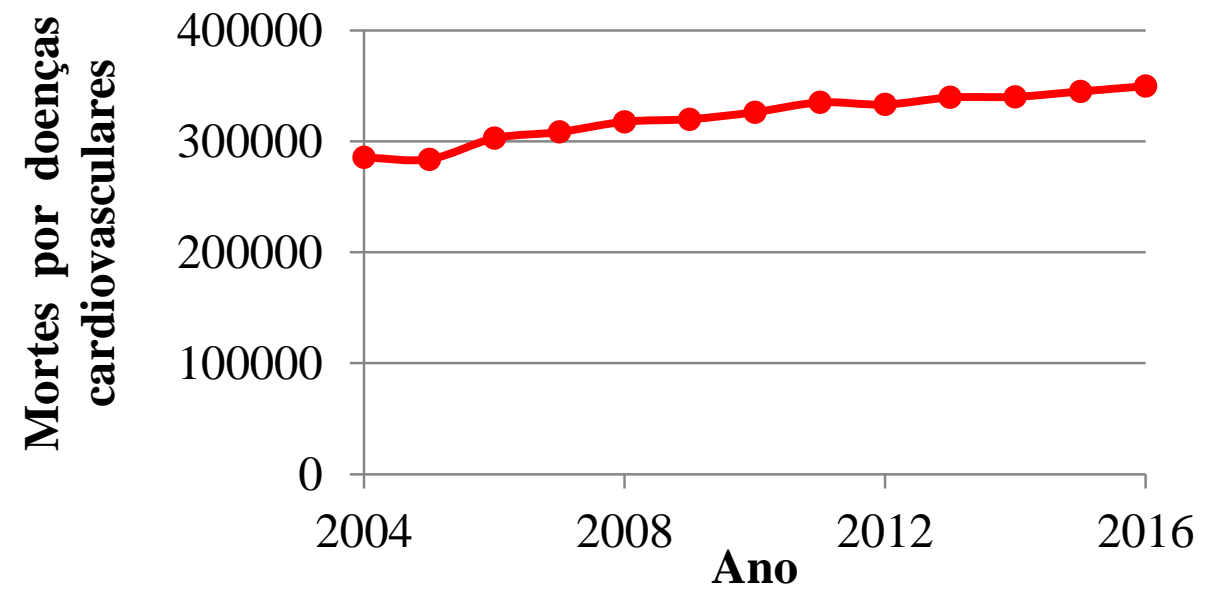

Figura 17 - Mortes associadas a doenças cardiovasculares no Brasil, entre 2004 e 2016 [52].

Estudos atuais suportam a hipótese de que a rigidez arterial é um determinante de eventos fatais e não fatais relacionados com doenças 
cardiovasculares, podendo ampliar o risco de acidentes vasculares cerebrais $[53,54]$. Por sua vez, múltiplos estudos têm constatado que alterações na rigidez da parede arterial, estimadas por medições da velocidade de onda de pulso (VOP), podem ser utilizadas como fator preditivo de doenças cardiovasculares e como indicador de risco de mortalidade [55].

Esta dissertação tem por objetivo o desenvolvimento de um novo transdutor de pressão, baseado na leitura das características de fase de elementos sensores GMI, incorporando uma câmara incompressível para amplificação mecânica, destinado a aplicações biomédicas, tais como a medição da onda de pulso arterial e da velocidade da onda de pulso.

A presente pesquisa dá particular atenção à maximização da sensibilidade do dispositivo e à otimização da razão sinal-ruído do transdutor, a fim de se permitir a adequada análise da morfologia dos sinais medidos e a consequente estimação dos parâmetros de interesse atrelados a tais registros.

O novo transdutor aqui proposto busca atender às importantes características preconizadas pela metrologia aplicada ao setor da saúde, como: inocuidade, nãoinvasividade, exatidão, precisão, baixo custo de operação e produção [56,57]. Dessa forma, pretende-se que os frutos deste trabalho contribuam para a inovação da instrumentação utilizada no setor biomédico.

\section{5 \\ Organização da Dissertação}

Este trabalho está subdividido em 4 capítulos, resumidamente descritos a seguir:

* O Capítulo 1 introduz os conceitos-chave dos principais temas abordados pela dissertação, como Magnetoimpedância Gigante, onda de pulso arterial e transdutores de pressão. Também é apresentada uma contextualização histórica, de forma que se possa visualizar o caminho percorrido até o estado da arte atual, evidenciando-se a relevância e as contribuições que esta dissertação pretende oferecer.

* O Capítulo 2 apresenta os métodos e procedimentos empregados para obtenção dos resultados experimentais de caracterização do sensor GMI utilizado neste trabalho. Apresentam-se as curvas características de 
módulo e fase da impedância das amostras GMI em função do campo magnético, além do modelo elétrico das amostras, que é fundamental para consecução das simulações computacionais do circuito de transdução. Detalham-se ainda os principais aspectos inerentes ao desenvolvimento do circuito eletrônico proposto para o transdutor. Por fim, são apresentados e discutidos os resultados computacionais e experimentais obtidos.

* O Capítulo 3 descreve o desenvolvimento do protótipo do transdutor de pressão GMI. Cada componente do transdutor é detalhado e são apresentadas as principais avaliações experimentais realizadas a fim de se analisar seu desempenho. Compara-se o desempenho do circuito em duas configurações, as quais se distinguem quanto ao tipo de fonte de campo magnético utilizada (agulha magnetizada e ímã permanente). Finalmente, são detalhados os procedimentos adotados nas medições da Onda de Pulso Arterial. Os resultados obtidos são apresentados e analisados, para cada uma das diferentes medições efetuadas.

O Capítulo 4 discute os pontos críticos associados ao funcionamento do circuito eletrônico do transdutor de pressão e apresenta as conclusões dos trabalhos de pesquisa realizados nesta dissertação. Finalmente, são sugeridos possíveis trabalhos futuros que permitam a otimização do desempenho e a expansão da funcionalidade do dispositivo aqui desenvolvido. 
2.

2.

\section{Circuito Eletrônico de Transdução}

Neste capítulo são apresentados os métodos e procedimentos empregados para a obtenção das curvas de impedância características do sensor GMI utilizado ao longo deste trabalho. As curvas características de módulo e fase da impedância das amostras GMI em função do campo magnético são analisadas e o modelo elétrico das amostras é obtido, sendo este modelo fundamental para consecução das simulações computacionais do circuito de transdução.

Nas seções 2.2, 2.3 e 2.4, detalham-se os principais aspectos inerentes ao desenvolvimento do circuito eletrônico proposto para o transdutor; os resultados computacionais e experimentais do circuito são avaliados e discutidos.

\section{1 \\ Caracterização Experimental do Sensor GMI}

A sensibilidade do transdutor de pressão GMI está diretamente relacionada à sensibilidade do sensor GMI, a qual é afetada por uma série de parâmetros como amplitude, frequência e nível $\mathrm{CC}$ da corrente de excitação; dimensões (comprimento, largura, espessura) das amostras GMI; campo magnético de polarização (gerado por uma fonte externa); entre outros [9]. Tendo em vista que se deseja implementar um transdutor baseado na leitura das características de fase do elemento sensor GMI, a fim de se otimizar a sensibilidade do transdutor, é preciso definir o conjunto de parâmetros responsável por maximizar a sensibilidade de fase $S_{\text {fase }}$ do sensor, a qual é dada por

$$
S_{\text {fase }}=\frac{d \theta_{\text {sens }}(H)}{d H}
$$

Neste trabalho utilizou-se uma amostra GMI do tipo LMI, em forma de fita, com espessura média de $60 \mu \mathrm{m}$, largura de $1,5 \mathrm{~mm}$, comprimento de 2,5 $\mathrm{cm}$ e composição química $\mathrm{Co}_{70} \mathrm{Fe}_{5} \mathrm{Si}_{15} \mathrm{~B}_{10}$. A amostra foi caracterizada de modo a analisar as variações de módulo $\left(\left|Z_{\text {sens }}\right|\right)$ e fase $\left(\theta_{\text {sens }}\right)$ da impedância em função de um campo magnético externo $\mathrm{CC}$ aplicado $(H)$. Em trabalhos anteriores [5,7] 
2.

verificou-se que amostras GMI com características similares à amostra aqui utilizada apresentaram sensibilidade de fase $S_{\text {fase }}$ ótima para uma corrente de excitação com $80 \mathrm{~mA}$ de nível CC, superposta a uma componente senoidal com $15 \mathrm{~mA}$ de amplitude e $100 \mathrm{kHz}$ de frequência. Assim, optou-se por arbitrar tais parâmetros para a corrente de excitação $\left(i_{c}\right)$, sendo esta corrente dada por

$$
i_{c}=[80+15 \cdot \operatorname{sen}(2 \pi(100 \mathrm{kHz}) t)] m A
$$

\subsection{1}

\section{Sistema de caracterização das amostras GMI}

Para a caracterização das amostras GMI, utiliza-se uma bobina de Helmholtz para a geração de um campo magnético contínuo e uniforme, sobre o volume da amostra, com magnitude ajustável por meio de uma fonte de corrente controlável. A Bobina de Helmholtz é uma estrutura convencionalmente utilizada para geração de campos magnéticos de baixa frequência, sendo composta por duas bobinas circulares de diâmetro idêntico, afastadas entre si por uma distância igual ao raio das bobinas. Cada bobina possui a mesma quantidade $\mathrm{N}$ de espiras, pelas quais circulam uma dada corrente $I$. A Figura 18 apresenta uma foto da estrutura real, utilizada no presente trabalho.

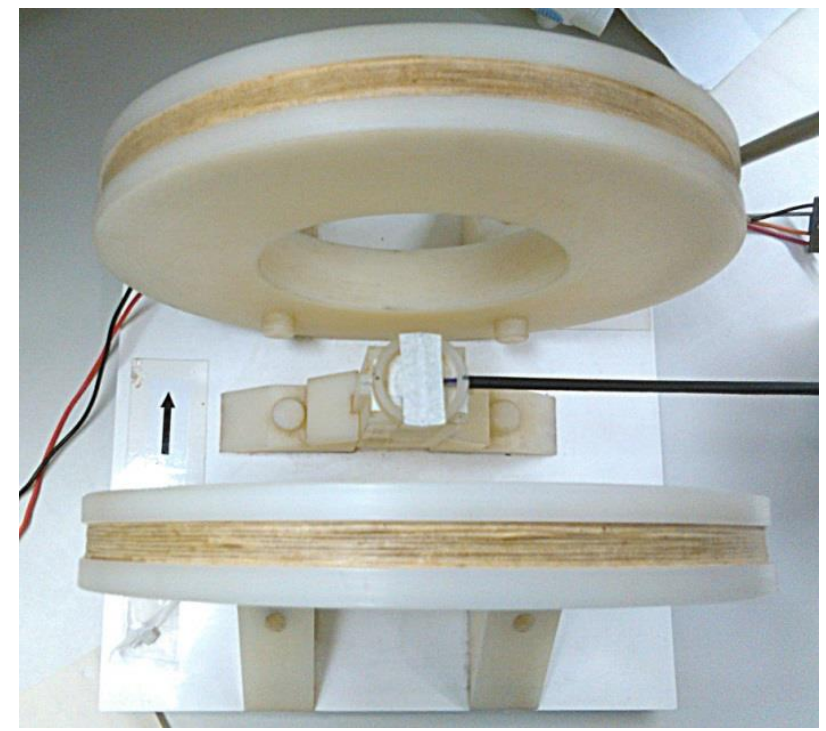

Figura 18 - Bobina de Helmholtz com uma amostra GMI posicionada em seu centro.

O campo magnético $(\mathrm{H})$ gerado no centro do par de Helmholtz, em função da corrente I que flui por suas espiras, pode ser calculado por meio da lei de BiotSavart e é dado por

$$
H=\frac{8 \cdot \mu_{0} \cdot N \cdot I}{5 \sqrt{5} R}
$$


2.

Circuito eletrônico de transdução

onde $\mathrm{N}$ é o número total de espiras em cada bobina e $\mathrm{R}$ é o raio das bobinas.

A Bobina de Helmholtz utilizada na caracterização experimental possui 48 espiras, em cada bobina, e um raio de $15 \mathrm{~cm}$. Logo, tem-se que o campo magnético $\mathrm{H}$, em oersteds, em função da corrente $\mathrm{I}$, em amperes, é dado aproximadamente por

$$
H \cong 2,877 \cdot I
$$

A Figura 19 apresenta de forma mais detalhada o sistema de caracterização utilizado. O sensor GMI é colocado no centro da Bobina de Helmholtz e posicionado de forma que o campo gerado pela Bobina seja longitudinal ao comprimento da amostra. Por sua vez, a fim de minimizar a influência do campo magnético da Terra nas medições, o conjunto sensor-bobina é posicionado de forma a garantir que o comprimento da amostra sensora seja perpendicular à direção do campo da Terra. Este ajuste de posição é feito com o auxílio de uma bússola.

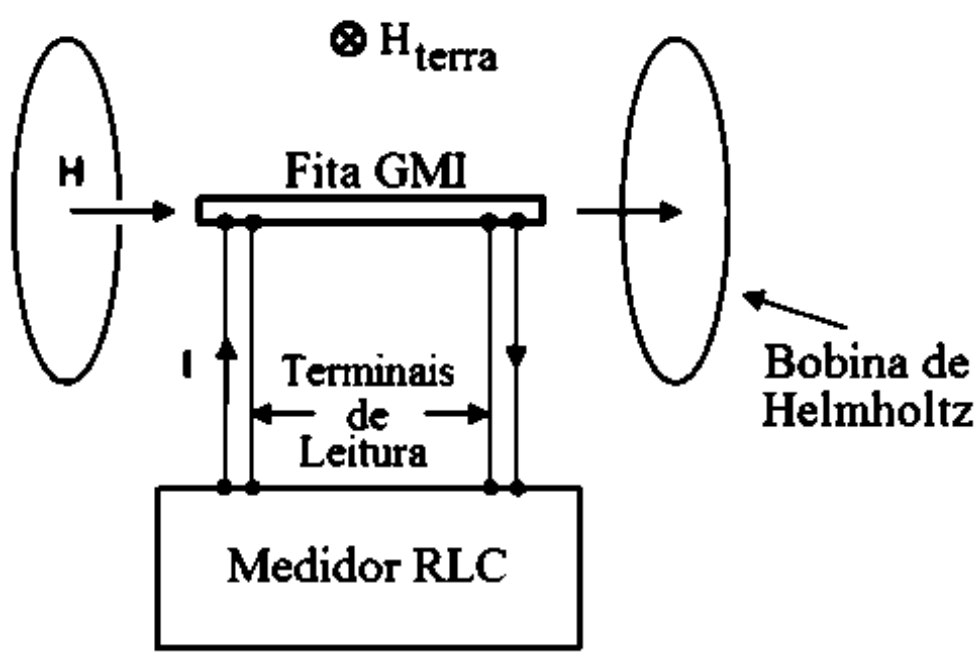

Figura 19 - Diagrama de Blocos do sistema utilizado na caracterização das amostras GMI.

O sistema de caracterização conta ainda com um medidor RLC (4285A, Agilent), o qual é responsável pela leitura de módulo e fase da amostra (Figura 19). Destaca-se que tal medidor também é capaz de excitar a amostra GMI com a corrente desejada, permitindo o ajuste dos parâmetros da corrente: níveis CC entre 0 mA e 100 mA, amplitudes rms entre 0 mA e 20 mA, e frequências entre $75 \mathrm{kHz}$ e $30 \mathrm{MHz}$. 
2.

\section{1 .2}

\section{Medições experimentais}

O sistema de caracterização descrito na subseção anterior foi empregado na obtenção experimental das curvas características de fase e módulo da impedância, do sensor GMI, em função do campo magnético. As medições foram realizadas de modo a se poder avaliar efeitos de histerese, os quais costumam afetar o comportamento de sensores magnéticos. Dessa forma, as medições têm início em $H_{\text {início }}=0$ Oe. A partir deste ponto, o campo é aumentado gradativamente até um valor máximo $H_{\operatorname{máx}}=2$ Oe. Na sequência, o campo é reduzido até um valor mínimo $H_{\min }=-2$ Oe. Finalmente, o ciclo de histerese é concluído ao se percorrer o trajeto de $H_{\min }$ até $H_{\text {início. As }}$ medições foram realizadas utilizando-se um passo $\Delta \mathrm{H}=0,1 \mathrm{Oe}$, sendo que a cada passo foram medidos os valores correspondentes de módulo e fase da amostra. Adotando-se o procedimento descrito, para cada valor de campo magnético avaliado obtêm-se dois valores de módulo e fase, com exceção dos extremos da curva $H_{m a ́ x}$ e $H_{m i n}$, que possuem apenas um valor, e de $H_{\text {início }}$, que possui três valores associados [5].

A interligação da amostra GMI ao circuito eletrônico de transdução foi feita por meio de um cabo de conexão, conforme indicado na Figura 20. Dessa forma, de modo a tornar as caracterizações aqui realizadas mais fidedignas, as mesmas apresentam os resultados das medições da impedância resultante da associação sensor-cabo, de modo a se poder identificar eventuais influências do cabo utilizado nos resultados. Neste intuito, foram realizadas medições utilizando-se dois comprimentos distintos de cabos, aqui denominados: cabo longo $(85 \mathrm{~cm}) \mathrm{e}$ cabo curto $(20 \mathrm{~cm})$.

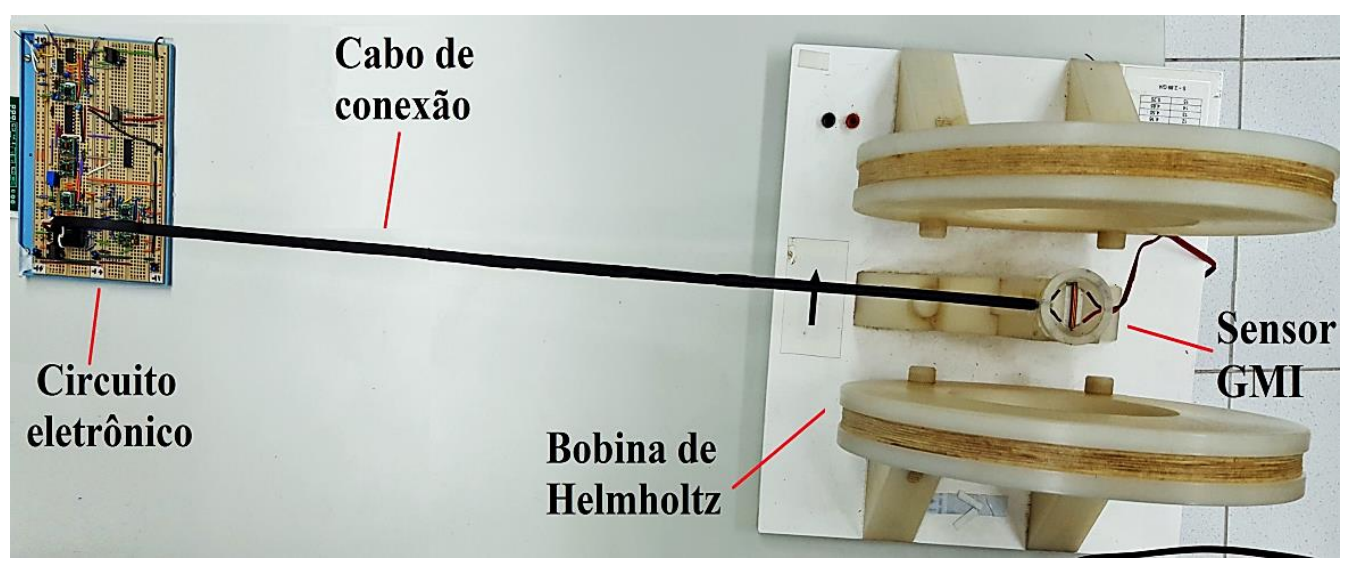

Figura 20 - Arranjo experimental implementado para a caracterização do sensor GMI. Nessa configuração é utilizado o cabo de conexão longo $(85 \mathrm{~cm})$ 
2.

Circuito eletrônico de transdução

As curvas experimentais de histerese de módulo $\left|\mathrm{Z}_{\text {sens }}(\mathrm{H})\right|$ e fase $\theta_{\text {sens }}(\mathrm{H})$ da impedância são apresentadas na Figura 21, para o cabo curto $(20 \mathrm{~cm})$, e na Figura 22 , para o cabo longo $(85 \mathrm{~cm})$.

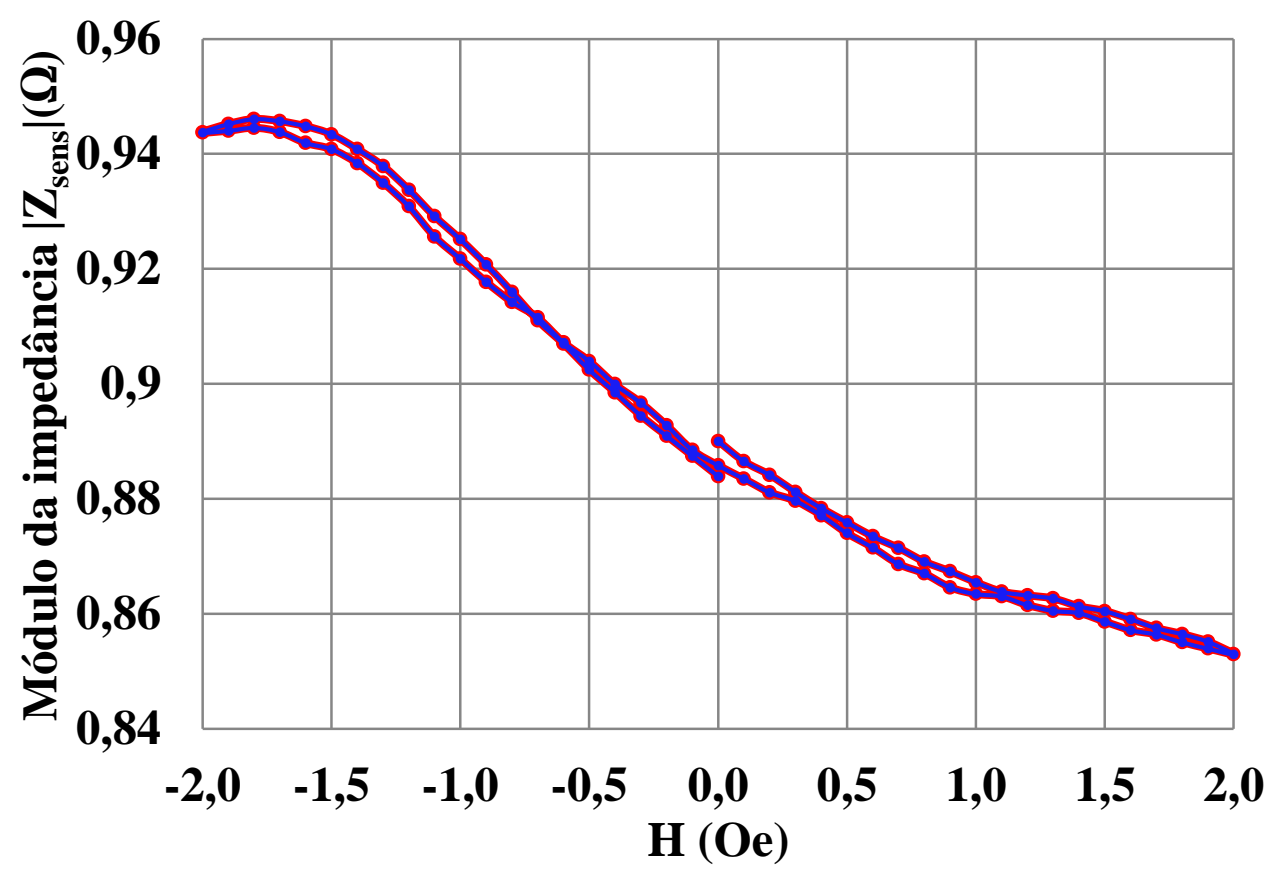

(a)

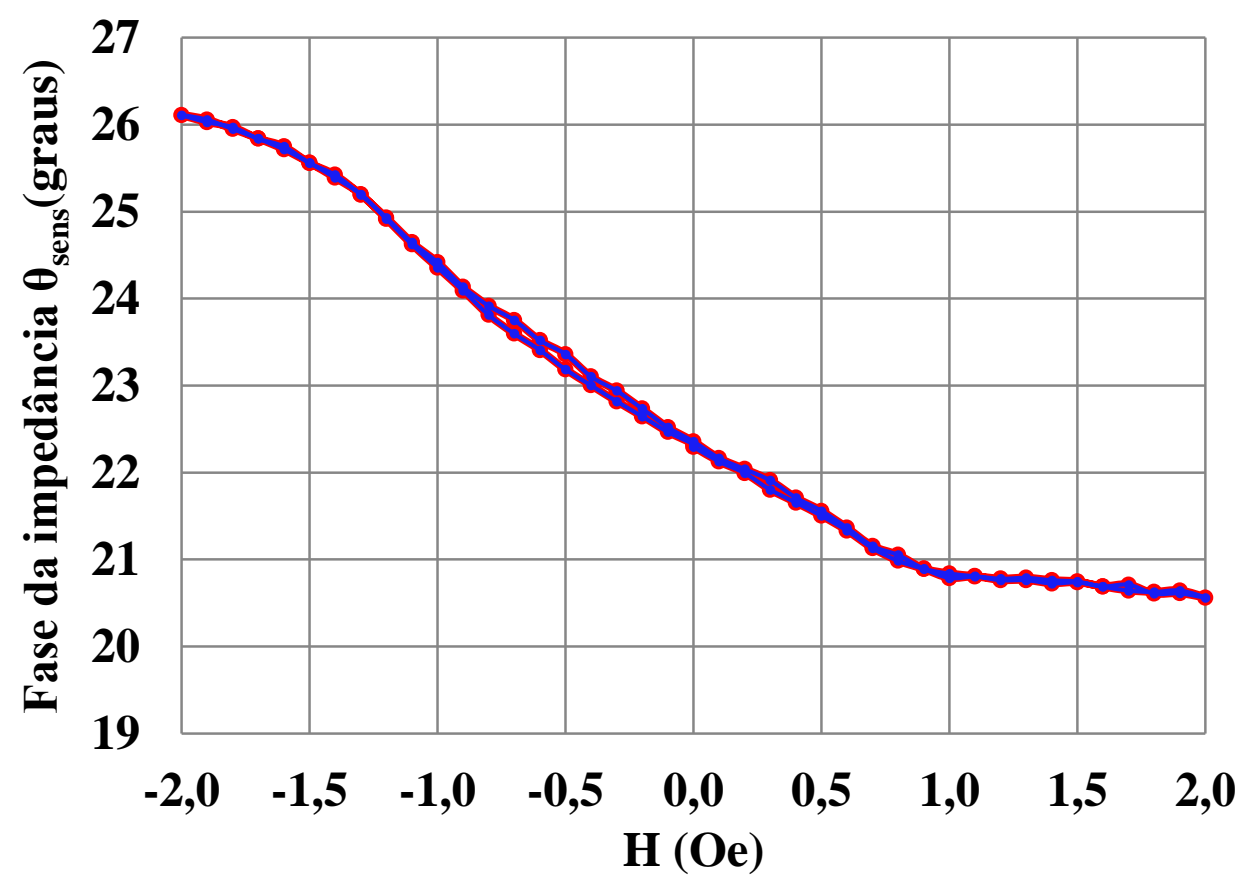

(b)

Figura 21 - Curvas de Histerese de a) Módulo e b) Fase da amostra GMl com $2,5 \mathrm{~cm}$ de comprimento, excitada por ic $=[80+15 \cdot \operatorname{sen}(2 \cdot \pi \cdot 100 \mathrm{k} \cdot \mathrm{t})] \mathrm{mA}$, utilizando-se um cabo curto $(20 \mathrm{~cm})$ para conexão do circuito com o elemento sensor. 
2.

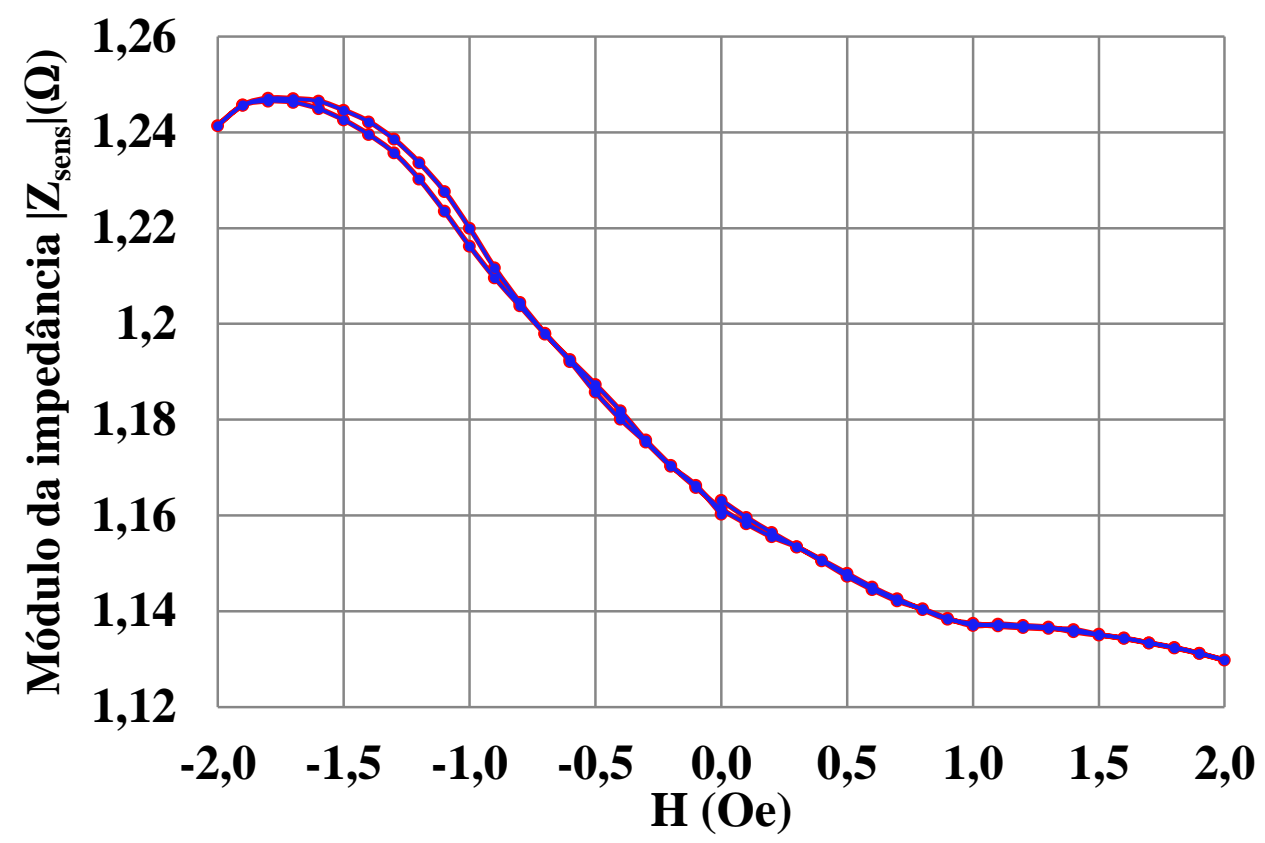

(a)

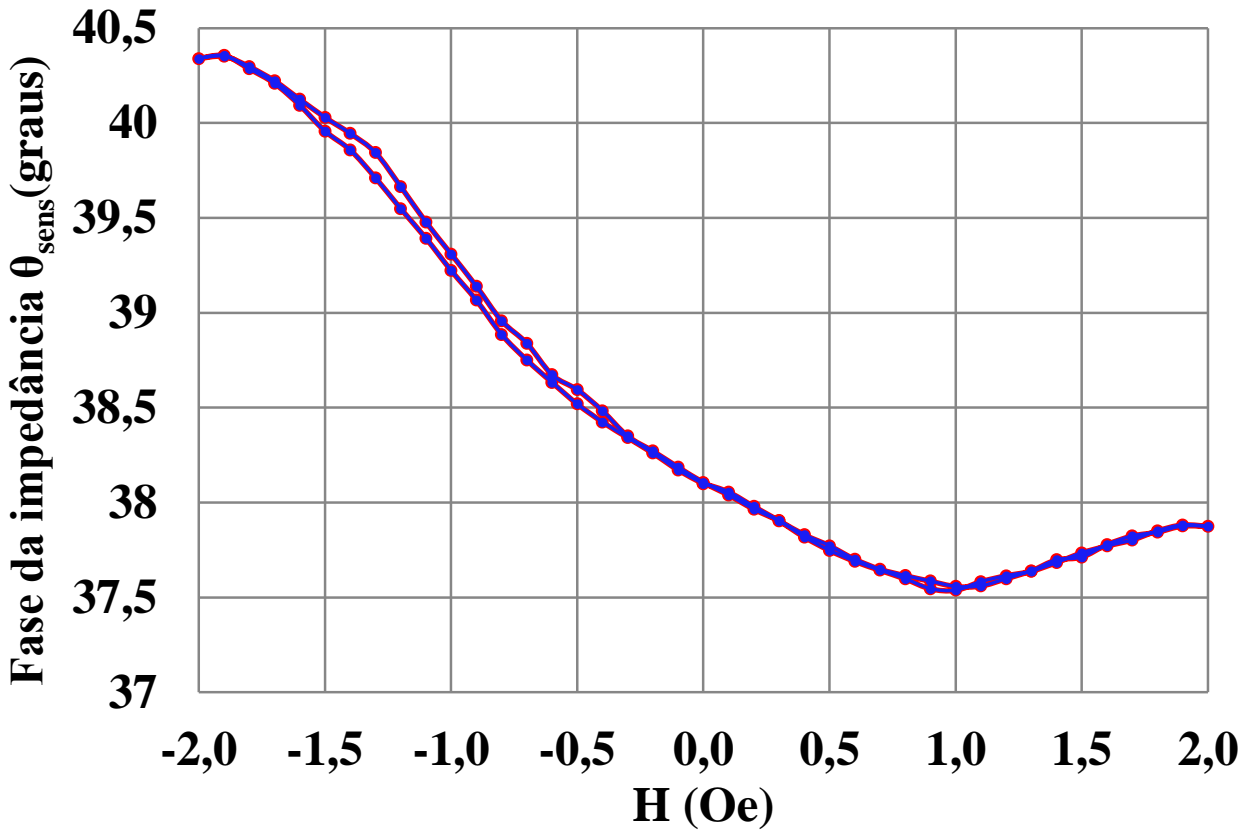

(b)

Figura 22 - Curvas de Histerese de a) Módulo e b) Fase da amostra GMI com 2,5 cm de comprimento, excitada por ic $=[80+15 \cdot \operatorname{sen}(2 \cdot \pi \cdot 100 \mathrm{k} \cdot \mathrm{t})] \mathrm{mA}$, utilizando-se um cabo longo $(85 \mathrm{~cm})$ para conexão do circuito com o elemento sensor.

Ao se inspecionar a Figura 21 e a Figura 22, percebe-se que em ambos os casos a histerese de módulo e fase foi satisfatoriamente pequena. Esta é uma característica extremamente desejável, tendo em vista a sua utilidade como elemento sensor de um transdutor.

Por sua vez, as curvas médias de módulo e fase da impedância de amostras GMI são explicitadas na Figura 23, para o cabo curto, e na Figura 24, para o cabo 
2.

Circuito eletrônico de transdução

longo. As curvas são calculadas fazendo-se a média ponto-a-ponto das respectivas curvas de histerese apresentadas nas Figuras 21 e 22.

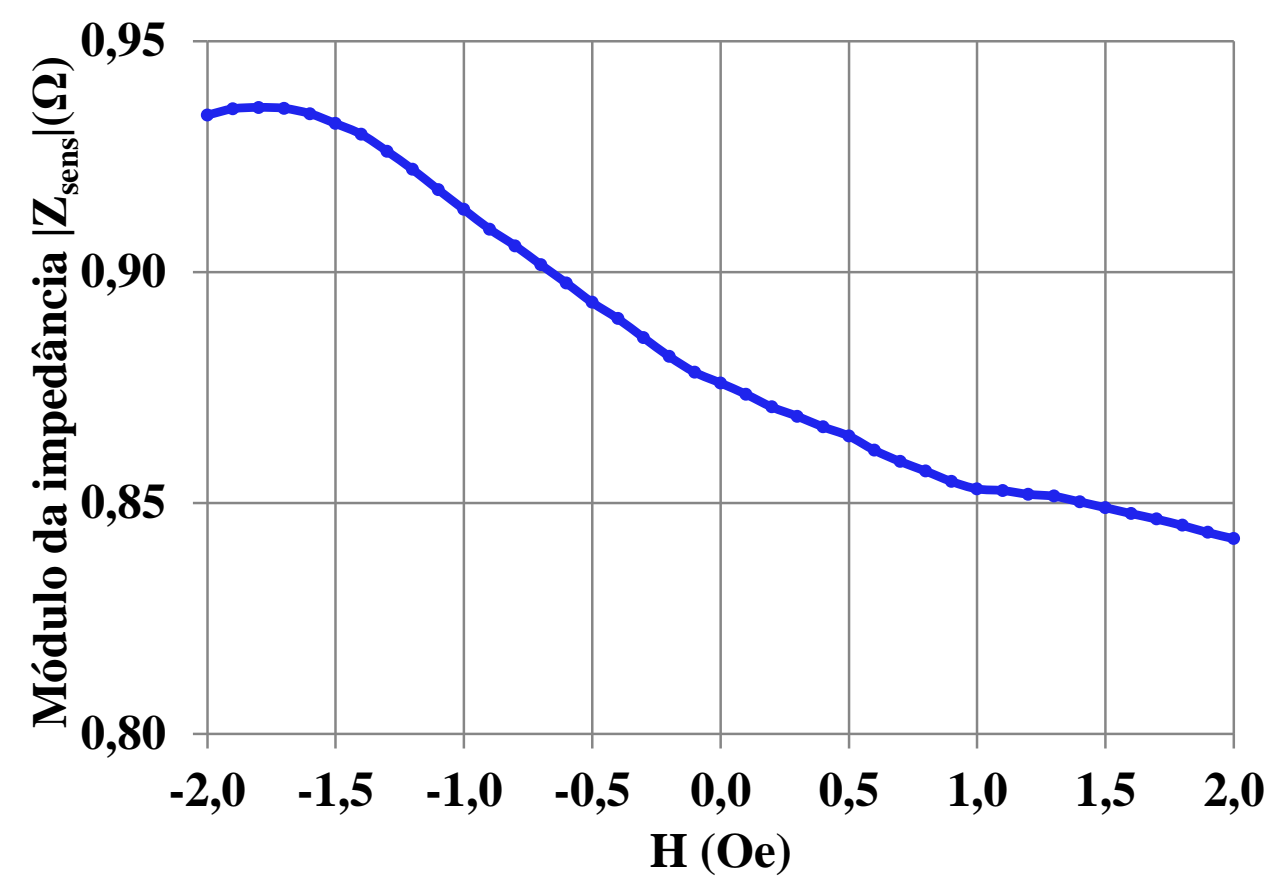

(a)

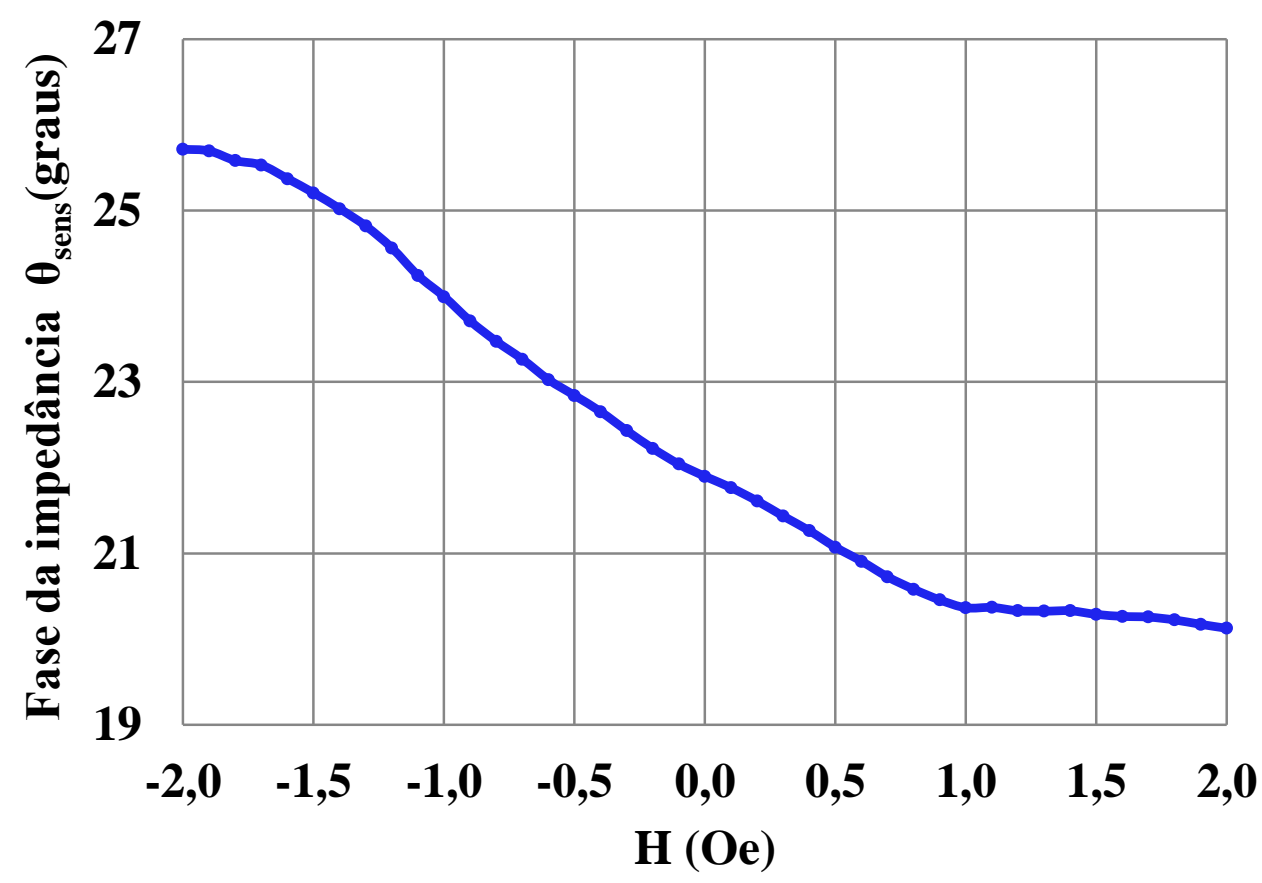

(b)

Figura 23 - Curvas Médias de a) Módulo e b) Fase da amostra GMl com 2,5 cm de comprimento, excitada por ic $=[80+15 \cdot \operatorname{sen}(2 \cdot \pi \cdot 100 \mathrm{k} \cdot \mathrm{t})] \mathrm{mA}$, utilizando-se um cabo curto $(20 \mathrm{~cm})$ para conexão do circuito com o elemento sensor. 
2.

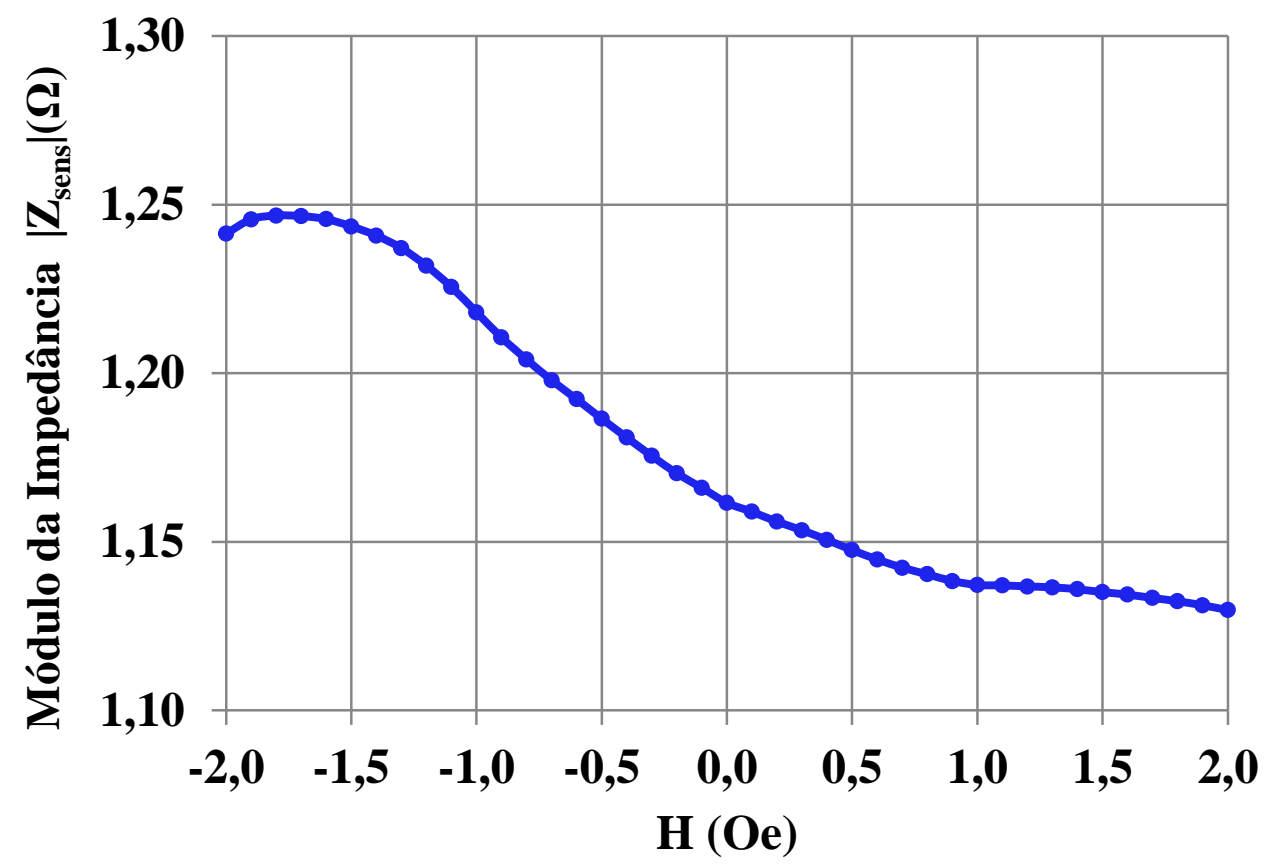

(a)

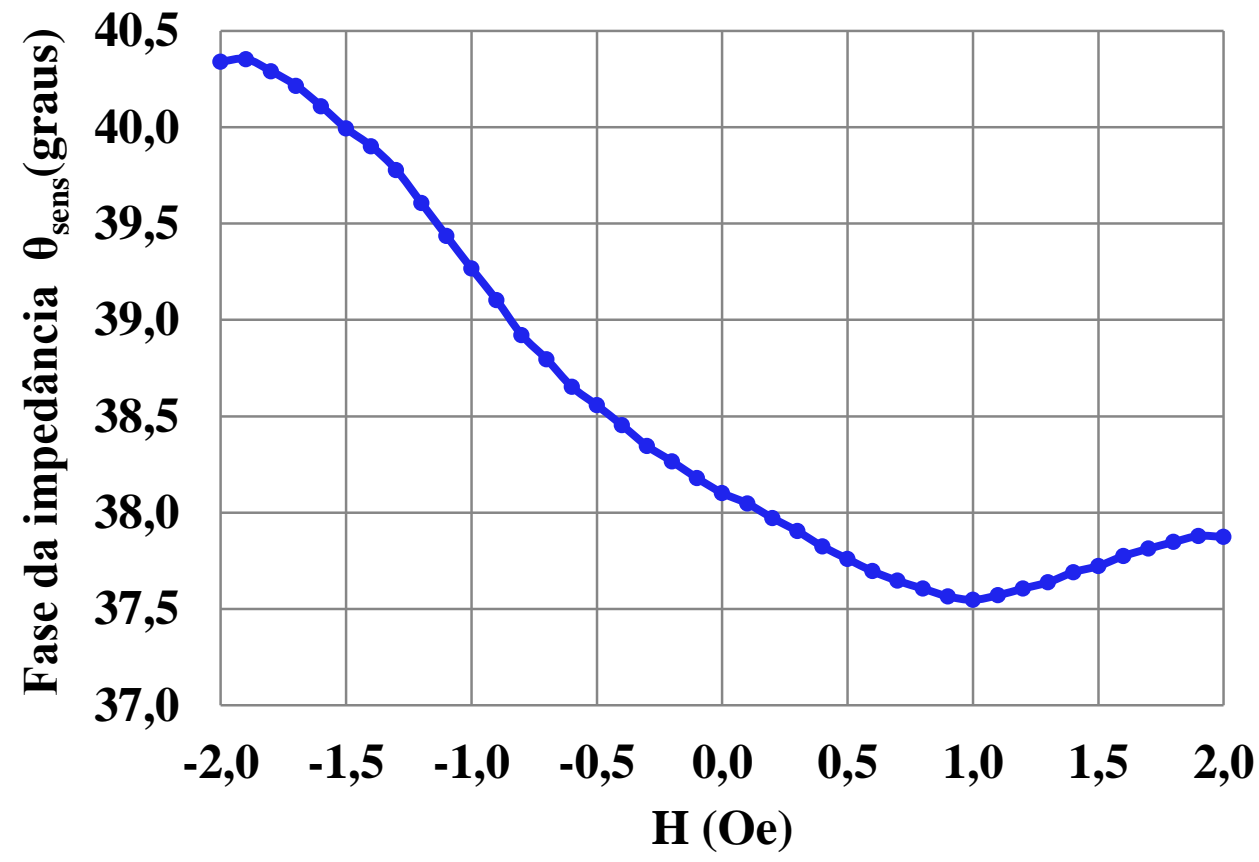

(b)

Figura 24 - Curvas Médias de (a) Módulo e (b) Fase da amostra GMI com 2,5 cm de comprimento, excitada por ic $=[80+15 \cdot \operatorname{sen}(2 \cdot \pi \cdot 100 \mathrm{k} \cdot \mathrm{t})] \mathrm{mA}$, utilizando-se um cabo longo $(85 \mathrm{~cm})$ para conexão do circuito com o elemento sensor.

Os resultados apresentados indicam claramente que o cabo utilizado afeta o comportamento das amostras. Assim, comparando-se as Figuras 23 e 24, verificase que os valores absolutos de módulo e fase obtidos são significativamente alterados, em função do tamanho de cabo utilizado. Tal comportamento era esperado, visto que os elementos sensores possuem impedâncias extremamente baixas, da ordem de ohms, as quais estão associadas em série com as impedâncias 
2.

Circuito eletrônico de transdução

dos cabos que, apesar de serem pequenas, apresentam valores próximos aos dos elementos sensores. Por sua vez, tendo em vista as curvas de fase obtidas na Figura 23(b) e 24(b), percebe-se que, em ambos os casos, a região entre -0,4 Oe e -1,5 Oe possui alta sensibilidade e é satisfatoriamente linear. Consequentemente, objetivando garantir a linearidade da resposta do transdutor e maximizar sua sensibilidade, decidiu-se operar o elemento sensor dentro desta região. Note que, para tal fim, é importante polarizar o sensor em $\mathrm{H}=-0,95$ Oe (ponto médio da região de operação), o que possibilita a maximização da excursão simétrica dentro desta região.

A Figura 25 apresenta com mais detalhes a região de operação selecionada, para as medições realizadas com o cabo curto, enquanto que a Figura 26 apresenta os resultados para as medições feitas com o cabo longo.

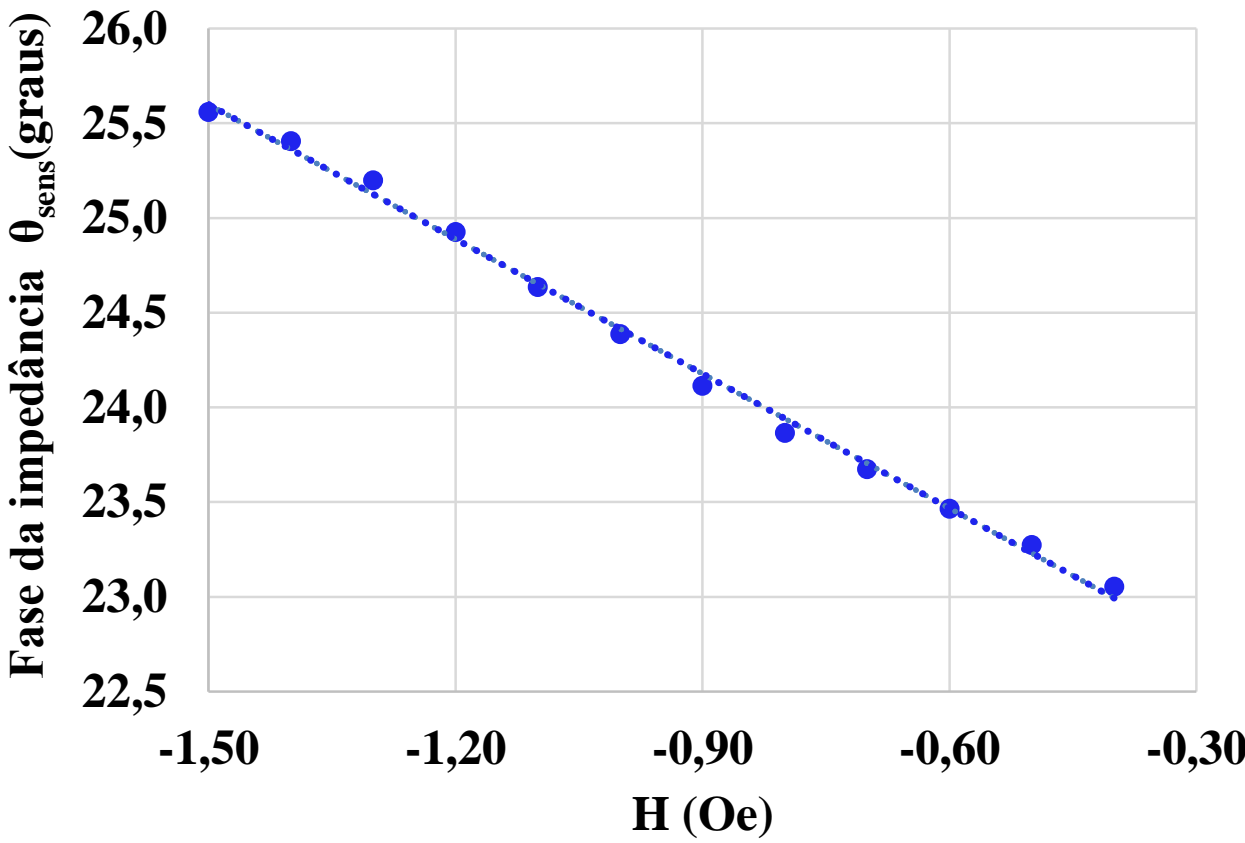

Figura 25 - Região Linear da curva média de fase $(-1,5 \mathrm{Oe}<\mathrm{H}<-0,4 \mathrm{Oe})$, obtida por meio de medições do elemento sensor associado ao cabo curto $(20 \mathrm{~cm})$. 
2.

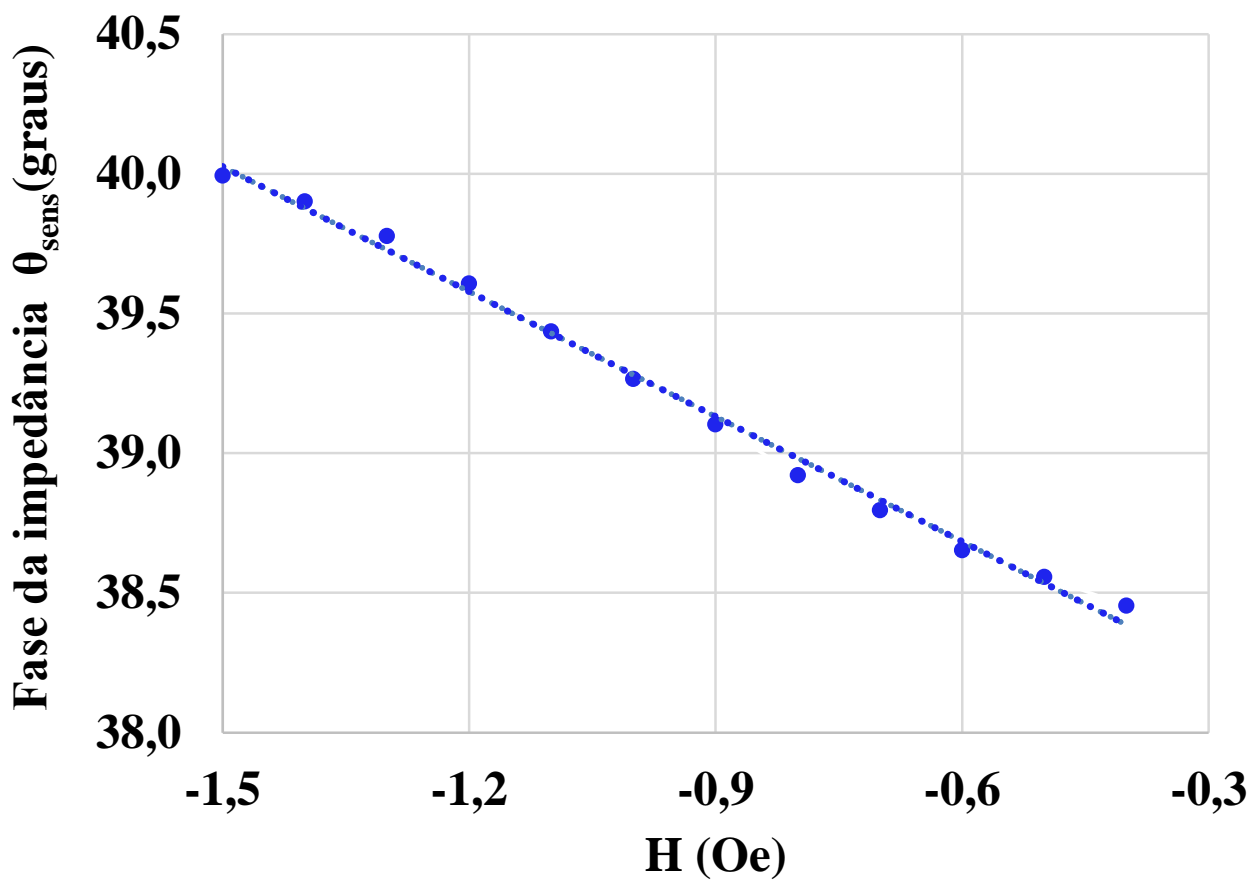

Figura 26 - Região Linear da curva média de fase $(-1,5 \mathrm{Oe}<\mathrm{H}<-0,4 \mathrm{Oe})$, obtida por meio de medições do elemento sensor associado ao cabo longo.

Inspecionando-se a Figura 25 (cabo curto), verifica-se que a região selecionada é fortemente linear e apresenta sensibilidade média de $2,37^{\circ} \cdot \mathrm{Oe}^{-1}$. Por sua vez, inspecionando-se a Figura 26 (cabo longo), verifica-se que a sensibilidade é de $1,49^{\circ} \cdot \mathrm{Oe}^{-1}$. Consequentemente, também é possível concluir que a sensibilidade é dependente do comprimento do cabo utilizado para interconexão do sensor ao circuito de transdução. Tal efeito era esperado, pois ao se aumentar o tamanho do cabo, aumenta-se a componente resistiva e indutiva da impedância equivalente formada pela associação cabo-sensor. Por sua vez, apenas a impedância do elemento sensor é dependente do campo magnético, o que acaba por reduzir a sensibilidade.

Tendo em vista que, na região de operação, o comportamento de fase em função do campo magnético é satisfatoriamente linear, em ambos os casos (Figura 25 e Figura 26), podem-se definir polinômios de ajuste linear, a fim de modelar tais comportamentos. A eq. (7) apresenta o polinômio de ajuste para a situação na qual a amostra sensora está associada a um cabo curto (Figura 25). Por sua vez, a eq. (8) apresenta o polinômio de ajuste para a situação na qual a amostra sensora está associada a um cabo longo (Figura 26).

$$
\begin{aligned}
& \theta_{\text {sens }}=\left(-2,37^{\circ} \cdot O e^{-1}\right) \cdot H+22,05^{\circ} \\
& \theta_{\text {sens }}=\left(-1,49^{\circ} \cdot O e^{-1}\right) \cdot H+37,79^{\circ}
\end{aligned}
$$


2.

\subsection{3}

Modelo elétrico da amostra GMI

As amostras GMI analisadas podem ser modeladas como uma resistência em série com uma indutância, cujos valores variam em função do campo magnético externo aplicado [6,7,15-17], conforme definido por

$$
Z_{\text {sens }}(H)=R_{\text {sens }}(H)+j \omega L_{\text {sens }}(H)
$$

A partir dos resultados de módulo $\left(\left|Z_{\text {sens }}\right|\right)$ e fase $\left(\theta_{\text {sens }}\right)$ apresentados nas Figuras 23 e 24, é possível calcular os respectivos valores de resistência $R_{\text {sens }}$ e indutância $\mathrm{L}_{\text {sens, }}$, por meio das eqs. (10) e (11). Por sua vez, a dependência destes valores com o campo magnético H é mostrada na Figura 27, para a situação na qual utilizou-se um cabo curto, e na Figura 28, para a situação na qual utilizou-se um cabo longo.

$$
R_{\text {sens }}(H)=\left|Z_{\text {sens }}(H)\right| \cdot \cos \theta_{\text {sens }}(H)
$$

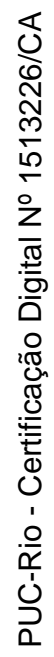

$$
L_{\text {sens }}(H)=\frac{\left|Z_{\text {sens }}(H)\right| \cdot \operatorname{sen} \theta_{\text {sens }}(H)}{\omega}
$$

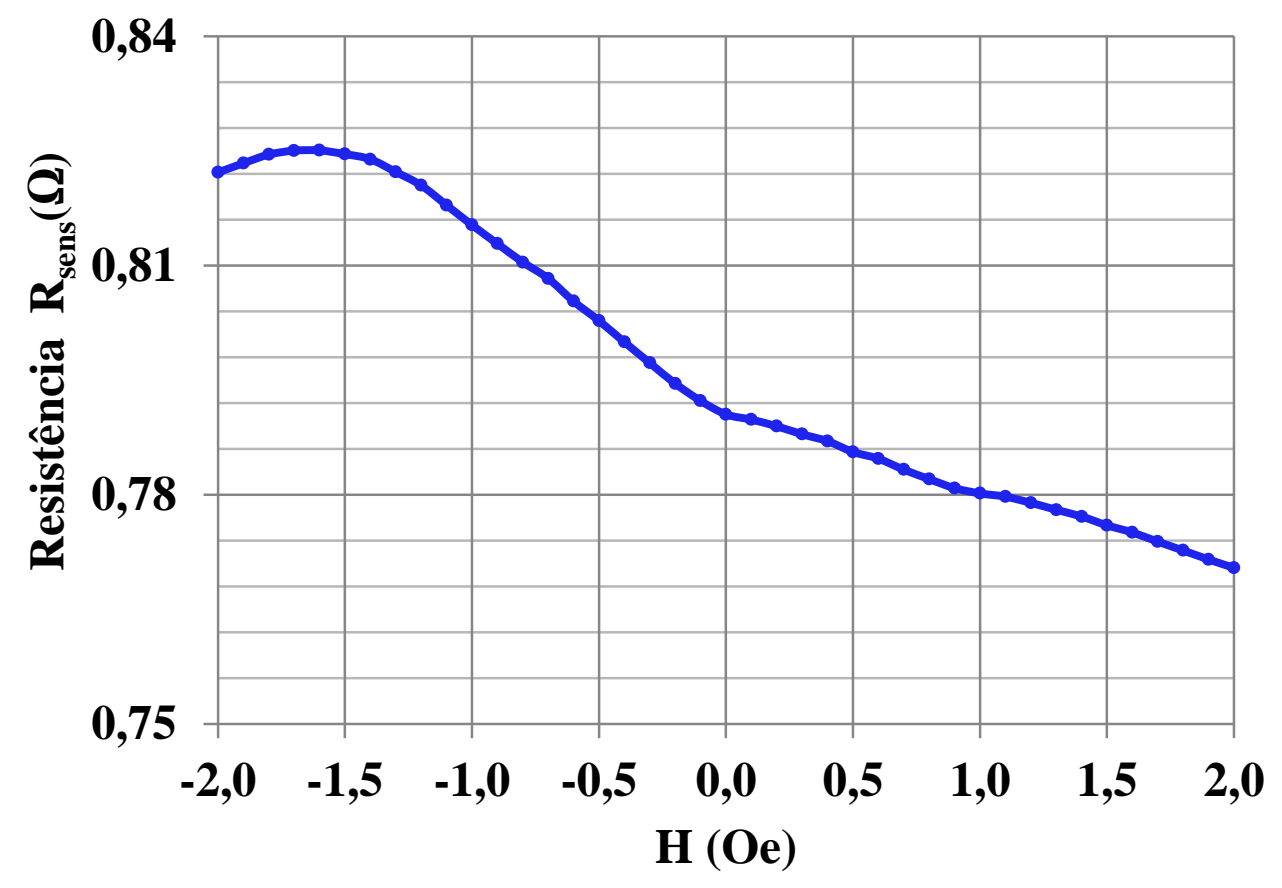

(a) 
2.

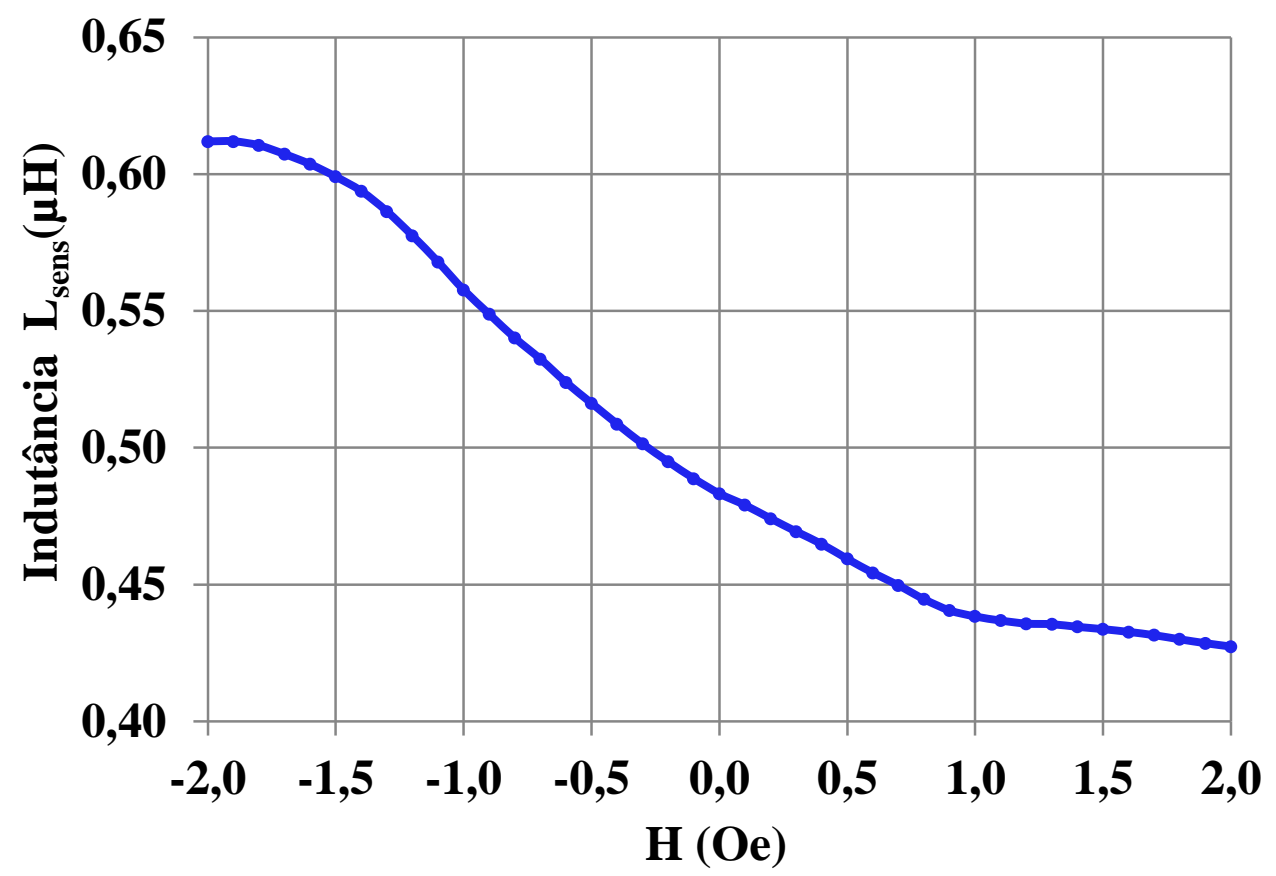

(b)

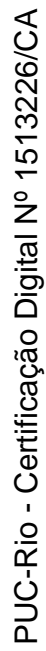

Figura 27 - Curvas Médias de (a) Resistência e (b) Indutância da amostra GMl com 2,5 cm de comprimento, excitada por ic $=[80+15 \cdot \operatorname{sen}(2 \cdot \pi \cdot 100 \mathrm{k} \cdot \mathrm{t})] \mathrm{mA}$, utilizando-se um cabo curto $(20 \mathrm{~cm})$ para conexão do circuito com o elemento sensor.

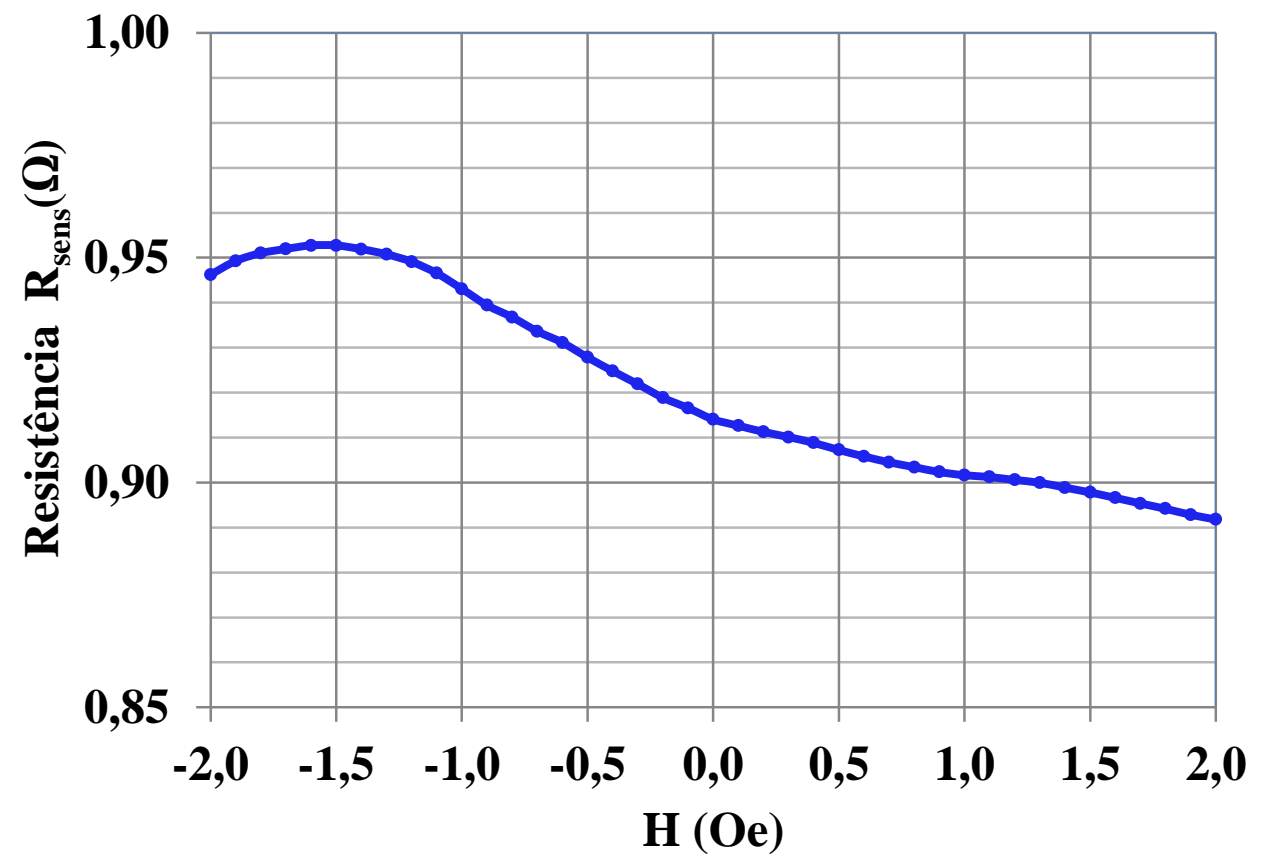

(a) 
2.

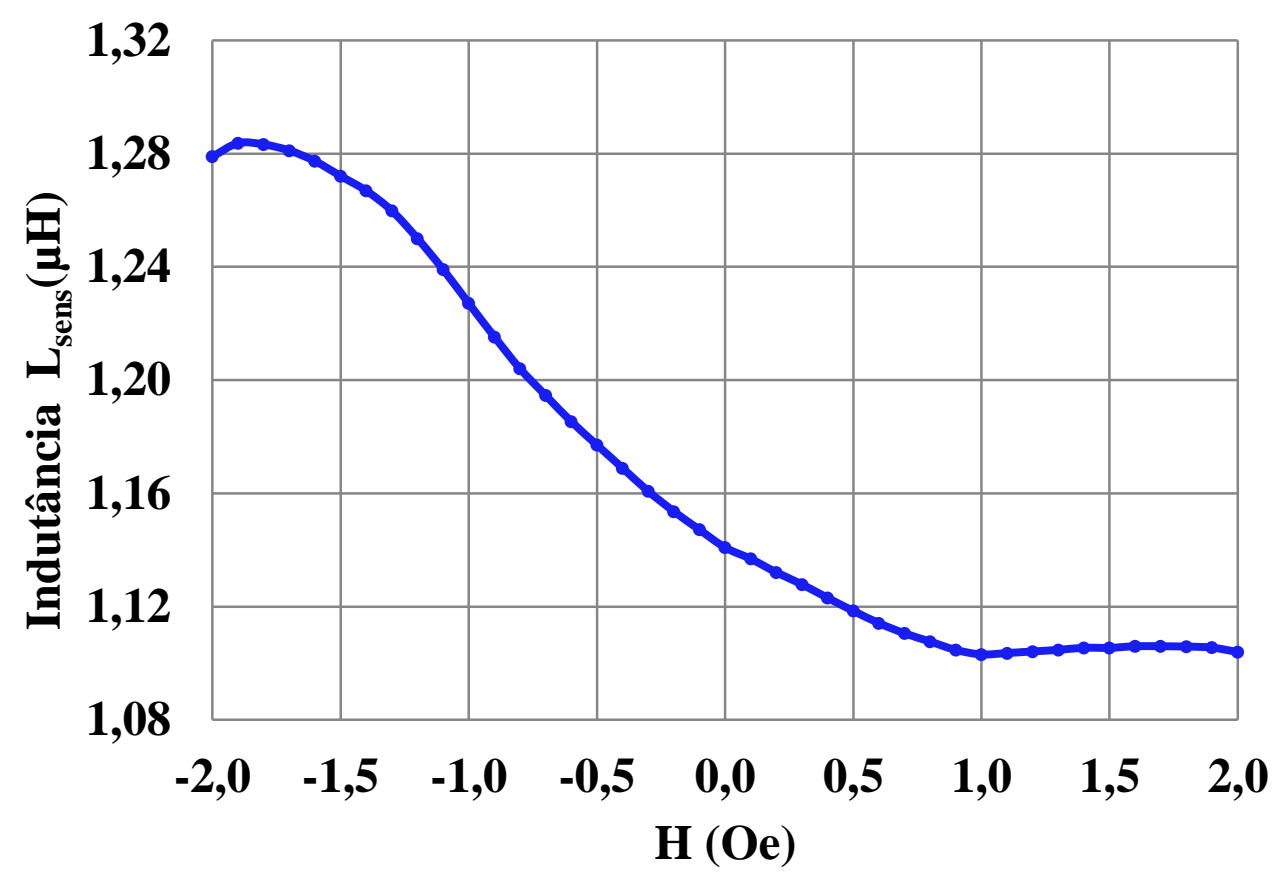

(b)

Figura 28 - Curvas Médias de (a) Resistência e (b) Indutância da amostra GMl com 2,5 cm de comprimento, excitada por ic $=[80+15 \cdot \operatorname{sen}(2 \cdot \pi \cdot 100 \mathrm{k} \cdot \mathrm{t})] \mathrm{mA}$, utilizando-se um cabo longo $(85 \mathrm{~cm})$ para conexão do circuito com o elemento sensor.

Os resultados obtidos indicam novamente que o tamanho dos cabos afeta o comportamento das amostras, entretanto pode-se notar que, na região de operação (-0,4 Oe até -1,5 Oe), as curvas de resistência e indutância apresentadas são satisfatoriamente lineares, tanto aquelas apresentadas na Figura 27 quanto as da Figura 28. Dessa forma, as mesmas podem ser adequadamente modeladas por polinômios de ajuste de primeiro grau. Consequentemente, na região de operação, a dependência de $\mathrm{R}_{\text {sens }}$ e $\mathrm{L}_{\text {sens }}$ com o campo magnético $(H)$ pode ser aproximadamente expressa por meio das eqs. (12) e (13), para a situação na qual é empregado um cabo curto (Figura 27), e por meio das eqs. (14) e (15), para a situação na qual é empregado um cabo longo (Figura 28).

$$
\begin{aligned}
& R_{\text {sens }}(H)=\left(-0,023 \Omega \cdot O e^{-1}\right) \cdot H+0,792 \Omega \\
& L_{\text {sens }}(H)=\left(-0,086 \mu \mathrm{H} \cdot \mathrm{Oe}^{-1}\right) \cdot H+0,473 \mu \mathrm{H} \\
& R_{\text {sens }}(H)=\left(-0,027 \Omega \cdot O e^{-1}\right) \cdot H+0,915 \Omega \\
& L_{\text {sens }}(H)=\left(-0,099 \mu \mathrm{H} \cdot \mathrm{Oe}^{-1}\right) \cdot H+1,127 \mu \mathrm{H}
\end{aligned}
$$


2.

Circuito eletrônico de transdução

O modelo elétrico das amostras GMI é fundamental para consecução das simulações computacionais do circuito, sendo que os valores aqui explicitados serão utilizados nas simulações descritas detalhadamente na seção 2.3

\section{2}

\section{Circuito eletrônico proposto}

O circuito eletrônico proposto para o transdutor possui as funções de alimentar eletricamente a amostra GMI e propiciar uma tensão de saída proporcional à variação de fase das amostras, a qual é diretamente proporcional ao campo magnético, na região de operação. Note que, a rigor, este circuito desempenha a função de transdutor magnético, sendo parte integrante da cadeia de transdução de pressão em tensão elétrica, a qual é baseada na transdução de pressão em campo magnético e, na sequência, deste em tensão elétrica. A representação simplificada do circuito é apresentada na Figura 29, por meio de um diagrama de blocos.

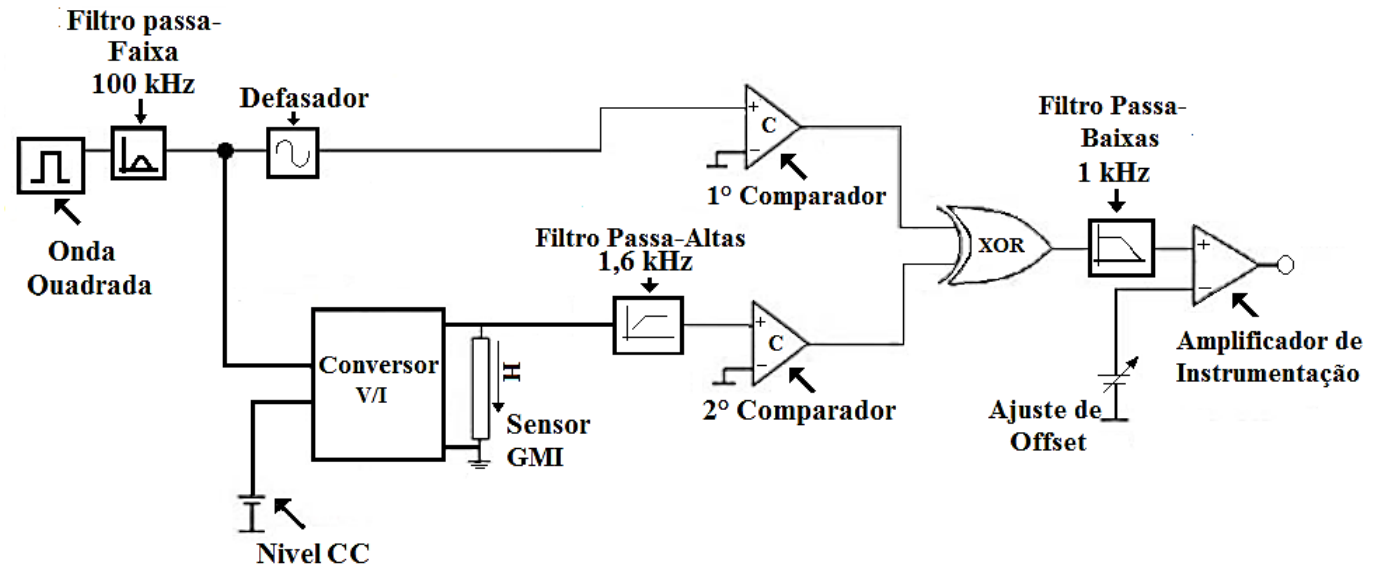

Figura 29 - Diagrama de blocos do circuito de transdução de campo magnético em tensão, baseado na leitura de fase da amostra GMI, o qual é parte integrante do transdutor de pressão desenvolvido.

Conforme indicado na Figura 29, o circuito aqui proposto possui um estágio de excitação composto por um oscilador, responsável por gerar uma onda quadrada com $100 \mathrm{kHz}$ de frequência, a qual passa por um filtro passa-faixa de $6^{\mathrm{a}}$ ordem, centrado em $100 \mathrm{kHz}$. Dessa forma, este filtro altamente seletivo privilegia a componente fundamental da onda quadrada $(100 \mathrm{kHz})$, enquanto atenua as demais componentes espectrais. Consequentemente, o sinal de saída do filtro torna-se uma onda senoidal de $100 \mathrm{kHz}$.

$\mathrm{Na}$ sequência, esta onda senoidal de $100 \mathrm{kHz}$ passa por um estágio defasador e, também, é conectada a um conversor de tensão em corrente 
2.

(conversor V/I), ajustado de modo a converter a onda senoidal de tensão em uma corrente alternada de mesma frequência e com amplitude ajustada para $15 \mathrm{~mA}$. Adicionalmente, o conversor V/I também recebe um nível $\mathrm{CC}$ fornecido por um regulador de tensão e converte-o em uma corrente contínua de $80 \mathrm{~mA}$. Finalmente, estas correntes são superpostas e utilizadas para excitar o sensor GMI com a corrente especificada na seção 2.1 , isto é, $i_{c}=[80+15 \cdot \operatorname{sen}(2 \pi \cdot 100 \mathrm{k} \cdot \mathrm{t})] \mathrm{mA}$. Por sua vez, o sensor GMI é polarizado por um campo magnético de polarização $\mathrm{H}=-0,95 \mathrm{Oe}$, responsável por garantir que o sensor opere em sua faixa ótima, conforme a subseção 2.1 .2

O estágio de leitura de fase incia-se com os dois comparadores, configurados como detectores de nulo, a fim de converter os sinais senoidais de entrada em uma onda quadrada com níveis de tensão compatíveis com as entradas do ou-exclusivo $(X O R)$. O primeiro é conectado a um sinal senoidal de referência, com frequência $100 \mathrm{kHz}$, cuja fase é fixa e independente do campo magnético. Por outro lado, o segundo comparador recebe um sinal advindo do conversor V/I, ao qual o sensor GMI está conectado, que varia sua fase em função do campo magnético $(H)$.

Ressalta-se que o sinal de saída do conversor V/I não pode ser conectado diretamente ao $2^{\circ}$ comparador, configurado como detector de nulo, pois este nunca passa por zero volts devido à presença de um nível $\mathrm{CC}$ de tensão. Consequentemente, objetivando-se remover o nível CC de tensão, utiliza-se um filtro passa-altas com frequência de corte ajustada para aproximadamente1,6 kHz. Elimina-se, assim, o nível CC do sinal e deixa-se passar a componente de interesse, com frequência de $100 \mathrm{kHz}$. Ressalta-se que este estágio também é responsável por amplificar em cerca de 10 vezes o sinal senoidal de $100 \mathrm{kHz}$, a fim de se fornecer níveis de tensão mais adequados às entradas do segundo comparador. Dessa forma, tem-se que variações do campo magnético H induzirão alterações na fase do sinal de saída do $2^{\circ}$ comparador, enquanto a fase do $1^{\circ}$ comparador permanecerá fixa.

Na sequência, as saídas dos comparadores são conectadas às entradas do ouexclusivo (XOR), fazendo com que este gere em sua saída uma onda quadrada com duty cycle de aproximadamente $50 \%$ e frequência de $200 \mathrm{kHz}$, para $\mathrm{H}=-0,95$ Oe (campo de polarização). Para tal fim, ajusta-se a defasagem inserida pelo defasador de modo a garantir que as ondas quadradas geradas pelos dois 
2.

comparadores estejam $90^{\circ}$ defasadas entre si, em $\mathrm{H}=-0,95$ Oe. É importante destacar que este duty cycle é função da defasagem entre as ondas de entrada e, consequentemente, irá variar em função do campo magnético $\mathrm{H}$.

Em seguida, a onda de saída do XOR passa por um filtro passa-baixas de $4^{\mathrm{a}}$ ordem, com frequência de corte de $1 \mathrm{kHz}$, que é 200 vezes inferior à frequência da onda de saída do XOR. Dessa forma, garante-se que este filtro extraia o nível CC do sinal de saída do XOR, o qual é proporcional à defasagem. Quanto menor a frequência de corte deste filtro, mais puro é o nível CC gerado, pois este será menos afetado pelas demais componentes espectrais presentes na onda quadrada com duty cycle variável. Entretanto, ressalta-se que, em contrapartida, ao se reduzir a frequência de corte deste filtro, reduz-se a banda do circuito e, consequentemente, aumenta-se o tempo de resposta do sistema. Dessa forma, é importante ajustar este parâmetro com cuidado, a fim de garantir que as componentes espectrais do sinal de interesse (onda de pulso) não sejam atenuadas por este estágio de filtragem.

Por fim, o sinal de saída do filtro é conectado à entrada de um amplificador de instrumentação com baixo nível ruído 1/f, e com ganho ajustado para $100 \mathrm{~V} / \mathrm{V}$. Conforme destacado na Figura 29, uma das entradas deste amplificador de instrumentação é conectada a um estágio de ajuste de offset, implementado a fim de garantir que a saída do circuito seja nula quando o sensor está submetido ao campo de polarização. Dessa forma, tem-se que a saída do amplificador de instrumentação (saída do circuito) será proporcional às variações de fase dos elementos sensores e, consequentemente, ao campo magnético aplicado que, por sua vez, é dependente das variações de pressão.

A fim de facilitar a análise, é apresentado na Figura 30 de forma mais detalhada o diagrama esquemático do circuito eletrônico desenvolvido. 
2.

Circuito eletrônico de transdução

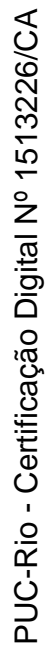

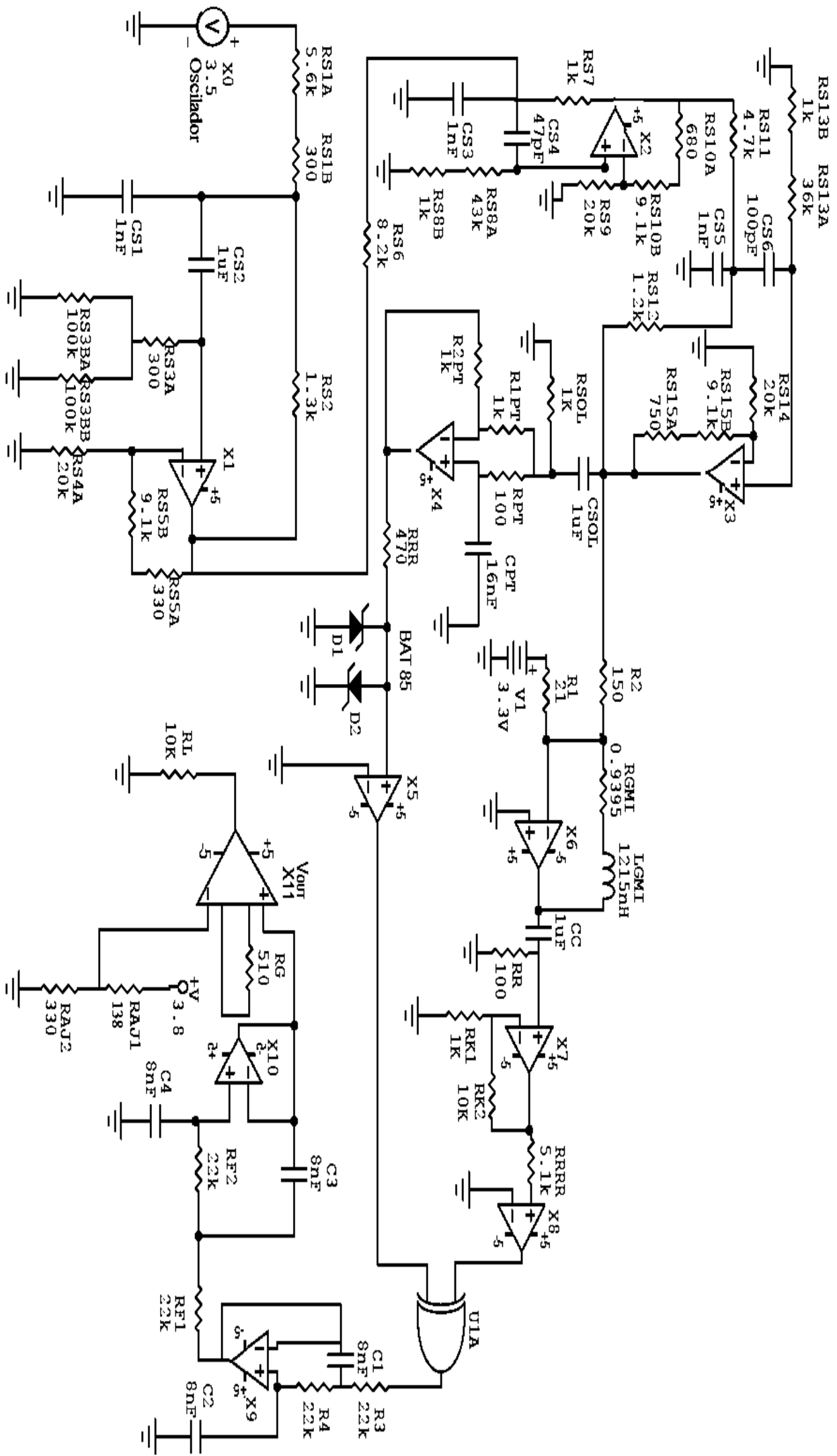

Figura 30 - Representação esquemática do circuito eletrônico completo, desenvolvido para o magnetômetro GMI.

Por sua vez, o quadro 2 indica os componentes ativos utilizados na implementação do circuito explicitado na Figura 30. 
2.

Circuito eletrônico de transdução

Quadro 2. Componentes ativos utilizados na implementação do circuito eletrônico.

\begin{tabular}{|c|c|c|c|}
\hline Símbolo & Descrição & Função & $\begin{array}{l}\text { Modelo do } \\
\text { Componente }\end{array}$ \\
\hline $\mathrm{X}_{0}$ & $\begin{array}{c}\text { Oscilador - Onda } \\
\text { Quadrada }\end{array}$ & Gerador de onda quadrada. & LTC6900 \\
\hline $\mathrm{X}_{1}$ & $\begin{array}{l}\text { Amplificador } \\
\text { Operacional }\end{array}$ & \multirow{3}{*}{$\begin{array}{c}\text { Filtro passa faixa com } \\
\text { frequência de corte ajustada } \\
\text { para } 100 \mathrm{kHz}\end{array}$} & OPA2822 \\
\hline $\mathrm{X}_{2}$ & $\begin{array}{l}\text { Amplificador } \\
\text { Operacional }\end{array}$ & & OPA2822 \\
\hline $\mathrm{X}_{3}$ & $\begin{array}{l}\text { Amplificador } \\
\text { Operacional }\end{array}$ & & OPA2822 \\
\hline $\mathrm{X}_{4}$ & $\begin{array}{l}\text { Amplificador } \\
\text { Operacional }\end{array}$ & Defasador & DM0D8599 \\
\hline $\mathrm{X}_{5}$ & Comparador & Primero comparador & AD8611 \\
\hline $\mathrm{X}_{6}$ & $\begin{array}{l}\text { Amplificador } \\
\text { Operacional }\end{array}$ & Conversor $\mathrm{V} / \mathrm{I}$ & OPA2822 \\
\hline $\mathrm{X}_{7}$ & $\begin{array}{l}\text { Amplificador } \\
\text { Operacional }\end{array}$ & $\begin{array}{c}\text { Filtro passa altas com } \\
\text { frequência de corte ajustada } \\
\text { para } 1,6 \mathrm{kHz}\end{array}$ & DM0D8599 \\
\hline $\mathrm{X}_{8}$ & Comparador & Segundo comparador & AD8611 \\
\hline $\mathrm{U}_{1 \mathrm{~A}}$ & Ou-exclusivo & XOR & 74F86 \\
\hline $\mathrm{X}_{9}$ & $\begin{array}{l}\text { Amplificador } \\
\text { Operacional }\end{array}$ & Filtro passa baixas com & DM0D8599 \\
\hline $\mathrm{X}_{10}$ & $\begin{array}{l}\text { Amplificador } \\
\text { Operacional }\end{array}$ & para $1 \mathrm{kHz}$ & DM0D8599 \\
\hline $\mathrm{X}_{11}$ & $\begin{array}{l}\text { Amplificador de } \\
\text { Instrumentação }\end{array}$ & $\begin{array}{c}\text { Ganho de tensão e ajuste de } \\
\text { offset }\end{array}$ & INA129E \\
\hline
\end{tabular}


2.

Circuito eletrônico de transdução

Por fim, ressalta-se que tanto os resultados computacionais apresentados na seção 2.3 quanto os resultados experimentais explicitados na seção 2.4 referem-se aos dados advindos das medições do sensor GMI associado ao cabo longo $(85 \mathrm{~cm})$, vide subseções 2.1 .2 e 2.1.3.

\section{3}

\section{Resultados computacionais do circuito eletrônico}

O circuito proposto, apresentado na Figura 30, foi avaliado por meio de simulações computacionais implementadas com auxílio de um software SPICE, a fim de se analisar o comportamento de pontos críticos do circuito eletrônico idealizado e avaliar sua adequação ao comportamento teórico esperado. Destacase que as simulações realizadas utilizaram os modelos computacionais dos componentes reais utilizados no circuito, explicitados no quadro 2. Ressalta-se que os resultados apresentados nas Figuras 31 até 39 referem-se à condição de equilíbrio, ou seja, a situação para a qual $\mathrm{H}=-0,95$ Oe e pressão nula, como será explicitado no capitulo 3.

A Figura 31 apresenta o sinal gerado pelo oscilador $\mathrm{X}_{0}$, configurado a fim de gerar uma quadrada perfeita (duty cycle de 50\%), com frequência de $100 \mathrm{kHz}$ e amplitude de cerca de 3,5 V. Percebe-se que o sinal simulado possui características satisfatoriamente próximas do comportamento teórico esperado.

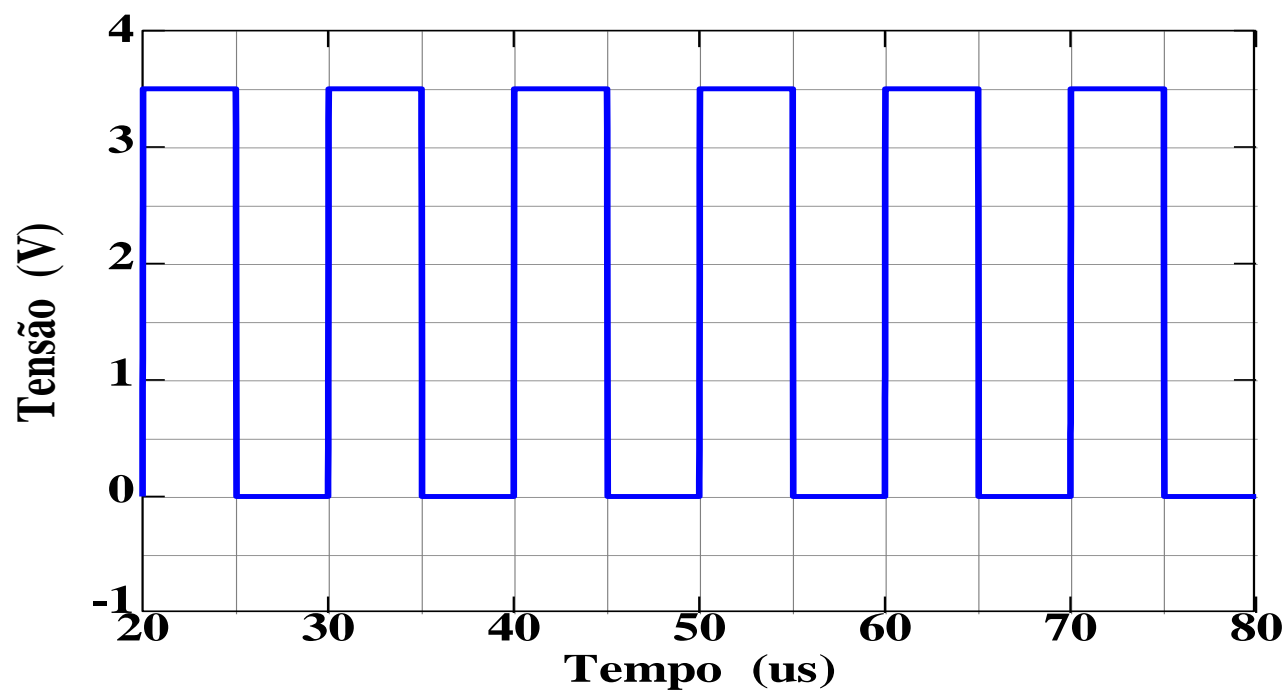

Figura 31 - Tensão de entrada do transdutor de pressão.

Por sua vez, a Figura 32 apresenta a tensão de saída do filtro passa-faixa (linha sólida), e a saída do defasador (linha pontilhada). 
2.

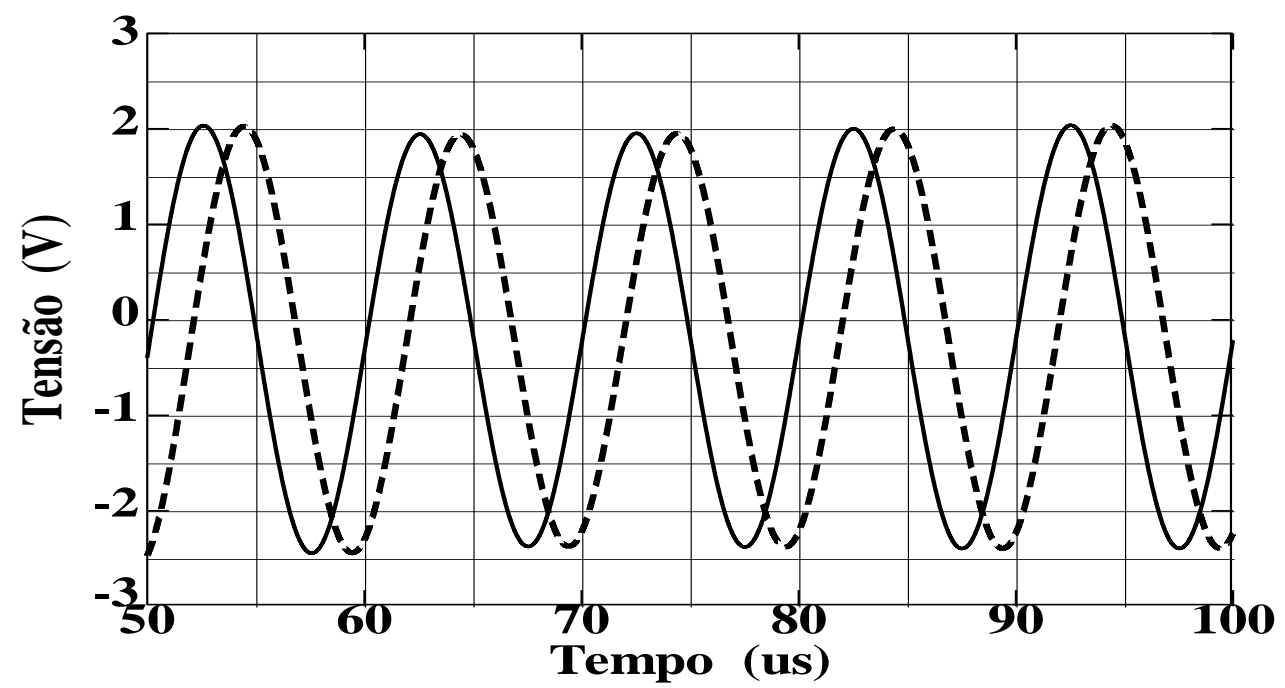

Figura 32 - Tensões de saída do filtro passa-faixa e do defasador.

Ao observar a Figura 32, percebe-se que, conforme esperado, tem-se dois sinais senoidais com frequências de aproximadamente $100 \mathrm{kHz}$. Ainda, também verifica-se que a amplitude de ambos os sinais senoidais é aproximadamente a mesma, o que indica que circuito defasador introduz ganho praticamente unitário, o que está de acordo com a previsão teórica. Por outro lado, nota-se que a amplitude desses sinais é cerca de 2,03 V, ou seja, inferior à amplitude da onda quadrada (Figura 31). Dessa forma, percebe-se que o filtro passa-faixa introduz certa atenuação ao sinal de entrada. Como o filtro projetado possui banda muito estreita e é altamente seletivo ( $6^{\mathrm{a}}$ ordem), é razoável admitir que a frequência central do mesmo tenha sido ligeiramente deslocada em relação ao valor previsto em teoria (100 kHz), em função de aspectos não-ideais presentes nos modelos dos amplificadores operacionais reais utilizados na simulação. Dessa forma, o filtro introduz um ganho menor do que 1 à componente espectral em $100 \mathrm{kHz}$. Adicionalmente, as curvas apresentadas na Figura 32 estão defasadas $51,94^{\circ}$ entre si. Note que, o defasador é ajustado a fim de garantir que as saídas dos comparadores estejam $90^{\circ}$ defasadas entre si. Consequentemente, conforme esperado, a defasagem introduzida por ele não pode ser igual a $90^{\circ}$, pois são adicionadas defasagens adicionais introduzidas principalmente pela amostra GMI (cerca de 39,2 em $\mathrm{H}=-0,95 \mathrm{Oe}$ ) e, de forma secundária, pelo filtro passa-altas com ganho. Por fim, ressalta-se que a amplitude destes sinais pode ser ajustada por meio do ganho do filtro passa-faixa, e sua defasagem pode ser definida por meio da configuração do defasador. 
2. Circuito eletrônico de transdução

Na sequência da cadeia de processamento, a Figura 33(a) apresenta a tensão de saída do conversor V/I, implementado por $\mathrm{X}_{6}$, enquanto que a Figura 33(b) explicita a corrente que flui pelo sensor GMI.

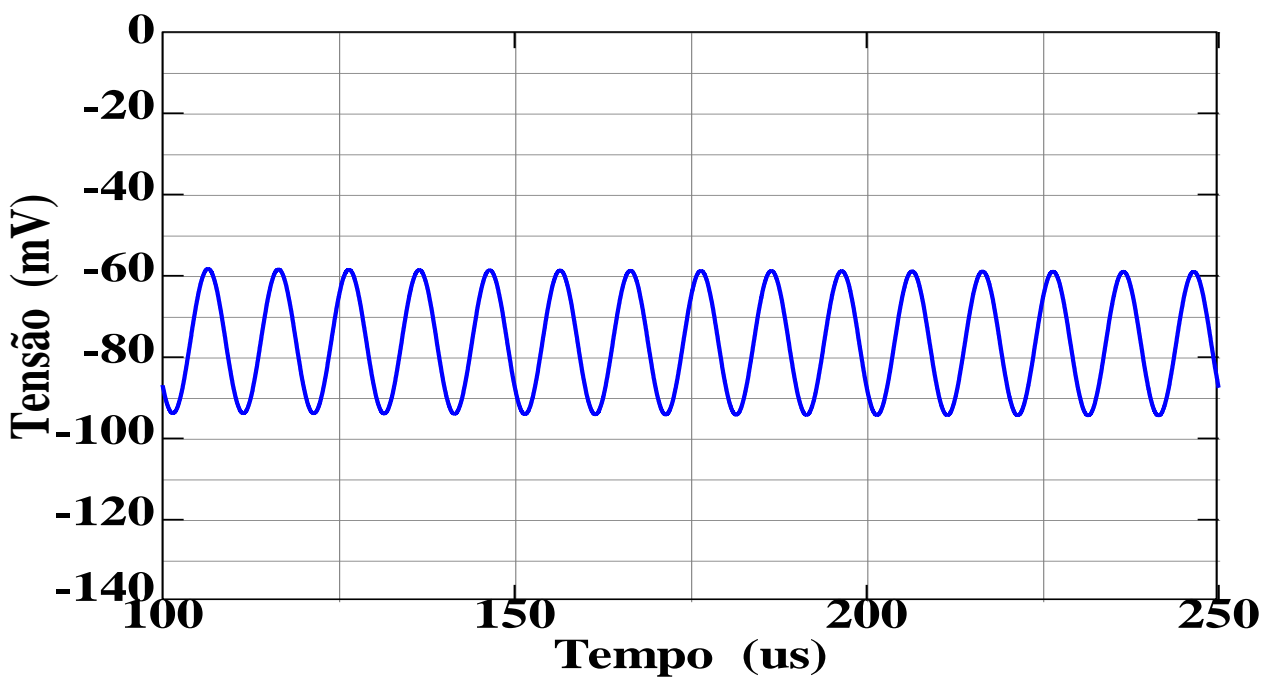

(a)

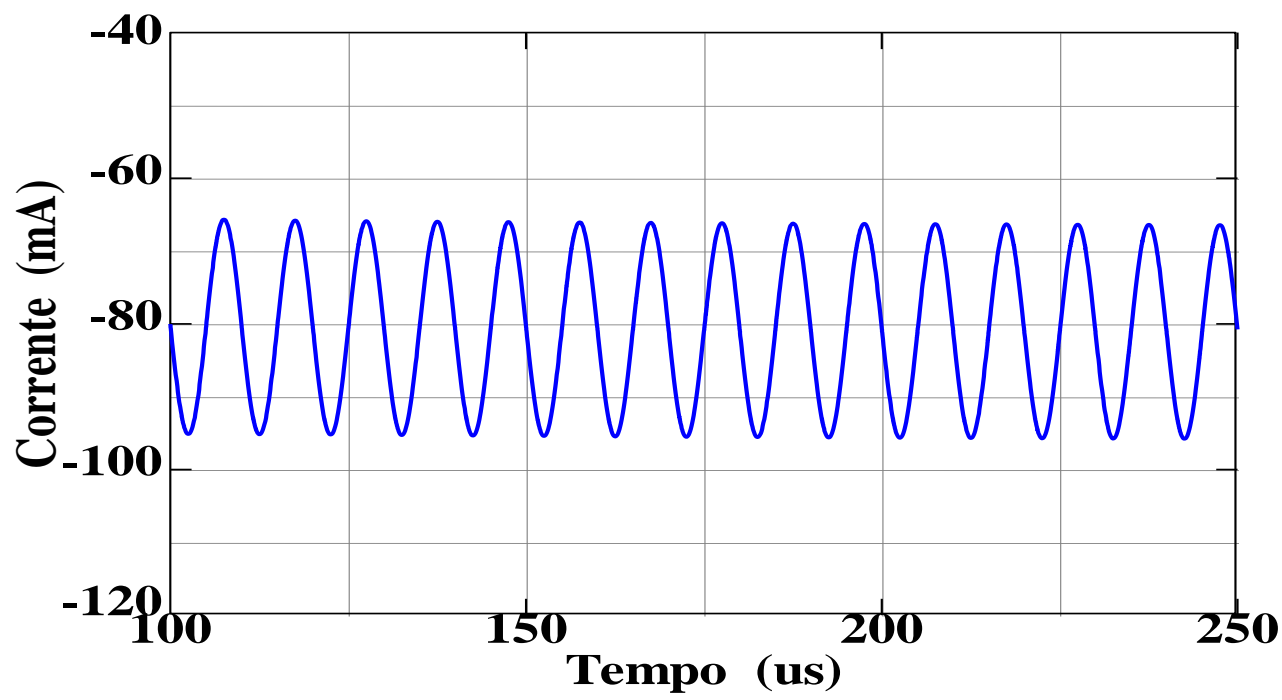

(b)

Figura 33 - a) Tensão de saída do conversor V/l e b) Corrente que flui pela amostra GMI.

A partir das informações contidas na Figura 33 é possível verificar que os resultados computacionais indicaram que o sinal de saída do conversor V/I possui um nível CC de -78 mA, uma amplitude de 15 mA e uma frequência de $100 \mathrm{kHz}$. Por sua vez, também se verifica que a corrente de excitação do sensor GMI apresenta nível CC de $-80 \mathrm{~mA}$, amplitude de $15 \mathrm{~mA}$ e frequência de $100 \mathrm{kHz}$. Dessa forma, nota-se que os resultados computacionais são satisfatoriamente próximos das previsões teóricas. Adicionalmente, por meio da Figura 33 (a), é possível notar claramente a presença de um nível CC negativo na tensão de saída 
2.

Circuito eletrônico de transdução

do conversor V/I, que faz com que a onda nunca passe por $0 \mathrm{~V}$. Tal comportamento era esperado, de acordo com a descrição do circuito explicitada na seção 2.2.

Este nível CC precisa ser removido para que o estágio detector de nulo, implementado pelo comparador $\left(\mathrm{X}_{8}\right)$, funcione adequadamente. Para tal fim, propôs-se o emprego de um filtro passa-altas, que além de eliminar o nível CC introduz um ganho de cerca de 10 vezes na componente espectral de $100 \mathrm{kHz}$, a fim de elevar o nível de tensão que efetivamente chega as entradas do $2^{\circ}$ comparador. A tensão de saída deste filtro passa-altas pode ser observada na Figura 34

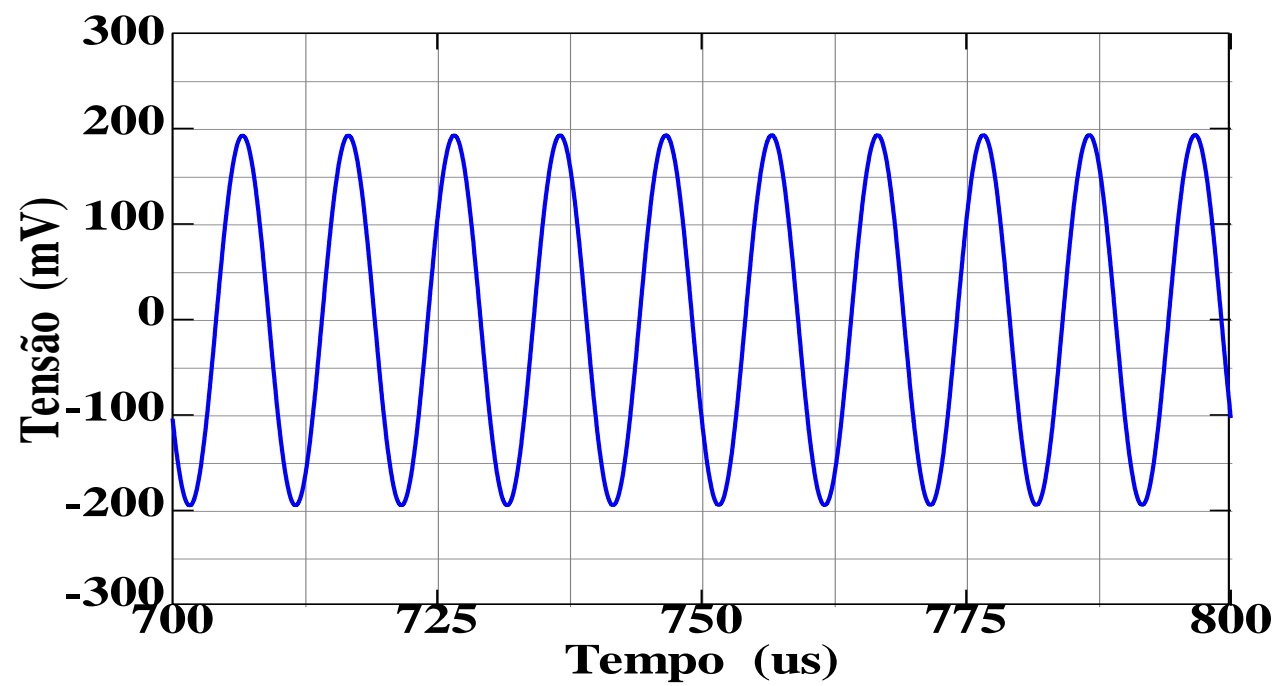

Figura 34 - Tensão na saída do filtro passa-altas.

Inspecionando-se a Figura 34, verifica-se que, conforme esperado, o filtro passa-altas praticamente remove por completo o nível CC presente na saída do conversor V/I $\left(\mathrm{X}_{6}\right)$ e deixa passar a componente espectral de $100 \mathrm{kHz}$. Adicionalmente, também pode-se notar que o filtro insere um ganho de cerca de $12 \mathrm{~V} / \mathrm{V}$, o qual é satisfatoriamente próximo de seu valor teórico $(10 \mathrm{~V} / \mathrm{V})$. Consequentemente, percebe-se que o filtro passa-altas cumpre adequadamente sua função, apresentando em sua saída níveis de tensão adequados à conexão com as entradas do $2^{\circ}$ comparador $\left(\mathrm{X}_{8}\right)$.

A parte inicial do estágio de detecção de fase é implementada pelos 2 comparadores $\left(\mathrm{X}_{5}\right.$ e $\left.\mathrm{X}_{8}\right)$. O comparador $\mathrm{X}_{8}$ recebe o sinal de saída do filtro passaaltas (Figura 34), enquanto que o comparador $\mathrm{X}_{5}$ recebe o sinal da saída do defasador (Figura 32). As tensões de saída dos comparadores $\mathrm{X}_{5}$ e $\mathrm{X}_{8}$ são apresentadas na Figura 35. 
2.

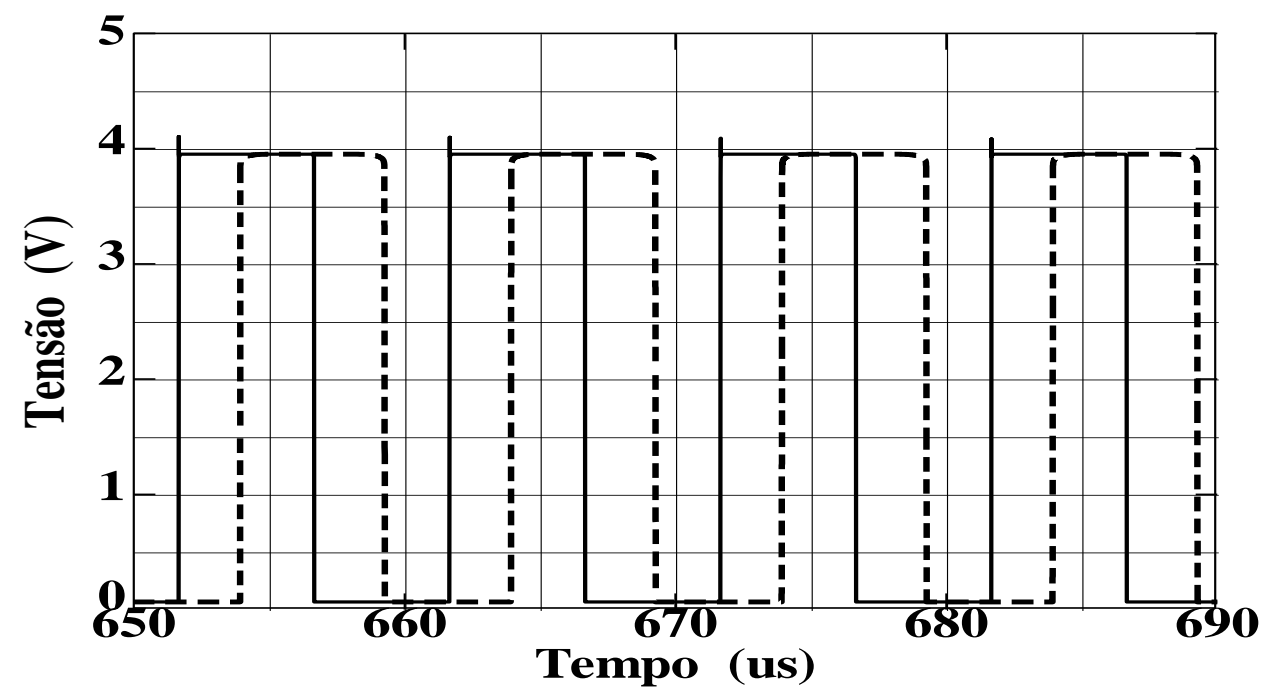

Figura 35 - Tensões de saída dos comparadores.

Observando-se a Figura 35, percebe-se que os resultados obtidos por meio das simulações computacionais indicam que as saídas dos comparadores estão $89,6^{\circ}$ defasadas entre si, a qual é satisfatoriamente próxima da defasagem projetada $\left(90^{\circ}\right)$. Também, constata-se que, conforme projetado, os patamares de tensão ("baixo" e "alto") presentes nas saídas dos comparadores são compatíveis com os níveis de tensão TTL, demandados pelas entradas da porta lógica XOR

Em seguida, aplicam-se as saídas dos comparadores (Figura 35) às entradas do XOR. Nesta situação, a forma que aparece na saída do ou-exclusivo é explicitada na Figura 36. O duty cycle deste sinal é função da defasagem entre as ondas apresentadas na Figura 35.

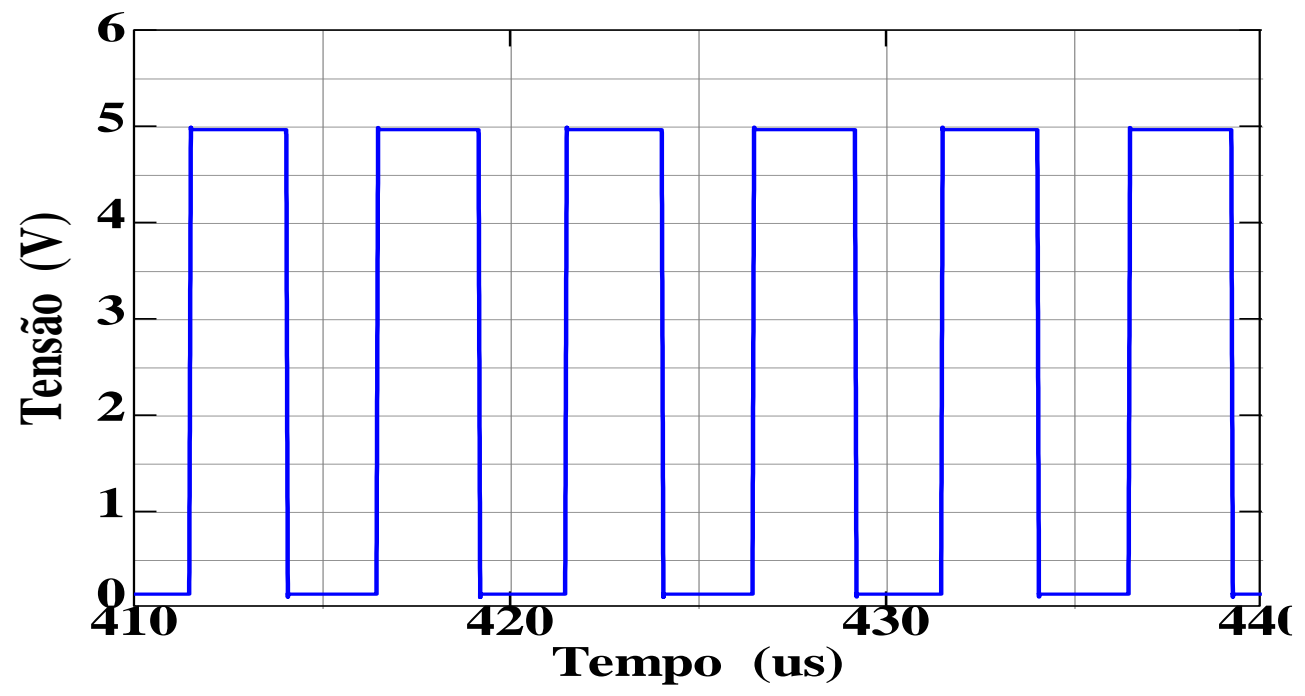

Figura 36 - Tensão na saída do XOR. 
2.

Os resultados computacionais indicam que, para $\mathrm{H}=-0,95$ Oe, o duty cycle do sinal de saída do XOR é de 51,5\%, o qual é satisfatoriamente próximo do valor esperado (50\%). Ressalta-se que o duty cycle deste sinal é função da defasagem entre as ondas apresentadas na Figura 35 e, consequentemente, irá variar em função do campo magnético. Por meio da inspeção da Figura 36, é possível perceber que o XOR está funcionando adequadamente, pois quando os sinais advindos das saídas dos comparadores estão no mesmo nível de tensão, a saída do XOR assume nível lógico "baixo" (aproximadamente $0 \mathrm{~V}$ ). Por outro lado, quando os sinais de entrada estão em níveis diferentes, a saída do XOR assume nível lógico "alto", neste caso aproximadamente $5 \mathrm{~V}$.

Na sequência da cadeia de transdução, a onda passa por um filtro passabaixas $\mathrm{RC}$ ativo de $4^{\mathrm{a}}$ ordem, implementado por $\mathrm{X}_{9}$ e $\mathrm{X}_{10}$, com frequência de corte ajustada para $1 \mathrm{kHz}$. Como a frequência de corte deste filtro é significativamente inferior à frequência da componente fundamental do sinal de entrada $(200 \mathrm{kHz})$, tem-se que o filtro extrai o nível $\mathrm{CC}$ do sinal de saída do XOR, o qual é proporcional à defasagem. A saída do filtro passa-baixas, para $\mathrm{H}=-0,95 \mathrm{Oe}$, pode ser observada na Figura 37.

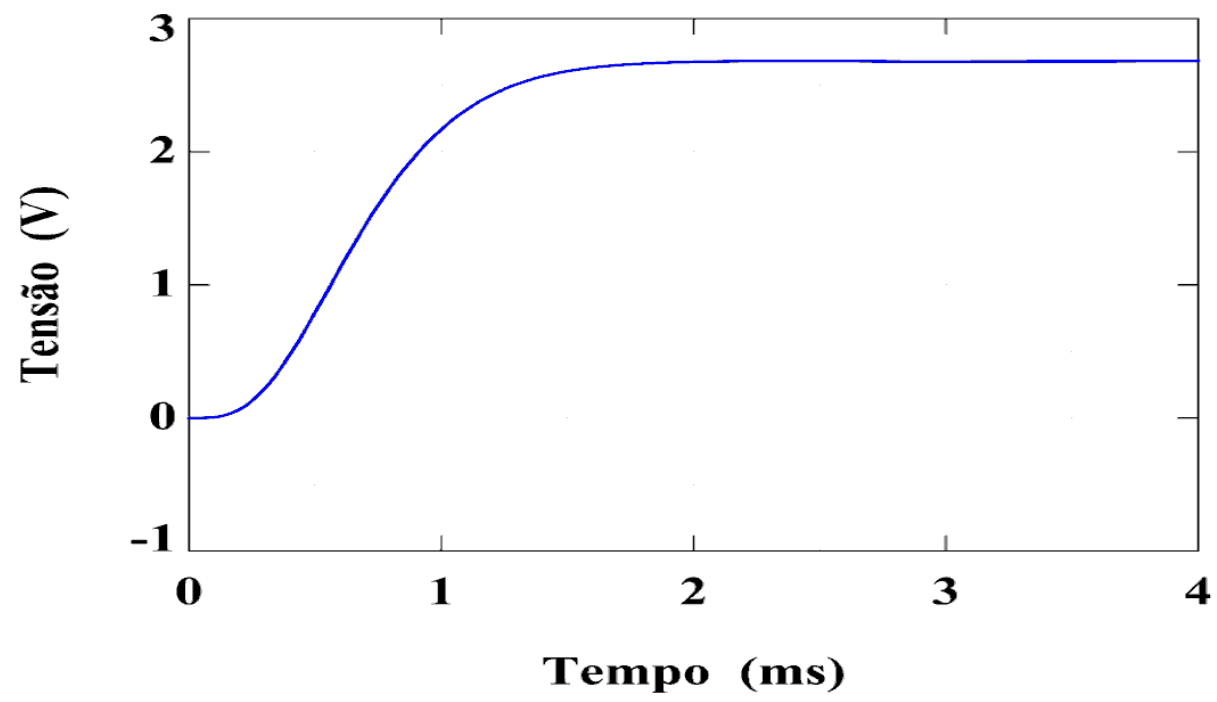

Figura 37 - Tensão de saída do filtro passa-baixas, para $\mathrm{H}=-0,95$ Oe.

Observando-se a Figura 37, pode-se concluir que o filtro projetado está funcionando adequadamente, atenuando as altas frequências e, após o transitório inicial, apresentando em sua saída um sinal quase que puramente CC. Na situação aqui simulada, tem-se que o nível CC resultante é de aproximadamente 2,64 V. Por sua vez, nota-se que este valor é satisfatoriamente próximo da previsão teórica $(2,5 \mathrm{~V})$, a qual admitia que a entrada do filtro (saída do XOR) fosse uma onda 
2.

quadrada com duty cycle de 50\%, nível "baixo" de aproximadamente $0 \mathrm{~V}$ e nível "alto" de cerca de $5 \mathrm{~V}$. Dessa forma, conclui-se que a pequena diferença entre os níveis CC teórico e computacional é decorrente de sutis alterações nos valores computacionais do duty cycle, nível "alto" e nível "baixo" do sinal de saída do XOR simulado, em relação a suas respectivas previsões teóricas.

Para que o circuito de transdução funcione adequadamente, é necessário que a tensão de saída do circuito completo (saída do amplificador de instrumentação $\left(\mathrm{X}_{11}\right)$ ) seja nula na condição de equilíbrio, ou seja, quando a amostra estiver submetida a uma pressão nula na membrana (seção 3.1) e ao campo de polarização $(\mathrm{H}=-0,95 \mathrm{Oe})$. Para tal fim, deve-se garantir que, nesta situação, as tensões nas entradas do amplificador de instrumentação $\left(\mathrm{X}_{11}\right)$ sejam iguais. Conforme indicado no esquemático do circuito apresentado na Figura 30, a saída do filtro passa-baixas é conectada à entrada não-inversora de $\mathrm{X}_{11}$. Por outro lado, a entrada inversora de $\mathrm{X}_{11}$ é conectada a um circuito de ajuste de offset, implementado por meio de um divisor resistivo entre $\mathrm{R}_{\mathrm{AJ} 1}$ e $\mathrm{R}_{\mathrm{AJ} 2}$, cujo ajuste possibilita que a tensão de saída de $\mathrm{X}_{11}$ seja efetivamente nula na condição de equilíbrio.

Por meio da análise da Figura 37, verifica-se que, para $\mathrm{H}=-0,95 \mathrm{Oe}$, o valor da tensão na entrada não-inversora de $X_{11}$ é aproximadamente 2,64 V. Consequentemente, ajustou-se os valores das resistências $\mathrm{R}_{\mathrm{AJ} 1}$ para $118 \Omega$ e $\mathrm{R}_{\mathrm{AJ} 2}$ para $330 \Omega$, a fim de se obter uma tensão de saída do divisor resistivo aproximadamente igual à presente na entrada inversora. A Figura 38 apresenta as duas tensões de entrada de $\mathrm{X}_{11}$ : a tensão presente na entrada inversora em linha pontilhada $\left(\mathrm{V}_{\mathrm{X} 11-}\right)$ e em linha sólida a tensão entrada não-inversora $\left(\mathrm{V}_{\mathrm{X} 11+}\right)$. 
2.

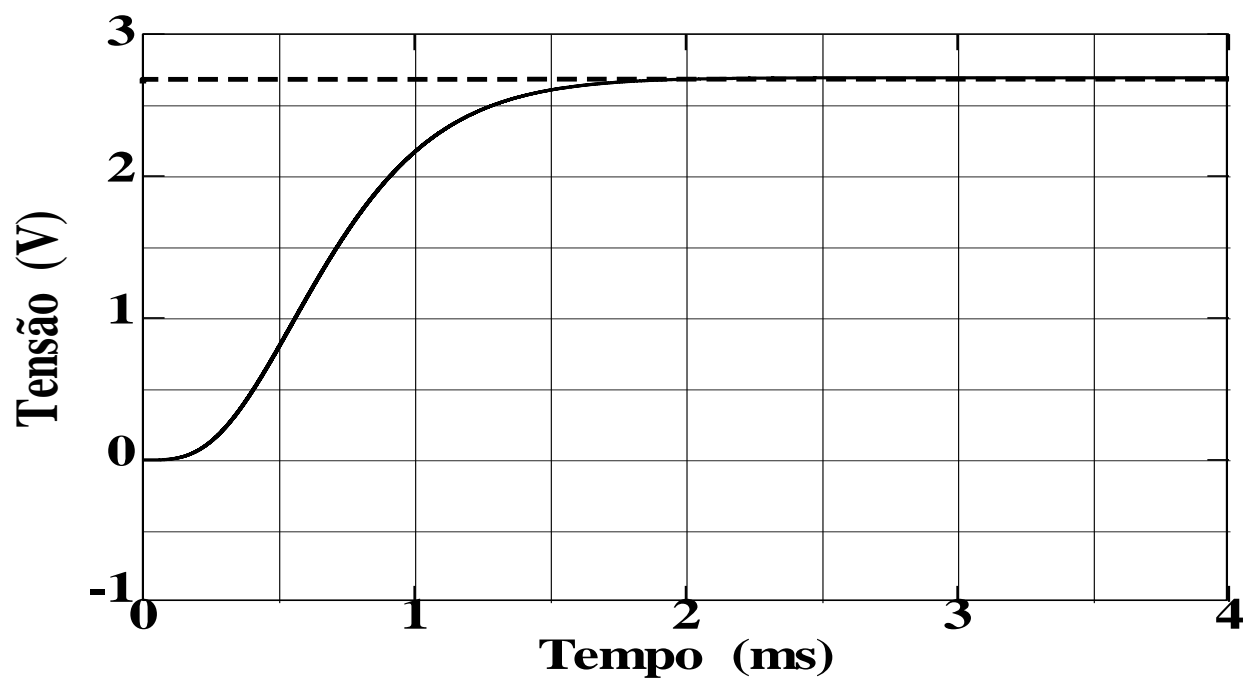

Figura 38 - Tensões de entrada do Amplificador de Instrumentação, para $\mathrm{H}=-0,95$ Oe.

É possível notar que, conforme esperado, em regime permanente, ambas as curvas da Figura 38 apresentam valores satisfatoriamente próximos, sendo que o erro relativo percentual (E) entre as duas, calculado por meio da eq. (16), é aproximadamente $0,0019 \%$. Dessa forma, pode-se considerar que as entradas do amplificador de instrumentação são suficientemente próximas.

$$
E \%=\frac{\left|V_{X 11+}-V_{X 11-}\right|}{V_{X 11-}} \cdot 100 \%
$$

Por sua vez, o ganho do amplificador de instrumentação $\mathrm{X}_{11}$ é ajustado por meio de uma resistência externa $\mathrm{R}_{\mathrm{G}}$. Tendo em vista a equação fornecida no datasheet deste componente, tem-se que o ganho de tensão é dado por

$$
G=1+\frac{49,4 k \Omega}{R_{G}}
$$

Decidiu-se adotar um ganho $\mathrm{G}$ igual a aproximadamente $100 \mathrm{~V} / \mathrm{V}$, para o circuito proposto. Dessa forma, tendo em vista a eq. (17), percebe-se que é necessário empregar um resistor $\mathrm{R}_{\mathrm{G}}$ de aproximadamente $510 \Omega$ (valor comercial).

É importante ressaltar que, enquanto a tensão gerada pelo ajuste de offset é fixa ( $\left.\mathrm{V}_{\mathrm{X} 11-}\right)$, a tensão advinda da saída do filtro passa-baixas $\left(\mathrm{V}_{\mathrm{X} 11+}\right)$ irá variar em função do campo magnético. Consequentemente, conforme desejado, a tensão de saída do circuito de transdução irá depender do valor do campo $\mathrm{H}$, sendo idealmente nula para $\mathrm{H}=0,95 \mathrm{Oe}$

A fim de avaliar a resposta da tensão de saída do circuito em função de variações de campo magnético, decorrentes de variações de pressão, a Figura 39 indica as tensões de saída do circuito para campos variando de $-0,4$ Oe até $-1,5$ 
2.

Circuito eletrônico de transdução

69

Oe, em passos de 0,1 Oe, a qual é a faixa de operação linear do sensor GMI utilizado (vide seção 2.1). Para cada valor de $\mathrm{H}$ analisado, a amostra GMI foi modelada por uma resistência $\mathrm{R}_{\text {sens }}$ em série com uma indutância $\mathrm{L}_{\text {sens }}$, de acordo com o estabelecido na subseção 2.1.3. A Tabela 1, indica os respectivos valores utilizados.

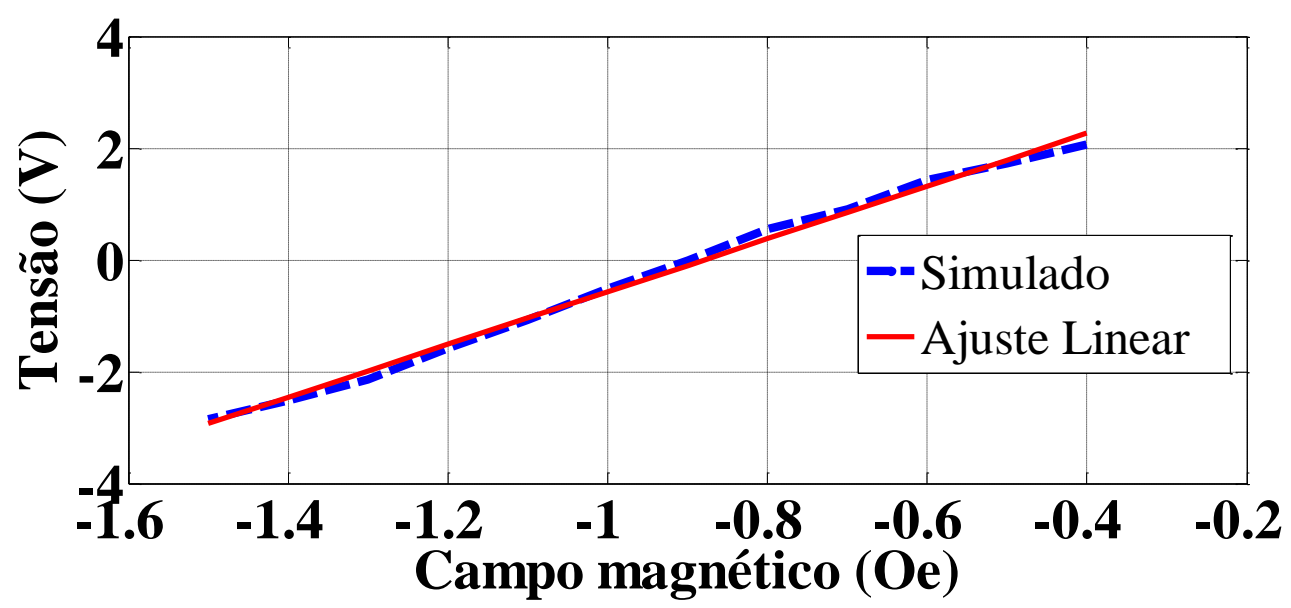

Figura 39 - Resposta simulada da tensão de saída do circuito eletrônico para diferentes valores de $\mathrm{H}$, expressos em Oe.

Tabela 1. Valores das componentes resistivas e indutivas da impedância equivalente formada pela associação do sensor GMI com o cabo longo, em função de cada valor de campo magnético analisado.

\begin{tabular}{|c|c|c|}
\hline $\mathbf{H}(\mathbf{O e})$ & $\mathbf{R}_{\text {sens }}(\mathbf{\Omega})$ & $\mathbf{L}_{\text {sens }}(\boldsymbol{\mu H} \mathbf{H})$ \\
\hline$-1,50$ & 0,953 & 1,272 \\
\hline$-1,40$ & 0,952 & 1,267 \\
\hline$-1,30$ & 0,951 & 1,260 \\
\hline$-1,20$ & 0,949 & 1,250 \\
\hline$-1,10$ & 0,947 & 1,239 \\
\hline$-1,00$ & 0,943 & 1,227 \\
\hline$-0,90$ & 0,939 & 1,215 \\
\hline$-0,80$ & 0,937 & 1,204 \\
\hline$-0,70$ & 0,934 & 1,195 \\
\hline$-0,60$ & 0,931 & 1,185 \\
\hline$-0,50$ & 0,928 & 1,177 \\
\hline$-0,40$ & 0,925 & 1,169 \\
\hline
\end{tabular}

Conforme esperado, os resultados simulados indicam que, para o campo de polarização $(\mathrm{H}=-0,95 \mathrm{Oe})$, o circuito apresenta uma tensão de saída aproximadamente nula. Também é possível perceber um comportamento 
2.

Circuito eletrônico de transdução

fortemente linear da tensão de saída em função das variações de campo avaliadas, em toda a região de operação. Consequentemente, é possível modelar satisfatoriamente a resposta do transdutor por meio de um polinômio de ajuste linear, dado por

$$
V_{\text {out }}=\left(4,72 \mathrm{~V} \cdot \mathrm{Oe}^{-1}\right) \cdot H+4,39 \mathrm{~V}
$$

Dessa forma, tem-se que a sensibilidade média do circuito simulado é 4,72 $\mathrm{V} \cdot \mathrm{Oe}^{-1}$, na região de operação.

\section{4}

\section{Resultados experimentais do circuito eletrônico}

A fim de se efetuar uma avaliação experimental inicial do circuito eletrônico aqui proposto, fez-se uma montagem completa do mesmo em uma protoboard, conforme indicado na Figura 40.

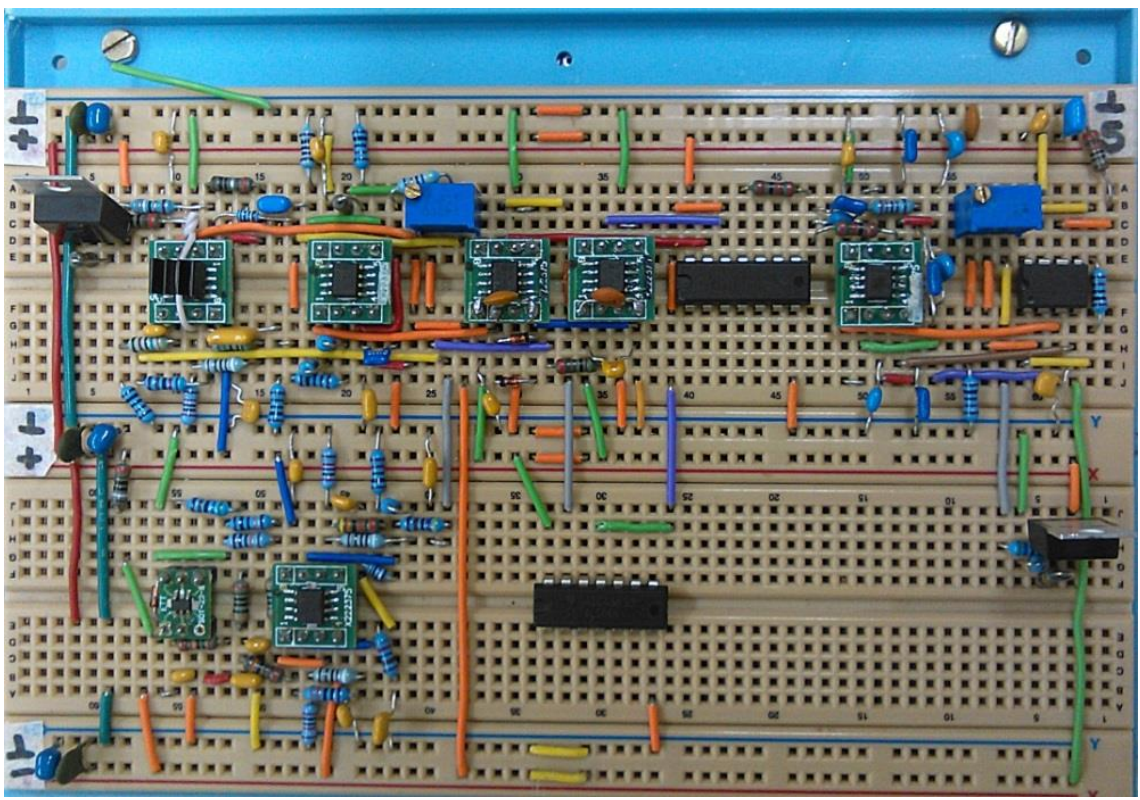

Figura 40 - Circuito eletrônico transdutor de pressão.

Na sequência, o circuito da Figura 40 foi avaliado experimentalmente, por meio de medições de tensões em determinados pontos de interesse. As medições foram realizadas com auxílio de um osciloscópio de alta resolução HRO 64Zi, da Lecroy, e pós-processadas por scripts implementados em Matlab, visando à adequada apresentação das curvas mostradas nas Figuras 41 até 49, as quais foram obtidas para $\mathrm{H}=-0,95$ Oe.

A Figura 41 apresenta o resultado da medição experimental do sinal gerado pelo oscilador $\mathrm{X}_{0}$, configurado a fim de gerar uma onda quadrada perfeita. Inspecionando os resultados obtidos, tem-se que a frequência do sinal gerado foi 
2.

de aproximadamente $99,86 \mathrm{kHz}$, a qual é satisfatoriamente próxima do valor ideal (100 kHz). Ainda, verifica-se que a amplitude do sinal experimental foi de cerca de 3,44 V e seu duty cycle aproximadamente 49,1\%. Dessa forma, comparando-se os resultados experimentais aqui obtidos com os resultados simulados, apresentados na Figura 31, verifica-se uma boa adequação entre eles.

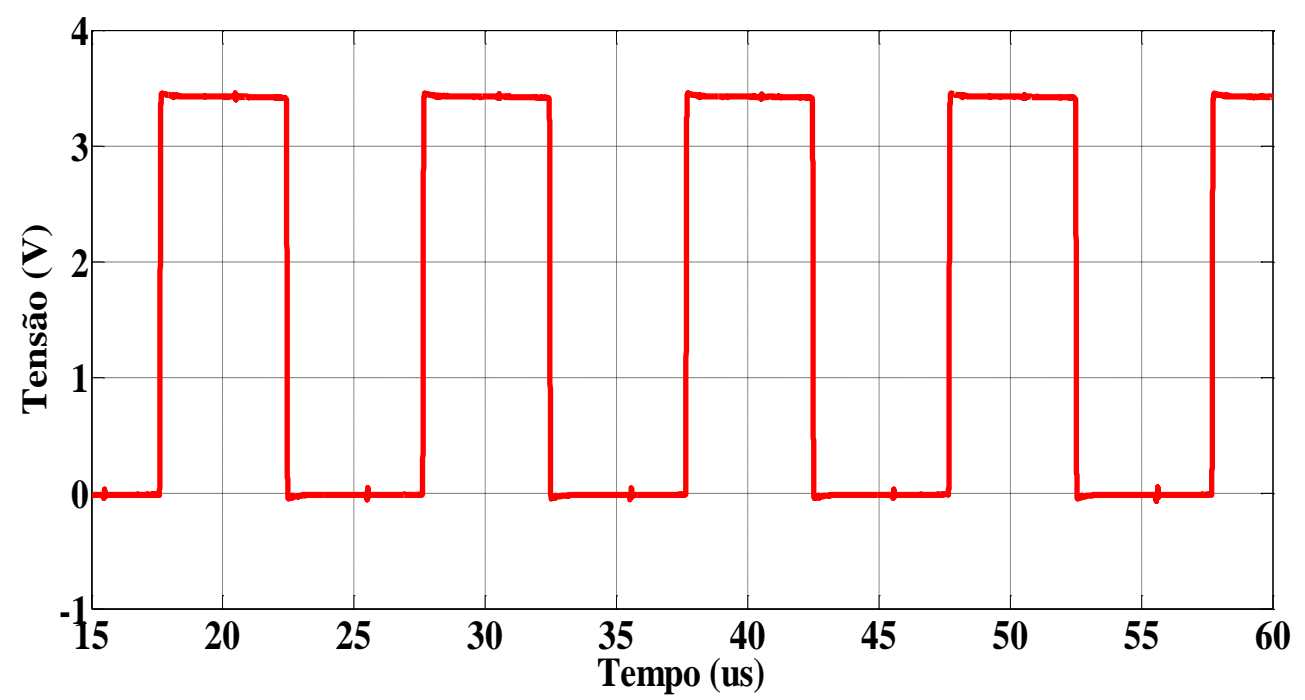

Figura 41 - Resultado da medição da tensão de entrada do protótipo implementado.

A Figura 42 apresenta os resultados das medições experimentais da tensão de saída do filtro passa-faixa (linha sólida) e da saída do defasador (linha pontilhada).

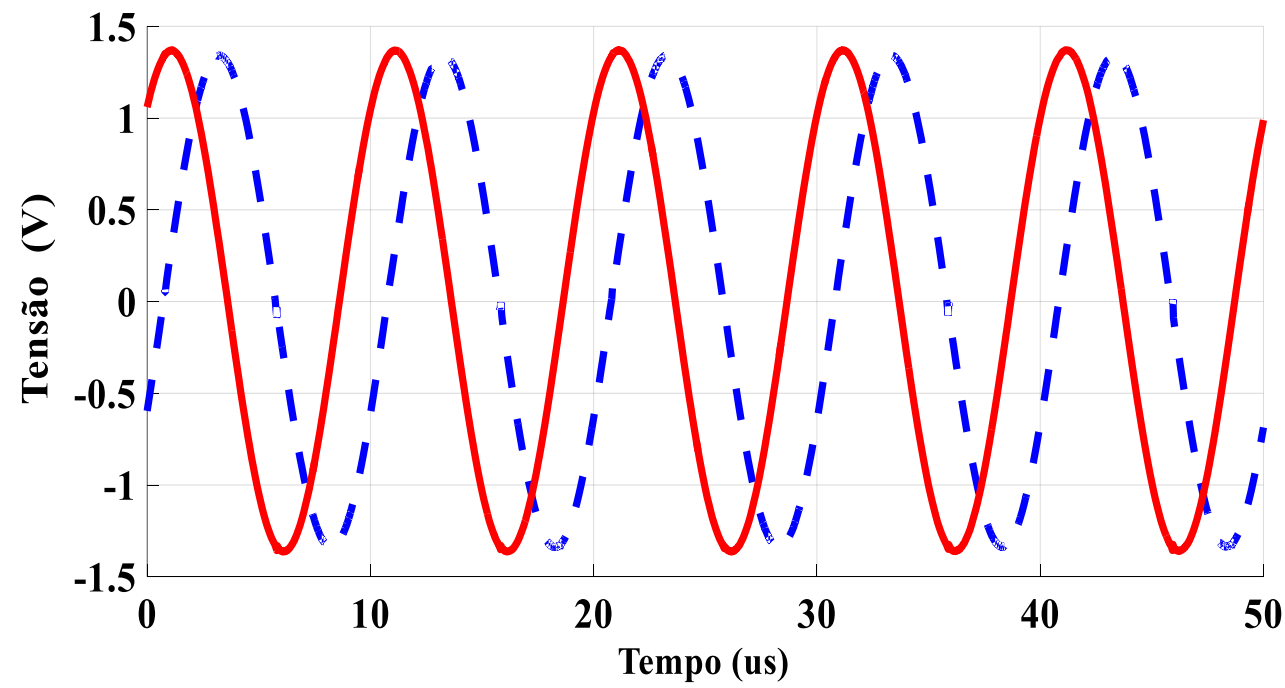

Figura 42 - Resultado da medição experimental das tensões de saída do filtro passa-faixa (linha solida) e do defasador (linha pontilhada).

Analisando-se estes resultados é possível verificar que a frequência dos sinais é de aproximadamente $100,5 \mathrm{kHz}$, a qual é satisfatoriamente próxima de $100 \mathrm{kHz}$. Por sua vez, tem-se que a defasagem entre estes sinais foi de $57,52^{\circ}$, 
2.

também bastante similar ao valor simulado na seção 2.3. Por fim, nota-se que a amplitude (1,37 V) de ambos os sinais apresentados na Figura 42 é razoavelmente distinta do simulado apresentado na Figura $32(2,03 \mathrm{~V})$.

Tal discrepância é atribuída ao fato do filtro passa faixas implementado ser altamente seletivo e possuir banda estreita. Dessa forma, uma pequena variação da frequência central do filtro (idealmente $100 \mathrm{kHz}$ ) pode acarretar em uma considerável atenuação do sinal de interesse. É razoável assumir que tal alteração seja decorrente das tolerâncias dos elementos passivos utilizados no circuito de filtragem montado, adicionadas às variações dos parâmetros dos AmpOps reais utilizados em relação aos valores adotados em seus modelos computacionais.

Entretanto é importante destacar que a redução da amplitude destes sinais para cerca de 0,66 V não é um problema significativo. Em particular, essa atenuação poderia implicar a redução da amplitude da corrente CA gerada pelo conversor V/I, porém é possível atuar sobre a resistência $\mathrm{R}_{2}$ do circuito (vide Figura 30), reduzindo-a, a fim de contrabalançar tal efeito.

A Figura 43 apresenta o resultado da medição experimental da tensão de saída do conversor V/I, implementado por $\mathrm{X}_{6}$, cujo resultado foi apresentado na Figura 33(a).

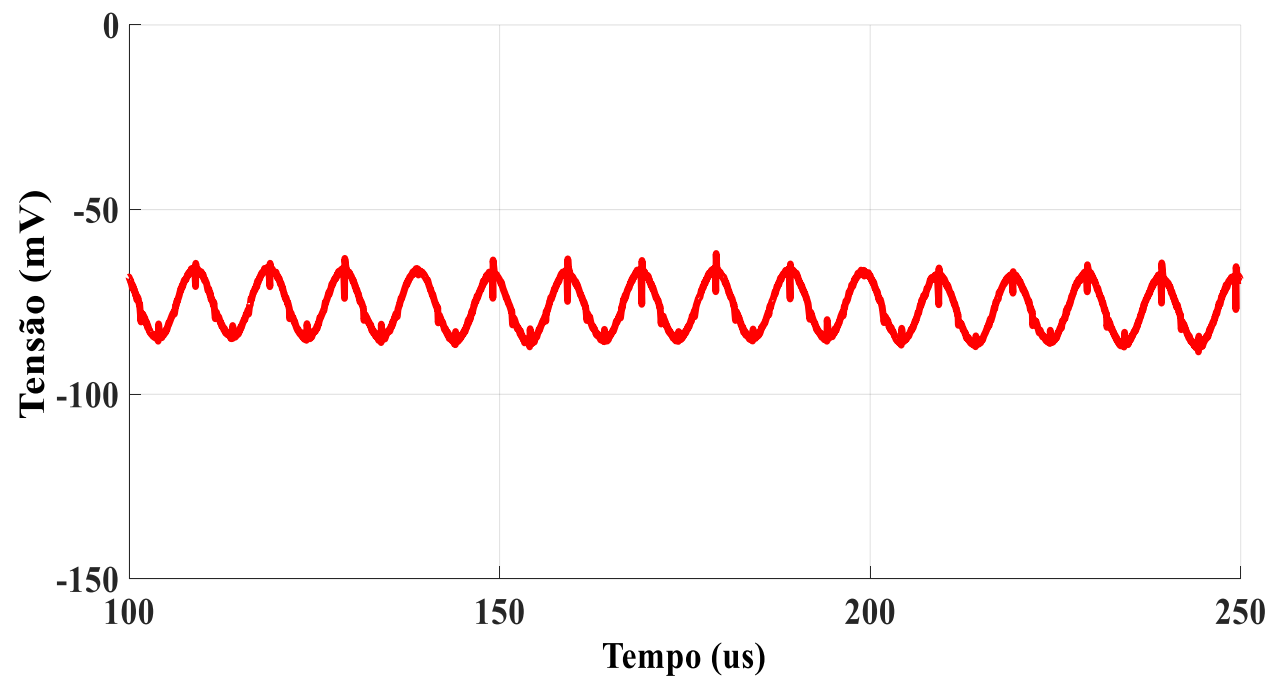

Figura 43 - Medição experimental da tensão de saída do conversor V/l.

Avaliando-se os dados experimentais apresentados na Figura 43, percebe-se que o sinal possui um nível $\mathrm{CC}$ de $-75 \mathrm{mV}$, uma amplitude de $10 \mathrm{mV}$ e uma frequência de $101 \mathrm{kHz}$. A partir dos resultados apresentados na Figura 43 também é possível estimar a corrente que flui pelo sensor GMI, a qual apresenta um nível CC de -79,79 mA e uma amplitude de 8,3 mA. O nível CC da corrente é obtido 
2.

dividindo-se o nível CC da tensão apresentada na Figura $43(-75 \mathrm{mV})$ pelo valor da componente resistiva $\mathrm{R}_{\text {sens }}$ do sensor em $\mathrm{H}=-0,95$ Oe, aproximadamente 0,94. Por outro lado, a amplitude da corrente é obtida dividindo-se a amplitude da tensão apresentada na Figura $43(10 \mathrm{mV})$ pelo valor do módulo $\left|Z_{\text {sens }}\right|$ do sensor em $\mathrm{H}=-0,95$ Oe que é aproximadamente $1,21 \Omega$.

Comparando-se os resultados experimentais aqui obtidos com as simulações apresentadas na seção 2.3, verifica-se que a amplitude da tensão de saída do conversor V/I e a amplitude da corrente de excitação do sensor GMI apresentam valores inferiores aos simulados. Tal redução é atribuída à diminuição da amplitude do sinal de saída do filtro passa-faixas, a qual foi reduzida de 2,03 V (valor simulado) para 1,37 V (valor experimental). A redução da corrente poderia ser corrigida atuando-se sobre a resistência $R_{2}$ do circuito (vide Figura 30), reduzindo-a, a fim de contrabalancear tal efeito. Entretanto, destaca-se que a redução da amplitude destes sinais não é um problema significativo, visto que a sensibilidade das amostras GMI não é significativamente afetada pela amplitude da corrente [10]. Dessa forma, optou-se por não implementar tal correção na montagem experimental.

Pode-se notar ainda um ruído superposto ao sinal apresentado na Figura 43, o que é natural, principalmente tendo em vista a pequena amplitude do sinal de interesse. Por fim, destaca-se que, tal como previsto nas simulações, existe o nível CC negativo nesta onda de tensão, que impede que a mesmo passe por zero, tornando necessária a adição de um filtro passa-altas a fim de eliminar o nível CC indesejável e amplificar a componente espectral de interesse $(100 \mathrm{kHz})$.

A medição experimental da tensão de saída do filtro passa-altas implementado é explicitada na Figura 44. Destaca-se que a análise computacional deste mesmo sinal já foi anteriormente exibida na Figura 34. 
2.

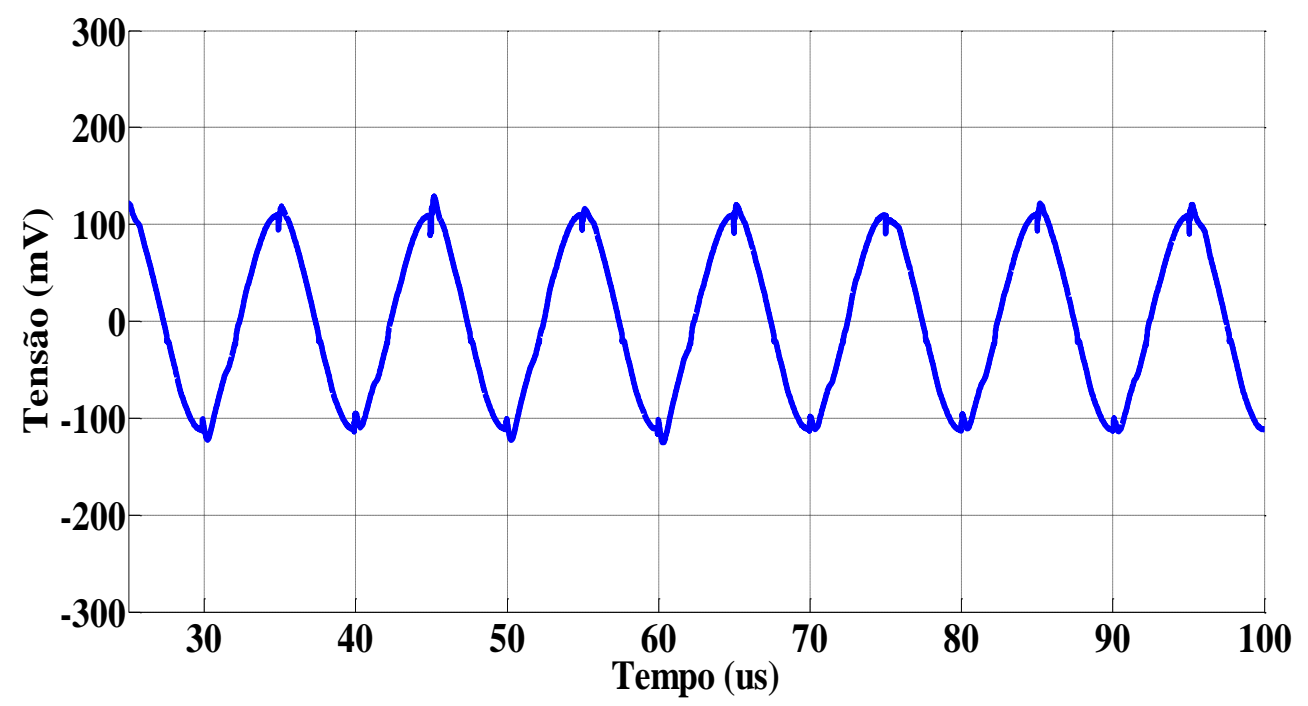

Figura 44 - Registro experimental da tensão de saída do filtro passa-altas.

Conforme esperado, observando a Figura 44, é perceptível que o filtro passa-altas elimina praticamente por completo o nível CC do sinal de entrada do filtro. Por sua vez, tem-se que a amplitude do sinal de saída é de $100 \mathrm{mV}$, o que indica que o ganho do filtro é aproximadamente $10 \mathrm{~V} / \mathrm{V}$. Assim, comparando-se tais resultados com os extraídos da forma de onda equivalente, apresentada na Figura 34, verifica-se que a amplitude do sinal experimental foi reduzida aproximadamente em $100 \mathrm{mV}$, sendo tal redução atribuída à diminuição da amplitude do sinal de saída do filtro passa-faixas.

$\mathrm{Na}$ sequência, apresentam-se na Figura 45 os resultados das medições experimentais das tensões de saída dos comparadores $\mathrm{X}_{5}$ e $\mathrm{X}_{8}$.

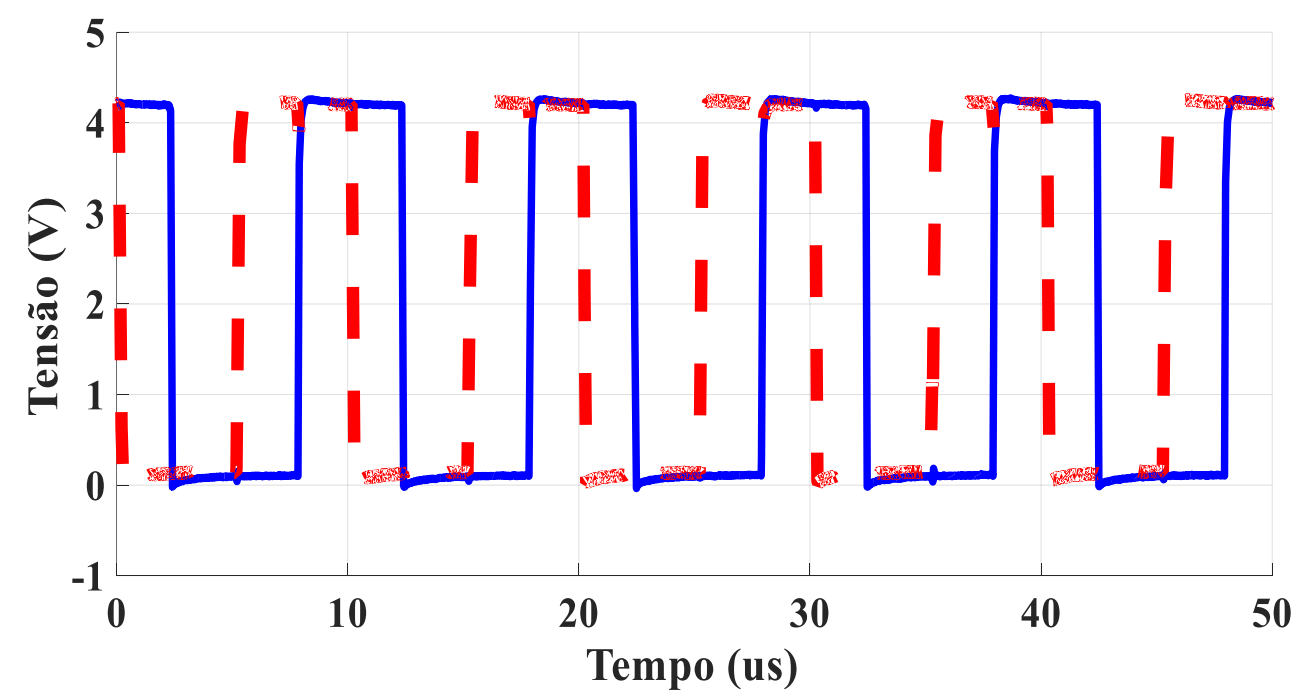

Figura 45 - Resultado da medição experimental das tensões de saída dos comparadores.

Por meio da análise dos resultados experimentais explicitados na Figura 45, é possível verificar que os comparadores, de fato, convertem as tensões senoidais 
2.

de entrada em ondas quadradas com níveis lógicos compatíveis com a lógica TTL. Também, observa-se que a defasagem entre as formas de onda de saída dos comparadores é cerca de $93,3^{\circ}$, a qual é satisfatoriamente próxima do valor teórico $\left(90^{\circ}\right)$ e do valor retornado pelas simulações computacionais (Figura 35).

Na Figura 46 é apresentado o resultado da medição experimental do sinal de saída do XOR, cuja resposta simulada foi anteriormente apresentada na Figura 36.

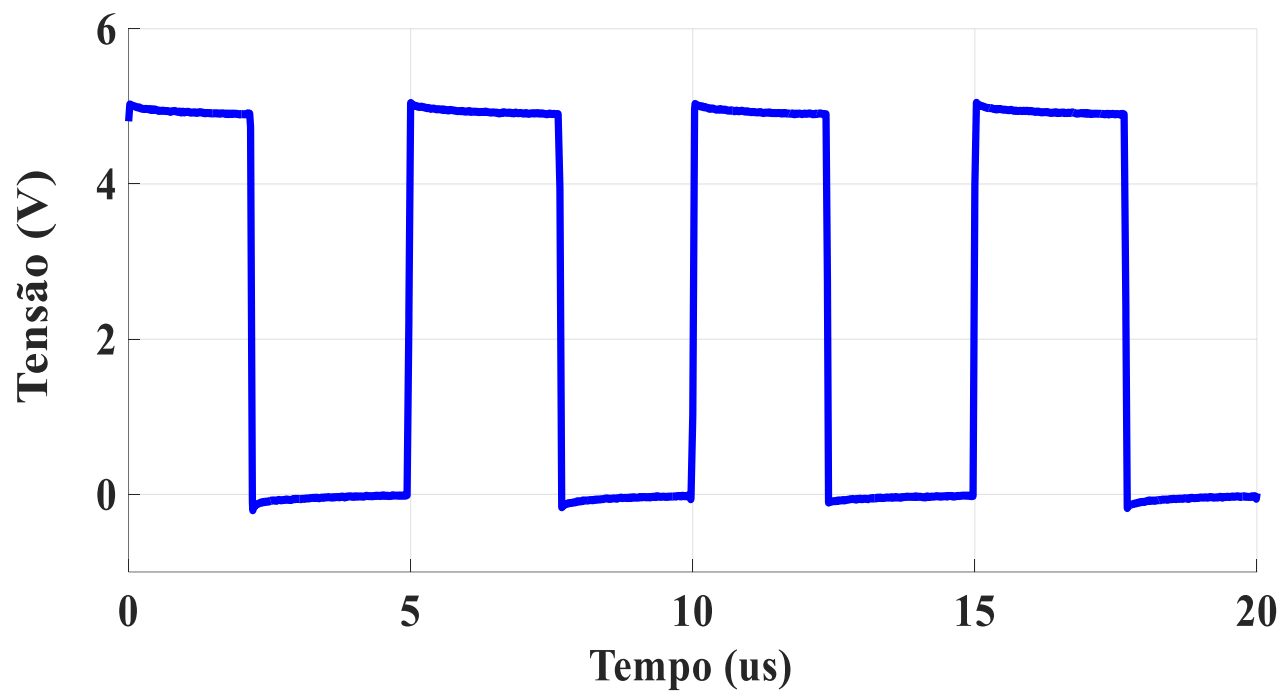

Figura 46 - Resultado da medição experimental da tensão na saída do XOR.

Os resultados experimentais apresentados na Figura 46 indicam que a onda de saída do XOR possui uma frequência fundamental de cerca de $201 \mathrm{kHz}$, duty cycle próximo a 49,7 \%, nível "baixo" de aproximadamente $0 \mathrm{~V}$ e nível "alto" de cerca de $5 \mathrm{~V}$. Os valores experimentais obtidos são aderentes às expectativas teóricas e ao comportamento simulado, evidenciado na Figura 36. Destaca-se que pequenas variações no duty cycle podem ser observadas ao se comparar períodos sucessivos do sinal experimentalmente obtido. Por sua vez, tais variações não estavam presentes na análise computacional. Dessa forma, é importante destacar que se trata de um comportamento plenamente aceitável, tendo em vista que, na análise computacional, o campo é perfeitamente fixado em $\mathrm{H}=-0,95 \mathrm{Oe}$, enquanto que nas medições experimentais existe ruído magnético que faz com que o valor de campo não seja exatamente $\mathrm{H}=-0,95 \mathrm{Oe}$, o que afeta o duty cycle do sinal de saída do XOR.

Por sua vez, a Figura 47 apresenta o resultado da medição experimental da saída do filtro passa-baixas que recebe como entrada o sinal apresentado na Figura 46, para $\mathrm{H}=-0,95$ Oe. 
2.

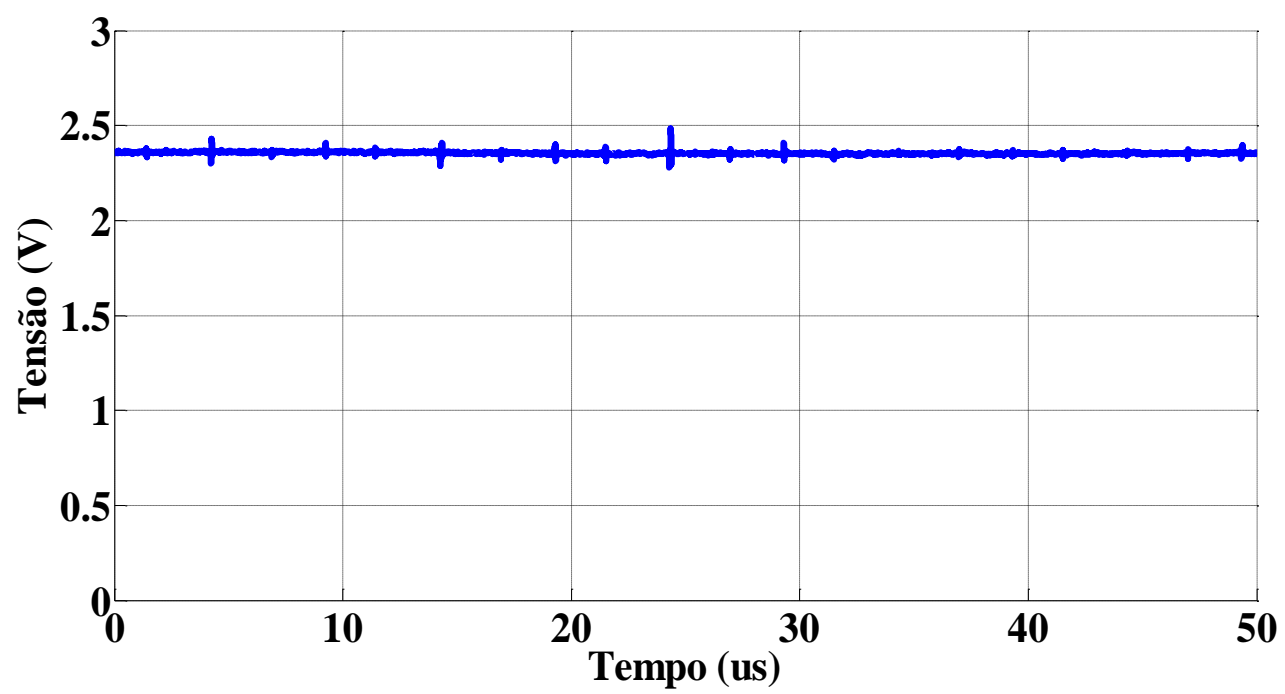

Figura 47 - Resultado da medição experimental da tensão de saída do filtro passa-baixas.

O sinal mostrado na Figura 47, possui nível CC de aproximadamente 2,4 V, o qual é significativamente próximo do obtido por meio da simulação computacional exibida na Figura 37. Ressalta-se ainda que, no registro experimental, é possível perceber a presença de componentes espectrais espúrias superpostas ao sinal CC de interesse.

A Figura 48 explicita o resultado da medição experimental da tensão de saída do circuito eletrônico de transdução, para $\mathrm{H}=-0,95$ Oe. Conforme esperado, os resultados experimentais indicam que, para o campo de polarização, o circuito apresenta uma tensão de saída aproximadamente nula. Ainda, é perceptível a presença de componentes espectrais indesejáveis que distorcem levemente o sinal de saída. Note que, além do sinal de interesse, eventuais níveis de ruído presentes nos terminais de entrada do amplificador de instrumentação também são amplificados por seu ganho, $\mathrm{G}=100 \mathrm{~V} / \mathrm{V}$. 
2.

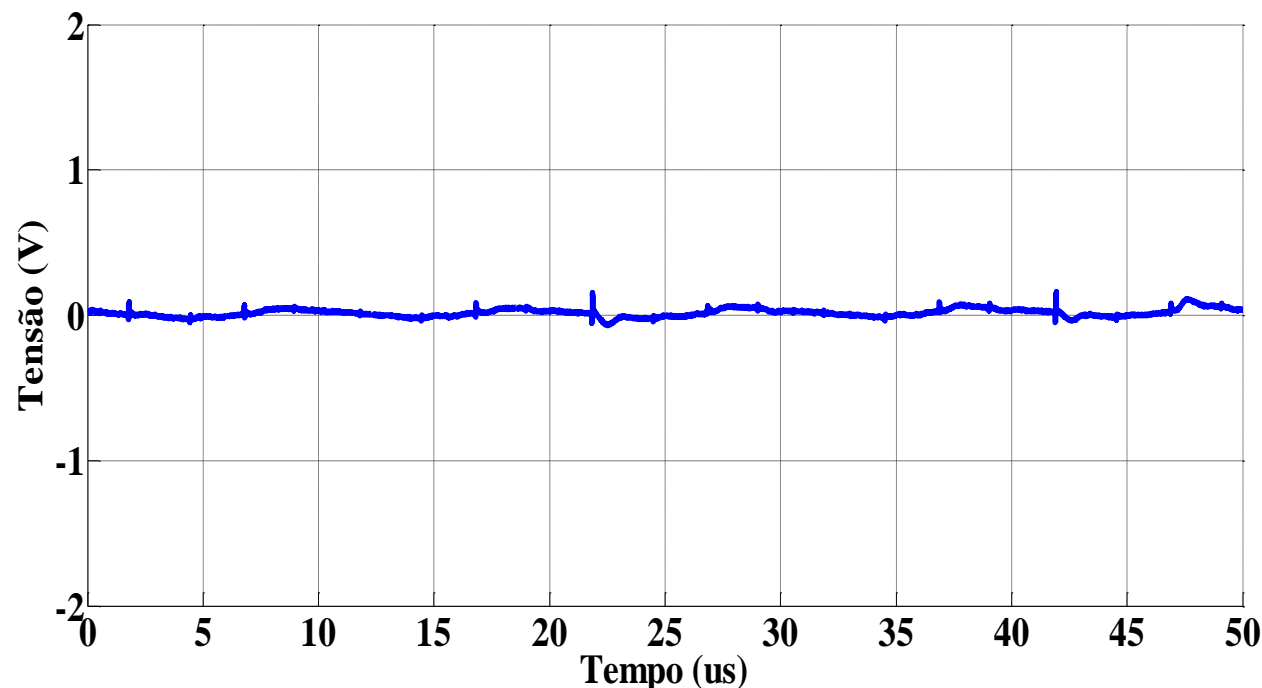

Figura 48 - Resultado da medição experimental da tensão de saída do circuito eletrônico, para $\mathrm{H}$ = $-0,95 \mathrm{Oe}$.

Os resultados obtidos experimentalmente para o protótipo montado foram bastante satisfatórios. Na maioria dos casos, as formas de onda apresentadas apresentaram comportamentos similares às curvas obtidas nas simulações computacionais.

Por fim, realizou-se a medição experimental das tensões de saída do circuito para campos variando de -0,4 Oe até -1,5 Oe, em passos de 0,1 Oe, ou seja, dentro da faixa de operação linear do sensor GMI utilizado (vide seção 2.1). Os resultados destas medições são mostrados na Figura 49, os quais podem ser diretamente comparados às curvas obtidas por simulação computacional, apresentadas na Figura 39.

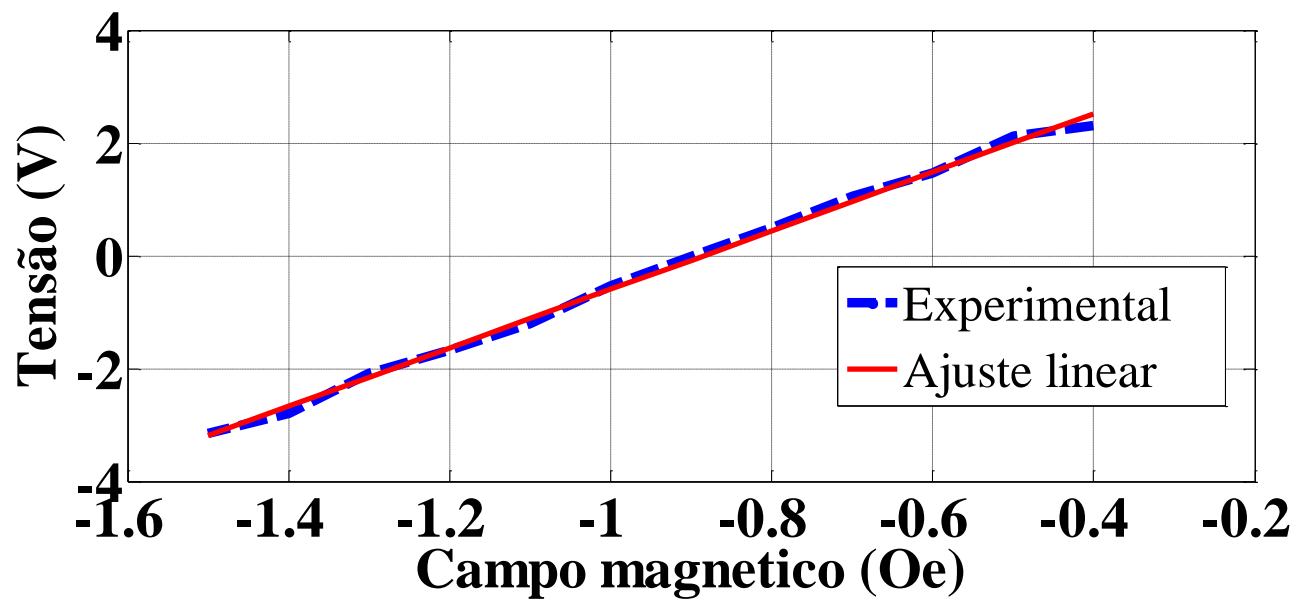

Figura 49 - Resultado da medição experimental das tensões de saída do circuito eletrônico para diferentes valores de $\mathrm{H}$, expressos em Oe.

Conforme esperado, os resultados apresentados na Figura 49 indicam que, para o campo de polarização $(H=-0,95 \mathrm{Oe})$, o circuito apresenta uma tensão de 
2.

saída aproximadamente nula. Também é possível verificar que, dentro da faixa de operação proposta, a resposta da tensão de saída do circuito experimental, em função do campo magnético, é fortemente linear, o que é extremamente desejável. Tais resultados comprovam a análise computacional, que também indicou uma resposta com comportamento fortemente linear. Consequentemente, é possível modelar adequadamente o comportamento desta tensão de saída experimental por meio de um polinômio de ajuste linear, dado por

$$
V_{\text {out }}=\left(5,12 \mathrm{~V} \cdot \mathrm{Oe}^{-1}\right) \cdot H+4,77 \mathrm{~V}
$$

Dessa forma, tem-se que a sensibilidade média do circuito experimental é $5,12 \mathrm{~V} \cdot \mathrm{Oe}^{-1}$, na região de operação. Destaca-se ainda que a sensibilidade obtida a partir da curva experimental é satisfatoriamente próxima da prevista por meio das simulações computacionais $\left(4,72 \mathrm{~V} \cdot \mathrm{Oe}^{-1}\right)$. 
3.

3.

\section{Protótipo do Transdutor de Pressão GMI}

O presente capítulo descreve o desenvolvimento do protótipo do transdutor de pressão GMI destinado à medição da onda de pulso arterial, baseado nas características de fase da impedância de sensores GMI, cuja configuração incorpora amplificação mecânica por meio de uma câmara incompressível.

O elemento sensor GMI deve ser polarizado por um valor bem definido de campo magnético, de modo a garantir que o mesmo opere em sua região linear. Este campo de polarização é dado pela combinação do campo gerado por uma fonte móvel com o campo proveniente de um solenoide. Assim, foram idealizadas e testadas duas configurações para o transdutor de pressão, diferenciadas pelo tipo de fonte móvel (ímã permanente ou agulha magnetizada) usada para gerar um campo magnético contínuo e uniforme, paralelo à fita. Nas seções 3.2 e 3.3 as duas configurações são detalhadas e os resultados obtidos são apresentados e discutidos. Finalmente, na última seção do capítulo, são detalhados os procedimentos adotados para realização das medições da Onda de Pulso Arterial e apresentados os resultados experimentais.

\section{1 Descrição do protótipo do transdutor de pressão}

A estrutura idealizada para o transdutor de pressão desenvolvido neste trabalho é apresentada na Figura 50. O arranjo experimental é o mesmo para as duas configurações previstas de fonte móvel para geração de campo magnético de polarização. Assim, a estrutura inclui uma câmara incompressível para transdução mecânica, de modo que uma variação de pressão $\Delta \mathrm{P}$, aplicada sobre a membrana semirrígida, é transmitida pela câmara incompressível e gera um deslocamento da membrana elástica. Por sua vez, tal deslocamento faz com que a fonte de campo magnético móvel (agulha magnetizada ou ímã permanente) se desloque em relação a um sensor magnético GMI disposto sobre a base da estrutura, provocando uma variação do campo magnético resultante sobre ele $(\Delta \mathrm{H})$. Na 
3.

Protótipo do transdutor de pressão GMI

sequência da cadeia de processamento do sinal, tem-se que a variação de campo $\Delta \mathrm{H}$ implica a alteração da fase da impedância do elemento sensor, a qual é, posteriormente, convertida em tensão, por meio do circuito eletrônico de transdução descrito no capitulo 2. Dessa forma, gera-se uma tensão elétrica de saída diretamente associada à variação de pressão $\Delta \mathrm{P}$ à qual a membrana semirrígida foi submetida.

É importante ajustar adequadamente o valor do campo magnético de polarização a fim de permitir que a amostra sensora opere em uma faixa satisfatoriamente linear e com boa sensibilidade. Define-se aqui campo magnético de polarização, como o campo resultante sobre a amostra GMI na situação de equilíbrio, ou seja, quando $\Delta \mathrm{P}=0$. Note que, na situação de equilíbrio, a fonte de campo magnético móvel gera um campo magnético sobre a amostra GMI, entretanto tal campo pode não apresentar o valor ideal para adequada polarização da amostra. Dessa forma, coloca-se a amostra sensora no interior de um solenoide, de forma a garantir que o campo gerado pelo mesmo seja longitudinal ao comprimento do sensor GMI. Assim, o campo magnético de polarização é dado pela associação do campo magnético gerado pela fonte de campo magnético móvel com o campo magnético gerado pelo solenoide. Consequentemente, ajustando-se à corrente que flui pelo solenoide, é possível ajustar o valor do campo de polarização para um valor satisfatório.

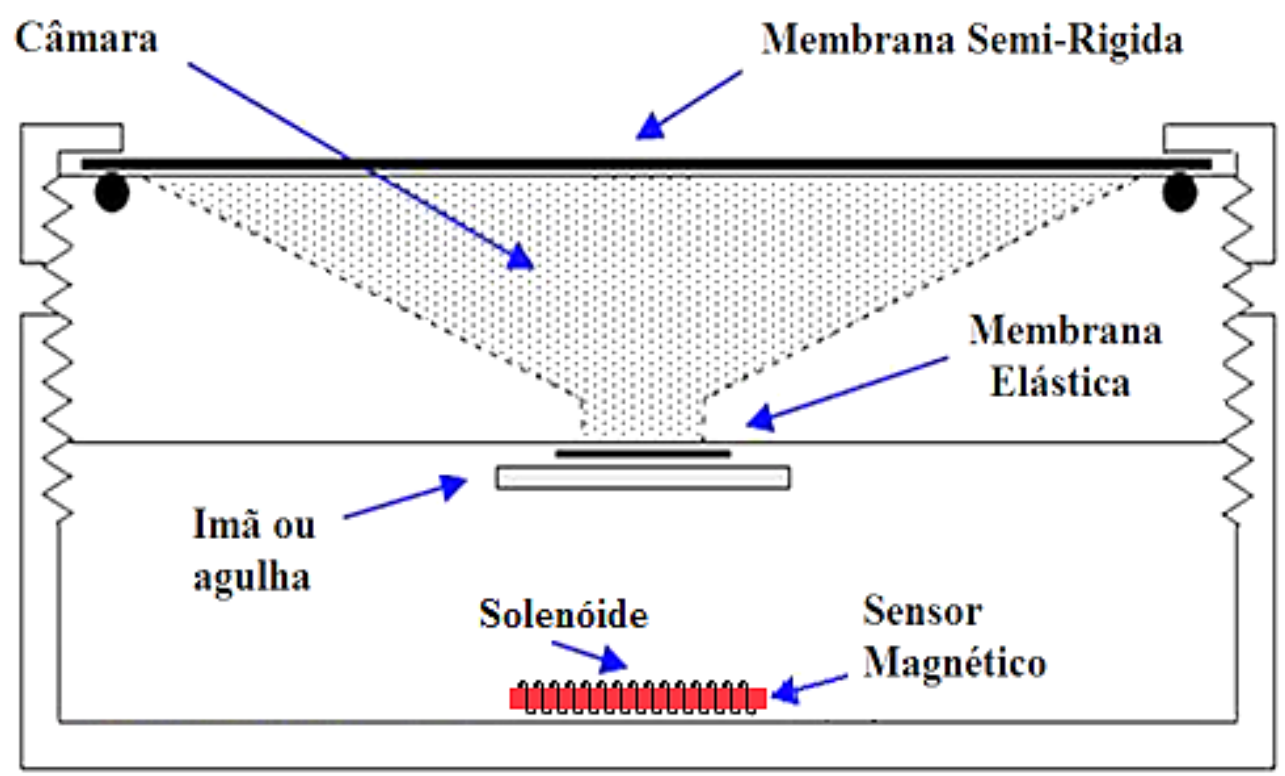

Figura 50 - Descrição esquemática do transdutor de pressão desenvolvido. 
3.

\section{2}

\section{Agulha magnetizada como fonte de campo magnético}

Nas fotos apresentadas na Figura 51 podem-se observar as partes que compõem a estrutura mecânica do transdutor de pressão. Em (a), observa-se a base da estrutura do transdutor, onde estão posicionados o solenoide de polarização, com a amostra GMI em seu interior. Por sua vez, em (b), visualiza-se a membrana elástica com uma agulha aderida a mesma, a qual foi utilizada como fonte de campo magnético móvel.

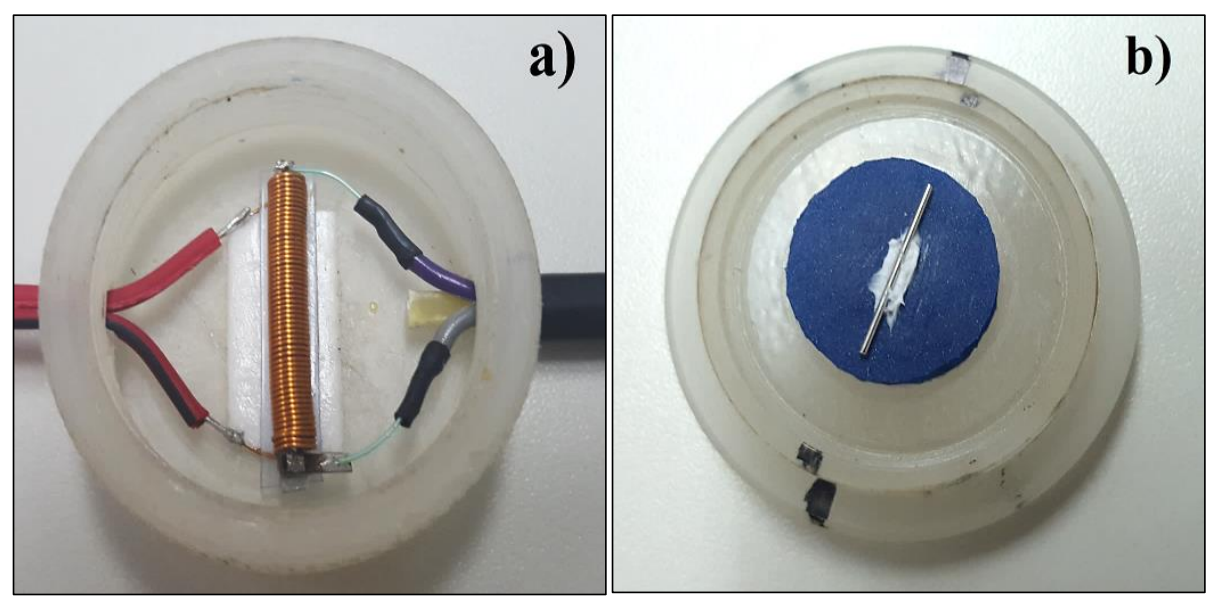

Figura 51 - Partes do Transdutor de Pressão, baseado na utilização de uma agulha magnetizada como fonte de campo móvel.

Ressalta-se que, nos testes realizados com a agulha como fonte de campo móvel, utilizou-se o sensor GMI associado a um cabo curto $(20 \mathrm{~cm})$. Dessa forma, os resultados computacionais e experimentais, apresentados nas seções 2.3 e 2.4, não são válidos, visto que os mesmos foram obtidos considerando-se a associação do elemento sensor a um cabo longo $(85 \mathrm{~cm})$.

Dessa forma, as simulações computacionais foram refeitas, utilizando-se os resultados das medições apresentadas na seção 2.1 correspondentes à associação do elemento sensor com o cabo curto $(20 \mathrm{~cm})$. Para cada valor de $\mathrm{H}$ analisado, a amostra GMI foi modelada por uma resistência $\mathrm{R}_{\text {sens }}$ em série com uma indutância

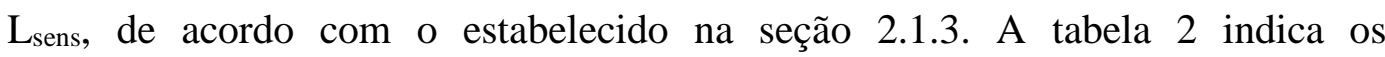
respectivos valores dos componentes resistivos e indutivos utilizados. 
3.

Tabela 2. Valores das componentes resistivas e indutivas da impedância equivalente formada pela associação do sensor GMI com o cabo curto, em função de cada valor de campo magnético analisado.

\begin{tabular}{|c|c|c|}
\hline $\mathbf{H}(\mathbf{O e})$ & $\mathbf{R}_{\text {sens }}(\mathbf{\Omega})$ & $\mathbf{L}_{\text {sens }}(\boldsymbol{\mu H})$ \\
\hline$-1,50$ & 0,825 & 0,599 \\
\hline$-1,40$ & 0,824 & 0,594 \\
\hline$-1,30$ & 0,822 & 0,586 \\
\hline$-1,20$ & 0,821 & 0,577 \\
\hline$-1,10$ & 0,818 & 0,568 \\
\hline$-1,00$ & 0,815 & 0,558 \\
\hline$-0,90$ & 0,813 & 0,549 \\
\hline$-0,80$ & 0,810 & 0,540 \\
\hline$-0,70$ & 0,808 & 0,532 \\
\hline$-0,60$ & 0,805 & 0,524 \\
\hline$-0,50$ & 0,803 & 0,516 \\
\hline$-0,40$ & 0,800 & 0,509 \\
\hline
\end{tabular}

Por sua vez, utilizando-se os dados contidos na Tabela 2, é possível simular a resposta da tensão de saída do circuito em função de variações de campo magnético, decorrentes de variações de pressão. A Figura 52 indica as tensões de saída do circuito para campos variando de $-0,4$ Oe até $-1,5$ Oe, em passos de 0,1 Oe, a qual é a faixa de operação linear do sensor GMI utilizado (vide seção 2.1).

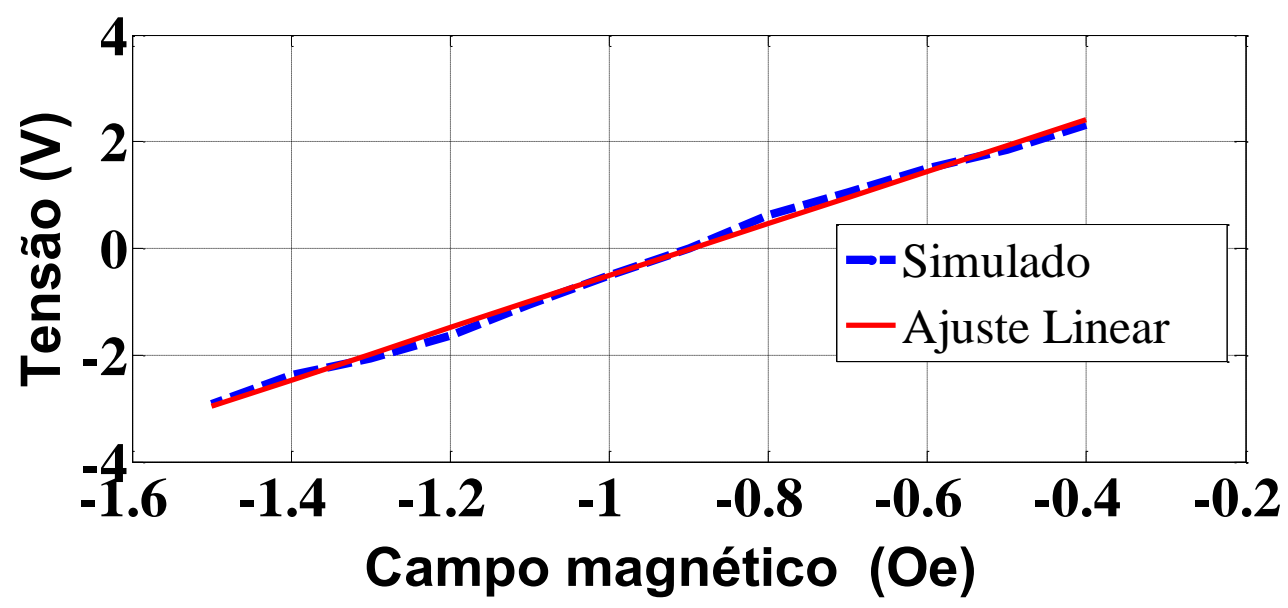

Figura 52 - Resposta simulada da tensão de saída do circuito eletrônico para diferentes valores de $H$, expressos em Oe, para a situação na qual o sensor GMl é associado a um cabo curto.

Conforme esperado, os resultados simulados indicam que, para o campo de polarização $(H=-0,95$ Oe $)$ o circuito apresenta uma tensão de saída aproximadamente nula. Observa-se um comportamento fortemente linear da 
3.

Protótipo do transdutor de pressão GMI

tensão de saída em função das variações de campo avaliadas, em toda a região de operação. Consequentemente, é possível modelar satisfatoriamente a resposta do transdutor por meio de um polinômio de ajuste linear, dado por

$$
V_{\text {out }}=\left(4,88 \mathrm{~V} \cdot \mathrm{Oe}^{-1}\right) \cdot H+4,37 \mathrm{~V}
$$

Dessa forma, tem-se que a sensibilidade média do circuito simulado é 4,88 $\mathrm{V} \cdot \mathrm{Oe}^{-1}$, na região de operação.

Por sua vez, na Figura 53 são apresentados os resultados experimentais da resposta da tensão de saída do circuito em função de campos magnéticos variando de $-0,4$ Oe até $-1,5$ Oe, em passos de 0,1 Oe.

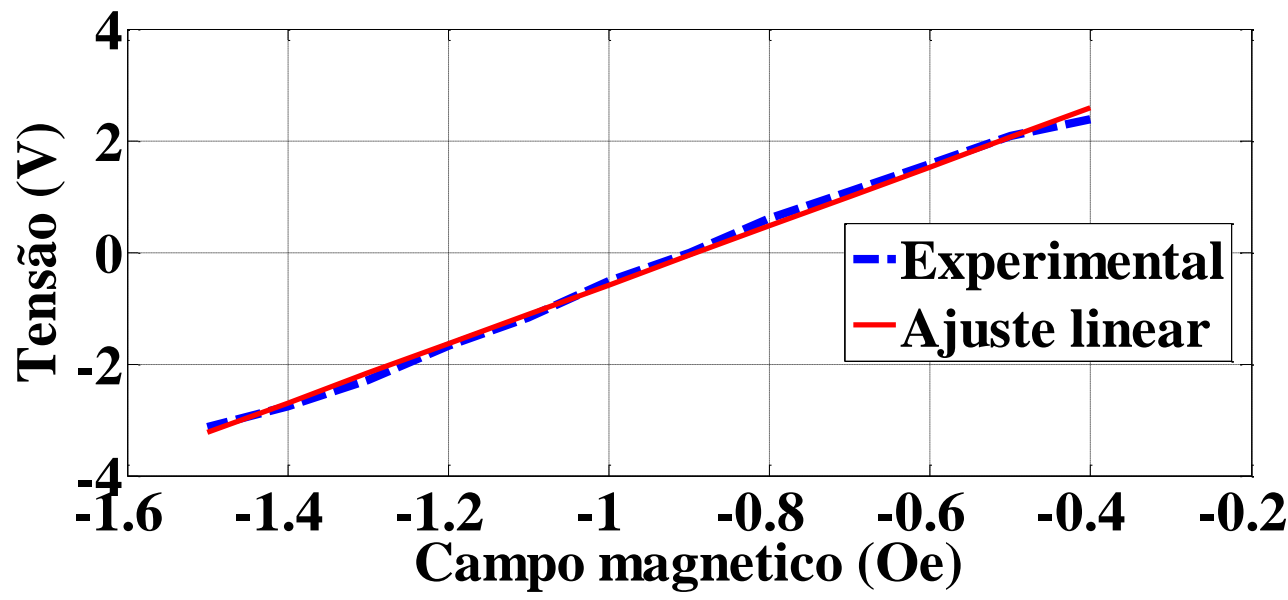

Figura 53 - Resultado da medição experimental das tensões de saída do circuito eletrônico, para diferentes valores de $\mathrm{H}$, expressos em Oe.

Conforme esperado, os resultados experimentais indicam que na situação de equilíbrio $(\mathrm{H}=-0,95 \mathrm{Oe})$ o circuito apresentará uma tensão de saída nula. Ainda, percebe-se que o comportamento do circuito é, de fato, fortemente linear e, consequentemente, pode ser adequadamente modelado por um polinômio de $1^{\circ}$ grau, dado por:

$$
V_{\text {out }}=\left(5,28 \mathrm{~V} \cdot \mathrm{Oe}^{-1}\right) \cdot H+4,70 \mathrm{~V}
$$

Dessa forma, tem-se que a sensibilidade média do circuito experimental é $5,28 \mathrm{~V} \cdot \mathrm{Oe}^{-1}$ na região de operação, a qual é satisfatoriamente próxima da prevista por meio das simulações computacionais $\left(4,88 \mathrm{~V} \cdot \mathrm{Oe}^{-1}\right)$.

\subsection{1}

\section{Sensibilidade e linearidade}

A sensibilidade do transdutor de pressão pode ser significativamente afetada pela distância de separação entre a fonte de campo magnético móvel, neste caso 
3.

uma agulha magnetizada, e o sensor GMI, vide Figura 50. Reduzindo-se esta distância, aumenta-se a variação do campo magnético sobre o sensor para uma mesma pressão exercida sobre a membrana elástica e, consequentemente, aumenta-se a sensibilidade do transdutor. Por outro lado, ao se aproximar a fonte de campo móvel do sensor, aumenta-se o campo de polarização, o qual deve ser mantido em $\mathrm{H}=-0.95 \mathrm{Oe}$, a fim de que o transdutor o opere na sua região linear, conforme discutido na seção 2.1. Dessa forma, a fim de se manter o valor do campo de polarização fixo na situação de equilíbrio (pressão nula), deve-se fazer com que o solenoide gere um campo capaz de compensar o campo da fonte móvel, conforme detalhado na seção 3.1.

Dessa forma, no intuito de avaliar qual é a corrente de excitação necessária para o solenoide, obtiveram-se experimentalmente as curvas da fase da impedância do sensor GMI em função da corrente de excitação do solenoide, para 6 diferentes distâncias de separação entre a fonte de campo e o sensor. Foram obtidas curvas de fase para afastamentos entre $0 \mathrm{~mm}$ e $5 \mathrm{~mm}$, em passos de $1 \mathrm{~mm}$. Nestas medições, a fonte de campo foi fixada à base de um plano milimetrado, colocado em paralelo com o comprimento do sensor GMI, conforme indicado na Figura 54.

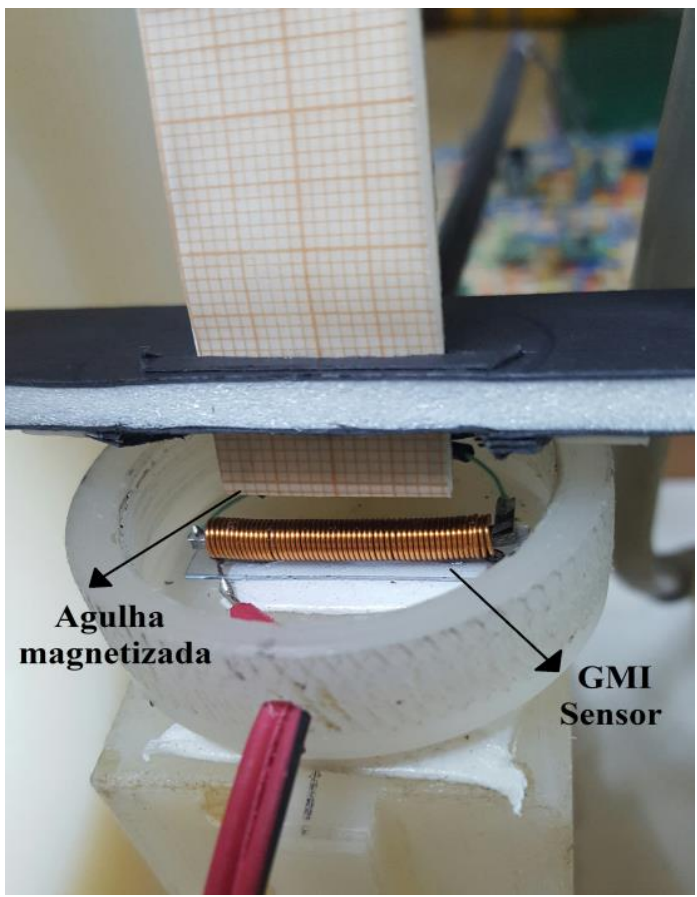

Figura 54 - Arranjo experimental utilizado para obtenção das curvas de fase do sensor GMI em função da corrente de excitação do solenoide, para diferentes distâncias de separação entre sensor e fonte de campo. 
3.

Protótipo do transdutor de pressão GMI

No processo de caracterização, posiciona-se a agulha magnetizada a uma dada distância do sensor GMI e excita-se o solenoide com uma corrente contínua controlável, de modo que o mesmo gere um campo magnético CC. Dessa forma, o campo resultante ao qual a amostra GMI está submetida é dado pela associação do campo da agulha com o campo do solenoide. Na sequência, utiliza-se um medidor RLC (4285A, Agilent), para excitação da amostra GMI com a corrente desejada, $\mathrm{i}_{\mathrm{c}}=[80+15 \operatorname{sen}(2 \pi \cdot 100 \mathrm{kHz} \cdot \mathrm{t})] \mathrm{mA}$, e para leitura de módulo e fase da amostra.

As curvas de caracterização da amostra GMI foram obtidas para correntes do solenoide variando de $-300 \mathrm{~mA}$ até $300 \mathrm{~mA}$, em passos de $10 \mathrm{~mA}$, sendo que se faz uma leitura de módulo e fase a cada passo de corrente. Os resultados são apresentados na Figura 55. As curvas obtidas para as diferentes distâncias analisadas (0 mm a $5 \mathrm{~mm}$ ) foram sobrepostas de maneira a se evidenciar como o comportamento do campo varia à medida que se aproxima a agulha magnetizada do sensor magnético.

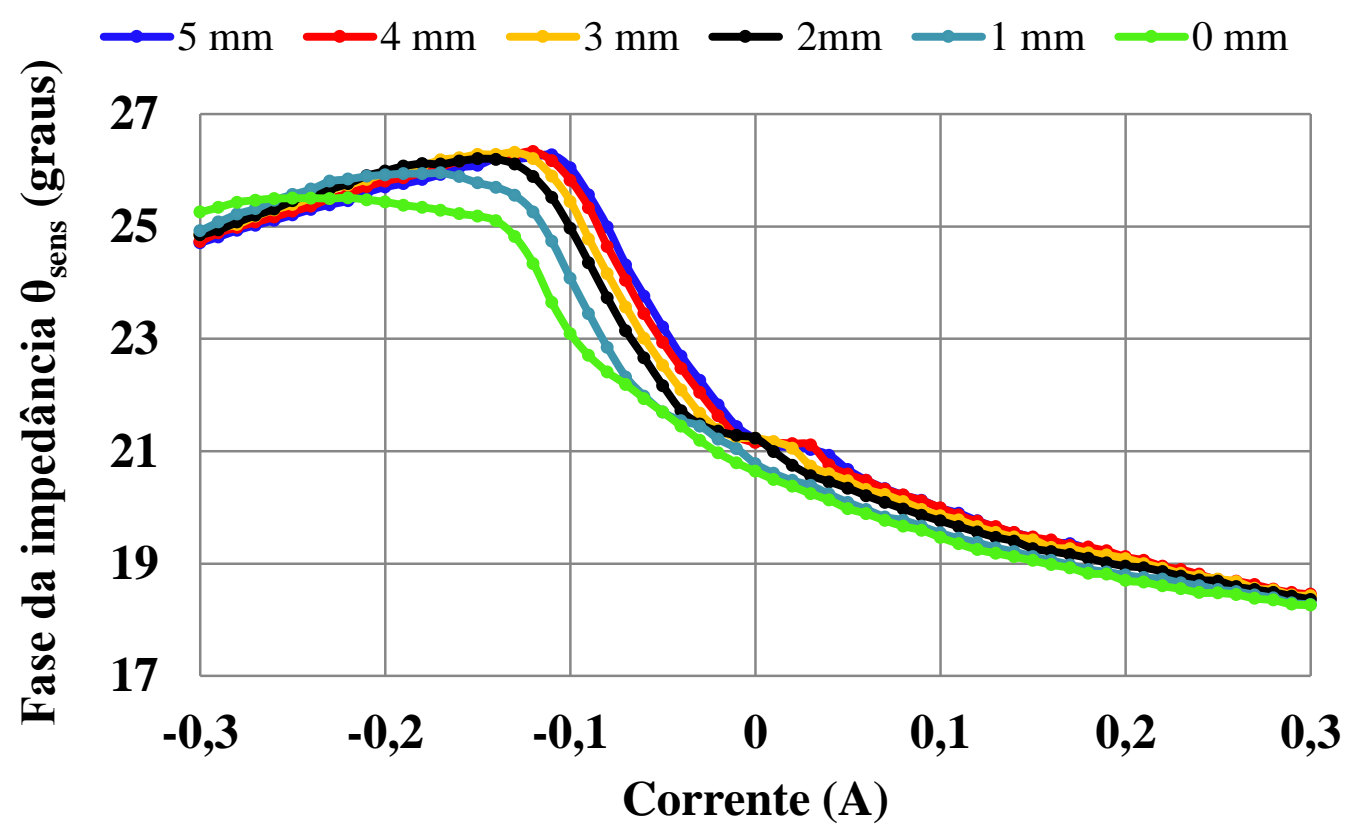

Figura 55 - Caracterização experimental da fase da impedância do sensor GMl em função da corrente que atravessa o solenoide, para diferentes distâncias de afastamento entre a agulha e o sensor.

Por meio da Figura 55, pode-se notar que, ao se reduzir a distância de afastamento, as curvas apresentam um deslocamento à esquerda, bem como uma diminuição no valor absoluto da fase. Verifica-se ainda que, para afastamentos muito pequenos (em especial: $0 \mathrm{~mm}$ e $1 \mathrm{~mm}$ ), a linearidade da curva de fase é significativamente comprometida. Tendo em vista os resultados obtidos, optou-se 
3.

Protótipo do transdutor de pressão GMI

por fixar a distância de separação em $3 \mathrm{~mm}$, que é a menor distância para a qual a amostra exibe um comportamento satisfatoriamente linear, na região de operação sendo esta curva apresentada mais detalhadamente na Figura 56.

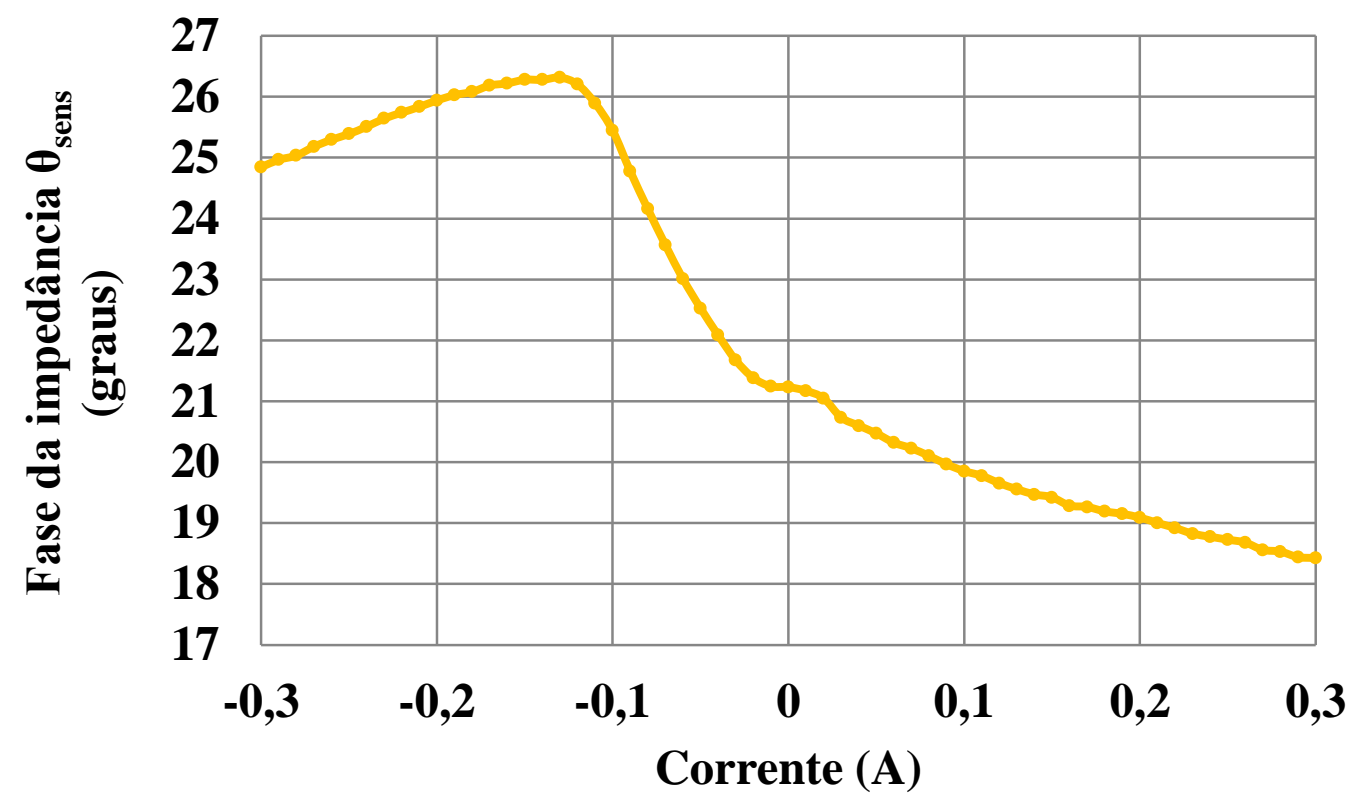

Figura 56 - Caracterização experimental da fase da impedância do sensor GMI em função da corrente que atravessa o solenoide, para $3 \mathrm{~mm}$ de afastamento entre a agulha e o sensor.

A curva apresentada na Figura 56, referente ao afastamento de $3 \mathrm{~mm}$, possui uma região satisfatoriamente linear para correntes de excitação do solenoide entre cerca de $-20 \mathrm{~mA}$ e $-100 \mathrm{~mA}$, a qual também é claramente a região onde o sensor apresenta sua sensibilidade máxima.

Tendo em vista a estrutura do transdutor de pressão, apresentada na Figura 50, e a descrição de sua operação, detalhada na seção 3.1, é possível verificar que, conforme aumenta-se a pressão exercida sobre a membrana semirrígida do transdutor de pressão, o valor absoluto do campo magnético sobre a amostra também aumenta gradativamente. Dessa forma, tem-se que a situação de equilíbrio $(\Delta \mathrm{P}=0)$ é o caso onde a amostra GMI está sujeita ao menor campo magnético, em valor absoluto.

Consequentemente, optou-se por não ajustar a corrente de polarização do solenoide para o ponto médio da faixa linear (-60 mA). Ao invés disso, ajustou-se esta corrente para $-35 \mathrm{~mA}$, a fim de permitir uma maior excursão das variações de campo magnético decorrentes da aproximação da fonte móvel (agulha) do sensor GMI, induzidas pelo aumento da pressão na membrana. Dessa forma, permite-se que o transdutor opere em sua região linear para uma faixa maior de pressões, ou 
3.

Protótipo do transdutor de pressão GMI

seja, aumenta-se o fundo de escala, sem comprometer a sensibilidade. Destaca-se que é importante orientar adequadamente a posição da agulha magnetizada, de modo que ao aproximá-la do elemento sensor sejam induzidos deslocamentos à esquerda na curva da Figura 55. Ressalta-se ainda que escolhe-se $-35 \mathrm{~mA}$, ao invés do extremo da faixa linear (-20 mA), a fim de se operar com uma margem de segurança em relação a este ponto crítico.

Com base nas análises aqui realizadas ajustou-se a distância de afastamento entre agulha magnetizada e sensor para $3 \mathrm{~mm}$, e excitou-se o solenóide com -35 mA. Nesta configuração, a fim de se medir experimentalmente a sensibilidade do transdutor de pressão, aplicaram-se diferentes pressões à membrana do transdutor, cuja área é conhecida $\left(0,71 \cdot 10^{-3} \mathrm{~m}^{2}\right)$, e mediu-se o seu respectivo sinal de saída, em cada caso analisado. As variações de pressão foram feitas por meio da colocação de massas padrão conhecidas (1, 2, 5, 10, 20, 50, 100 gramas), apresentadas na Figura 57, sobre a membrana do transdutor. Utilizou-se um anteparo para adequado posicionamento destas massas sobre a membrana do transdutor, conforme destacado na imagem apresentada na Figura 58.

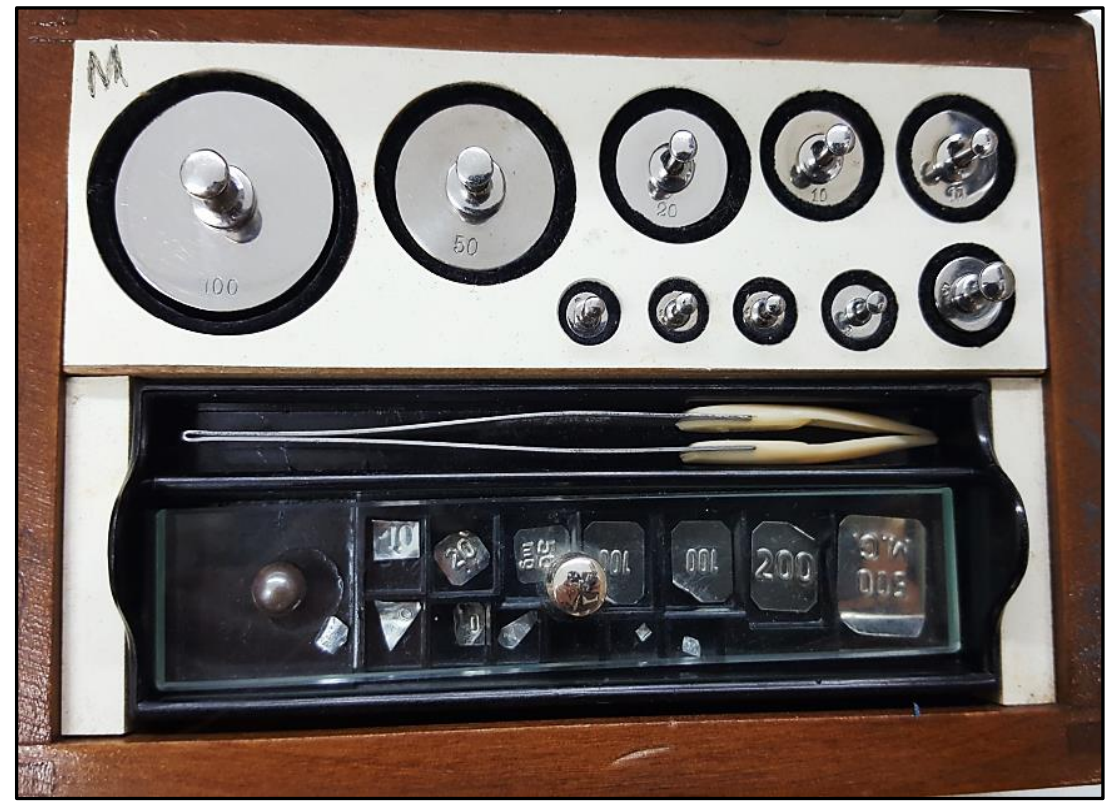

Figura 57 - Massas padrão utilizadas na caracterização da sensibilidade do transdutor. 
3.

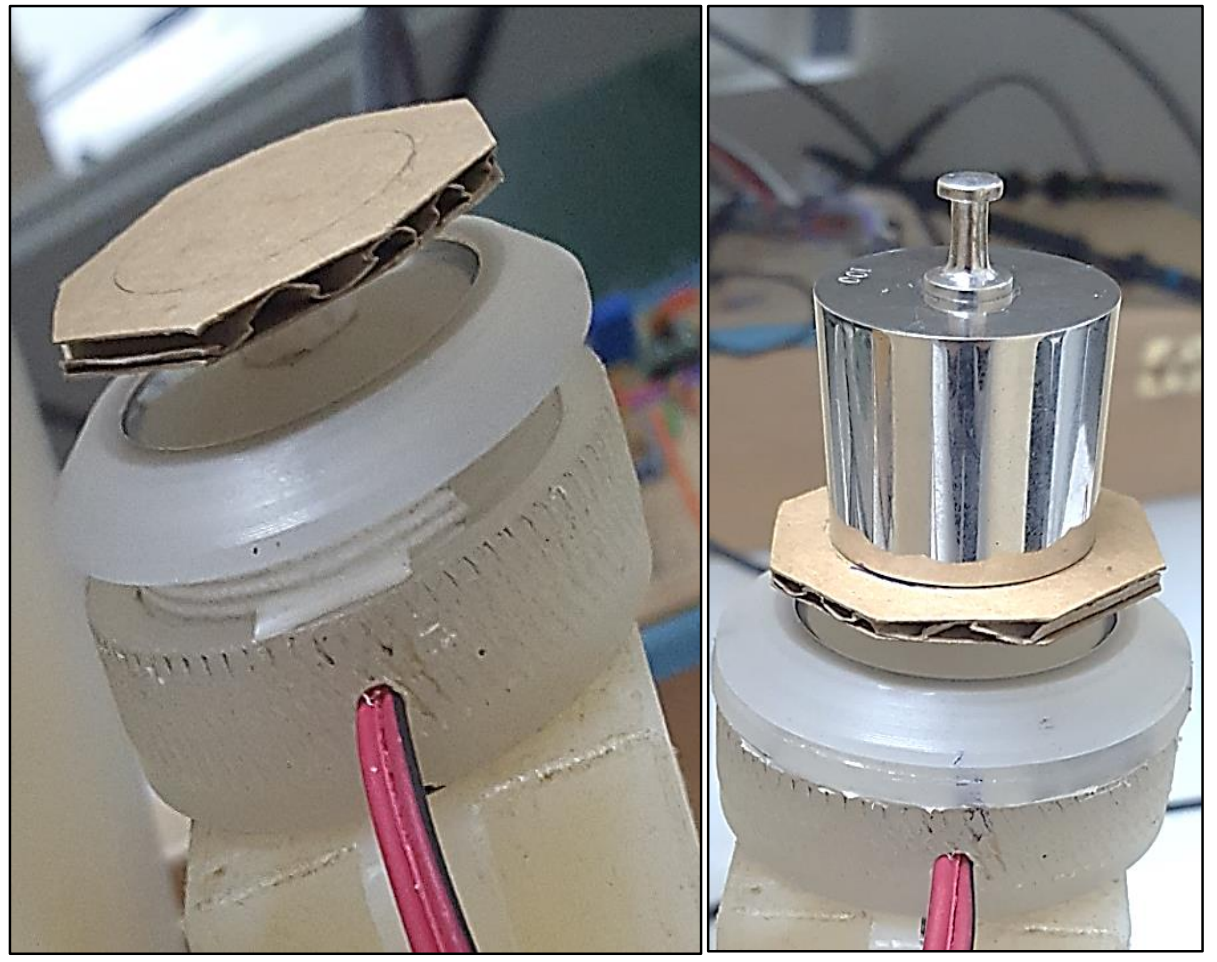

Figura 58 - Arranjo utilizado para o posicionamento das massas padrão sobre a membrana do transdutor.

A tensão de saída do transdutor é dependente da pressão aplicada, visto que a impedância da amostra GMI varia devido aos incrementos de campo magnético causados pela aproximação gradual da fonte de campo em relação ao sensor, decorrentes dos incrementos de pressão. A Figura 59 apresenta o comportamento da tensão de saída do transdutor em função da pressão exercída sobre a membrana.

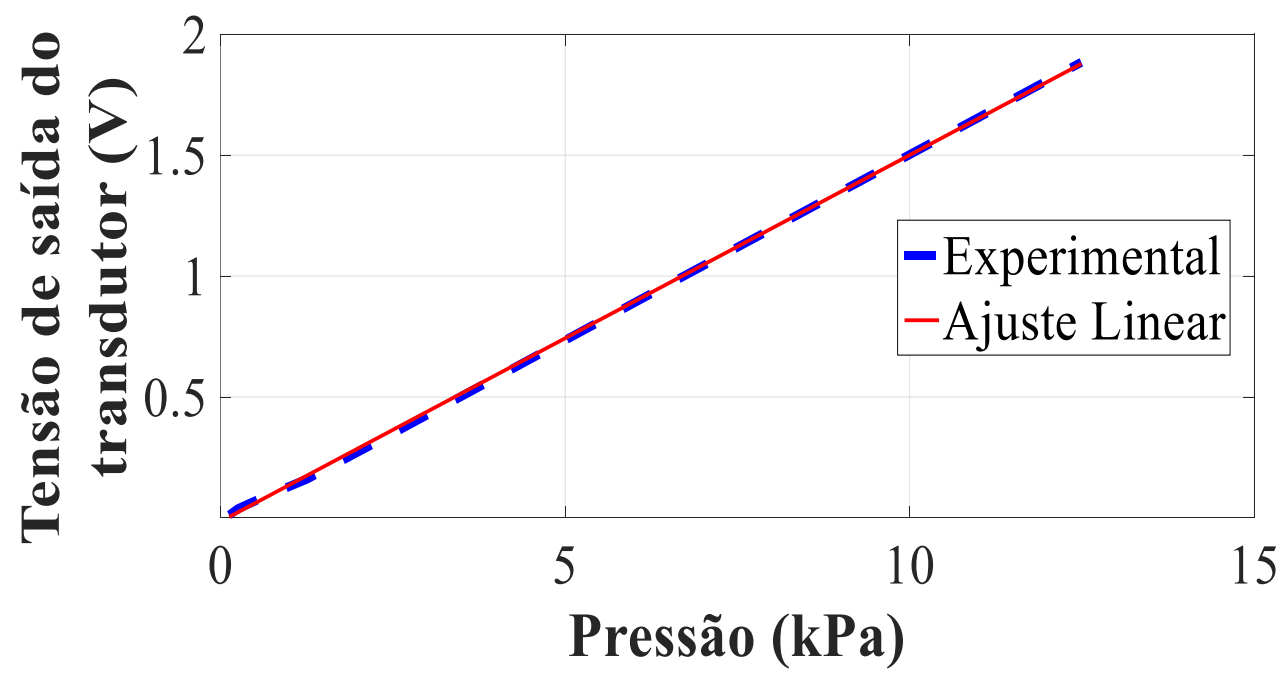

Figura 59 - Tensão de saída do transdutor em função da pressão, utilizando-se uma agulha magnetizada como fonte de campo magnético. 
3.

Os resultados experimentais apresentados na Figura 59 exibem um comportamento satisfatoriamente linear na faixa de pressões avaliada, que vai até 12,5 $\mathrm{kPa}$. Dessa forma, tem-se que os dados experimentais podem ser aproximados por um polinomio de ajuste linear, cuja expressão é dada por

$$
V_{\text {out }}=(151,51 \mathrm{mV} / \mathrm{kPa}) \cdot P-0,01 \mathrm{~V}
$$

onde $\mathrm{P}$ é a pressão em $\mathrm{kPa}$.

Assim, tem-se que a sensibilidade experimental obtida é de aproximadamente $151,51 \mathrm{mV} / \mathrm{kPa}$.

\subsection{2 \\ Resposta em frequência}

O comportamento da sensibilidade do magnetômetro GMI desenvolvido, que é parte integrante do transdutor de pressão implementado, foi experimentalmente avaliado em função da frequência do sinal de interesse. Tais resultados permitem que se estime a banda de passagem do transdutor de pressão proposto. $\mathrm{O}$ arranjo experimental adotado é apresentado na Figura 60.

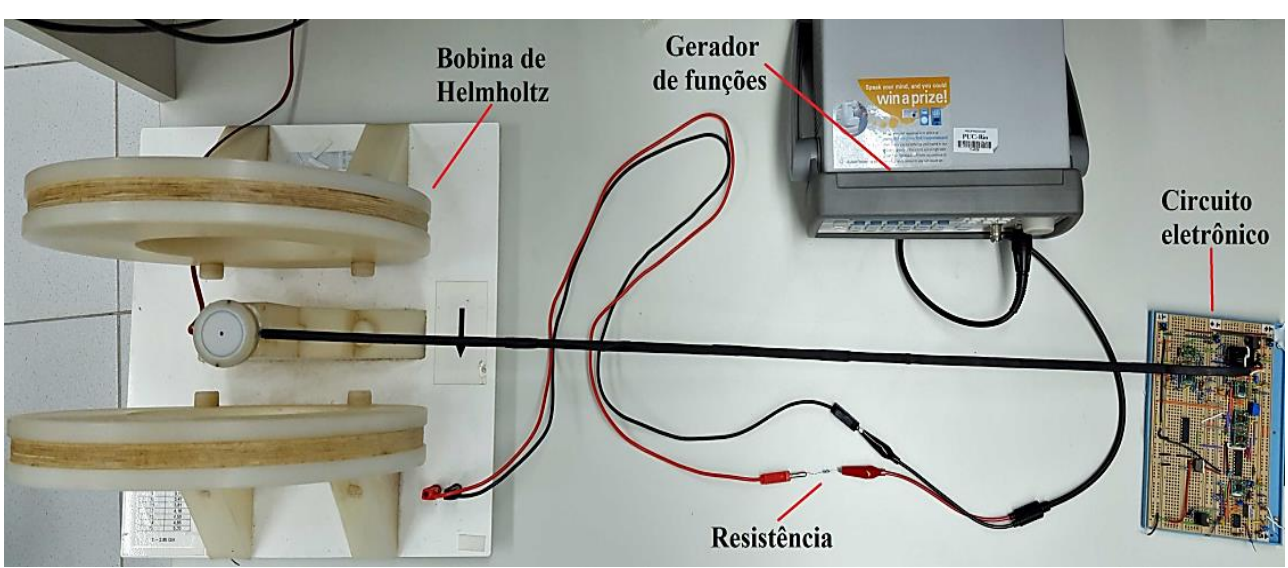

Figura 60 - Arranjo experimental para avaliação da resposta em frequência do transdutor.

Destaca-se que todas as medições apresentadas nesta seção foram realizadas para o transdutor configurado com um afastamento de $3 \mathrm{~mm}$ entre a agulha magnetizada e o elemento sensor, e excitando-se o solenoide com uma corrente de -60 mA. É importante destacar que nas medições apresentadas nesta seção optouse por excitar o solenoide com -60 mA, ao invés de -35 mA (subseção 3.2.1), a fim de permitir que o sensor seja polarizado no ponto médio de sua região linear.

Nesta situação, inseriu-se a parte sensora do transdutor no centro de uma Bobina de Helmholtz, utilizada a fim de gerar campos magnéticos senoidais com 
3.

Protótipo do transdutor de pressão GMI

amplitudes e frequências conhecidas. Para tal fim, a Bobina de Helmholtz foi excitada por um gerador de funções (33220A, Agilent). Por sua vez, entre a saída do gerador e os terminais de alimentação da bobina de Helmholtz foi conectada uma resistência de $10 \Omega$, conforme indicado na Figura 61. A impedância da bobina de Helmholtz é denotada por $\mathrm{Z}_{\mathrm{H}}$.

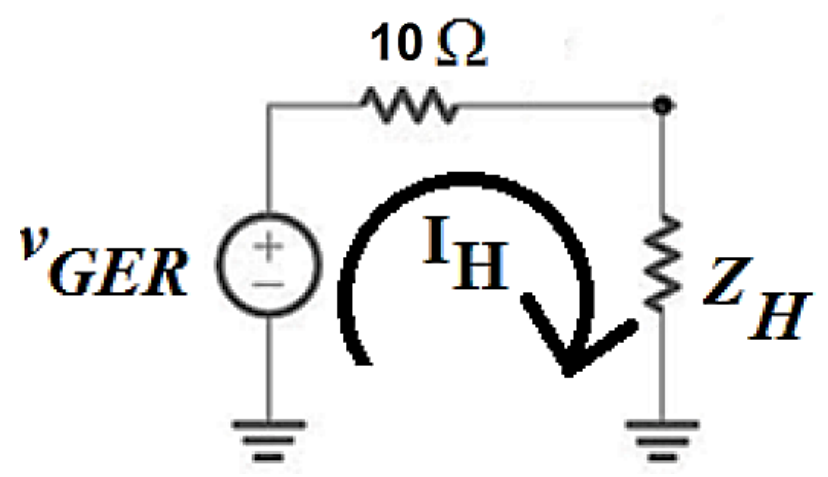

Figura 61 - Representação esquemática da configuração utilizada para excitação da Bobina de Helmholtz, para a avaliação da banda de passagem do transdutor.

O campo magnético gerado pela bobina de Helmholtz é função da corrente $\mathrm{I}_{\mathrm{H}}$ que flui por seus enrolamentos. Por sua vez, tendo em vista a Figura 61, percebe-se que a corrente $\mathrm{I}_{\mathrm{H}}$ será função da impedância $\mathrm{Z}_{\mathrm{H}}$, a qual possui comportamento predominantemente indutivo e consequentemente varia em função da frequência. Dessa forma, utilizando-se a eq. (23) e sabendo que 1 Oe é numericamente igual a $10^{-4} \mathrm{~T}$, pode-se definir a densidade de fluxo magnético $\mathrm{B}_{\mathrm{H}}$, em teslas, no centro da bobina de Helmholtz, por meio de

$$
B_{H}=2,87 \cdot 10^{-4} \cdot I_{H}=2,87 \cdot 10^{-4} \cdot\left(\frac{V_{G E R}}{10 \Omega+Z_{H}}\right)
$$

Devido a $\mathrm{Z}_{\mathrm{H}}$ ser dependente da frequência, verifica-se que, caso se deseje garantir a geração de densidades de fluxo magnético, $\mathrm{B}_{\mathrm{H}}$, com a mesma amplitude em diferentes frequências, deve-se ajustar a amplitude de $V_{G E R}$ a fim de se compensar as variações de $\mathrm{Z}_{\mathrm{H}}$. Consequentemente, deve-se definir um valor adequado de $\mathrm{V}_{\mathrm{GER}}$ para cada frequência selecionada, de modo a garantir que a amplitude da corrente $\mathrm{I}_{\mathrm{H}}$ seja sempre mantida constante. Destaca-se que, em baixas frequências, tem-se $Z_{H}<<10 \Omega$ e, consequentemente, a influência de $Z_{H}$ sobre a corrente $I_{H}$ é desprezível, não sendo necessário fazer ajustes em $V_{\mathrm{GER}}$ a fim de compensar a dependência de $\mathrm{Z}_{\mathrm{H}}$ com a frequência. Por outro lado, para frequências mais elevadas, a partir de $1 \mathrm{kHz}$ para a Bobina de Helmholtz utilizada, o valor de $Z_{\mathrm{H}}$ deixa de ser significativamente inferior a $10 \Omega$ e passa a afetar a 
3.

Protótipo do transdutor de pressão GMI

amplitude de $\mathrm{I}_{\mathrm{H}}$ e consequentemente de $\mathrm{B}_{\mathrm{H}}$. Nesta situação, é necessário atuar sobre $\mathrm{V}_{\mathrm{GER}}$ a fim de se manter constante a amplitude de $\mathrm{B}_{\mathrm{H}}$.

Optou-se por manter a amplitude de $\mathrm{B}_{\mathrm{H}}$ fixa em $16 \mu \mathrm{T}$, ou equivalentemente 0,16 Oe, em todas as medições aqui apresentadas. Esse valor de amplitude implica uma excursão total de 0,32 Oe dentro da faixa linear. Dessa forma, pode-se avaliar que a sensibilidade se mantém efetivamente constante ao longo desta faixa, pois eventuais distorções na senoide de saída do circuito eletrônico de transdução podem ser associadas a não-linearidades na resposta.

Consequentemente, tendo em vista os aspectos discutidos nesta seção, a fim de manter a amplitude de $\mathrm{B}_{\mathrm{H}}$ fixa em $16 \mu \mathrm{T}$, deve-se ajustar o valor de $\mathrm{V}_{\mathrm{GER}}$ em função da frequência do campo gerado, de acordo com a curva apresentada na Figura 62.

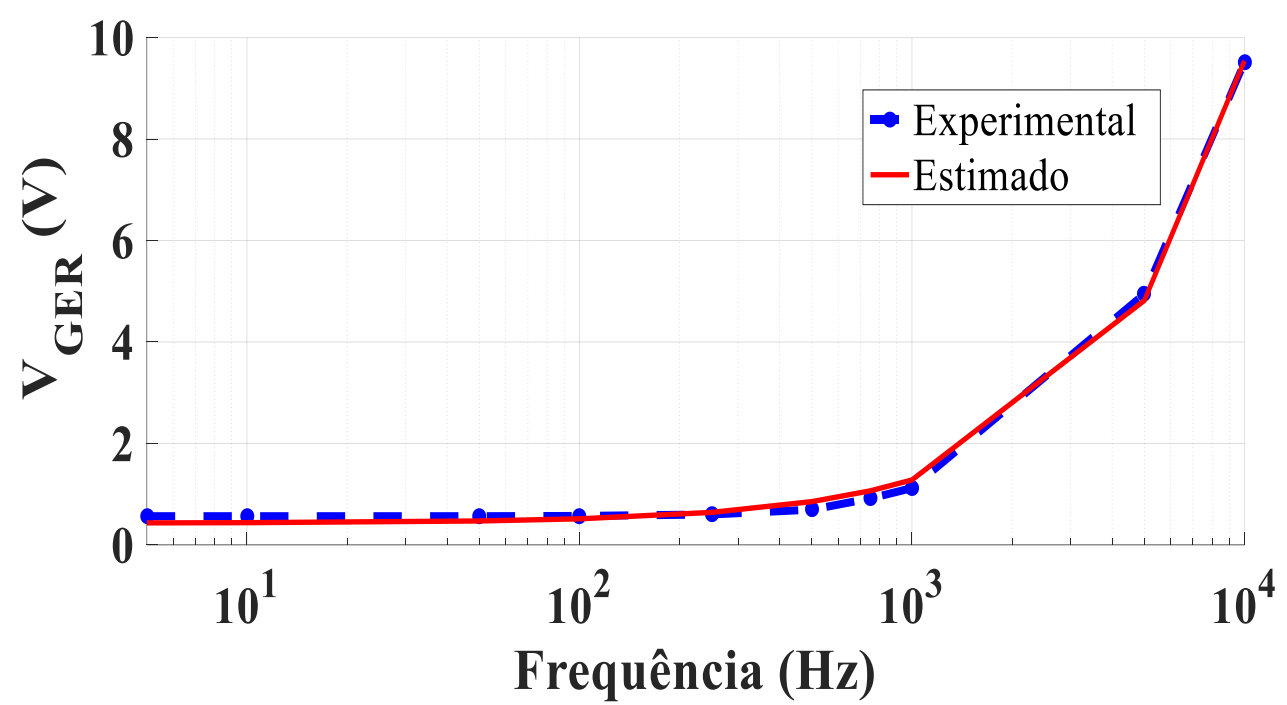

Figura 62 - Dependência da amplitude da tensão do gerador $V_{G E R}$ em função da frequência de $B_{H}$.

Observando-se a Figura 62, pode-se perceber que, conforme esperado, em baixas frequências não são necessários ajustes significativos em $V_{\mathrm{GER}}$ a fim de se manter constante a amplitude do campo magnético. Entretanto, também percebese claramente que frequências acima de $1 \mathrm{kHz}$ demandam ajustes consideráveis em $V_{\text {GER }}$.

Realizou-se uma análise sistemática da tensão de saída do circuito em função da frequência de $\mathrm{B}_{\mathrm{H}}$; cuja amplitude foi mantida constante em todos os testes realizados. A Figura 63 apresenta as formas de onda de saída do circuito analisadas para quatro frequências $(5 \mathrm{~Hz}, 50 \mathrm{~Hz}, 250 \mathrm{~Hz}$ e $750 \mathrm{~Hz})$.] 
3.

Protótipo do transdutor de pressão GMI

(a) $5 \mathrm{~Hz}$

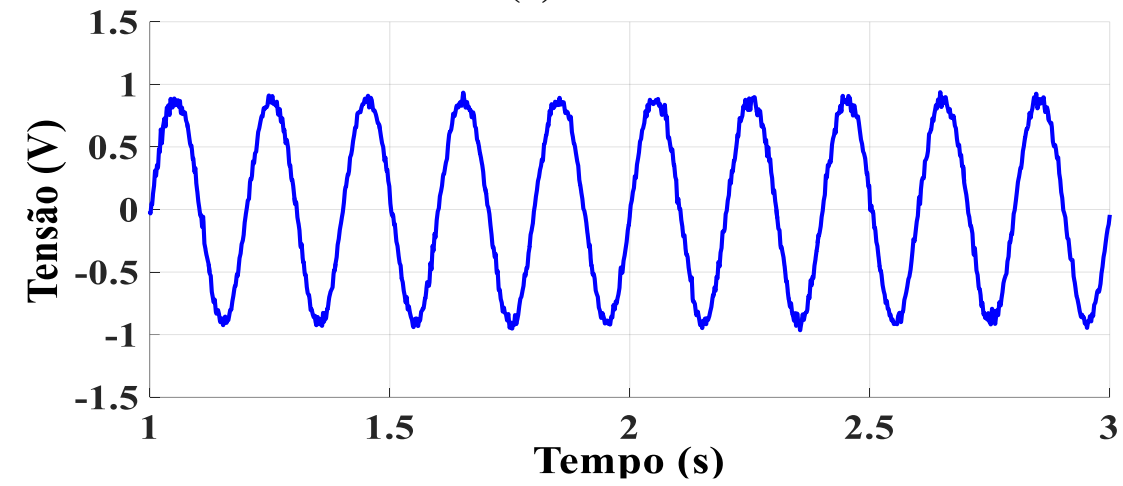

(b) $50 \mathrm{~Hz}$

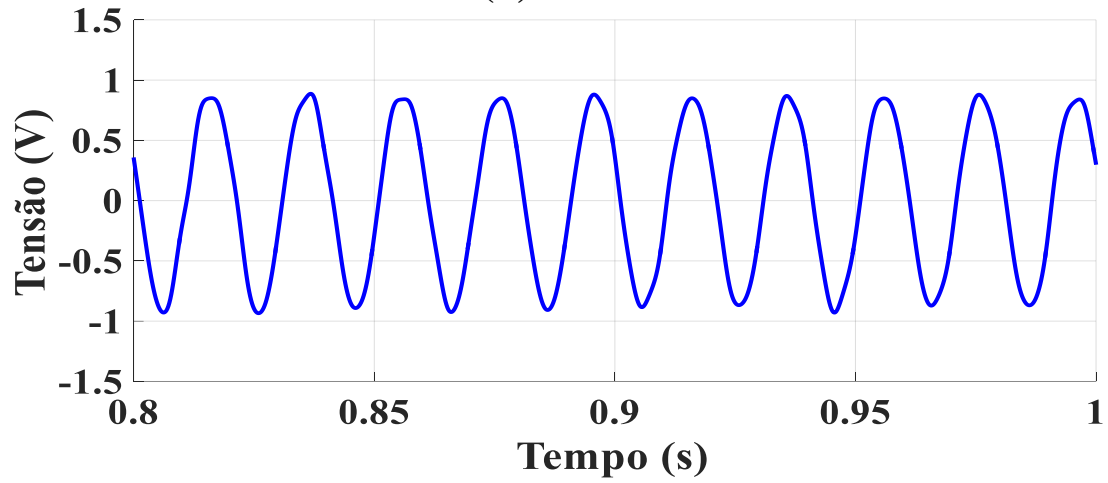

(c) $250 \mathrm{~Hz}$

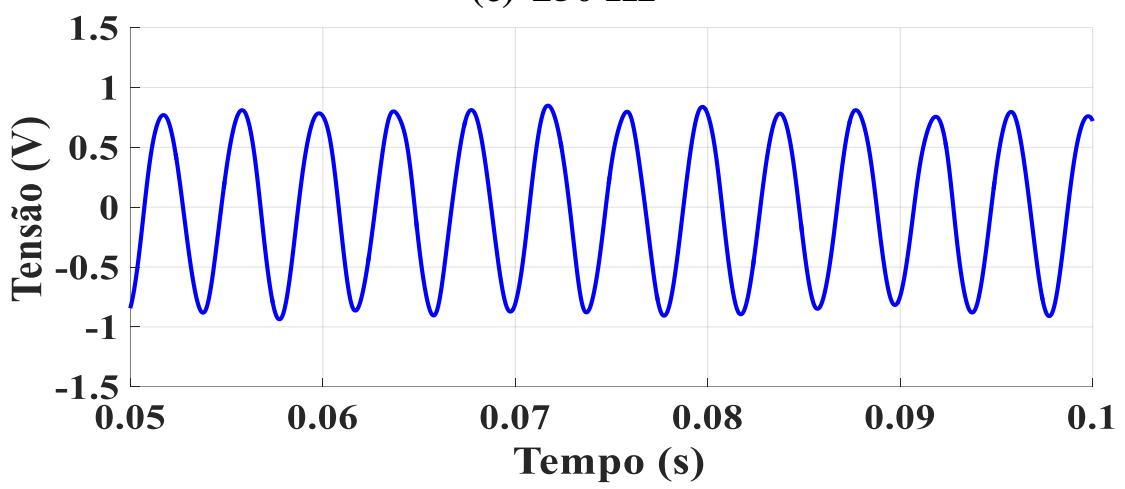

(d) $750 \mathrm{~Hz}$

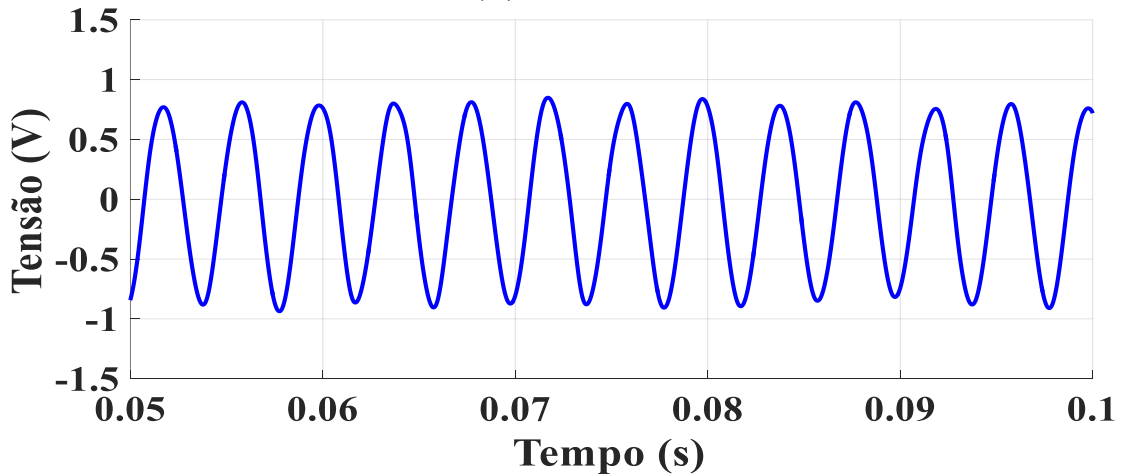

Figura 63 - Tensão de saída do transdutor desenvolvido para densidades de fluxo magnético senoidais de mesma amplitude (16 $\mu \mathrm{T})$ e com diferentes frequências: a) $5 \mathrm{~Hz}$, b) $50 \mathrm{~Hz}$, c) $250 \mathrm{~Hz}$ e d) $750 \mathrm{~Hz}$. 
3.

Por meio dos resultados apresentados na Figura 63, percebe-se que, conforme esperado, a componente espectral fundamental do sinal de saída do transdutor possui a mesma frequência do campo magnético utilizado para excitar a amostra GMI. Por sua vez, também é perceptível que os sinais senoidais de saída apresentam baixo nível de distorção, em todos os casos analisados. Consequentemente, verifica-se que o circuito de transdução introduz baixa distorção harmônica, o que é uma característica extremamente desejável. Por sua vez, comparando-se os resultados obtidos, para as diferentes frequências inspecionadas, verifica-se que o aumento da frequência do campo reduz a amplitude da tensão de saída e, consequentemente, a sensibilidade do dispositivo.

A fim de se avaliar mais detalhadamente tal efeito, apresenta-se na Figura 64 o comportamento da sensibilidade do circuito em função da frequência do campo, em hertz. Na Figura 64(a) apresenta-se a curva da sensibilidade expressa em $\mathrm{mV} / \mathrm{nT}$, enquanto que na Figura 64(b) exibe-se a curva da sensibilidade expressa em dB. Ressalta-se que, a sensibilidade é expressa em dB de acordo com

$$
\operatorname{Sens}(d B)=20 \cdot \log \left(\frac{\operatorname{Sens}(V / T)}{52,80 \cdot 10^{3}(V / T)}\right),
$$

onde $52,80 \cdot 10^{3} \mathrm{~V} / \mathrm{T}$ é a sensibilidade experimental do circuito para campos CC, vide equação (21).

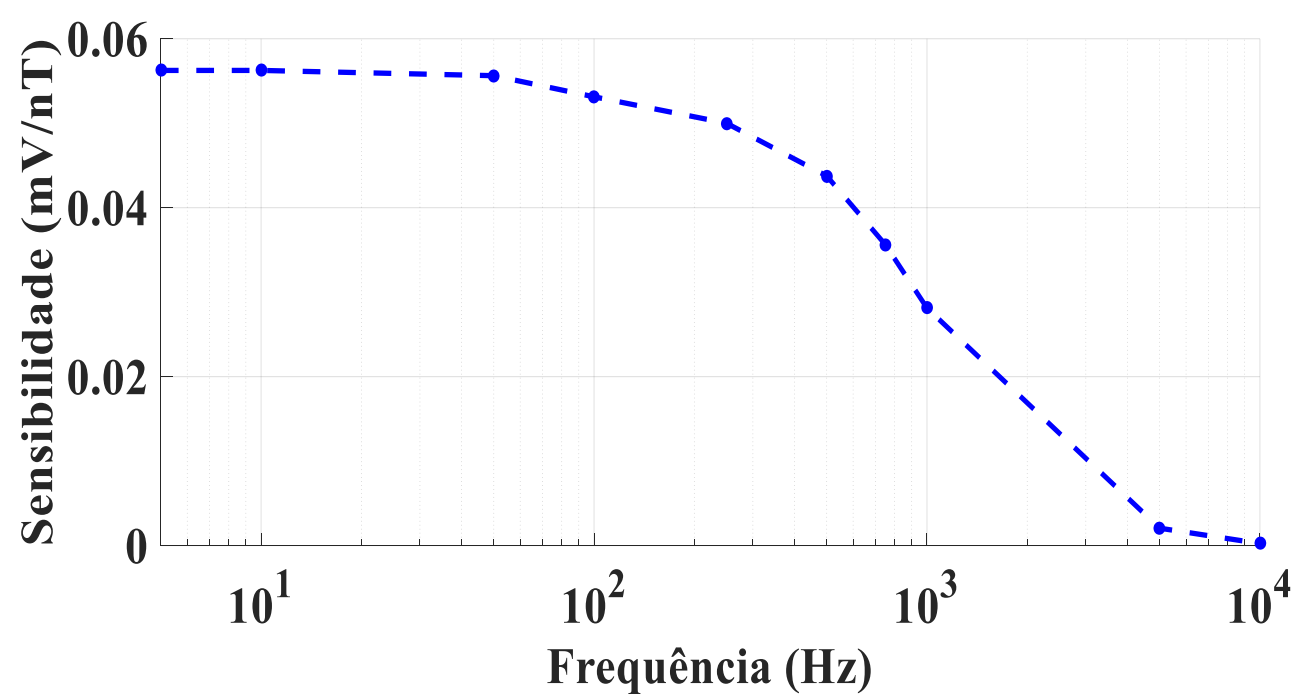

(a) 
3.

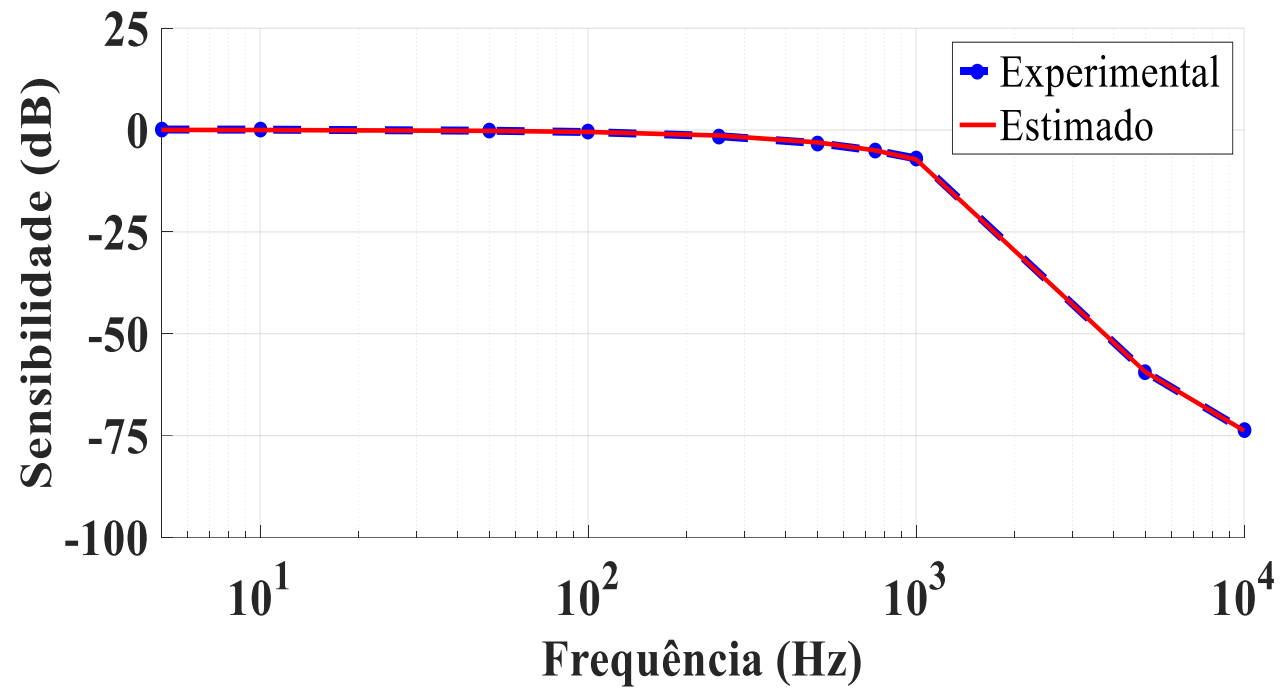

(b)

Figura 64 - Dependência da sensibilidade do transdutor em função da frequência do campo magnético de excitação: (a) sensibilidade em $\mathrm{mV} / \mathrm{nT}$ e (b) sensibilidade em dB.

As curvas experimentais, apresentadas na Figura 64, podem ser satisfatoriamente modeladas por meio de polinômios de ajuste de $2^{\mathrm{a}}$ ordem e de $3^{\mathrm{a}}$ ordem respectivamente. Dessa forma, é possível obter estimativas das expressões analíticas tanto da sensibilidade $\mathrm{S}_{\text {ens, }}$ expressa em $\mathrm{mV} / \mathrm{nT}$, quanto da sensibilidade $\mathrm{S}_{\text {ensdB, }}$ expressa em $\mathrm{dB}$, em função da frequência $\mathrm{f}$, expressa em $\mathrm{Hz}$. Os respectivos polinômios de ajuste são explicitados por meio de

$$
\begin{gathered}
\operatorname{Sen} s(f)=1,20 \cdot 10^{-9} \cdot f^{2}-17,19 \cdot 10^{-6} \cdot f+53,25 \\
\operatorname{Sens}_{d B}(f)=228,54 \cdot 10^{-12} \cdot f^{3}-2,53 \cdot 10^{-6} \cdot f^{2}-4,95 \cdot 10^{-3} \cdot f+63,10 \cdot 10^{-3}
\end{gathered}
$$

Analisando-se o comportamento da curva apresentada na Figura 64(b), verifica-se que a banda do transdutor desenvolvido é de aproximadamente 250 Hz. Por sua vez, também percebe-se que a sensibilidade é satisfatoriamente constante para frequências dentro desta banda.

\subsection{3}

\section{Análise de ruído}

Inicialmente, esta subseção apresenta a avaliação experimental da densidade espectral de ruído do magnetômetro GMI desenvolvido, que é parte integrante do transdutor de pressão projetado. Todas as medições apresentadas foram realizadas para o transdutor configurado com um afastamento de $3 \mathrm{~mm}$ entre a agulha magnetizada e o elemento sensor, e excitando-se o solenoide com uma corrente de $-60 \mathrm{~mA}$. Adotou-se exatamente a mesma configuração do transdutor empregada 
3.

na subseção 3.1.2. O arranjo experimental utilizado nas medições realizadas para obter a densidade espectral de ruído é apresentado na Figura 65.

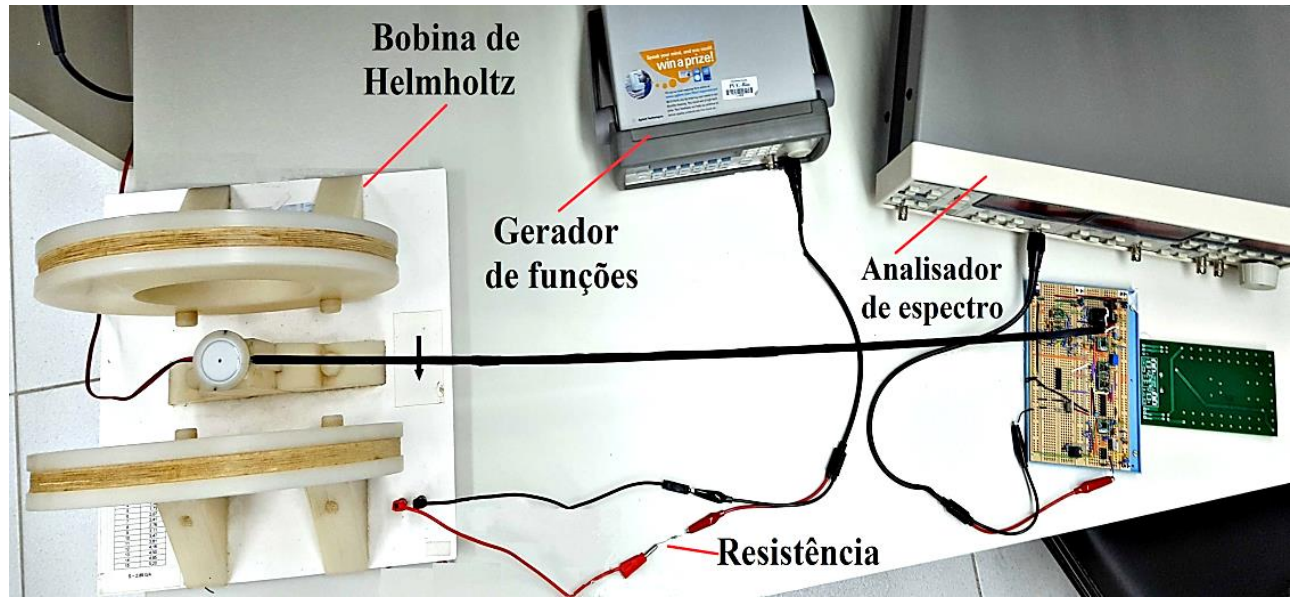

Figura 65 - Arranjo experimental para avaliação da densidade espectral de ruído.

Para se obter a curva de densidade espectral de ruído do magnetômetro, é importante excitá-lo com um campo magnético de amplitude e frequência conhecidas, de modo a se ter um sinal de referência que sirva como base para a estimativa da sensibilidade. Assim, a fim de medir as características de ruído de saída do circuito eletrônico, excitou-se a amostra GMI com um campo magnético senoidal de $16 \mu \mathrm{T}$ de amplitude e $100 \mathrm{~Hz}$ de frequência. Na sequência, calculouse a Transformada Rápida de Fourier (FFT - Fast Fourier Transform) do sinal de saída do magnetômetro com auxílio de um analisador de espectro (SR785, Stanford Research Systems). A Figura 66 apresenta os resultados obtidos. Na Figura 66(a) apresentam-se medições para frequências entre $0 \mathrm{~Hz}$ e $400 \mathrm{~Hz}$, e na Figura 66(b) para frequências entre $0 \mathrm{~Hz}$ e $200 \mathrm{~Hz}$. Por sua vez, os resultados explicitados na Figura 66(c), referem-se à mesma faixa de frequências avaliada na Figura 66(b); entretanto limita-se o valor máximo da escala de tensões em $50 \mathrm{mV}$, a fim de se poder avaliar em maiores detalhes os níveis de ruído presentes. 
3.

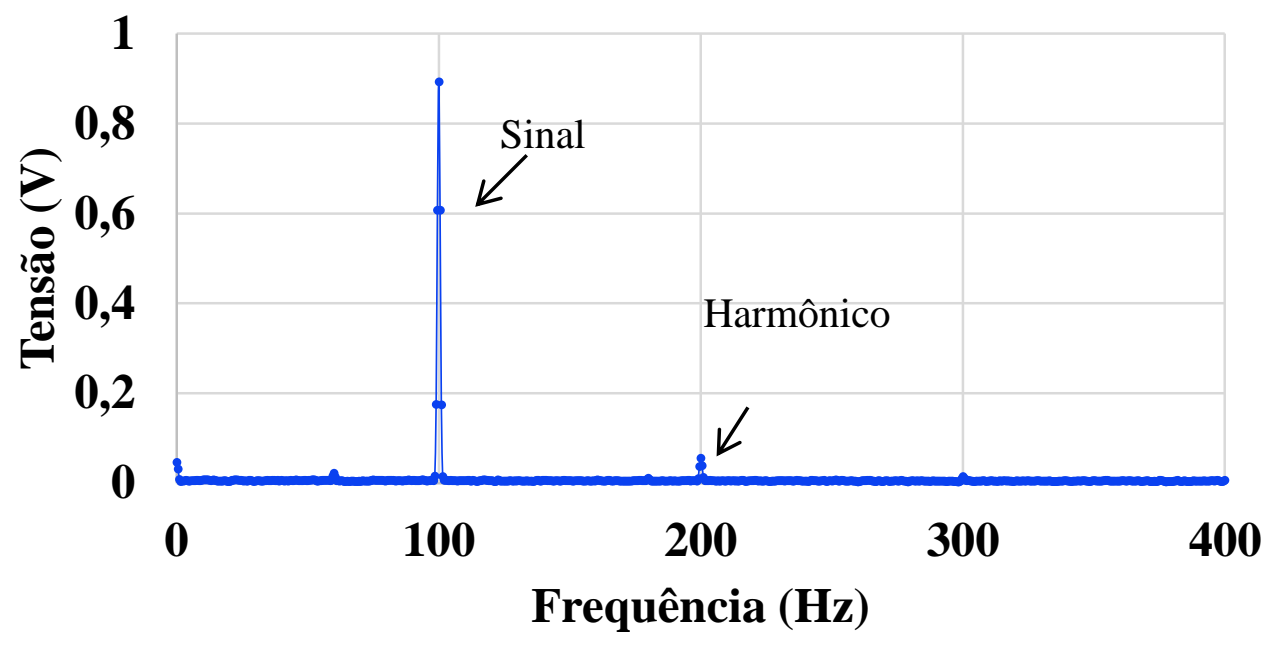

(a)

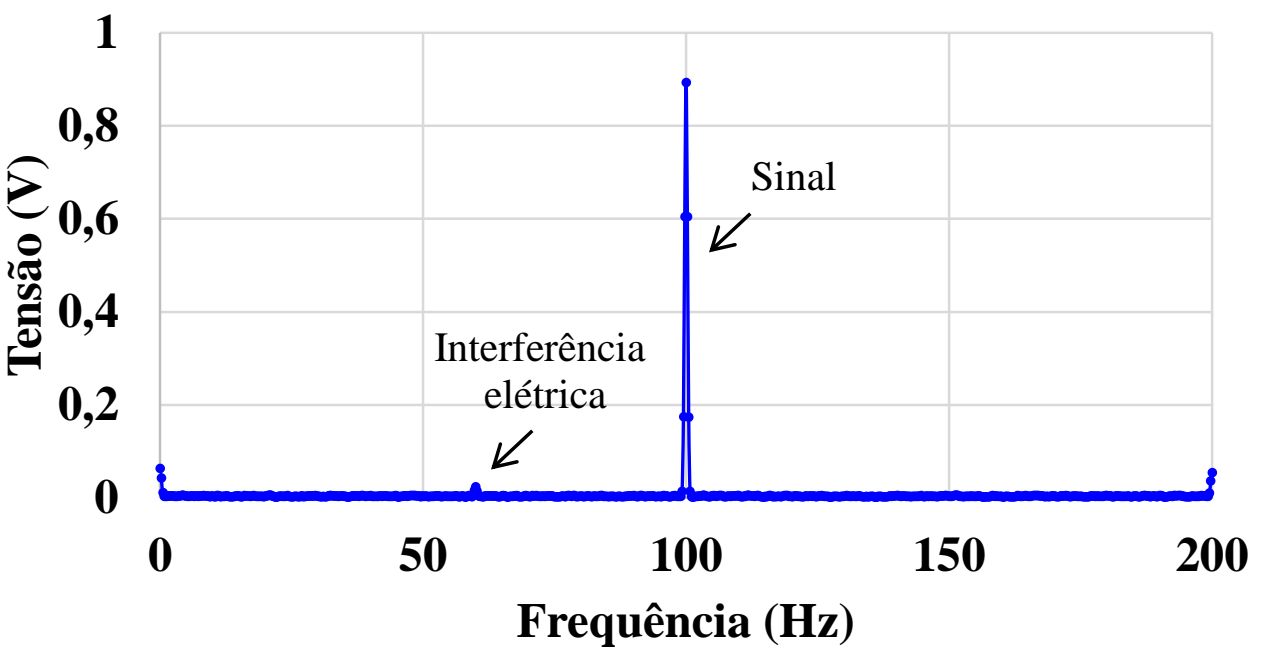

(b)

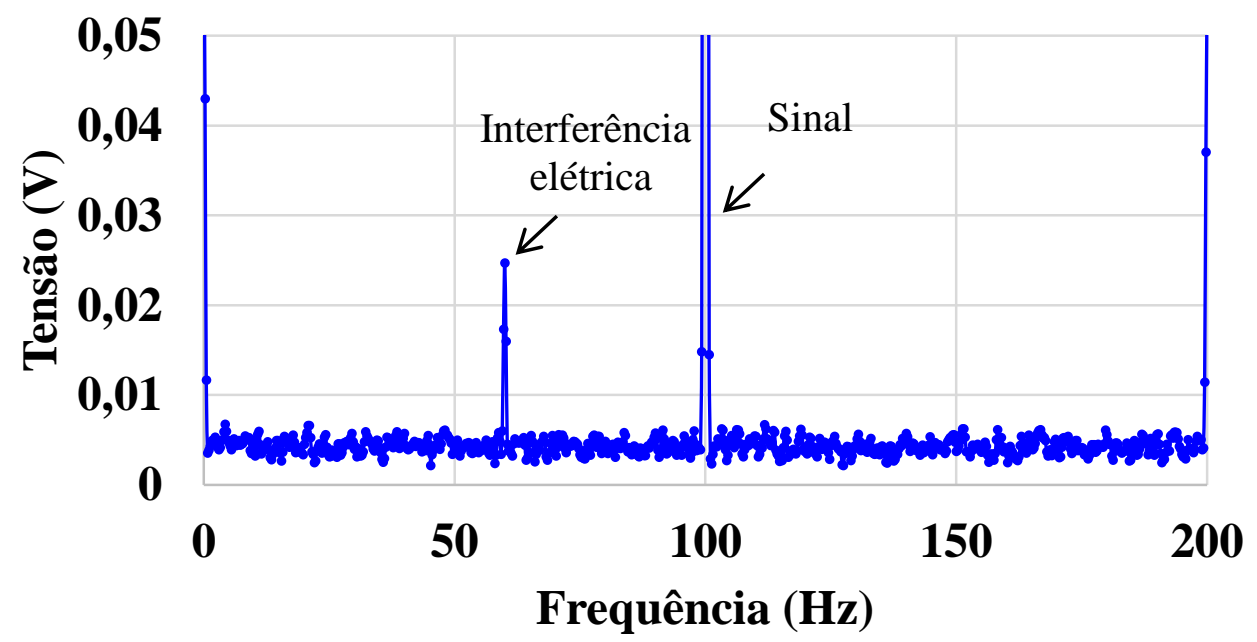

(c)

Figura 66 - Transformada Rápida de Fourier (FFT) do sinal de saída do transdutor, utilizando-se uma agulha magnetizada como fonte magnética móvel: (a) para frequências entre $0 \mathrm{~Hz}$ e $400 \mathrm{~Hz}$; (b) para frequências entre $0 \mathrm{~Hz}$ e $200 \mathrm{~Hz}$; e (c) para frequências entre $0 \mathrm{~Hz}$ e $200 \mathrm{~Hz}$, com limite do valor máximo da escala de tensões em $50 \mathrm{mV}$. 
3. Protótipo do transdutor de pressão GMI

A componente espectral em $100 \mathrm{~Hz}$, presente na Figura 66, foi induzida pelo campo magnético senoidal de excitação, cuja amplitude é de $16 \mu$ T. Pela Figura 66, verifica-se que a amplitude, em tensão, desta componente espectral é de aproximadamente $0,89 \mathrm{~V}$. Consequentemente, a presença desta componente espectral com amplitude conhecida, tanto em unidades de tensão quanto de campo magnético permite que se defina a sensibilidade do magnetômetro GMI como

$$
\text { Sensibilidade }=\frac{0,89 \mathrm{~V}}{16 \mu T}=55,63 \frac{\mathrm{mV}}{\mu T}
$$

Conforme esperado, é possível verificar que a sensibilidade obtida por meio da eq. (27) é satisfatóriamente próxima do valor equivalente obtido na subseção 3.2.1. Além da componente espectral de $100 \mathrm{~Hz}$, também é possível observar a presença de outras duas componentes espectrais significativas na Figura 66. Uma delas aparece em $60 \mathrm{~Hz}$ e é atribuida à interferência da rede elétrica $(60 \mathrm{~Hz}$, no Brasil). Por outro lado, a outra está em $200 \mathrm{~Hz}$, sendo claramente uma componente proveniente de distorções harmônicas do sinal de $100 \mathrm{~Hz}$. É importante destacar que a componente fundamental do sinal $(100 \mathrm{~Hz})$ possui amplitude cerca de 10 vezes superior à distorção hamonica em $200 \mathrm{~Hz}$, o que indica que o circuito apresenta baixo nível de distorção harmônica, conforme desejado.

Na sequência, desligou-se a fonte de campo em $100 \mathrm{~Hz}$ e configurou-se o analisador de espectro para fornecer a densidade espectral de ruído do magnetômetro GMI, em V·Hz ${ }^{-1 / 2}$. Por sua vez, considerando que a sensibilidade do magnetômetro é dada pela eq. (25), é possível converter os valores de tensão obtidos em valores de densidade de fluxo magnético, a fim de se obter a curva de densidade espectral de ruído, expressa em nT. $\mathrm{Hz}^{-1 / 2}$, a qual é explicitada na Figura 67.

Considerando que a sensibilidade do magnetômetro é dada pela eq. (25) e sabendo que a sensibilidade do transdutor de pressão é de $151,51 \mathrm{mV} / \mathrm{kPa}$, conforme verificado na subseção 3.2.1, pode-se expressar a relação entre nT e kPa por meio de

$$
\frac{n T}{k P a}=\frac{151,51 m V / k P a}{1,20 \cdot 10^{-9} \cdot f^{2}-17,19 \cdot 10^{-6} \cdot f+53,25}
$$


3.

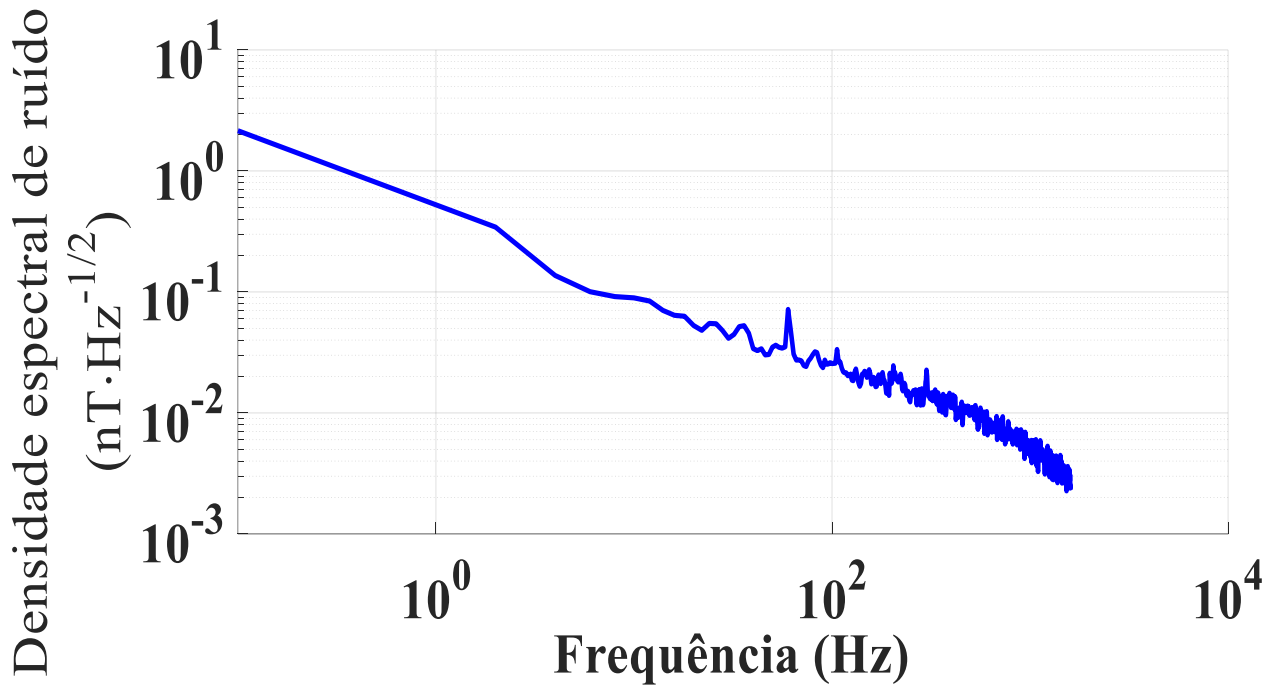

Figura 67 - Densidade espectral de ruído da tensão de saída do magnetômetro GMI, expressa em $\mathrm{nT} \cdot \mathrm{Hz}^{-1 / 2}$, utilizando-se uma agulha magnetizada como fonte de campo móvel.

Por meio da eq. (28) percebe-se que esta relação é dependente da frequência. Na sequência, os valores de densidade espectral de ruído em $\mathrm{nT} \cdot \mathrm{Hz}^{-1 / 2}$, apresentados na Figura 67, são divididos pela eq. (28) a fim de se determinar a densidade espectral de ruído total do transdutor de pressão desenvolvido, os quais são expressos em $\mathrm{Pa} \cdot \mathrm{Hz}^{-1 / 2}$ na Figura 68.

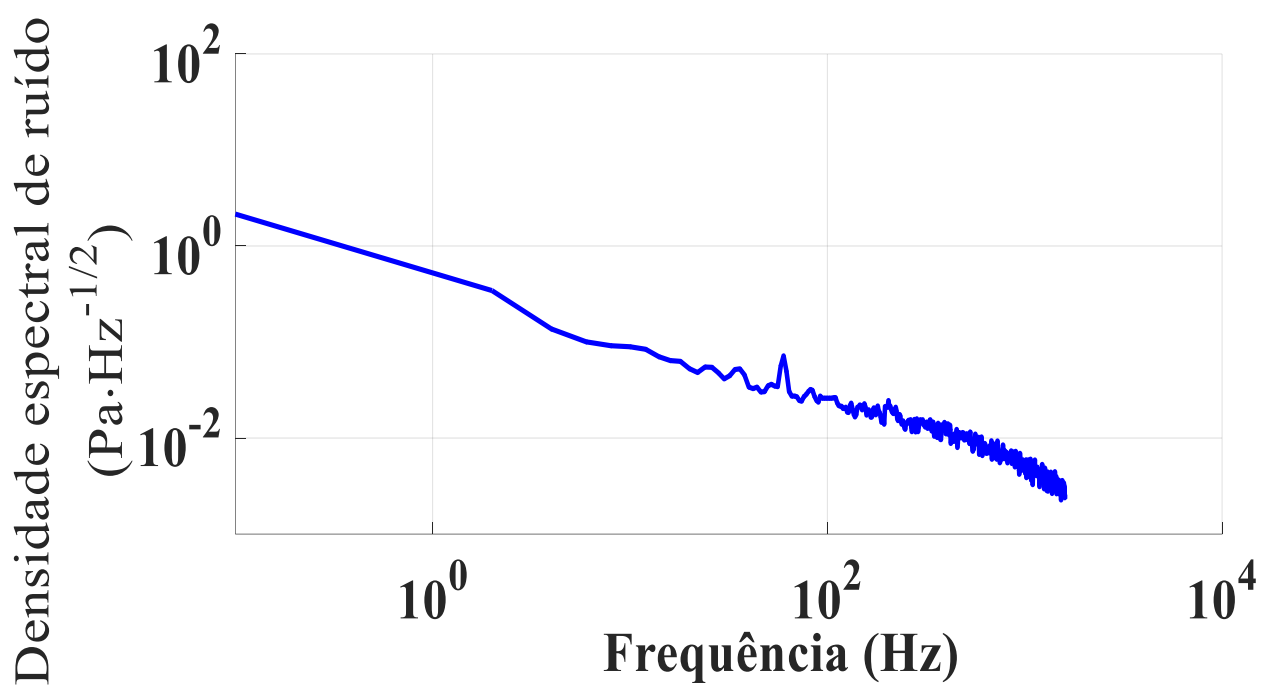

Figura 68 - Densidade espectral de ruído da tensão de saída do transdutor de pressão desenvolvido, expresso em $\mathrm{Pa} \cdot \mathrm{Hz}^{-1 / 2}$, utilizando-se uma agulha magnetizada como fonte de campo móvel.

Tanto na Figura 67 quanto na Figura 68 é possível observar que, conforme esperado, o circuito capta a interferência da rede elétrica em $60 \mathrm{~Hz}$, devido a utilizar-se de um sensor magnético como parte da cadeia de transdução. Os resultados indicam que, na banda de 0 a $250 \mathrm{~Hz}$, a resolução do magnetômetro 
3.

GMI é de 3,4 nT (Figura 67) e a do transdutor de pressão desenvolvido é de 0,28 $\mathrm{Pa}$ (Figura 68).

As resoluções de campo magnético e pressão foram calculadas a partir das curvas apresentadas, respectivamente, nas Figuras 67 e 68. As curvas de densidade espectral de ruído apresentadas nestas figuras podem ser aproximadas por meio de polinômios de ajuste $(g(f))$. Por sua vez, é possível inferir a resolução integrandose o quadrado destes polinômios na banda de passagem do transdutor, que se estende de $0 \mathrm{~Hz}$ a $250 \mathrm{~Hz}$, e, posteriormente, calculando a raiz quadrada do valor obtido, conforme apresentado em

$$
R=\sqrt{\int_{0}^{250} g^{2}(f) d f}
$$

Ressalta-se que a resolução obtida pelo transdutor de pressão aqui desenvolvido propicia medir com qualidade os sinais biomédicos de interesse.

Por meio da Figura 67, é possível verificar que o magnetômetro GMI desenvolvido, como parte integrante do sistema do transdutor de pressão proposto, apresenta densidades espectrais de ruído inferiores a $1 \mathrm{nT} \cdot \mathrm{Hz}^{-1 / 2}$, em toda a sua banda de passagem. Dessa forma, ressalta-se que, por si só, este módulo individual já apresenta potencial para aplicação em uma ampla gama de aplicações cientificas, biomédicas, entre outras, que demandem medições magnéticas de alta resolução, com níveis de ruído inferiores a $1 \mathrm{nT} \cdot \mathrm{Hz}^{-1 / 2}$. Atualmente, poucos sensores são efetivamente capazes de mensurar campos tão pequenos, o que aumenta a relevância do magnetômetro aqui projetado.

\section{3 \\ Ímã permanente como fonte de campo magnético}

Nesta seção foram realizadas alterações em relação à estrutura do transdutor de pressão apresentada na seção 3.2. Em particular, utilizou-se como fonte de campo móvel um pequeno ímã permanente, ao invés de uma agulha magnetizada. Considerando a possibilidade de decaimento da magnetização da agulha com o tempo e o fato de ser afetada por fontes de campo magnético presentes no ambiente de medição, optou-se por substituí-la por uma configuração que possua maior estabilidade com o tempo e seja pouco afetada por interferência magnética ambiental. Nas fotos apresentadas na Figura 69 pode-se observar as partes que 
3.

compõem a estrutura mecânica do transdutor de pressão, usando um ímã como fonte de campo magnético externo. Na Figura 69 (a), observa-se a base da estrutura do transdutor, onde estão posicionados o solenoide de polarização, com a amostra GMI em seu interior. Por sua vez, na Figura 69 (b), visualiza-se a membrana elástica com o ímã permanente aderido à mesma, o qual foi utilizada como fonte de campo magnético móvel.
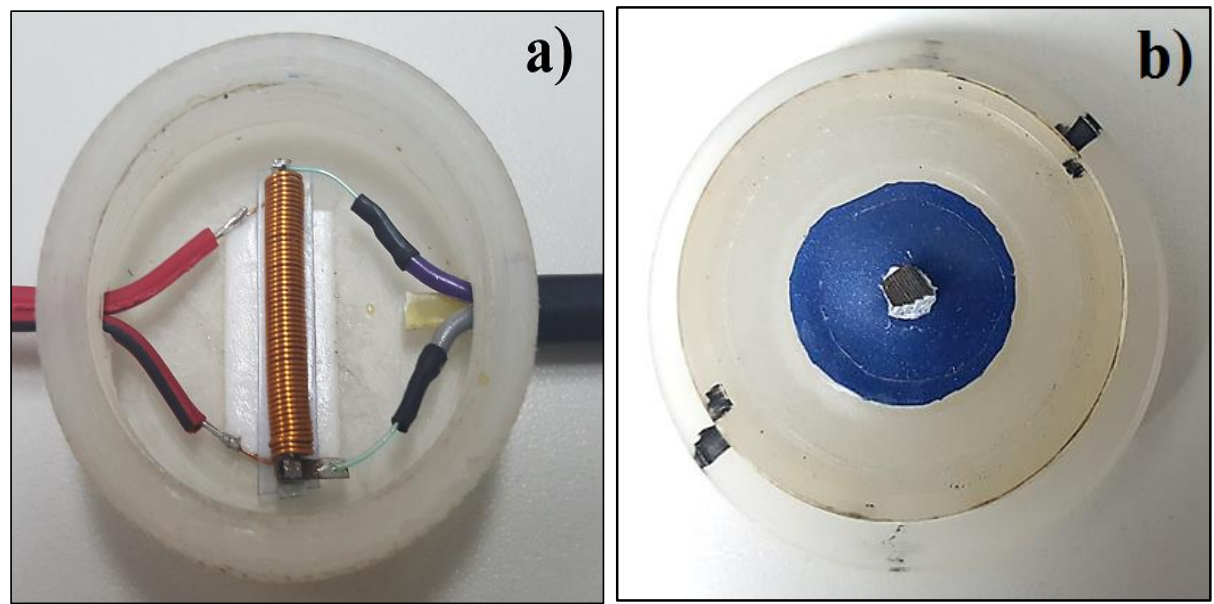

Figura 69 - Partes do Transdutor de Pressão, baseado na utilização de um ímã permanente como fonte de campo móvel.

Além da troca da fonte de campo magnético por um ímã permanente e as alterações de configuração devidas ao aumento do comprimento do cabo utilizado para interconexão do sensor ao circuito, verificou-se que a princípio é interessante que este comprimento seja o menor possível, a fim de reduzir a influência do cabo sobre o comportamento do circuito de transdução. Entretanto, o aumento do comprimento do cabo facilita o manuseio do transdutor e seu posicionamento anatômico, facilitando seu uso nas aplicações biomédicas de interesse, em especial na medição de onda de pulso arterial. Dessa forma, os testes realizados nesta seção foram realizados utilizando-se um cabo longo, de $85 \mathrm{~cm}$, enquanto que na seção anterior (seção 3.2) foram apresentados resultados utilizando-se um cabo curto $(20 \mathrm{~cm})$. A Figura 70 apresenta o arranjo experimental utilizado, evidenciando o cabo longo $(85 \mathrm{~cm})$ de conexão entre o sensor GMI e o circuito. Ressalta-se que os resultados da caracterização experimental da impedância do sensor GMI, associado ao cabo longo, já foram anteriormente explicitados na seção 2.1. 
3.

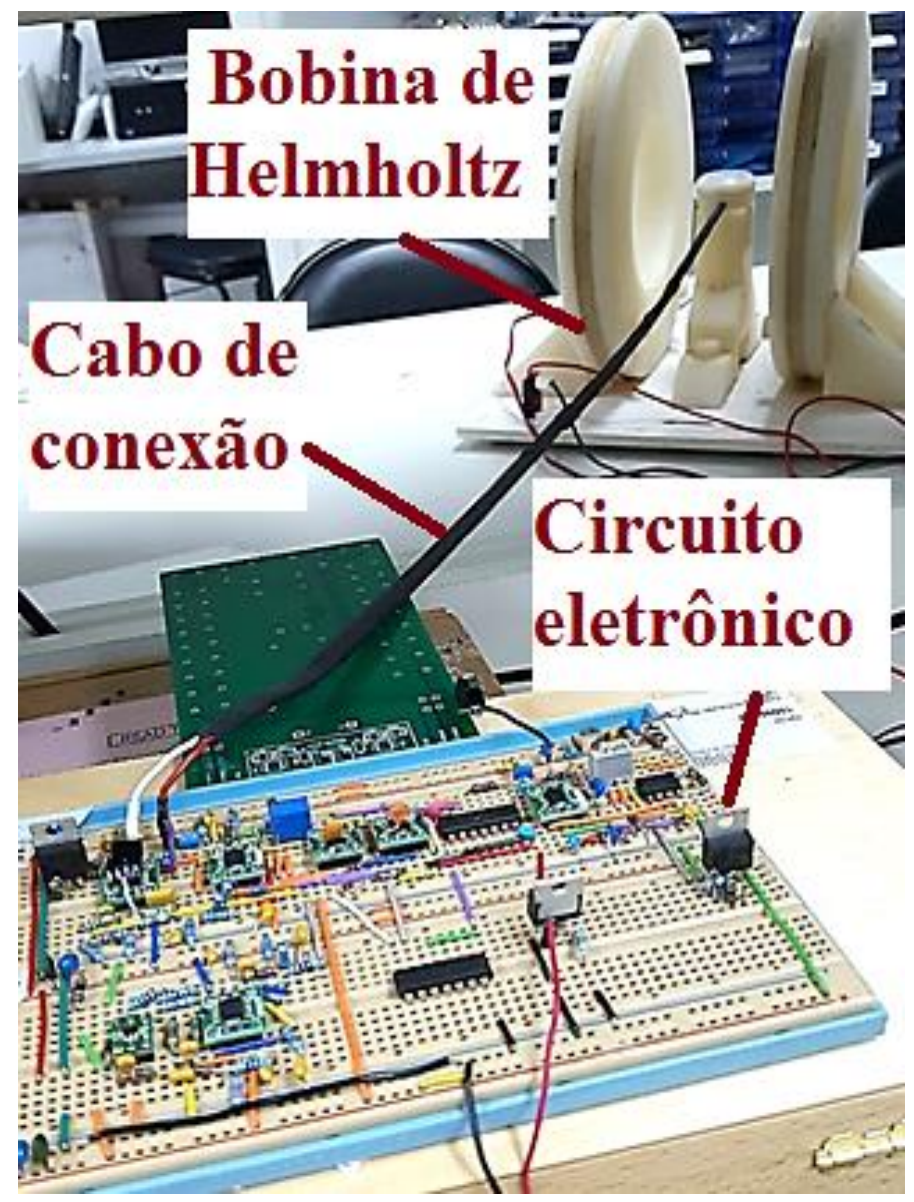

Figura 70 - Protótipo final do transdutor de pressão, utilizando um ímã permanente como fonte de campo magnético.

Também, é importante destacar que os resultados computacionais e experimentais apresentados nas seções 2.3 e 2.4 foram obtidos considerando-se a associação do elemento sensor GMI ao cabo longo de $85 \mathrm{~cm}$. Consequentemente, os resultados obtidos nestas seções são diretamente associados à configuração aqui analisada.

\subsection{1}

\section{Sensibilidade e linearidade}

Conforme descrito anteriormente, utilizou-se um ímã permanente como fonte de campo magnético móvel. Visto que o sensor utilizado é do tipo LMI, a fim de se maximizar a sensibilidade do arranjo, o ímã permanente aderido à membrana elástica do transdutor (Figura 69) foi orientado de forma que as suas linhas de campo fossem paralelas ao comprimento do sensor GMI. Ajustou-se para $3 \mathrm{~mm}$ a distância de afastamento entre o ímã e o solenoide que circunda o sensor GMI. Verificou-se que esta distância é suficiente para garantir que o ímã 
3.

nunca encoste no solenoide, mesmo quando se exerce a máxima pressão admissível sobre a membrana do transdutor de pressão. Destaca-se ainda que selecionou-se um ímã tal que, quando posicionado à distância de $3 \mathrm{~mm}$ do sensor, gerasse um campo resultante sobre o elemento sensor com valor da ordem de no máximo alguns oersteds, pois dessa forma é possível estabelecer um campo de polarização aceitável por meio do emprego do solenoide de compensação, excitado por correntes não superiores a $100 \mathrm{~mA}$.

A fim de se avaliar a sensibilidade e a linearidade do arranjo aqui definido, efetuou-se a caracterização experimental da fase do sensor GMI, acoplado ao cabo longo, em função da corrente que flui pelo solenoide de excitação, variando-se as correntes entre -100 mA e $100 \mathrm{~mA}$, em passos de $5 \mathrm{~mA}$. Fez-se uma leitura de fase, por meio do medidor RLC, a cada passo de corrente. Ressalta-se ainda que em todas as medições aqui apresentadas, o sensor GMI é excitado por uma corrente $i_{c}=[80+15 \operatorname{sen}(2 \pi \cdot 100 \mathrm{kHz} t)] \mathrm{mA}$. A curva de caracterização obtida é apresentada na Figura 71.

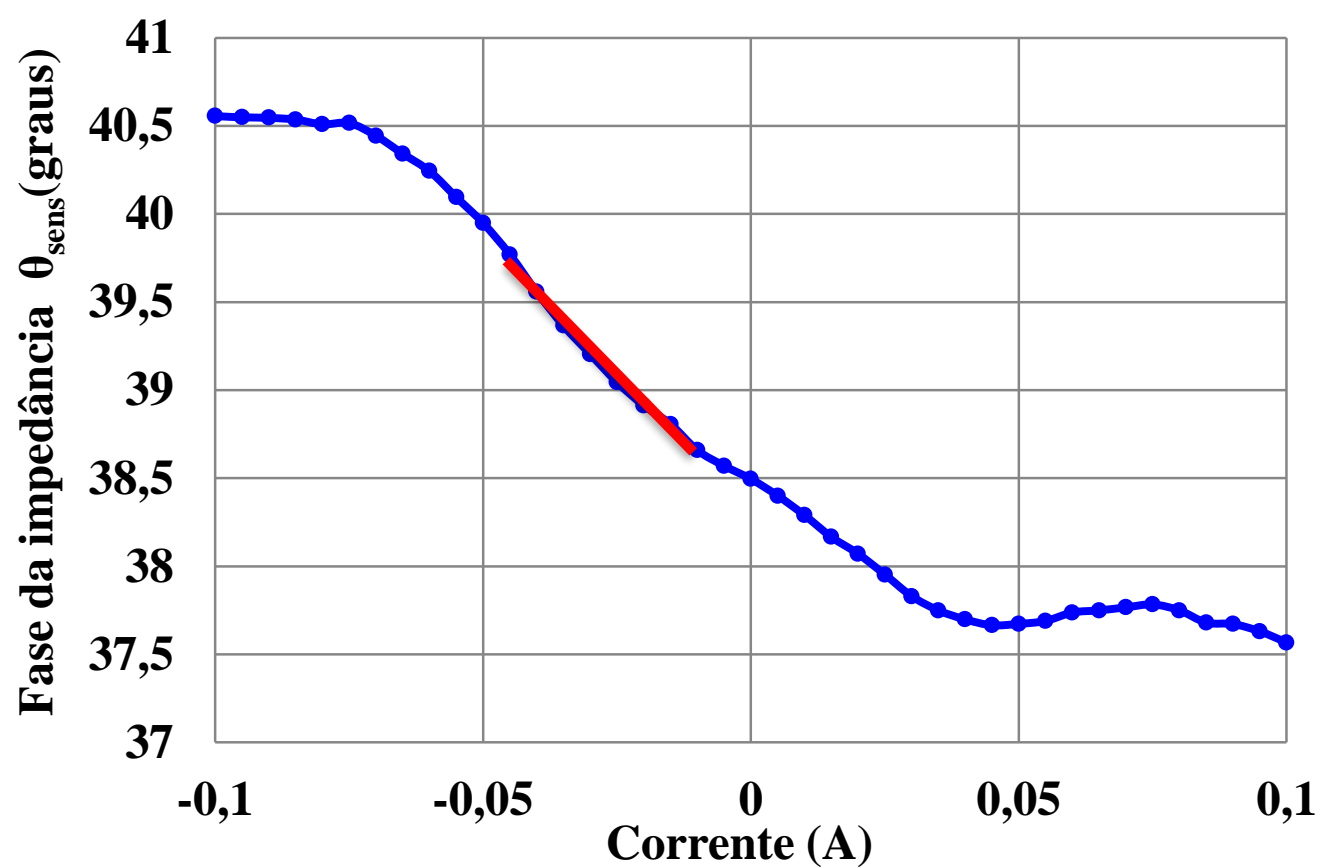

Figura 71 - Caracterização experimental do sensor GMI, acoplado a um cabo longo (85 cm), em função da corrente que atravessa o solenoide de excitação, para $3 \mathrm{~mm}$ de afastamento entre o ímã permanente e o solenoide. A reta vermelha indica a região aproximadamente linear que se estende de $-10 \mathrm{~mA}$ a $-45 \mathrm{~mA}$.

A Figura 71 apresenta uma região satisfatoriamente linear para correntes de excitação do solenoide entre cerca de $-45 \mathrm{~mA}$ e $-10 \mathrm{~mA}$, a qual também é claramente a região onde o sensor apresenta sua sensibilidade máxima. Dessa 
3.

Protótipo do transdutor de pressão GMI

forma, ajustou-se a corrente de excitação para $-27,5 \mathrm{~mA}$, a fim de se maximizar a excursão simétrica dentro desta região linear.

Uma vez tendo determinado a distância de afastamento entre o ímã permanente e o solenoide $(3 \mathrm{~mm})$ e a corrente de excitação do solenoide $(-27,5$ mA), realizou-se a avaliação experimental do transdutor de pressão. Para tal fim, aplicaram-se diferentes pressões à membrana do transdutor, cuja área é conhecida $\left(0,71 \cdot 10^{-3} \mathrm{~m}^{2}\right)$, e mediu-se o seu respectivo sinal de saída, em cada caso analisado. O procedimento de caracterização experimental aqui adotado é similar ao descrito na subseção 3.2.1. A Figura 72 apresenta o comportamento da tensão de saída do transdutor em função da pressão exercída sobre a membrana.

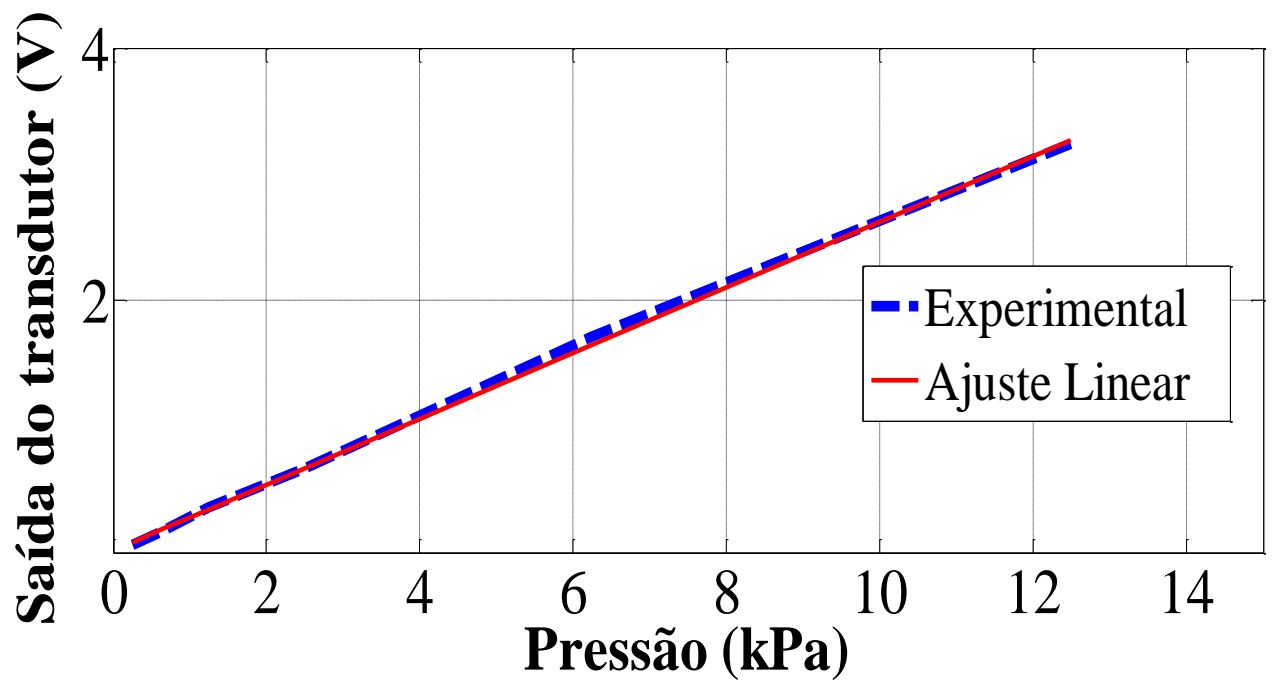

Figura 72 - Sensibilidade do transdutor de pressão, utilizando-se um ímã permanente como fonte de campo magnético móvel.

Os resultados experimentais apresentados na Figura 72 exibem comportamento satisfatoriamente linear na faixa de pressões avaliada, que vai até 12,5 kPa. Dessa forma, tem-se que os dados experimentais podem ser aproximados por um polinomio de ajuste linear, cuja expressão é dada por

$$
V_{\text {out }}=\left(260,2 \cdot 10^{-3} \mathrm{mV} / \mathrm{kPa}\right) \cdot P+0,0186 \mathrm{~V}
$$

onde $\mathrm{P}$ é a pressão em $\mathrm{kPa}$.

Assim, tem-se que a sensibilidade experimental obtida é de aproximadamente $260,2 \mathrm{mV} / \mathrm{kPa}$.

\subsection{2}

\section{Resposta em frequência}

O comportamento da sensibilidade do magnetômetro GMI desenvolvido, que é parte integrante do transdutor de pressão implementado, foi experimentalmente 
3.

Protótipo do transdutor de pressão GMI

avaliado em função da frequência do sinal de interesse. Tais resultados permitem que se estime a banda de passagem do transdutor de pressão desenvolvido. Assim como proposto na subseção 3.3.1, ressalta-se que em todas as medições aqui apresentadas, a distância de afastamento entre o ímã permanente e o solenoide foi de $3 \mathrm{~mm}$, e a corrente de excitação do solenoide foi fixada em -27,5 mA.

O procedimento experimental detalhado na subseção 3.2.2, foi aqui repetido, para obtenção da resposta em frequência do magnetômetro GMI. Assim, a amplitude da densidade de fluxo magnético senoidal $\mathrm{B}_{\mathrm{H}}$, utilizada para excitar o sensor, foi fixada em $16 \mu \mathrm{T}$. Dessa forma, conforme anteriormente indicado na Figura 62, para cada frequência de excitação avaliada ajustou-se adequadamente a amplitude da tensão de saída do gerador de sinais $\mathrm{V}_{\mathrm{GER}}$, a fim de se compensar as variações na impedância $Z_{H}$ da Bobina de Helmholtz e, consequentemente, manter a amplitude de $\mathrm{B}_{\mathrm{H}}$ constante.

A Figura 73 apresenta o comportamento da sensibilidade do circuito em função da frequência do campo, em hertz. Na Figura 73 (a) apresenta-se a curva da sensibilidade expressa em $\mathrm{mV} / \mathrm{nT}$, enquanto a sensibilidade em $\mathrm{dB}$ (Figura 73 (b)) é expressa de acordo com

$$
\operatorname{Sens}(d B)=20 \cdot \log \left(\frac{\operatorname{Sens}(V / T)}{51,20 \cdot 10^{3}(V / T)}\right)
$$

onde $51,20 \cdot 10^{3} \mathrm{~V} / \mathrm{T}$ é a sensibilidade experimental do circuito para campos CC, vide equação (19).

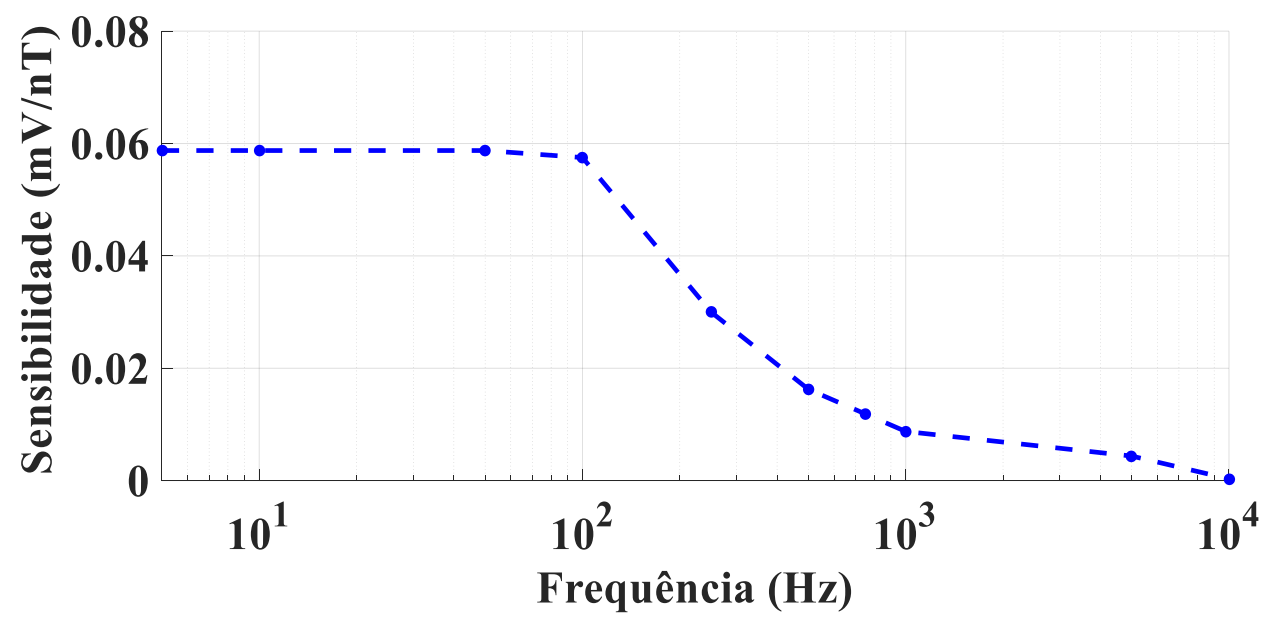

(a) 
3.

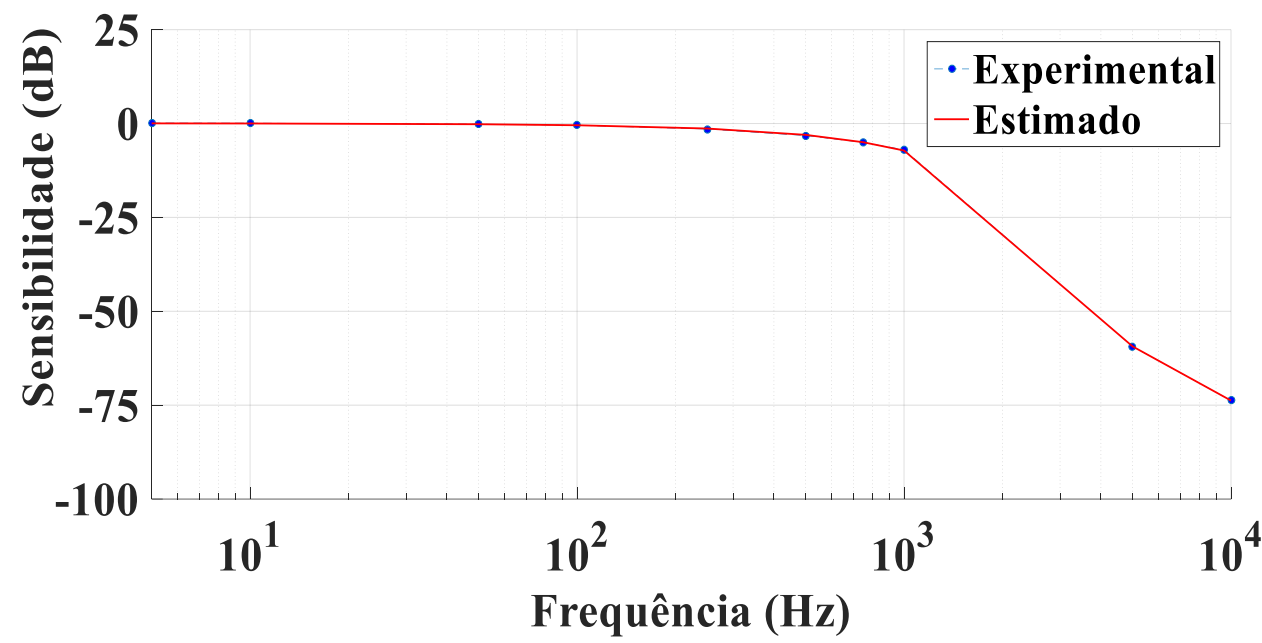

(b)

Figura 73 - Dependência da sensibilidade do transdutor em função da frequência do campo magnético de excitação: (a) sensibilidade em $\mathrm{mV} / \mathrm{nT}$ e (b) sensibilidade em dB.

As curvas experimentais, apresentadas na Figura 73, podem ser satisfatoriamente modeladas por meio de polinômios de ajuste de $3^{\text {a }}$ ordem. Dessa forma, é possível obter estimativas das expressões analíticas tanto da sensibilidade Sens, expressa em $\mathrm{mV} / \mathrm{nT}$, quanto da sensibilidade Sens $\mathrm{dB}_{\mathrm{dB}}$, expressa em $\mathrm{dB}$, em função da frequência $\mathrm{f}$, expressa em Hz. Os respectivos polinômios de ajuste são explicitados por meio de

$$
\begin{gathered}
\operatorname{Sens}(f)=-338,41 \cdot 10^{-15} \cdot f^{3}+6,14 \cdot 10^{-9} \cdot f^{2}-33,26 \cdot 10^{-6} \cdot f+57,05 \cdot 10^{-3} \\
\operatorname{Sens}_{d B}(f)=228,54 \cdot 10^{-12} \cdot f^{3}-2,53 \cdot 10^{-6} \cdot f^{2}-4,95 \cdot 10^{-3} \cdot f+63,10 \cdot 10^{-3}
\end{gathered}
$$

Analisando-se o comportamento da curva explicitada na Figura 73 (b), verifica-se que a banda do transdutor desenvolvido é de aproximadamente 250 Hz. Por sua vez, também se percebe que a sensibilidade é satisfatoriamente constante para frequências dentro desta banda. Destaca-se ainda que banda de passagem da configuração proposta nesta subseção $(250 \mathrm{~Hz})$ é igual à àquela da subseção 3.2.2 $(250 \mathrm{~Hz})$.

\subsection{3}

\section{Análise de ruído}

Inicialmente, esta seção apresenta a avaliação experimental da densidade espectral de ruído do magnetômetro GMI desenvolvido, que é parte integrante do transdutor de pressão projetado. Todas as medições apresentadas nesta seção foram realizadas com uma distância de afastamento de $3 \mathrm{~mm}$ entre o ímã e o solenoide, excitando-se o solenoide com uma corrente de $-27,5 \mathrm{~mA}$. Isto é, 
3.

Protótipo do transdutor de pressão GMI

adotou-se exatamente a mesma configuração do transdutor empregada nas subseções 3.3.1 e 3.3.2.

O procedimento experimental empregado nas medições aqui apresentadas é equivalente ao descrito na subseção 3.2.3. Objetivando-se medir as características de ruído de saída do circuito eletrônico, excitou-se a amostra GMI com um campo magnético senoidal de $16 \mu \mathrm{T}$ de amplitude e $10 \mathrm{~Hz}$ de frequência. Na sequência, calculou-se a Transformada Rápida de Fourier (FFT - Fast Fourier Transform) do sinal de saída do magnetômetro com auxílio do analisador de espectro. A Figura 74 apresenta os resultados obtidos. Na Figura 74(a) apresentam-se medições para frequências entre $0 \mathrm{~Hz}$ e $400 \mathrm{~Hz}$, e na Figura 74(b) para frequências entre $0 \mathrm{~Hz}$ e $100 \mathrm{~Hz}$. Por sua vez, os resultados explicitados na Figura74(c), referem-se a uma faixa de frequências de $0 \mathrm{~Hz}$ a $50 \mathrm{~Hz}$ e limita-se o valor máximo da escala de tensões em $400 \mathrm{mV}$, a fim de se poder avaliar em maiores detalhes os níveis de ruído presentes.

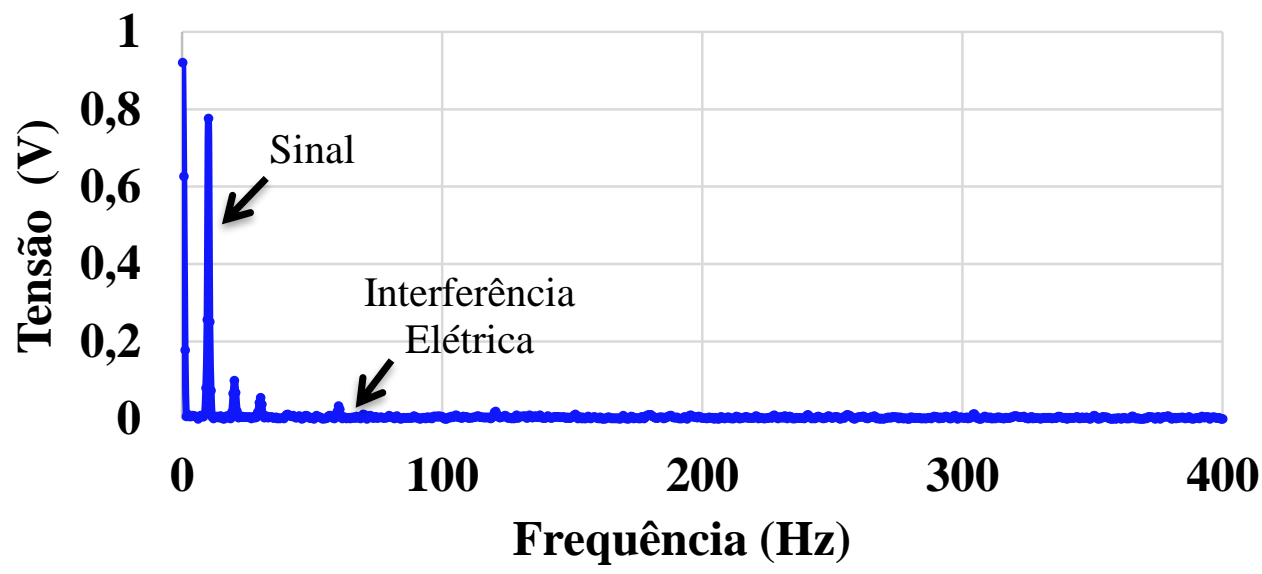

a)

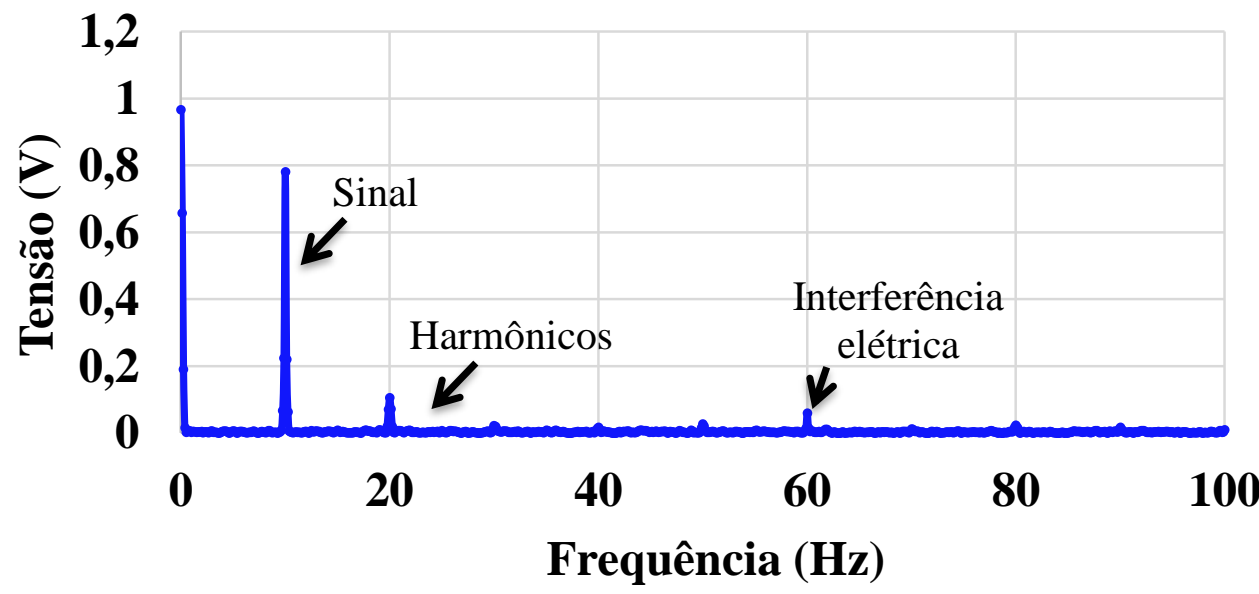

b) 
3.

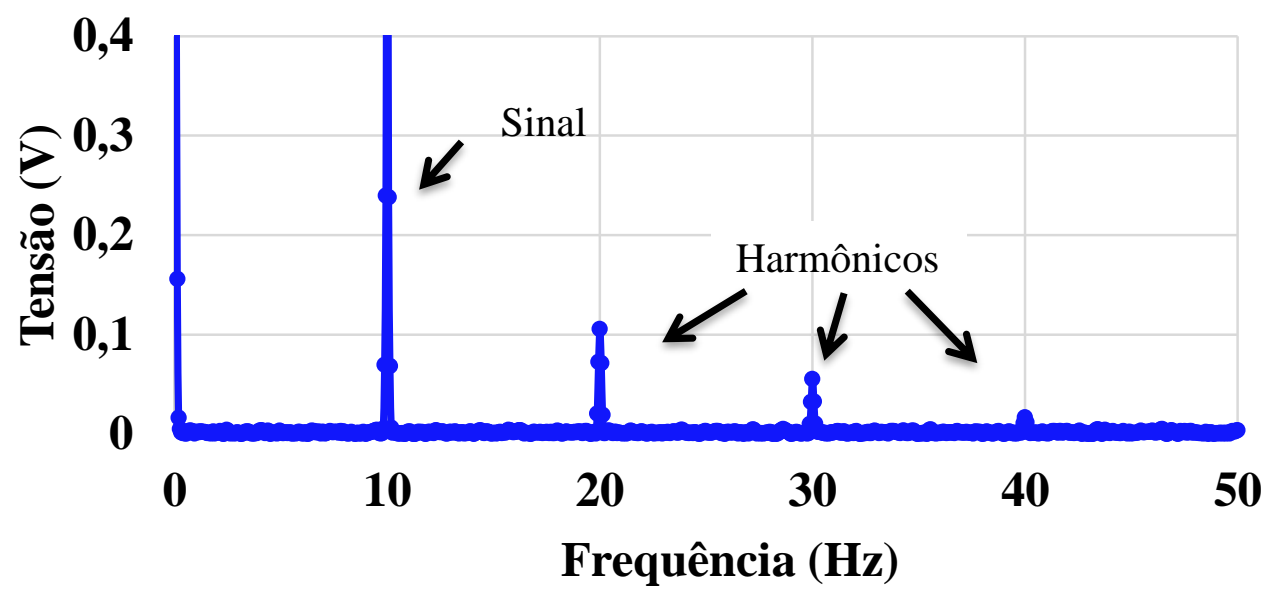

c)

Figura 74 - Transformada Rápida de Fourier (FFT) do sinal de saída do transdutor, utilizando-se um ímã permanente como fonte de campo móvel.

A componente espectral em $10 \mathrm{~Hz}$, presente na Figura 74 (a), (b), (c), foi induzida pelo campo magnético senoidal de excitação, cuja amplitude é de $16 \mu \mathrm{T}$. Verifica-se que a amplitude, em tensão, desta componente espectral é de aproximadamente $0,78 \mathrm{~V}$. Consequentemente, a presença desta componente espectral com amplitude conhecida, tanto em unidades de tensão quanto de campo magnético, permite que se defina a sensibilidade do magnetômetro GMI como

$$
\text { Sensibilidade }=\frac{0,78 \mathrm{~V}}{16 \mu \mathrm{T}}=48,8 \frac{\mathrm{mV}}{\mu \mathrm{T}}
$$

Conforme esperado, é possível verificar que a sensibilidade obtida por meio da eq. (34) é satisfatoriamente próxima do valor equivalente obtido na seção 2.4. Além da componente espectral de $10 \mathrm{~Hz}$, também é possível observar na Figura 74 a presença de outras componentes espectrais significativas, uma delas em 60 $\mathrm{Hz}$ sendo atribuida à interferência da rede elétrica $(60 \mathrm{~Hz}$, no Brasil). Por outro lado, também é perceptível uma componente CC e distorções harmônicas do sinal de $10 \mathrm{~Hz}$, evidenciadas por componentes em $20 \mathrm{~Hz}, 30 \mathrm{~Hz}$ e $40 \mathrm{~Hz}$. É importante destacar que a componente fundamental do sinal $(10 \mathrm{~Hz})$ possui amplitude cerca de 5 vezes superior à componente de distorção harmônica de maior intensidade, localizada em $20 \mathrm{~Hz}$.

$\mathrm{Na}$ sequência, desligou-se a fonte de campo em $10 \mathrm{~Hz}$ e configurou-se o analisador de espectro para fornecer a densidade espectral de ruído do magnetômetro GMI, em V·Hz ${ }^{-1 / 2}$. Por sua vez, considerando que a sensibilidade do magnetômetro é dada pela eq. (32), é possível converter os valores de tensão obtidos em valores de densidade de fluxo magnético, a fim de se obter a curva de 
3.

densidade espectral de ruído, expressa em nT· $\mathrm{Hz}^{-1 / 2}$, a qual é explicitada na Figura 75.

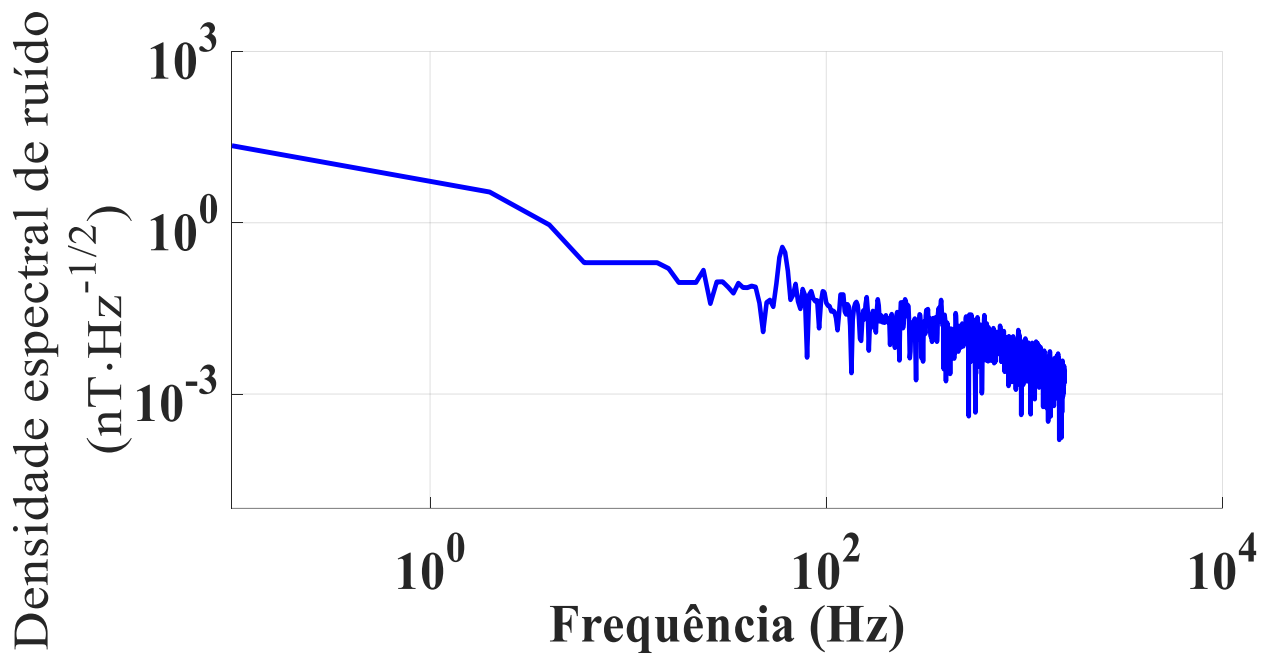

Figura 75 - Densidade espectral de ruído da tensão de saída do magnetômetro GMI desenvolvido, expressa em $\mathrm{nT} \cdot \mathrm{Hz}^{-1 / 2}$, utilizando-se um ímã permanente como fonte de campo magnético móvel.

Por sua vez, a fim de se determinar a densidade espectral de ruído total do transdutor de pressão desenvolvido, conectou-se sua saída ao analisador de espectro, e realizou-se uma medição da FFT na situação de equilibrio, isto é, pressão nula exercida sobre sua membrana. Com base nos dados provenientes desta medição e sabendo que a sensibilidade do transdutor de pressão é de 260,2 $\mathrm{mV} / \mathrm{kPa}$, conforme verificado na subseção 3.2.1, é possível inferir a curva de densidade espectral de ruído do transdutor de pressão, expressa em $\mathrm{Pa}_{\mathrm{H}} \mathrm{Hz}^{-1 / 2}$, a qual é apresentada na Figura 76.

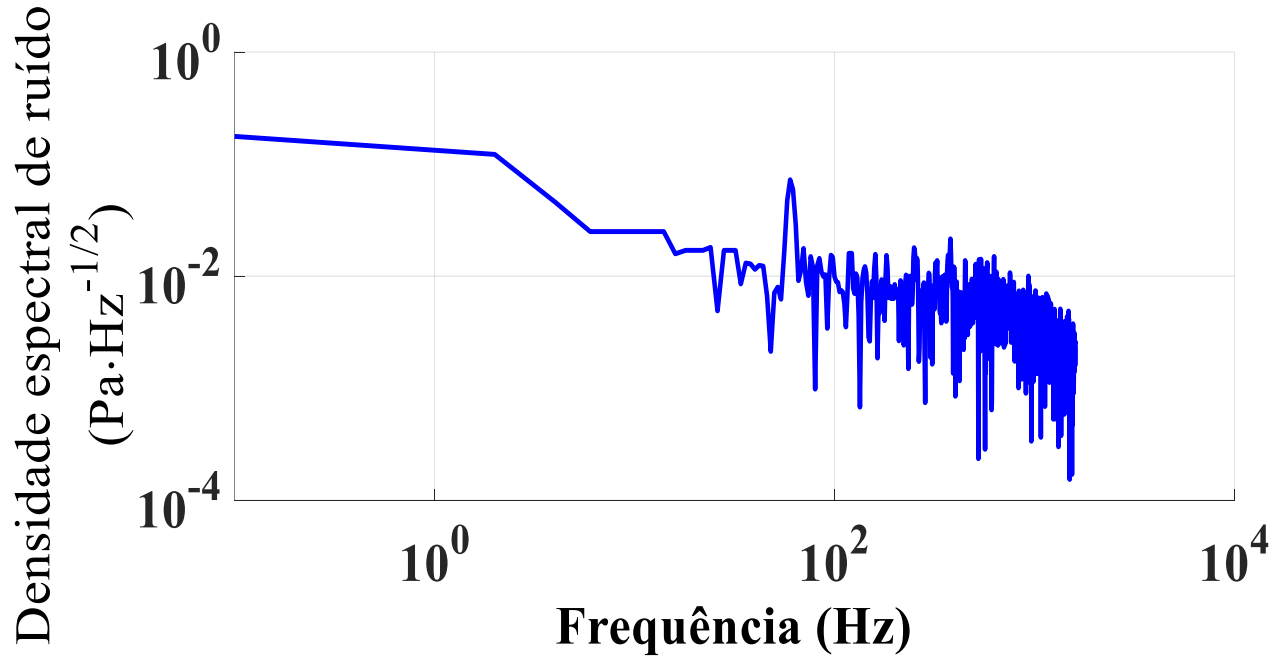

Figura 76 - Densidade espectral de ruído da tensão de saída do transdutor de pressão desenvolvido, expressa em $\mathrm{Pa} \cdot \mathrm{Hz}^{-1 / 2}$, utilizando-se um ímã permanente como fonte de campo magnético móvel. 
3. Protótipo do transdutor de pressão GMI

Tanto na Figura 75 quanto na Figura 76 é possível observar que, conforme esperado, o circuito capta a interferência da rede elétrica em $60 \mathrm{~Hz}$. Apesar de estar presente em todos os tipos de transdutores elétricos, destaca-se que esta interferência é particularmente mais intensa em sensores magnéticos, visto que neste caso os elementos sensores são sensíveis a mesma. Os resultados indicam que, na banda de 0 a $100 \mathrm{~Hz}$, a resolução do magnetômetro GMI é de 3,6 nT (Figura 75) e a do transdutor de pressão desenvolvido é de 0,19 Pa (Figura 76). Ressalta-se que a resolução obtida pelo transdutor de pressão aqui desenvolvido propicia medir com qualidade os sinais biomédicos de interesse.

Por sua vez, também se observa que o comportamento das curvas de densidade espectral de ruído obtidas apresenta dependência inversamente proporcional a uma potência da frequência. Dessa forma, na literatura, é convencional denominar tais curvas de curvas de ruído 1/f.

\section{4 Medição experimental da onda de pulso arterial}

O novo transdutor de pressão GMI desenvolvido nesta dissertação, descrito na seção 3.3, foi utilizado a fim de se obter o registro de sinais provenientes do sistema cardiovascular, tais como as ondas de pulso arterial, o pulso carotídeo e o pulso radial. Assim, foi utilizada a configuração composta por o ímã permanente e o cabo longo $(85 \mathrm{~cm})$ para a conexão do circuito com o sensor GMI. Para aquisição e registro dos sinais de interesse, conectou-se a saída do transdutor de pressão desenvolvido a uma das entradas de um osciloscópio de alta resolução (HRO 64Zi, Lecroy).

Conforme indicado na Figura 77, para a medição da onda de pulso, posicionou-se a membrana semirrígida do transdutor em contato direto com a pele do voluntário, nas regiões do corpo adequadas para medição das ondas de interesse: pulso carotídeo (Figura 77(a)) e pulso radial (Figura 77(b)). 
3.

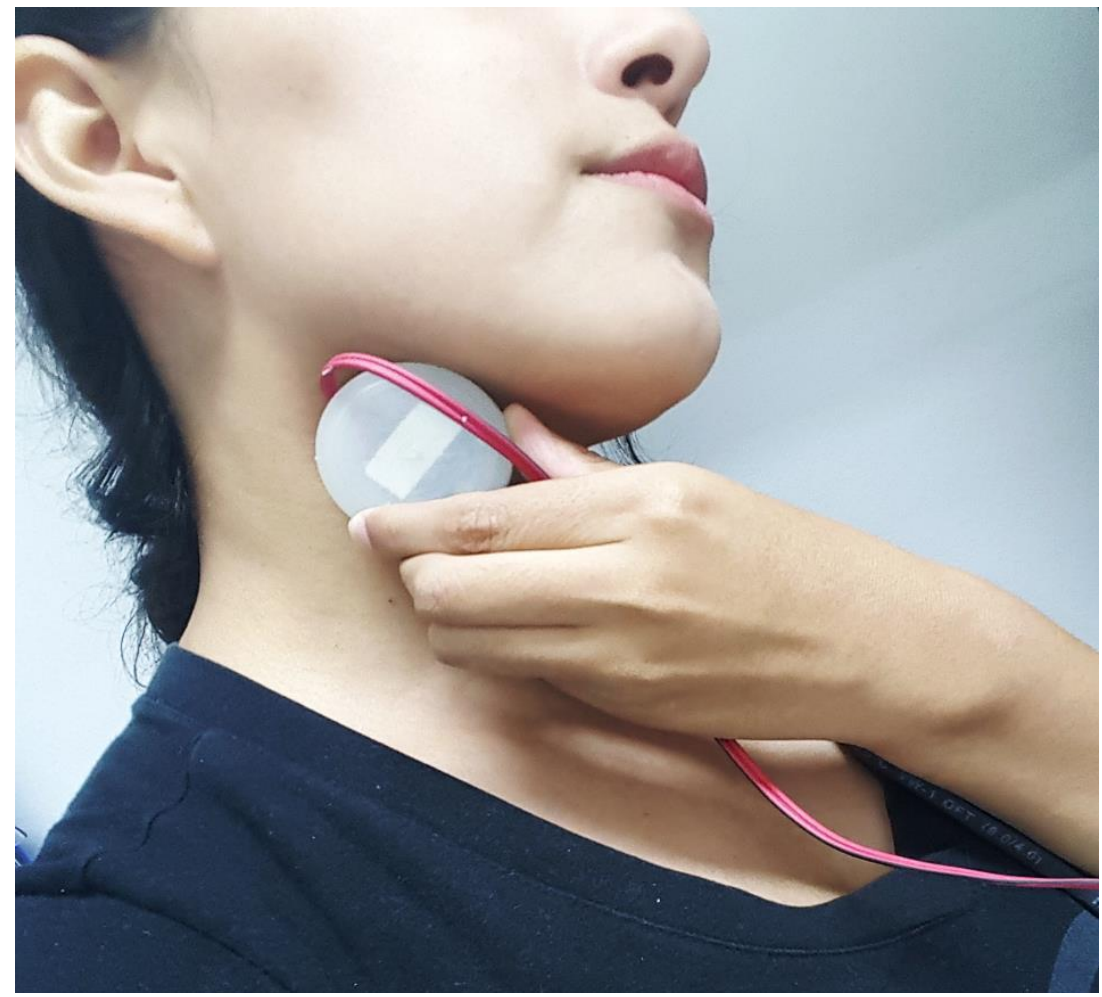

(a)

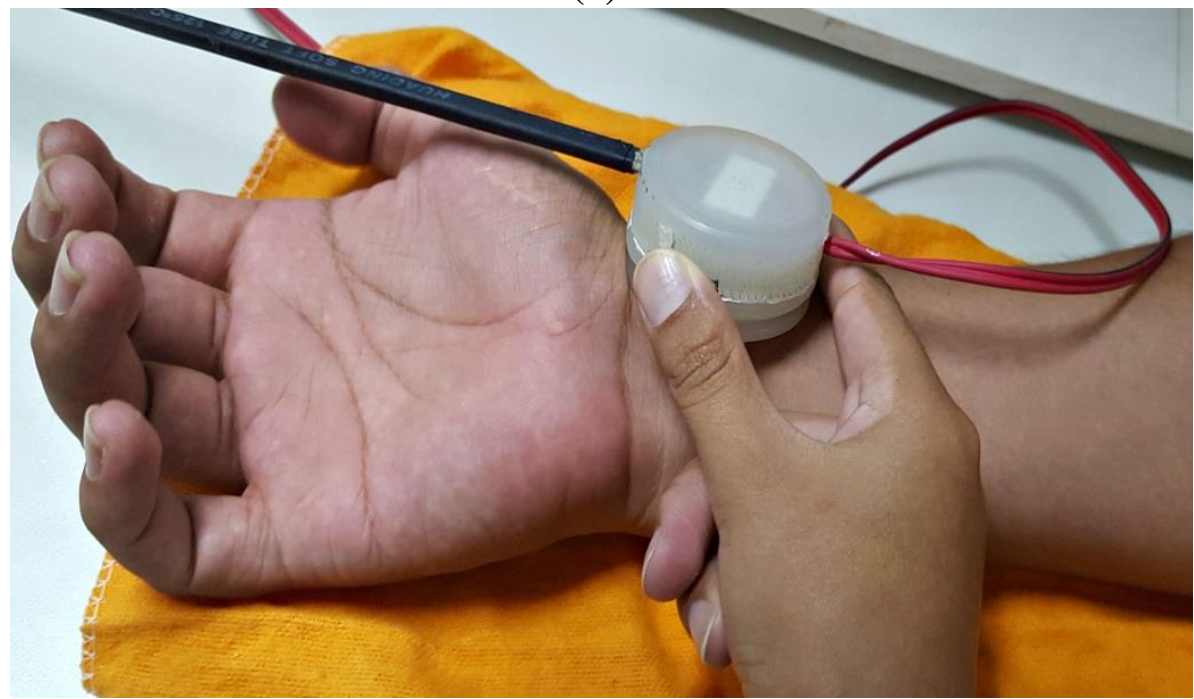

(b)

Figura 77 - Posicionamento do transdutor desenvolvido para medição experimental da onda de pulso a) carotídea e b) radial.

Os sinais adquiridos foram pós-processados por meio de uma rotina de filtragem digital implementada no Matlab, baseada em um filtro digital passabaixas de $6^{\mathrm{a}}$ ordem, do tipo Butterworth, com frequência de corte em $10 \mathrm{~Hz}$. A princípio, ao se reduzir a frequência de corte melhora-se a qualidade do sinal. Entretanto, deve-se garantir que a frequência de corte selecionada não atenue as componentes de interesse do sinal medido. A frequência de corte de $10 \mathrm{~Hz}$ 
3.

permite a passagem das componentes espectrais relevantes contidas na onda de pulso. A filtragem digital melhora a qualidade do sinal adquirido por reduzir a influência de componentes espectrais espúrias, advindas de diversas fontes de ruído/interferência. Na Figura 78, apresentam-se tanto os sinais adquiridos diretamente da saída do circuito, em vermelho, quanto aqueles obtidos após a filtragem digital em azul. Dessa forma, evidencia-se a melhora obtida devido ao processo de filtragem, que permite uma melhor visualização dos detalhes morfológicos da onda.

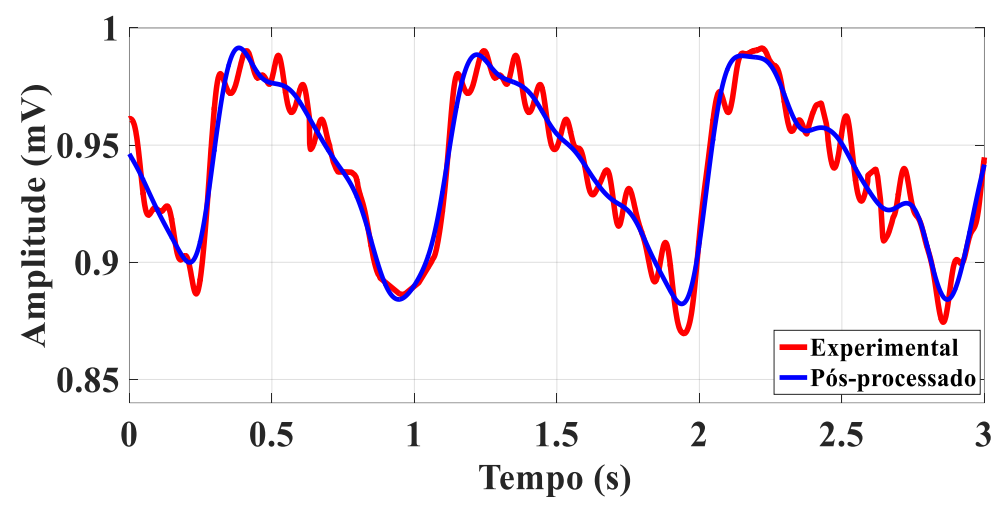

a)

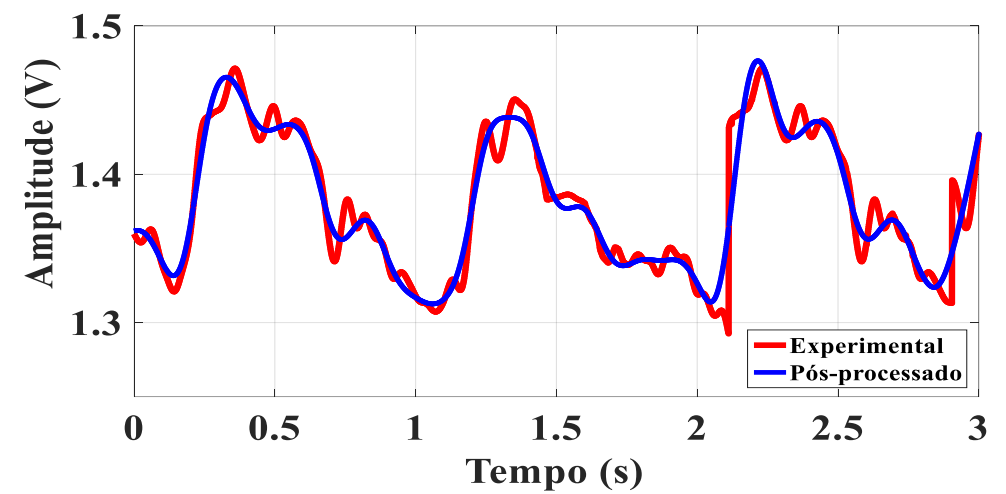

b)

Figura 78 - Resultado das medições experimental do Pulso a) carotídeo e b) radial, adquiridos com o transdutor de pressão desenvolvido.

Inspecionando-se a Figura 78, fica notório que os sinais não processados pelo filtro apresentam significativo ruído em alta frequência, dificultando a visualização da onda de pulso. Tal comportamento pode ser melhor avaliado no domínio da frequência. Dessa forma, na Figura 79 apresentam-se as transformadas de Fourier dos sinais de ondas de pulso carotídeo e radial adquiridos diretamente da saída do circuito de transdução (vermelho), no intervalo de tempo de $12 \mathrm{~s}$. 
3.

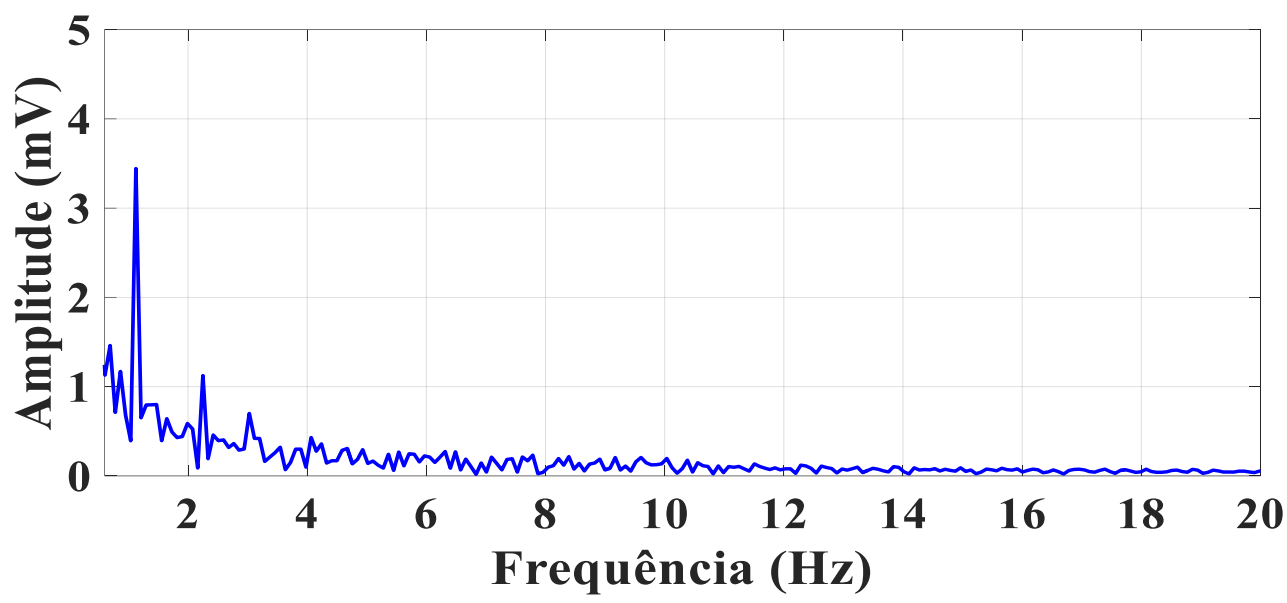

(a)

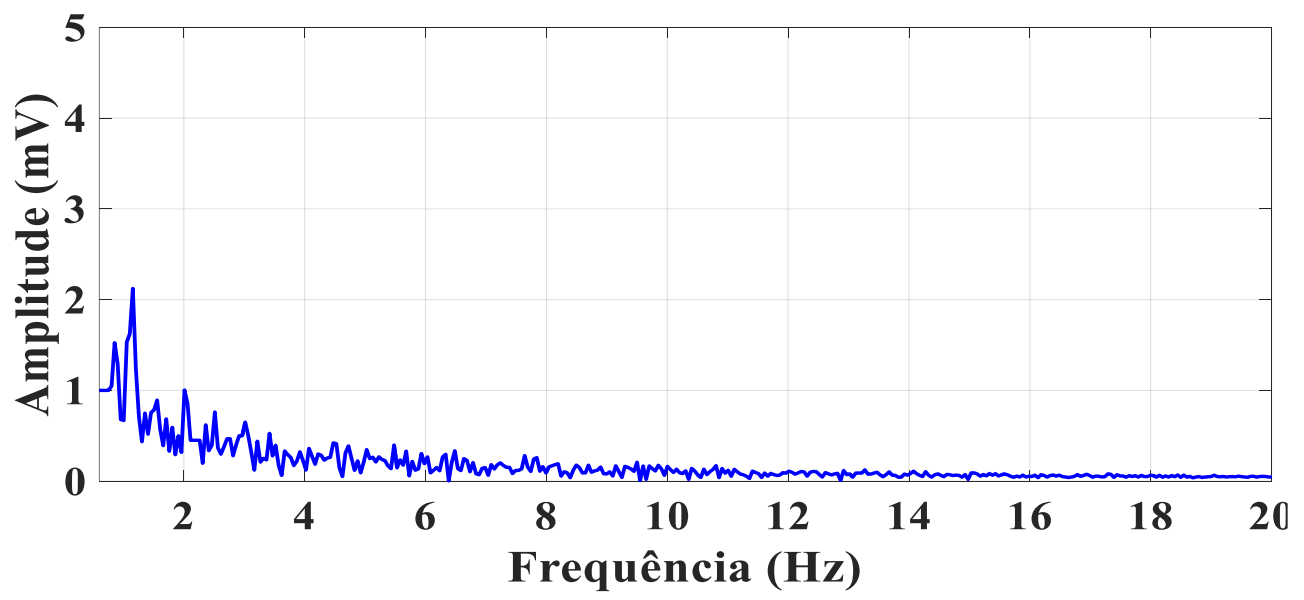

(b)

Figura 79 - Componentes de frequência de interesse do sinal medido, em a) FFT do pulso radial e b) FFT do pulso carotídeo.

Percebe-se que o sinal de interesse é um sinal de baixa frequência, cuja componente principal situa-se em torno de $1 \mathrm{~Hz}$. Além dessa componente, o espectro do sinal de interesse é composto por outras componentes relevantes devido à morfologia da forma de onda, entretanto, de fato, não existem componentes relevantes em frequências acima de $10 \mathrm{~Hz}$.

Na Figura 80(a) é apresentada o comportamento teórico normal de um período da forma da onda de pulso carotídeo, convencionalmente destacado na literatura [7]. Por sua vez, para fins de comparação, a Figura 80(b) indica aproximadamente três períodos da forma de onda do pulso carotídeo adquirida por meio do transdutor desenvolvido nesta dissertação. Pode-se observar que há uma grande similaridade entre os resultados experimentais e aqueles esperados, conforme a literatura. 
3.

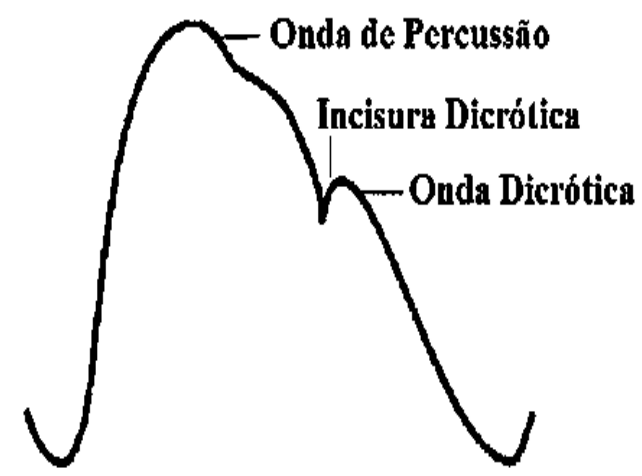

(a)

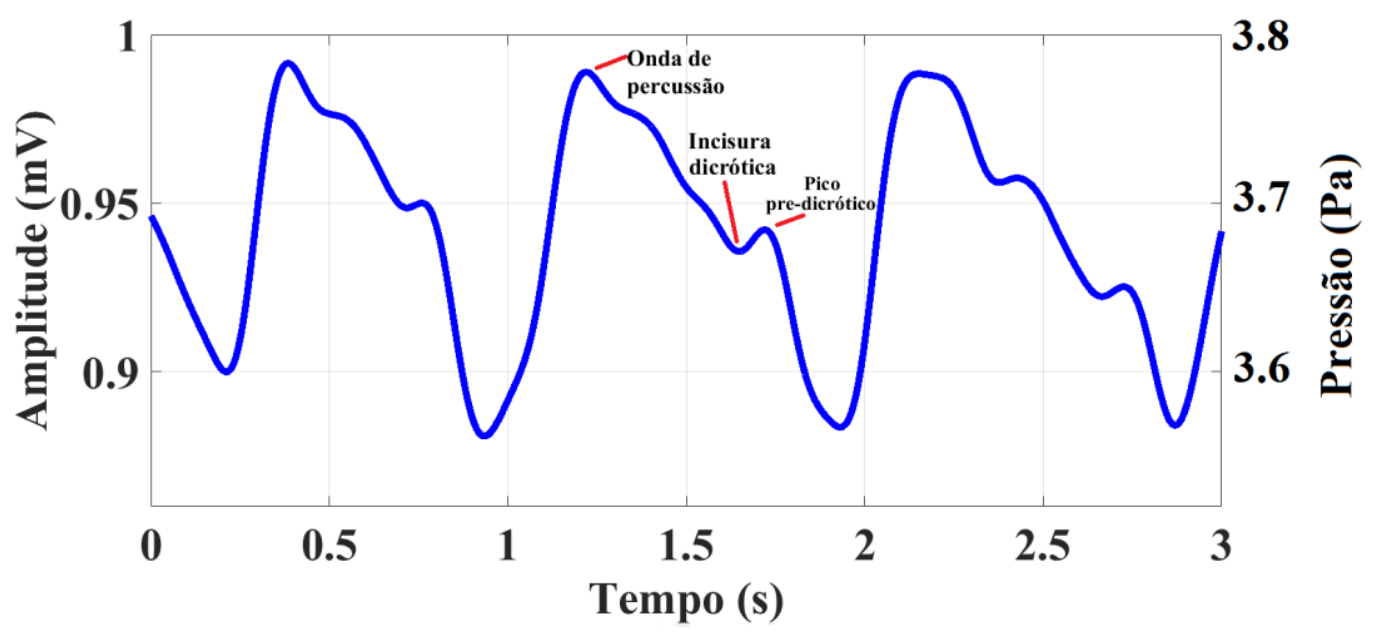

(b)

Figura 80 - Identificação de pontos caraterísticos da onda de pulso carotídeo, a) comportamento tí́ico em pacientes normais (literatura), b) sinal adquirido com o transdutor de pressão desenvolvido.

Na Figura 81(a) é apresentada o comportamento teórico normal de um período da forma da onda de pulso radial, indicando 3 pontos caraterísticos, chamados triple-humped wave, presentes na onda de pulso: pico sistólico, pico pré-dicrótico e incisura dicrótica [45]. Por sua vez, conforme indicado na Figura 81(b), também é possível identificar tais pontos característicos no sinal medido por meio do transdutor desenvolvido. 
3.

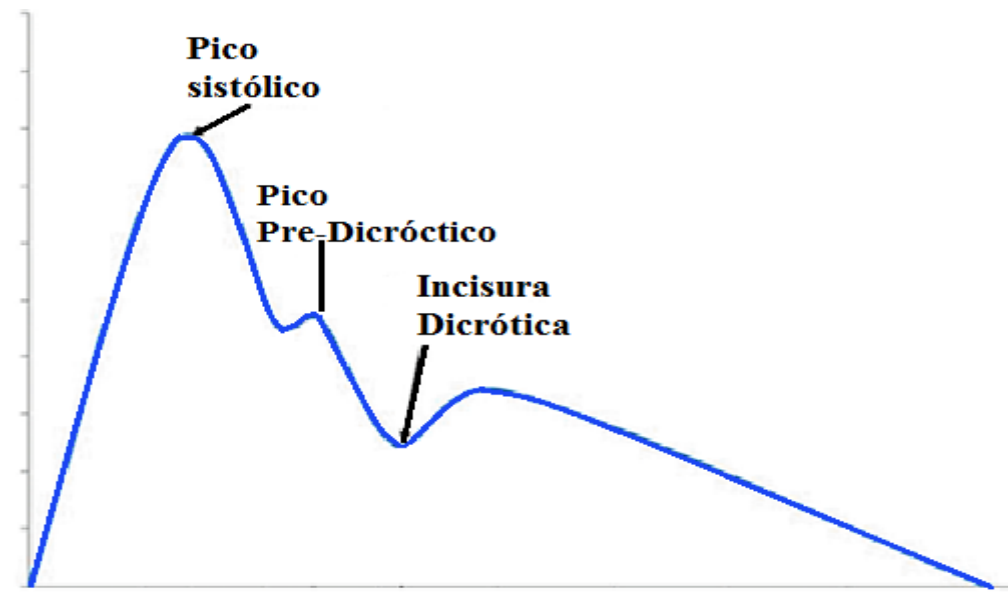

(a)

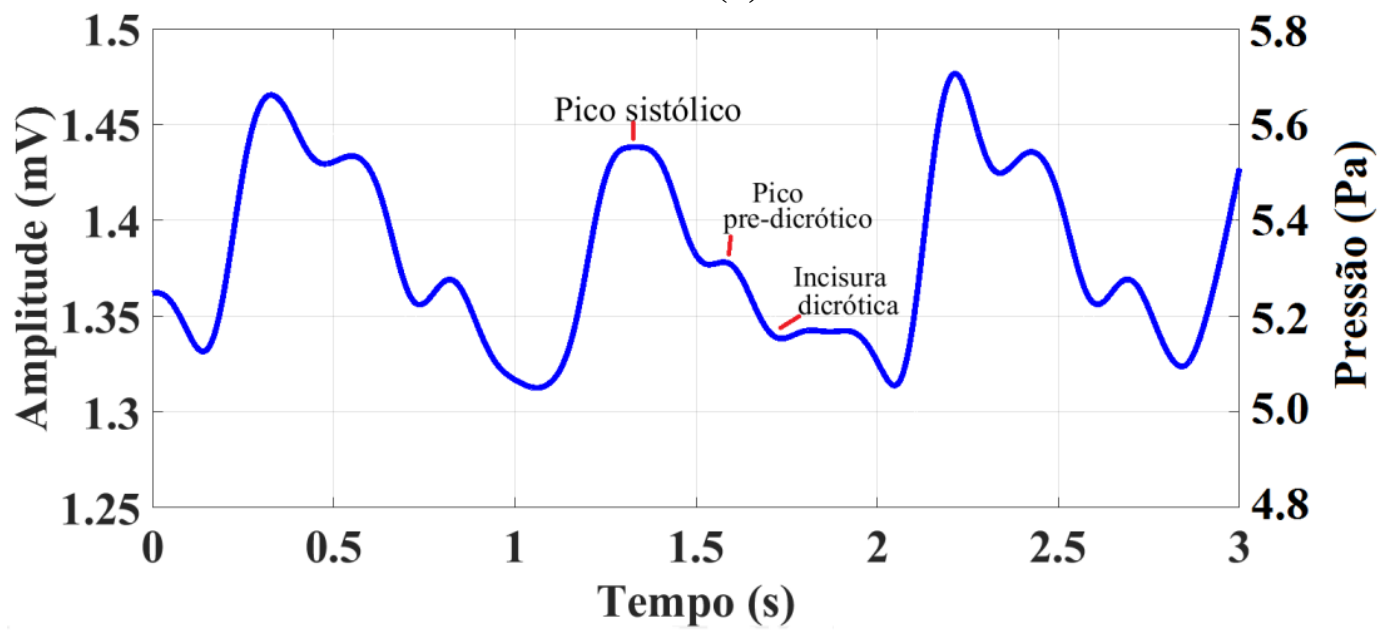

(b)

Figura 81 - Identificação de pontos caraterísticos da onda de pulso radial, a) comportamento típico em pacientes normais (literatura), b) sinal adquirido com o transdutor de pressão desenvolvido.

Tanto na Figura 80(b), quanto na Figura 81(b) é possível observar que, conforme esperado, o transdutor de pressão desenvolvido permitiu delinear as especificidades do contorno dos registros de onda de pulso medida sobre as artérias carótida e radial, em conformidade com a configuração teórica prevista na literatura 
4.

Conclusões e trabalhos futuros

\section{1}

\section{Conclusões}

Trabalhos anteriormente apresentados na literatura abordaram o projeto de transdutores de pressão GMI baseados na leitura do módulo da impedância do elemento sensor [3-5]. Entretanto, estudos conduzidos nos últimos anos indicaram que o desempenho de transdutores baseados em amostras GMI pode ser aprimorado, por meio da leitura das características de fase. Dessa forma, os trabalhos realizados nesta dissertação focaram no desenvolvimento de um transdutor de pressão de alta sensibilidade, baseado na leitura das características de fase de elementos sensores GMI, destinado a aplicações biomédicas, particularmente para medição da onda de pulso arterial.

O comportamento da impedância do sensor GMI em forma de fita de 2,5 cm de comprimento e composição química $\mathrm{Co}_{70} \mathrm{Fe}_{5} \mathrm{Si}_{15} \mathrm{~B}_{10}$, em função do campo magnético, foi experimentalmente avaliado e seu modelo elétrico equivalente foi obtido. Os resultados confirmaram a alta sensibilidade e linearidade do sensor GMI na faixa de operação. Destaca-se ainda que a influência do comprimento do cabo utilizado para fazer a interconexão dos sensores GMI ao circuito eletrônico de transdução também foi avaliada. Verificou-se que as dimensões deste cabo podem afetar o comportamento do transdutor devido à impedância extremamente baixa do elemento sensor, da ordem de $1 \Omega$.

Duas configurações alternativas para o transdutor foram implementadas e avaliadas, conforme discutido no capítulo 3. Na primeira foi utilizada uma agulha magnetizada como fonte de campo magnético móvel, tendo essa configuração apresentado uma sensibilidade de $0,151 \mathrm{mV} / \mathrm{Pa}$, banda de passagem de $250 \mathrm{~Hz}$, fundo de escala de 12,49 $\mathrm{kPa}$ e resolução de 0,28 Pa. Por outro lado, na segunda configuração utiliza-se um ímã permanente, alcançando uma sensibilidade de 0,260 $\mathrm{mV} / \mathrm{Pa}$, uma banda de passagem de $250 \mathrm{~Hz}$, fundo de escala de 12,49 $\mathrm{kPa}$ e uma resolução de 0,19 $\mathrm{Pa}$. Destaca-se ainda que a segunda configuração é 
4.

Conclusões e trabalhos futuros

consideravelmente mais estável ao longo do tempo, pois o campo magnético gerado pelo ímã não apresenta variações significativas, enquanto que o campo magnético gerado pela agulha magnetizada decai com o tempo e pode ser significativamente afetado pelo campo magnético ambiental. Por sua vez, é importante ressaltar que as figuras de mérito obtidas, para os protótipos desenvolvidos, são significativamente superiores às apresentadas pela grande maioria dos transdutores comerciais disponíveis [31-32]. Como por exemplo os apresentados na tabela 3 .

Tabela 3. Comparação de sensibilidade e fundo de escala entre alguns transdutores de pressão.

\begin{tabular}{|c|c|c|}
\hline Transdutor de Pressão & $\begin{array}{l}\text { Sensibilidade } \\
\qquad(\mathbf{m V} / \mathbf{P a})\end{array}$ & $\begin{array}{c}\text { Fundo de } \\
\text { escala }(\mathbf{k P a})\end{array}$ \\
\hline Piezo resistivo (IC-Sensor model 84) & 0,015 & 40 \\
\hline Piezo resistivo (ATP015, APM) & 0,029 & 40 \\
\hline $\begin{array}{l}\text { Magnetoimpedância Gigante (GMI) } \\
\text { baseado em módulo }\end{array}$ & 0,131 & 0,42 \\
\hline Protótipo 1 (agulha) & 0,151 & 12,49 \\
\hline Protótipo 2 (imã permanente) & 0,260 & 12,49 \\
\hline
\end{tabular}

Os resultados das medições experimentais da onda de pulso arterial, realizadas com o transdutor de pressão aqui desenvolvido, confirmaram a possibilidade da adequada configuração dos aspectos característicos da morfologia do registro da onda de pulso carotídeo e radial.

Medições não invasivas da onda de pulso arterial por meio do dispositivo de baixo custo e alta sensibilidade desenvolvido poderão contribuir de forma ampla e significativa para a eficiência no diagnóstico clínico, monitoramento adequado de tratamentos e prevenção de distúrbios cardíacos.

\section{2}

\section{Trabalhos Futuros}

Tendo em vista as principais dificuldades vivenciadas durante o desenvolvimento do transdutor, pôde-se definir um conjunto de trabalhos a serem realizados no futuro, a fim de aprimorar o desempenho do protótipo aqui desenvolvido. Dessa forma, recomenda-se que em trabalhos futuros a influência do comprimento do cabo seja avaliada em maiores detalhes. Também, espera-se 
4.

que o desempenho possa ser aprimorado por meio da montagem do circuito em uma placa de circuito impresso e por meio de variações na configuração mecânica do protótipo, que possibilitem a redução da distância entre o circuito eletrônico e o elemento sensor, sem comprometer o posicionamento anatômico.

O circuito eletrônico proposto na seção 2.2 opera em malha aberta. Objetivando a otimização do circuito, serão futuramente implementadas malhas de realimentação, a fim de reduzir ainda mais os níveis de ruído observados. Ademais, pode-se implementar um controle ativo da corrente que flui pelo solenoide de polarização, a fim de se garantir que fontes espúrias de campo magnético (p.ex. campo da Terra) não afetem o campo de polarização ao qual o elemento sensor está submetido.

Recomenda-se que em trabalhos futuros sejam realizadas medições adicionais no intuito de se avaliar a incerteza dos resultados aqui obtidos, a fim de tornar mais confiável a estimativa das figuras de mérito calculadas no presente trabalho. Sugere-se que também sejam efetuadas novas medições a fim de se avaliar a repetitividade e reprodutibilidade do protótipo desenvolvido.

Recomenda-se que a resolução do transdutor GMI seja futuramente avaliada com o mesmo inserido em uma câmara magnética blindada, a fim de se verificar se o fator limitante da resolução do protótipo montado é o ruído magnético ambiental. Caso tal hipótese seja comprovada, sugere-se a implementação de protótipos futuros baseados em configurações gradiométricas dos sensores [58]. Nestas configurações, realiza-se uma leitura diferencial entre, pelo menos, dois sensores de comportamento idêntico, um próximo à fonte de interesse e outro a uma distância suficiente para que este não seja significativamente afetado pela fonte de sinal. Dessa forma, convencionalmente consegue-se aprimorar significativamente a relação sinal/ruído, devido à atenuação dos níveis de interferência magnética ambiental.

Sugere-se que sejam realizadas medições adicionais da onda de pulso arterial, assim como da velocidade da onda de pulso, utilizando o transdutor desenvolvido. Por sua vez, a estrutura mecânica do transdutor também pode ser aprimorada a fim de facilitar seu posicionamento anatômico. A área da superfície de contato da membrana semirrígida do transdutor com o corpo do paciente deverá ser minimizada, de modo a facilitar a medição da onda de pulso em pontos do corpo de difícil acesso. 
4.

Além disso, propõe-se que a resposta do transdutor seja avaliada quando o mesmo é submetido a formas de onda de pulso arterial padrão (anacrônico, dicrótico, bisferiens, entre outras), sintetizadas por um gerador de sinais responsável por excitar um elemento piezoelétrico aderido à membrana do transdutor de pressão aqui desenvolvido. Dessa forma, pode-se avaliar a confiabilidade das medições, comparando-se a tensão de saída do transdutor com as formas de onda padrão sintetizadas.

Finalmente, para garantir a confiabilidade das medições tendo em vista a aplicação biomédica [57], é importante que sejam propostos requisitos para avaliação de aspectos de segurança e desempenho do equipamento desenvolvido [56,57,59]. 


\section{Referências bibliográficas}

[1] ALZIRO, J.; SIQUEIRA B., H.; BERNARDES, A.; DE OLIVEIRA, J. V.; SALVADOR, A.; ROCHA, A. Vocabulário Internacional de Metrologia Conceitos fundamentais e gerais e termos associados (VIM 2012). Inmetro, n. Edição Luso-Brasileira, 2012.

[2] TANDESKE, D. Pressure sensors: Selection and application. CRC Press, 1990.

[3] LOUZADA, R.D. Desenvolvimento de um transdutor de pressão de alta sensibilidade, baseado no fenômeno de magnetoimpedância gigante, para aplicação biomédica. Dissertação de mestrado. 2006

[4] RAMOS LOUZADA, D., COSTA MONTEIRO, E., GUSMÃO, L.A.P., BARBOSA, C.R.H. Medição não-invasiva de ondas de pulso arterial utilizando transdutor de pressão MIG. In: IV latin american Congress on Biomedical Engineering. Brazil: 2007,

[5] CAVALCANTI, F.M.P. desenvolvimento e caracterização de um transdutor magnético baseado no fenômeno da magnetoimpedância gigante. Dissertação de mestrado. 2005

[6] SILVA, E.C.; GUSMÃO, L. a P.; BARBOSA, C.R.H.; MONTEIRO, E.C.; MACHADO, F.L. a High sensitivity giant magnetoimpedance (GMI) magnetic transducer: magnitude versus phase sensing. Measurement Science and Technology, v. 22, n. 3, p. 35204, 2011.

[7] SILVA, E.C.; GUSMÃO, L.A.P.; HALL BARBOSA, C.; COSTA MONTEIRO, E. Medição da onda de pulso arterial por magnetômetro gmi e marcador magnético. XXIV Congresso Brasileiro de Engenharia BiomédicaCBEB, 2014.

[8] PHAN, M.H. \& PENG, H.X. giant magnetoimpedance materials: fundamentals and applications. progress in materials science, 53, 323-420. 2008 [9] GONÇALVES, L.A.P.; SOARES, J.M.; MACHADO, F.L.A.; RODRIGUES, A.R. Hall and giant magnetoimpedance effects in the Co70Fe5Si15B10 metallic glass. Journal of Non-Crystalline Solids, v. 352, n. 32-35, p. 3659-3662, 2006. 
[10] SILVA, E. costa DA magnetômetro gmi de alta sensibilidade para medição de campos magnéticos ultra-fracos. 2013

[11] MACHADO, F.L.A.; SILVA, B.L. DA; REZENDE, S.M.; MARTINS, C.S. Giant ac magnetoresistance in the soft ferromagnet Co70.4Fe 4.6Si15B10. Journal of Applied Physics, v. 75, n. 10, p. 6563-6565, 1994.

[12] RIPKA, P. magnetic sensors and magnetometers. measurement science and technology, 13, 645-645. 2002

[13] PHAN, M.H.; YU, S.C.; KIM, C.G.; VAZQUEZ, M. Origin of asymmetrical magnetoimpedance in a Co-based amorphous microwire due to dc bias current. Appl. Phys. Lett., v. 83, p. 2871-2873, 2003.

[14] MAKHNOVSKIY, D.P.; PANINA, L. V; MAPPS, D.J. Asymmetrical magnetoimpedance in as-cast $\mathrm{CoFeSiB}$ amorphous wires due to ac bias. Appl. Phys. Lett., v. 77, n. 1, p. 121-123, 2000.

[15] ZHOU, Z.; ZHOU, Y.; CHEN, L.; CHONG, L. Transverse, longitudinal and perpendicular giant magnetoimpedance effects in a compact multiturn meander $\mathrm{NiFe} / \mathrm{Cu} / \mathrm{NiFe}$ trilayer film sensor. Measurement Science and Technology, v. 22, n. 3, 2011.

[16] SOMMER, R.L.; CHIEN, C.L. Longitudinal, transverse, and perpendicular magnetoimpedance in nearly zero magnetostrictive amorphous alloys. Phys. Rev. B, v. 53, p. R5982--R5985, 1996.

[17] LENZ, J.; EDELSTEIN, S. Magnetic sensors and their applications. IEEE Sensors Journal, v. 6, n. 3, p. 631-649, 2006.

[18] COSTA DA SILVA, E. desenvolvimento de transdutor baseado na fase da magnetoimpedância gigante para medição de campos biomagnéticos.Dissertação de mestrado.2010

[19] GONÇALVES, L.A.P. efeito hall planar e magnetoimpedância gigante em liga ferromagnetica amorfa co70fe 5 si15b10. 2006

[20] BYON, K.S.; YU, S.-C.; KIM, C.G.; YOON, S.S. Asymmetric characteristics of magnetoimpedance in amorphous Fe77.5Si7.5B15 wire. Journal of Magnetism and Magnetic Materials, v. 226-230, p. 718-720, 2001. [21] MAKHNOVSKIY, D.P.; PANINA, L. V.; MAPPS, D.J. Field-dependent surface impedance tensor in amorphous wires with two types of magnetic anisotropy: helical and circunferential. Phys. Rev. B, v. 63, n. 14, p. 144424 144441, 2001. 
[22] PANINA, L. V. Asymmetrical giant magneto-impedance (AGMI) in amorphous wires. In: Journal of Magnetism and Magnetic Materials. v.249.2002, p. 278-287.

[23] KIM, C.G.; JANG, K.J.; KIM, D.Y.; YOON, S.S. Analysis of asymmetric giant magnetoimpedance in field-annealed Co-based amorphous ribbon. Applied Physics Letters, v. 77, n. 11, p. 2114-2116, 1999.

[24] BUZNIKOV, N.A.; KIM, C.G.; KIM, C.O.; YOON, S.S. A model for asymmetric giant magnetoimpedance in fieldannealed amorphous ribbons. Appl. Phys. Lett., v. 85, p. 3507-3509, 2004.

[25] DUFAY, B.; SAEZ, S.; DOLABDJIAN, C.; YELON, A.; MÉNARD, D. Physical properties and giant magnetoimpedance sensitivity of rapidly solidified magnetic microwires. Journal of Magnetism and Magnetic Materials, v. 324, n. 13, p. 2091-2099, 2012.

[26] LAGO-CACHÓN, D., MARTÍNEZ-GARCÍA, J.C., RIVAS, M., GARCÍA,

J.A. Biased giant magnetoimpedance and switching field distribution curves in Co 70Fe 5Si 15B 10 nanocrystalline ribbons. In: Journal of Alloys and Compounds. v.536.2012,

[27] MACHADO, F.L.A.; RODRIGUES, A.R.; PUÇA, A.A.; ARAUJO, A.E.P. DE Highly asymmetric giant magnetoimpedance. 1999.

[28] MCDERMOTT, J. sensors and transducers. edn, 28. 1983

[29] K. BEWOOR, A.; A. KULKARNI, V. Metrology \& Measurement. Tata Mc Graw-Hill Education, 2009.

[30] E. MAREY Research on the state of circulation according to the pulse wave characteristics by the new sphygmopraph. J physiol homme anim, v. 3, p. 241, 1869.

[31] SALTER, D.G. Design and validation of an arterial pulse wave analysis device. 2005

[32] KIM, E.G., NAM, K.C., HEO, H., HUH, Y. Development of an arterial tonometer sensor. In: Proceedings of the 31st Annual International Conference of the IEEE Engineering in Medicine and Biology Society: Engineering the Future of Biomedicine, EMBC 2009. 2009, p. 3771-3774.

[33] PAZIN-FILHO, A., SCHMIDT, A., MACIEL, B.C. Semiologia cardiovascular: Inspeção, palpação e percussão. In: Medicina. v.37.2004, p. $227-$ 239. 
[34] HORACIO, A. Semiología Médica. In: Semiología Médica. 2013, p. 271278.

[35] LLANIO NAVARRO, R.; GONZALES PERDOMO, G. Propedeutica Clinica y Semiologia Medica. 2003.

[36] LONGO, D.; FAUCI, A.; KASPER, D.; HAUSER, S.; LARRY, J.; JOSEPH,

L. Harrison Principios de Medicina Interna. 2012.

[37] O’ROURKE, M.F.; PAUCA, A.; JIANG, X.-J. Pulse wave analysis. British journal of clinical pharmacology, v. 51, n. 6, p. 507-522, 2001.

[38] CRAWFORD, M.H.; FLINN, R.S. Inspection and Palpation of Venous and Arterial Pulses. 1990.

[39] NEIL, B.; INGELS, G.; BAAN, J. Systolic and Diastolic Function of the Heart. 1995.

[40] RHOADES, R.; BELL, D. Medical Phisiology: Principles for Clinical Medicine. 2009.

[41] KLABUNDE, R.E. Cardiovascular Physiology Concepts. 2004.

[42] KORPAS, D., HÁLEK, J., \& DOLEŽAL, L. parameters describing the pulse wave. physiological research, 58, 473-479. 2009.

[43] SAFAR, M.E.; JANKOWSKI, P. Central blood pressure and hypertension: role in cardiovascular risk assessment. Clinical science (London, England: 1979), v. 116, n. 4, p. 273-82, 2009.

[44] MILLASSEAU, S.C.; RITTER, J.M.; TAKAZAWA, K.; CHOWIENCZYK, P.J. Contour analysis of the photoplethysmographic pulse measured at the finger. Journal of hypertension, v. 24, n. 8, p. 1449-56, 2006.

[45] CHUNG-SHING, H.; YU-FENG, C.; CHENG-CHAN, Y. Temporal and Spatial Properties of Arterial Pulsation Measurement Using Pressure Sensor Array. Evid Based Complement Alternat Med, 2012.

[46] MCVEIGH, G.E.; BRATTELI, C.W.; MORGAN, D.J.; ALINDER, C.M.; GLASSER, S.P.; FINKELSTEIN, S.M.; COHN, J.N. Age-related abnormalities in arterial compliance identified by pressure pulse contour analysis: aging and arterial compliance. Hypertension, v. 33, n. 6, p. 1392-1398, 1999.

[47] SALVI, P. Pulse waves: How vascular hemodynamics affects blood pressure. 2012.

[48] MITCHELL, G.F. arterial stiffness and wave reflection: biomarkers of cardiovascular risk. artery research, 3, 56-64. 2009 
[49] SILVA, C.E. DA; GUSMÃO, L. a P.; COSTA MONTEIRO, E.; BARBOSA, C.R.H. Transdutor De Pressão, Baseado Nas Características De Fase Do Efeito GMI, Destinado A Aplicações Biomédicas. Controle \& Automação, v. 21, n. 6, 2010.

[50] RIBEIRO, F.A.; THOEN, R.H.; KÖHLER, I.; DANZMANN, L.C.; TORRES, M.A.R. Síndrome metabólica: complacência arterial e a velocidade de onda de pulso. Revista da AMRIGS, v. 56, n. 1, p. 75-80, 2012.

[51] OMS. organização mundial da saúde. disponível em: 〈http://www.who.int >. [52] sociedade brasileira de cardiologia. disponível em: <http://www.cardiometro.com.br/>.

[53] KRISHNAMOORTHY, S.; KHOO, C.W.; LIM, H.S.; LIP, G.Y.H. Predictive value of atrial high-rate episodes for arterial stiffness and endothelial dysfunction in dual-chamber pacemaker patients. European Journal of Clinical Investigation, v. 44, n. 1, p. 13-21, 2014.

[54] GUSBETH-TATOMIR, P.; COVIC, A. Causes and consequences of increased arterial stiffness in chronic kidney disease patients. Kidney $\&$ blood pressure research, v. 30, n. 2, p. 97-107, 2007.

[55] BELliEN, J.; FAVRE, J.; IACOB, M.; GAO, J.; THUILlEZ, C.; RICHARD, V.; JOANNIDÈS, R. Arterial stiffness is regulated by nitric oxide and endothelium-derived hyperpolarizing factor during changes in blood flow in humans. Hypertension, v. 55, n. 3, p. 674-680, 2010.

[56] COSTA MONTEIRO, E. Biometrologia: confiabilidade nas biomedições e repercussões éticas. Metrologia e Instrumentação, v. 6, p. 6-12, 2007.

[57] COSTA MONTEIRO, E.; LEON, E.; L., F. Metrological Reliability of Medical Devices. Phys., n. Conference Series, p. 12032, 2015.

[58] ANDRÄ, W.; NOWAK, H. Magnetism in Medicine: A Handbook. 2007.

[59] MONTEIRO, E. C.; LESSA, M.L. a Metrologia Na Área De Saúde: Garantia Da Segurança E Da Qualidade Dos Equipamentos Eletromédicos. Engevista, v. 7, n. 2, p. 51-60, 2005. 